Illinois State University

ISU ReD: Research and eData

Theses and Dissertations

9-23-2014

\title{
College Student Unions: A Delphi Study Regarding Purposes, Amenities, Barriers and Future Influences
}

Michelle Annette Janisz

Illinois State University, michellejanisz@gmail.com

Follow this and additional works at: https://ir.library.illinoisstate.edu/etd

Part of the Architecture Commons, and the Higher Education Administration Commons

\section{Recommended Citation}

Janisz, Michelle Annette, "College Student Unions: A Delphi Study Regarding Purposes, Amenities, Barriers and Future Influences" (2014). Theses and Dissertations. 258.

https://ir.library.illinoisstate.edu/etd/258

This Dissertation is brought to you for free and open access by ISU ReD: Research and eData. It has been accepted for inclusion in Theses and Dissertations by an authorized administrator of ISU ReD: Research and eData. For more information, please contact ISUReD@ilstu.edu. 


\title{
COLLEGE STUDENT UNIONS: A DELPHI STUDY REGARDING PURPOSES, AMENTITIES, BARRIERS AND FUTURE INFLUENCES
}

\author{
Michelle A. Janisz
}

318 Pages

December 2014

This study was designed to understand and forecast the changing role of the student union in the modern era and specifically explored the purposes served by student unions, what specific amenities and services contribute to serving those purposes, the barriers student unions face in meeting those purposes, and the most important influences that will shape the college and university student union of the future. A review of the history of college and university student unions, the components of campus environments, the role of student unions in student recruitment and retention, and the influences of environmental psychology anchor the research. The study employed the Delphi method to collect and explore the knowledge and insights of experts in student union management, defined as individuals holding the title of Director of the Student Union, Student Center, or Student Activities, and having a minimum of five years' experience in student union management. Twenty two participants completed threerounds of survey questionnaires in an effort to determine expert consensus, defined as $75 \%$ or higher agreement on the importance of items in the survey. The results identified 
four core purposes of student unions, "building, creating or fostering community," "supporting student success," and serving as both the "welcome center," and the "living room" of the campus. Numerous results were derived concerning the specific services, amenities and physical and human attributes of the union that support these purposes, as well as critical physical, knowledge, financial and political constraints that impede their effectiveness. The results of the study will be of interest to higher education leadership, scholars and students, and all of those who are concerned about student recruitment, retention and success. 
COLLEGE STUDENT UNIONS: A DELPHI STUDY REGARDING PURPOSES, AMENITIES, BARRIERS AND FUTURE INFLUENCES

MICHELLE A. JANISZ

A Dissertation Submitted in Partial

Fulfillment of the Requirements for the Degree of

DOCTOR OF PHILOSOPHY

Department of Educational Administration and Foundations

ILLINOIS STATE UNIVERSITY 
Copyright 2014 Michelle A. Janisz 
COLLEGE STUDENT UNIONS: A DELPHI STUDY REGARDING PURPOSES, AMENITIES, BARRIERS AND FUTURE INFLUENCES

MICHELLE A. JANISZ

COMMITTEE MEMBERS:

Diane R. Dean, Chair

Elizabeth Timmerman Lugg

Lydia Kyei-Blankson

Phyllis McCluskey-Titus 


\section{ACKNOWLEDGMENTS}

Well, the time has finally arrived after eight long years. Completion of this manuscript would not have been possible if not for numerous individuals who have been part of my life. I extend my sincere thanks to each of you who have been part of my journey.

To Dr. Jim Palmer who laid the foundation for my study, who challenged my knowledge through constant research, and who helped me become a stronger writer. A very special thank you to Dr. Diane Dean who picked up the baton and ran with it! You came into this process during a "dark" time when I believed I would not finish. You helped me up, believed in my abilities, and guided me to successful completion. Words cannot express my gratitude for the time and energy you gave this past year. Many thanks as well to my committee members Drs. Betsy Lugg, Lydia Kyei-Blankson, and Phyllis McCluskey-Titus who guided me through this final stage. The wisdom and support each of you provided will remain forever etched in my memory.

To the Illinois State family who continually supported my professional endeavors, to my supervisors Dr. Jan Paterson, Mr. Rick Lewis, and Mr. Rick Olshak thank you for allowing me to complete my doctorate part time while assisting the fraternal world in my absence. To all my past ISU colleagues and staff who challenged me to push through when I wanted to give up, thank you for completing the tasks I could not get to and for having a listening ear when I needed to talk. Chrysalis Grodhaus, Suzette Walden, Barb 
Dallinger, Michael Zajac, Jamie Sennett, and Mary Weber - I am talking about you!

To my past graduate staff, thank you for the constant re-education about higher education issues and concerns and for showing me through your actions the continued requirements when working with the ever-changing college student. I learned as much from you all as you did from me.

A thank you cannot adequately convey the support and encouragement I received from Erin Thomas. Every question, concern, or challenge, we got through together. Erin, you were the best Ph.D. school buddy I could have had and no doubt I would not have completed without your emotional assistance. I did it!

To my current professional family at Western Illinois University, especially the Office of Student Activities staff, your ability to keep the office running smoothly in my absence has made the difference for our students. Special thanks to Ann Comerford, I appreciate the friendship you provided that allowed me to reach my educational goal.

To Bethany Deines, words cannot express my gratitude for the support and friendship you provided as I began this journey. You were a kind ear but most importantly never stopped believing in my abilities. You were my biggest champion and having you in my corner made all the difference.

My greatest thanks are extended to Dr. Cindy Piletic and our four-legged family. You listened, challenged, and educated me through this process, served as my research assistant, but most importantly provided constant love and support by taking care of the little things when I could not. The unconditional love you provided was essential to my success. I am a stronger and more confident because of you. 


\section{CONTENTS}

\section{Page}

ACKNOWLEDGMENTS

CONTENTS

iii

TABLES

$\mathrm{X}$

CHAPTER

I. INTRODUCTION TO THE STUDY 1

Overview 1

Statement of the Problem 1

Defining the Campus Environment 3

The Importance of Student Unions

Purpose of the Study and Research Questions 8

Significance of the Study 9

Overview of the Methodology 10

Delimitations $\quad 12$

Limitations $\quad 12$

Definition of Terms $\quad 14$

Organization of the Study 15

$\begin{array}{ll}\text { II. LITERATURE REVIEW } & 16\end{array}$

Introduction 16

Stages in the History and Development of Student Unions 16

Debate Stage (1815-1894) 17

Club Stage (1895-1918) 19

Campus Democracy Stage (1919 -1929) 20

Community Recreation Stage (1930-1945) 21

Educational Stage (1946-1956) 21 
Personalization Stage (1957-1966) 23

Humanization Stage (1967-1979) 24

Unnamed Present (1980-2014) 25

Unknown Future (2015- ?) 27

Components of Campus Environment 28

Physical Component $\quad 29$

Human Aggregate Component 35

Organizational Component 38

Constructed Component 41

Environmental Psychology and Campus Ecology 43

Environmental Psychology 44

Attention 44

Perception and cognitive maps $\quad 45$

Preferred environments 45

Environmental stress and coping 46

Participation and conservation behavior $\quad 46$

Connections with Campus Ecology and Campus Design $\quad 47$

The Role of Campus Facilities and the Student Union in

Recruitment and Retention 49

The Challenge of Recruitment and Retention 49

The Importance of Campus Facilities in Recruitment and

Retention

Gender differences in the importance of campus facilities

Racial differences in the importance of campus facilities

Differences in the importance of campus facilities by institutional type

The Importance of Community in Recruitment and

Retention

The role of facilities design in fostering campus community $\quad 57$

Campus location $\quad 58$

Human-scale design $\quad 59$ 
Layout $\quad 59$

Flexibility 61

"Third place" 62

Safety and security 62

The role of the student union in fostering campus community

Barriers to Campus Facility and Student Union Design 65

Knowledge Constraints $\quad 65$

Financial Constraints $\quad 66$

Political Constraints $\quad 68$

$\begin{array}{ll}\text { Summary } & 69\end{array}$

$\begin{array}{ll}\text { III. METHODOLOGY } & 73\end{array}$

$\begin{array}{ll}\text { Introduction } & 73\end{array}$

Research Questions $\quad 74$

Research Design: The Delphi Method 74

$\begin{array}{ll}\text { Study Population \& Sample } & 78\end{array}$

Study Population $\quad 78$

$\begin{array}{ll}\text { Study Sample } & 79\end{array}$

Sampling Procedure $\quad 80$

Data Collection Procedures $\quad 82$

Round I $\quad 82$

Round II $\quad 84$

Round III $\quad 85$

Data Analysis Procedures $\quad 86$

Formative Data Analyses $\quad 86$

Round I analysis $\quad 86$

Round II analysis $\quad 87$

$\begin{array}{ll}\text { Summative Data Analyses } & 87\end{array}$

Quantitative techniques $\quad 88$

Qualitative techniques $\quad 89$ 
Consideration of Human Subjects 90

Limitations of the Study 90

Response Rates $\quad 90$

Response Quality $\quad 91$

Panelists' Expertise $\quad 91$

Biases and Subjectivity $\quad 92$

$\begin{array}{ll}\text { Summary } & 93\end{array}$

IV. RESULTS 95

Introduction $\quad 95$

Round I Results $\quad 95$

Purpose and Mission of Student Unions 96

$\begin{array}{ll}\text { Purpose } & 97\end{array}$

Mission $\quad 98$

Populations served 98

Services, Programs, and Amenities of Student Unions 99

Services and amenities $\quad 100$

Programming 100

$\begin{array}{ll}\text { Spaces } & 102\end{array}$

Attributes of Student Unions 102

Barriers and Constraints for Student Unions 104

Influences on the Student Union of the Future 108

Round II and Round III Results 109

Purpose and Mission of Student Unions 111

Purpose $\quad 111$

Mission 113

$\begin{array}{ll}\text { Populations served } & 115\end{array}$

Services, Programs, Spaces and Amenities of Student Unions 119

$\begin{array}{ll}\text { Services } & 119\end{array}$ 
Programming $\quad 122$

Spaces 125

Amenities 127

Attributes of Student Unions 128

$\begin{array}{ll}\text { Physical attributes } & 128\end{array}$

Building locations $\quad 128$

Building exteriors $\quad 130$

Building interiors $\quad 131$

Human attributes 137

Union staff 137

Union interactions 139

Barriers and Constraints for the Student Union 144

Physical constraints $\quad 145$

Knowledge constraints 148

Financial constraints $\quad 151$

Political constraints 156

Influences on the Student Union of the Future 157

Sustaining forces 158

Changing forces 160

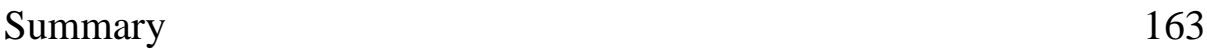

V. DISCUSSION, CONCLUSIONS, AND RECOMMENDATIONS 164

Introduction 164

Applying the Results to Address the Research Questions 165

RQ1: Purposes Served by College and University Student Unions 165

Purposes $\quad 165$

Missions 166

$\begin{array}{ll}\text { Populations served } & 167\end{array}$

RQ2: Amenities and Services That Should Exist in Student Unions 
Services

Programming and roles

Amenities

Attributes that Enhance Student Unions

Location

Building exteriors

Building interiors

172

Human attributes

173

RQ3: Barriers Faced by Student Unions

Physical constraints

174

Knowledge constraints

176

Financial constraints

178

Political constraints

RQ4: Influences on the Student Union of the Future

Physical component

Human aggregate component

Organizational component

183

Constructed component

Implications and Recommendations

Contributions to Literature and Theory

185

Considerations for Practice

189

Suggestions for Future Research

APPENDIX A: $\quad$ Letter Requesting Assistance with Population Identification and Sampling (Association of College Unions International) 
APPENDIX D: $\quad$ Second Follow Up, Round I 210

$\begin{array}{lll}\text { APPENDIX E: } & \text { Round I Questionnaire }\end{array}$

APPENDIX F: $\quad$ Invitation \& Instructions to Participate, Round II 215

APPENDIX G: $\quad$ First Follow Up, Round II 217

APPENDIX H: $\quad$ Second Follow Up, Round II 219

$\begin{array}{lll}\text { APPENDIX I: } & \text { Round II Questionnaire } & 221\end{array}$

APPENDIX J: $\quad$ Invitation \& Instructions to Participate, Round III 243

APPENDIX K: $\quad$ First Follow Up, Round III 245

APPENDIX L: $\quad$ Second Follow Up, Round III 248

APPENDIX M: $\quad$ Third Follow Up, Round III 251

$\begin{array}{lll}\text { APPENDIX N: } & \text { Round III Questionnaire } & 253\end{array}$

APPENDIX O: $\quad$ Thank You, Round III 281

APPENDIX P: $\quad$ Round II and III Results 282 


\section{TABLES}

Table

Page

1. Round I Comments - Purpose and Mission

2. Round I Comments - Services and Amenities

3. Round I Comments - Programming Types and Roles of Student Unions

4. Round I Comments - Types of Spaces in Student Unions

5. Round I Comments - Physical Attributes of Student Unions

6. Round I Comments - Human Attributes of Student Unions

7. Round I Comments - Physical Constraints for Student Unions

105

8. Round I Comments - Knowledge Constraints for Student Unions

9. Round I Comments - Financial and Political Constraints for Student Unions

10. Round I Comments - Influences on the Student Union of the Future

11. Round II and III Results - Purposes of Student Unions

12. Round II and III Results - Top Six Missions of Student Unions

13. Round II and III Results - Student Populations Served by Student Unions

14. Round II and III Results - Other Populations Served by Student Unions

15. Round II and III Results - Top Four Services of Student Unions 
16. Round II and III Results - Other Important Services in Student Unions

17. Round II and III Results - Programming Offered in Student Unions

18. Round II and III Results - Roles of Student Unions

19. Round II and III Results - Top Four Spaces in Student Unions

20. Round II and III Results - Other Important Spaces in Student Unions

21. Round II and III Results - Important Amenities in Student Unions

22. Round II and III Results - Physical Attributes of Student Union Locations

23. Round II and III Results - Physical Attributes of Student Union Exteriors

24. Round II and III Results - Top Five Physical Attributes of Student Union Interiors

25. Round II and III Results - Physical Attributes of Student Union Infrastructures

26. Round II and III Results - Physical Attributes of Student Union Interior Designs

27. Round II and III Results - Important Attributes of Student Union Furnishings

28. Round II and III Results - Important Attributes of Student Union Staff

29. Round II and III Results - Top Attributes of Union Interactions

30. Round II and III Results - Important Attributes that Address Service Demands

31. Round II and III Results - Important Attributes that Address Convenience Needs

32. Round II and III Results - Important Attributes that Address Inclusivity 
33. Round II and III Results - Top Five Physical Constraints

34. Round II and III Results - Other Important Physical Constraints

35. Round II and III Results - Top Five Knowledge Constraints

36. Round II and III Results - Additional Knowledge Constraints

37. Round II and III Results - Other Important Knowledge Constraints

38. Round II and III Results - Expense Constraints

39. Round II and III Results - Revenue Constraints

40. Round II and III Results - Auxiliary Financial Model Constraints

41. Round II and III Results - Political Constraints

42. Round II and III Results - Sustaining Influences on the Student Union of the Future

43. Round II and III Results - Changing Influences on the Student Union of the Future 


\section{CHAPTER I \\ INTRODUCTION TO THE STUDY}

\section{Overview}

The purpose of this study was to understand and forecast the changing role of the student union in the modern era as an approach towards addressing the problems of student recruitment, retention and success. This chapter introduces the study by presenting a statement of the problem; the purpose of the study and research questions; the significance of the study; and an overview of the methodology including delimitations and limitations. Key terms used throughout the study are defined, and the chapter concludes with an outline of the overall organization of the study.

\section{Statement of the Problem}

Student recruitment, retention and success are important public policy priorities (AASCU, 2014) and key goals for all colleges and universities. At the national level, President Barack Obama has recognized the growth in the proportion of American jobs requiring a higher education, yet our college educated workforce is dwindling as aging Baby Boomers retire, and we face a persistent gap in educational attainment between Americans according to income level and race (The White House, n.d.). As the United States loses ground internationally in terms of educational attainment, "[t]he President has ... set a new goal for the country: that by 2020 , America would once again have the highest proportion of college graduates in the world" (The White House, n.d., para 3). 
At the state level, governors and legislatures likewise recognize the need for higher college participation and attainment and its relation to state economic goals; yet they wrestle with budget shortfalls, rising tuition, declining enrollments, and college completion issues (AASCU, 2014). As a result, more and more states are considering linking higher education appropriations to institutional performance measures for student enrollments, completions and outcomes (AASCU, 2014, Bailey \& Morest, 2006).

At the institutional level, colleges and universities share these concerns and face the resultant pressures to recruit, retain, and graduate enough students needed to remain fiscally viable, meet performance expectations, and fulfill the nation's needs for a highly educated populace. If a student remains in college until their sophomore year, he or she will more likely graduate (Tinto, 1993). In this context, understanding students' college choice /decision criteria becomes vital knowledge (Price, Matzdorf, \& Smith, 2001), as does understanding what institutions can do to improve student retention (Lau, 2003).

Research demonstrates that the availability and quality of campus facilities is fundamentally related to student recruitment and retention (Price, Matzdorf, \& Smith, 2001; Price, Matzdorf, Smith \& Agahi, 2003; Reynolds \& Cain, 2006). A recent survey of 16,153 students in 46 colleges and universities across the United States and Canada, conducted by the Association of Higher Education Facilities Officers [AHEFO], "reinforces the notion that the facilities students see — or do not see — on a campus can mean the difference between whether they enroll or not" (June, 2006, para.7). Students in that survey deemed specific campus facilities as extremely important or very important to their choice of a college, including: facilities for their major (74\%), libraries (54\%), technology (51\%), classrooms (50\%), residence halls (42\%), exercise facilities $(36 \%)$, 
bookstores (35\%), open spaces (34\%), recreation facilities (32\%), science/engineering facilities (30\%), dining halls (29\%), performing arts centers (22\%), student unions (21\%), visual-arts centers (15\%), intramural-sports facilities (15\%), and varsity-athletic facilities (14\%) (June, 2006). ${ }^{1}$ In the same study, nearly $30 \%$ of the student reported rejecting potential colleges that lacked the buildings and amenities they wanted; $26 \%$ rejected a potential college because of inadequate facilities; and nearly $17 \%$ rejected a potential college whose facilities were poorly maintained (June, 2006).

Many college campuses have outdated buildings that need repairs, renovations or replacement. Unfortunately, capital funding for campus renovations and construction is scarce. Fiscal constraints are still a potential barrier to improving campus facilities (Chism, 2006), as state and federal funding for higher education projects have declined in recent years due to competing claimants seeking government funding (Zumeta, 2005).

\section{Defining the Campus Environment}

The AHEFO survey results were not entirely surprising. "[T]he college environment contains, supports, and communicates with the student, provides a setting for social and physical interactions, and links the student with the symbolic and the functional content of the college experience" (Schuetz, 2005, p. 62). When asked to define the campus environment, people usually focus on describing the physical surroundings of what they see, feel, or hear. What students experience when visiting campus - what the buildings look like, where different offices are located, the accessibility of services, and the general "feeling" they have when walking around

1 These percentages are rounded to the nearest whole number. 
campus - can form a strong first impression. The messages communicated from that physical environment can influence students' feelings of well-being, belonging and identity (Kuh, Kinzie, Schuh \& Whitt, 2005) which not only influence their enrollment decisions, but also may contribute to retention (Boyer, 1987).

However, the campus environment includes more than just the physical structure. Strange and Banning (2001) identify four dimensions of campus environments: (a) the design, layout and quality of physical features; (b) the characteristics of human aggregate, or groups of people who inhabit the environment; (c) the campus organizational structures and designs related to purposes and goals; and (d) the perceptions all inhabitants construct around these dimensions and what they attribute to them. Thus, as students look further, beyond the physical surroundings, they see the people who inhabit the campus including the diversity (or lack thereof) of students, faculty, or staff. They encounter the college's organizational structures that shape the delivery of student services and the academic program, and determine how students get their questions answered. They notice the traditions, symbols, or customs practiced by students, faculty or staff (Astin, 1993). Each of these dimensions of the campus environment may influence whether a student attends or remains at a particular college.

Taking a broader view, the field of environmental psychology offers understanding on how the environment influences human behavior. This field delves into how people notice aspects of, retain information about, and navigate their environments; and how certain aspects of the environment invoke stress and coping responses, while other aspects create preferred environments that invoke positive feelings and effective behaviors (DeYoung, 1999). Colleges and universities can create the conditions for 
effective person-environment fit by building an array of preferred environments ecological niches - that meet the diverse needs of college students and contribute to their success (Banning \& Bryner, 2001).

In their seminal work on campus facility planning, Educating by design: Creating campus learning environments that work, Strange and Banning (2001) noted that: colleges and universities establish conditions to attract, satisfy, and retain students for purposes of challenging them to develop qualities of the educated person, including a capacity for complex critical reasoning, communication, leadership, a sense of identity and purpose, and appreciation for differences, and a commitment to lifelong learning (p. 2).

\section{The Importance of Student Unions}

One important facility in the campus environment is the student union. The student union has taken many forms since its inception in England hundreds of years ago. What originally began as student debating societies (i.e. clubs) at both Oxford and Cambridge universities has evolved into a multipurpose building for students' use including places to hang out, dine, or study; and a central location for services such as banking and the campus bookstore. Often called the "hearthstone" of the college campus, or the "community center of the college," this important center of community life has become integral to the educational and student development mission of colleges and universities, and serves students, faculty, staff, alumni, and guests (ACUI, n.d.2). Humphreys' (1946) and Stevens' (1969) excellent works outline the long history of the student union in American colleges and universities and the ways in which these special facilities have supported and fostered student and campus-wide community. 
Their mission, purpose and usage have evolved over time with successive generations of students (Humphreys, 1949; Rudolph, 1962; Stevens, 1969; Towns, 2005). However, in Humphrey's (1946) work, she identified four general objectives for a student union:

1. To serve as an informal educational medium for supplementing the academic education of students and, is so far as possible, for relating the academic and non-academic factors of education...that the student's total training and experience may be well-rounded and complete.

2. To carry out the meaning implied by the word "union" or "community center" by centralizing, integrating, and democratizing the university community effort and activity.

3. To make possible, during leisure hours, individual and group selfdiscovery and expression through provision of a richly varied recreational life for the college community, particularly for students.

4. To maintain a physical center as an instrument for implementing the objectives stated above and for facilitating a communal life through whatever means possible (p.72).

The role or function of the college union, however, was not always easily understood and rarely articulated by individual campuses. To address this, in its 1956 Statement of Purpose, the Association of College Unions stated the role of the college union as:

1. The union is the community center of the college, for all the members of the college family...students, faculty, administration, alumni and 
guests. It is not just a building; it is also an organization and a program. Together they represent a well-considered plan for the community life of the college.

2. As the "living room" or "hearthstone" of the college, the union provides for the services, conveniences, and amenities the members of the college family need in their daily life on the campus and for getting to know and understand one another through informal association outside the classroom.

3. The union is part of the educational program of the college. As the center of college community life, it serves as the laboratory of citizenship, training students in social responsibility and for leadership in our democracy...Through its various boards, committees, and staff, it provides a cultural, social, and recreational program, aiming to make free time activity a cooperative factor with study in education...In all its processes, it encourages self-directed activity, giving maximum opportunity for self-realization and for growth in individual social competency and group effectiveness. Its goal is the development of persons as well as intellects.

4. The union serves as a unifying force in the life of the college, cultivating enduring regard for and loyalty to the college (The College Union Idea, p. 105).

Today, the student union continues to hold a deep value for students, symbolizing a student-centered institution (Reynolds \& Cain, 2006). In fact, the union may be the first 
building potential students visit, as activities meant to introduce the students to the college campus often begin or are held in the student union.

Research consistently establishes the importance of student unions / student centers in attracting student enrollments and keeping students on campus (Henry, 2004; Reynolds \& Cain, 2006; Romano \& Hanish, 2003). Given that one-fifth to one-third of students will reject a prospective college based on absent, inadequate or poorly maintained facilities (June, 2006), it is important that the student union not only provide the services that students need and want, but the environment (physical, human aggregate, organizational and created) should be consciously designed to help attract and retain students as well. Unfortunately, while we know a great deal about the history of these facilities, the needs and preferences of students change with succeeding generations, as society and culture evolve. We do not know which purposes, services, amenities and attributes of student unions are likely to emerge as most important in the future. This research study addressed this gap.

\section{Purpose of the Study and Research Questions}

The purpose of this study was to understand and forecast the changing role of the student union in the modern era. The following research questions guided the study:

1. What are the most important purposes served by college and university student unions?

2. What amenities and services should exist in the student union based on these purposes?

3. What are the barriers faced by student unions in meeting these purposes?

4. What are the most important influences that will shape the college and university student union of the future? 


\section{Significance of the Study}

Many college campuses continue to struggle with buildings that are outdated or need significant repair. The student union is one such building. Meeting the current needs of students and determining what services and amenities should exist need to be the priority. This study can assist union center directors, university/facility planners, policy makers, and construction firms determine the most important features to include that will meet the ever-changing needs of a variety of students.

As colleges and universities prepare for several more generations of college students, the physical spaces being created also need to be flexible enough to accommodate their changing needs. The college union was initially created to provide a social outlet for students in an environment that helped promote learning (Butts et al., 2012). However, other spaces on campus such as multi-cultural centers, campus recreation facilities, and residence halls are creating environments that promote learning as well. Understanding and accepting this will require professionals to stop competing with these other facilities and find a way to complement each other while providing a variety of resources that students require to assist them in achieving their educational goal. Knowing what services and amenities should be provided in the student union can assist both the academic and student services professionals to create or enhance facilities.

Student recruitment, retention and success are also key goals for all colleges and universities. Campus facilities are fundamentally related to these goals (Price, Matzdorf, \& Smith, 2001; Price, Matzdorf, Smith \& Agahi, 2003; Reynolds \& Cain, 2006). In particular, student unions / student centers influence college choice and help keep students on campus (Henry, 2004; Reynolds \& Cain, 2006; Romano \& Hanish, 2003). 
Unfortunately, despite the importance of campus facilities in promoting student recruitment, retention and success, this is an understudied area in American higher education.

The results of this study will add to the literature in the fields of college student affairs, campus facilities, student unions, college and university administration, and enrollment management by identifying the important purposes served by student unions; the barriers that prevent many campuses from fulfilling those purposes; the amenities and services that should be offered within student unions; and the influences that will shape the future of student unions. The findings will be of interest to higher education leaders, administrators, scholars and students, and all those who are concerned with campus facilities and with student recruitment, retention and success. The study will also be of interest to policymakers faced with decisions on higher education capital funding, aiding their understanding of the significance of the built campus environment and of student unions.

\section{Overview of the Methodology}

This study used the Delphi method to harness the expertise of directors of student unions to understand and forecast the changing role of the student union in US colleges and universities. Directors of student unions were selected as potential participants rather than students, because their expertise, based on multi-year careers in higher education, offers a more stable and objective view. Students' opinions, in contrast, would be more subjective to the individual, very significantly, and be anchored in the shorter timeframe of their individual years of enrollment. Additionally, student opinions would potentially 
overlook important information relative to other populations that use the union, such as faculty, staff, alumni and the public.

The strength of this method relied upon the consensus of expert opinion. There are hundreds, of student unions in the country with numerous staff and various opinions about what services should be available to students in their campus facility. No definitive inventory of US college and university student unions exists, perhaps because of their multiplicity of form and function. Even the Association of College Unions International does not maintain such a database (J. Cline, personal communication, February 7, 2014). Relying on the consensus from an expert panel - directors of student unions - can minimize the dissonance and assist in identifying and forecasting that changing role. The Delphi method allowed for an asynchronous group discussion while reaching consensus in a timely fashion. It offered more interaction among members than a simple survey, and less peer influence or groupthink than a focus group method.

The study relied on nested, purposive sampling strategies, including homogenizing and criterion strategies to gather information-rich participants (Patton, 2002) suitable for a Delphi study. The researcher used the Association of College Unions International (ACUI) to identify members of the study population and assist with recruiting a resulting panel of 22 directors of student unions / student centers / student activities in public and private, non-profit, non-specialized, four year colleges and universities in the US. Consistent with guidelines for the Delphi method (Hsu \& Sanford, 2007) the study involved administering three-rounds of survey questionnaires.

The study drew upon the theoretical framework proposed by Strange and Banning (2001) to help understand the role of the student union according to four important 
environmental components of college campuses: (a) the physical condition, design, and layout; (b) the characteristics of the people who inhabit the campus; (c) the organizational structures related to students' purposes and goals; and (d) the inhabitants' collective perceptions or constructions of the context and culture of the setting. Formative data analysis occurred throughout the data collection period to develop and administer successive rounds of surveys, and a summative data analysis of the final results occurred at the end to address the research questions. Combined, the results of the questionnaire administration and consensus-building process were used to address the major research questions of the study that help us understand and forecast the changing role of the student union. Chapter III provides a full review of the study's methodology.

\section{Delimitations}

This study focused on public and private, non-profit, non-specialized, four year colleges and universities in the US. While important to the overall landscape of higher education in the United States, two-year colleges, for-profit institutions, and specialized colleges and universities were omitted from the study to reduce the differences in various aspects of the campus environment that would be more pronounced with their inclusion. Specialized colleges and universities were also removed from the study because those institutions that have a majority or exclusively graduate/professional enrollment profile.

\section{Limitations}

The Delphi method posed several inherent limitations: response rates, response quality and panelists' expertise. First, the method asked prospective participants to commit to several repeated rounds of questionnaires. While vital for consensus-building, the likelihood for non-response increased with each round of survey administration. The 
study assumed that individuals who agree to participate were sufficiently motivated to provide adequately descriptive responses. Second, the study relied on quality and adequacy of the participants' responses based on their expertise. Careful selection of prospective participants helped address this limitation, as well as recruiting a panel that exceeded the lower ranges of recommended size. A critical mass of expert panelists helped smooth any effects of panelists who may have inadvertently had lower expertise despite meeting sampling criteria

The researcher's background and subjective perspectives often pose a limitation (Creswell, 2009) in research of a qualitative nature. In my professional role as a director of student activities, my daily work involves working directly with students, faculty, and staff in a college student union environment. Additionally, I was a member of a student union renovation project team at two prior institutions. These experiences, which are described more fully in the methodology chapter, influenced my interest in this study. Fortunately, the heavily participant-based Delphi method diminishes potential bias from the researcher. In contrast, my own experiences with student unions were an asset to the study, enabling me to better understand the panelists' comments.

Finally, the study assumed that there are discernable trends in what college students want from their student unions, despite variations in student demographics and college campuses. These limitations are discussed more fully in the methodology chapter III. 


\section{Definition of Terms}

Several terms are used in the study which may not be familiar to the lay reader. These are defined here in alphabetical order, not based upon their placement within this paper.

Amenities: any feature that provides comfort, convenience, or pleasure. Or any tangible or intangible benefits of a property (Dictionary.com)

Campus Ecology: the behavioral study of the complex transactional relationships among the social and physical dimensions of campus environments and those who inhabit them, students, staff, faculty, and visitors (Campusecologist.com)

Consensus: consensus is reached when $75 \%$ or more of the participants rated items within two adjacent ratings on the Likert scale (i.e. $1 \& 2,2 \& 3$, etc.)

Environmental Psychology: an interdisciplinary science that focuses on the interplay between human beings and their surrounding environment (environmentalpsychology.com)

Millennials: an abbreviation for the millennial generation used to describe a segment of the population typically born sometime between 1982-2000 (Howe \& Strauss, 2000)

Student Union: a building at a college or university that is used for students' social activities (Merriam-Webster.com). For the purposes of this paper, the terms "student union", “college union", and "student center" will be used synonymously.

True Consensus: true consensus is reached when $75 \%$ or more of the participants rated items within only one rating on the Likert scale (i.e. "very important", or "important") 


\section{Organization of the Study}

This research contains five chapters that describe and explain the study. Chapter I, "Introduction to the Study", introduces the research problem, questions, and all parts of the study's design. Chapter II, “Literature Review," discusses the relevant literature and theoretical constructs that provide the context and foundation for the study. Chapter III, "Methodology," presents the research design in detail. Chapter IV, "Data Analysis," presents the collected data and an analysis of that data. Chapter V, "Discussion," synthesizes the findings, presents conclusions regarding the study's research questions, and discusses implications toward addressing the underlying problem of student recruitment, retention and success. The completed study concludes with suggestions for future research. 


\section{CHAPTER II \\ LITERATURE REVIEW}

\section{Introduction}

This chapter provides a review of selected literature related to college and university student unions and their importance to the recruitment and retention of college students. First it provides a comprehensive overview of stages in the historical development of student unions, outlining how the purpose of student unions has evolved across centuries. Next it presents the components of the campus environment and environmental psychology, pointing to their intersection in the concept of campus ecology. Then it discusses the role that campus facilities and the student union have in influencing student recruitment and retention. Finally, the chapter outlines several considerations that are barriers to facilities design. It ends with a brief summary and critique that articulates how this collection of literature aids our understanding of the evolution of student unions and their importance, yet also points out how that literature is incomplete and insufficient to offer a current understanding of the changing and future role of student unions.

\section{Stages in the History and Development of Student Unions}

The concept of a student union has evolved throughout the centuries. What began as debating societies led to the creation of physical facilities that provided a safe place for 
students to gather for this and other forms of intellectual discourse. Over time, these facilities became home to more and various purposes and populations, as society, students, and higher education evolved. Debating societies, no longer prominent in student life, faded into the background. The contemporary student union has grown into a complex, multipurpose, multiservice facility that ably addresses the needs of a multitude of students.

Despite the lost prominence of debating societies, one constant has remained through the years: the importance of students' relationships with the student union. This section discusses the evolution of the student union beginning with its origins in Europe and concluding with its purpose and function in the $21^{\text {st }}$ century. Infused with histories from various sources, it draws upon Humphreys' (1946) seminal work on the stages of the student union movement, College Unions: A Handbook on College Community Centers; and Stevens' (1969) continuation of that stage development theory, The College Union: Past, Present and Future. It also offers observations about the current and future stages in the development of student unions. As with any attempt to name movements and eras in history, it is important to note that these stages are not fixed or hierarchal. The events and influences within each often overlap with each other throughout the years they represent. The first four stages (Debate, Club, Camus Democracy, and Community Recreation), were conceptualized by Humphreys (1946), and draw upon both her descriptions and those from other histories of US higher education.

\section{Debate Stage (1815-1894)}

Humphreys' Debate Stage (1815-1894) marked the dawn of the college student union (1946). The role of debate in the practice of free inquiry dates back to Greek and 
Roman philosophers. As the tradition of free inquiry matured and formalized, merging into what became higher education, the tradition of debate continued with it. For centuries, debate was part of the college curriculum (Berry, 1989), a signature pedagogy, along with recitation and disputation (Rudolph, 1962). The earliest student unions, formed at Cambridge and Oxford Universities, were independent student debating clubs that joined together to promote the ideals of free speech, free debate, and academic freedom (Humphreys, 1946; Parkinson, 2009). These groups were extracurricular in nature and helped provide an outlet for differences of opinion (Rudolph, 1962) that brought young men together.2

University support for these associations did not exist at the beginning of the union movement (Humphreys, 1946). In fact, universities during this time period did not officially recognize these debating societies, and thus offered no facilities for their use. Seeking safe places to meet on campus or in nearby towns, early student unions organized their own spaces in rental facilities and sometimes in private residences (Humphreys, 1946). These student-procured facilities included spaces for studying, debating and socializing over meals (Ellis, n.d.).

Debating societies and unions of students were eventually adopted in US colleges, which had been largely modeled upon and continued to emulate the colleges at Oxford and Cambridge universities (Rudolph, 1962).

2 At that time, college education was available exclusively for men. 


\section{Club Stage (1895-1918)}

The late $19^{\text {th }}$ century model of the student union was quite different from its earlier British origins. In time, British universities built physical structures that provided a space their student unions (Berry, 1989). As university students in that era were nearly all men, additional club facilities appealing to men developed within the unions, such as billiards, smoking and writing rooms. The union developed into fairly exclusive clubs similar to the English men's clubs (Berry, 1964).

Humphreys' Club Stage (1895-1918) was marked by the expansion of student unions on American college and university campuses (1946) as new colleges expanded throughout the country in the wake of forces such as denominationalism, the industrial revolution and nation-building (Rudolph, 1962). This stage also heralded a shift away from the union's original emphasis on debate. While still having familiar aspects of the old English model, American unions shifted from the purpose of housing debating societies to become a broader "association of social affiliation" (Towns, 2005, p. 16).

Unions also incorporated new purposes to adapt to changes in society and students. The Morrill Act of 1862, for example, expanded access to higher education, introducing new curricula and new public universities that increased the numbers of students attending college (Thelin, 2004). Along with increasing enrollments came the need to provide more practical services to students, such as a place to eat, relax, and buy needed materials, and a place for down-time in-between or after classes. Many colleges began to feel responsible for providing acceptable venues for extracurricular activities. 


\section{Campus Democracy Stage (1919 -1929)}

Humphreys' Campus Democracy Stage (1919-1929) clearly mirrored the influences of World War I and its aftermath (1946) The horrors of the 'great war' fostered changes in society, students, and higher education; instilled a democratic spirit in American colleges; and triggered subsequent developments in student unions across the nation (Butts et al., 2012). By the second decade of the $20^{\text {th }}$ century, student unions in America were being called "memorial unions" to honor fallen soldiers (Humphreys, 1946; Towns, 2005). These memorials also provided students a way to express their grief and sorrow.

At the same time, continually expanding student populations chipped away at elitism. More students began attending college as returning veterans pursued higher education (Cohen, 1998). While campuses would continue to see their veteran population increase in the aftermath of the next world war, this current influx of veterans helped crack class barriers in college participation. By the 1920s, women and persons of color were also more prevalent on college campuses (Cohen, 1998).

This emerging diversity on campus shifted the union's purpose. The idea of campus unity and a union for all became a motivating force in the development of student unions (Humphreys, 1946). New groups of students sought the same opportunities and programs that the "men only" unions had provided in the late 1800s. New campus organizations for women and the creation of fraternities for women and Blacks were only part of the many programs that college unions established. Resonating with the spirit of greater inclusion and democracy, co-operative student-faculty governments emerged in student unions during these times (Humphreys, 1946). The "seeds of a culturally and 
educationally social life for the entire college community [were] being planted" (Humphreys, 1946 p.23). New unions being built on university campuses were created for all students - not just a select few - as more people came together to share the common collegiate experience (Berry, 1989).

\section{Community Recreation Stage (1930-1945)}

Humphrey's Community Recreation Stage (1930-1945), was the final stage in her history of student unions (1946). It is marked by an expansion in more and new types of recreational services and amenities (Towns, 2005) as the populations served by the union expanded. Faculty, staff, and outside visitors to the campus joined students in the use of union services. This caused unions to jettison their prefix, "student unions," and acquire the name, "college unions," clearly indicating that they were campus centers for all (Towns, 2005). The college union became an organization and physical building, or community center, where students, faculty and alumni experienced informal education and self-discovery through social, cultural and recreational opportunities. (Humphreys, 1946).

Near the end of this stage, the student union's role again shifted to meet changes in society, students, and the services demanded of it. At that time, as the nation entered WWII, the unions provided facilities for various branches of the military to train on university campuses (Berry, 1964).

\section{Educational Stage (1946-1956)}

Humphreys' stage theories of student unions end at the year of her book's publication in 1946. Stevens (1969) subsequently expanded Humphrey's work with three 
additional stages. These include the Educational, Personalization, and Humanization stages.

Stevens' Educational Stage (1946-1956), which begins on the heels of WWII, predominantly featured explosive growth in the numbers of college student enrollments (1969). The landscape of American higher education was forever altered when thousands of WWII veterans, with GI Bill benefits in hand, arrived on campus to enroll in college. Many of these were the same men who had trained on campuses in preparation of war.

On many campuses, waves of veterans experienced resulting "crowded classrooms, inadequate housing and crammed libraries" (Olson, 1973, p. 596). Administrators scrambled to lodge waves of students; with some establishing trailer cities on former athletic fields to house vets and their families (NCSU, n.d.). Likewise, campuses expanded their student union facilities to accommodate this unprecedented influx of students, and their services and amenities evolved to meet the needs demands of the post-war generation.

Toward the end of the community recreation stage, the educational mission of the college union was being actively discussed. College faculty and administrators were taking an increasingly holistic view of education, considering what a student did for leisure outside the classroom in addition to what was happening in the classroom (Stevens, 1969). Student unions were recognized as an essential element in a college campus; a part of, not separate from, the educational program. Dr. Virgil M. Hancer, President of the University of Iowa in 1954, crystalized this philosophy in an address to the membership of the Association of College Unions, "It seems to me that the union should be thought of as a part of the total educational enterprise, as an integral part of the 
institution, as contributing a supplementary form of education-outside the classroom in a sense but certainly not unrelated to it" (Stevens, 1969, p.18).

\section{Personalization Stage (1957-1966)}

During the 1960s, legislation and events such as the Civil Rights Act, the Vietnam War, and the assassinations of Martin Luther King and the Kennedy brothers brought sweeping changes across society and increased social activism among American youth. On college campuses, students began voicing their rights, concerns and outrage causing campus upheaval (Berry, 1964; Stevens, 1969). The student union provided an important venue for free speech, just as it did for the debate clubs long ago.

Mass education was reaching unprecedented proportions during this time. Concurrently, advances in technology brought greater computerization and less staff-tostudent contact in institutional process and procedures. The combination of increased enrollments and computerization often created a depersonalizing experience, causing students to feel like they were just a number in the mix. Perhaps in an attempt to restore greater personalization to the collegiate experience, Stevens (1969) noted that during this time, students began to seek out small group experiences instead of large group functions. As smaller interest groups were formed in greater numbers, the college union joined forces with other campus organizations to maximize effort and limit duplication.

Stevens' Personalization Stage was, in its essence, truly about the students finding their own identity within the framework of an impersonal campus environment (1969). At this time the college union was attempting to provide services and programs that would create interpersonal opportunities for students to engage with others while allowing them the freedom to express their thoughts and needs. 


\section{Humanization Stage (1967-1979)}

The number of union facilities being built around the nation increased again in the aftermath of the 1960 s social upheaval, and college campuses also increased the number of student affairs staff in an effort to instill a sense of order on campus (Thelin, 2004). "[C]ollege administrators had an uneasy sense that the expanded numbers of students had put the institution in a precarious situation - namely, one of increased responsibility for student conduct and decreased ability to control it" (Thelin, 2004, p. 221). The late 1960s through the 1970s marked Stevens' Humanization Stage (1969) in the development of student unions.

Students in this era were eager to immerse themselves into the social issues of the day. While many students were not able to go where the "action" was, it was possible at this time to bring the "action" directly to the college campus (Stevens, 1969, p. 20). Students often achieved this close connection with social issues by demanding to college administrators that social activists and reformists be invited to speak on their campuses.

Additionally, students were becoming more involved in influencing policy development on campus and also in directly contributing to policy decisions. For example, students formed, joined and actively participated in an array of committees concerned specifically about student issues in the residence halls and across campus. The results of these committees informed college and university administrative decisions. On many campuses, students were given formal representation as part of institutional governing boards (e.g. student trustees) where they could directly voice their concerns, ensure that those concerns and requests would be heard, and also have a contributing vote 
in policy and decision making. Student involvement in governance created new opportunities for student expression and leadership development (Cohen, 1998).

As in many preceding stages, with more and different students on campus came the need for additional facilities to serve them, and the thirst for additional programs and amenities to respond to their needs. Not only had women gained vastly increased access to higher education, more and more minority students had gained access as well. Changing demographics in higher education and changes in society brought enlightenment - and new tensions - on college campuses. For example, Black students, feeling alienated at predominately white institutions, began gathering in groups and discussing their shared thoughts and commonalities (Williamson, 1999).

Student affairs staff ably and creatively responded to the demands of this everchanging, rapidly growing student body. The increased numbers of Black students on campus coupled with the increased racial consciousness of the time, for example, influenced the rise of the Black student union. College student unions gradually became permanent fixtures on campuses and were viewed as important centers of informal education and the focal point of student life (Berry, 1989).

\section{Unnamed Present (1980-2014)}

Stevens (1969), like Humphreys (1949), ended his projection of stages in student union development circa the date of his book's publication. The present stage remains unnamed. That task exceeds the scope of this study, and is best left to future historians of college student unions. Several distinctions in the present era, however, are clear. Although the unions continue to have a central role, trends such as: fluctuating funding for higher education, public demands for reduced costs, student consumerist demands for 
greater services and convenience, and campus needs for alternative sources of revenue have had an impact on student union operations. By the 1980s, unions increasingly functioned like business, relying on auxiliary services (e.g. outsourced functions like bookstores, convenience stores and food services) to help fund programs and services.

At the same time, changes in student populations influenced shifts in student union programming. For example, student behaviors such as high risk-drinking prompted a need for greater wellness education programming; and the continued increase in diverse populations on campus prompted a need for educational programming to foster greater awareness and acceptance of all students. By the 1990s, this blossomed into fuller co-curricular programming, as college union staff built upon and worked with academic programs to advance student knowledge and skill development.

The Association of College Unions International (ACUI), the professional association for administrators and staff who manage student unions on their campuses, defines what has become the integral role of the union on American college campuses:

The union is the community center of the college, serving students, faculty, staff, alumni, and guests. By whatever form or name, a college union is an organization offering a variety of programs, activities, services, and facilities that, when taken together, represent a wellconsidered plan for the community life of the college. ...[It] is an integral part of the educational mission of the college. As the center of the college community life, the union complements the academic experience through an extensive variety of cultural, educational, social, and recreational programs. These programs provide the opportunity to balance course 
work and free time as cooperative factors in education. ...[It] is a studentcentered organization that values participatory decision-making. ...[and] encourages self-directed activity ... The union's goal is the development of persons as well as intellects. Traditionally considered the "hearthstone" or "living room" of the campus, today's union is the gathering place of the college. The union provides services and conveniences that members of the college community need in their daily lives and creates an environment for getting to know and understand others through formal and informal associations. ... [It] serves as a unifying force that ...fosters a sense of community that cultivates enduring loyalty to the college. (n.d.2) As evident in the ACUI definition, the student union is no longer just for students. Continuing a naming trend that began in the Community Recreation Stage, these facilities are now "college unions" that serve the entire campus community, although students remain their primary focus. Also evident in the ACUI definition, students continue to cocreate and influence the student union through their direct involvement and changing needs.

\section{Unknown Future (2015- ?)}

The year, 2014, marked the 100 year anniversary of the Association of College Unions International (ACUI). Throughout their history, student unions evolved in stages as they adapted to the expanding populations and changing needs of college students. The trends evident across these stages include (a) the widening of communities served by college unions; (b) a proliferation and spread of services and amenities offered; (c) a deepening of the union's role in the intellectual and social development of students; and 
(d) a widened increase and extension in union facilities. As the number and scope of union services has expanded, a more recent trend has been the outsourcing of noneducational functions, such as the bookstore and dining services. Similarly, due to decreased funding for higher education and rising college costs, another recent trend has been to fiscally manage the entire student union as an auxiliary service itself, in which union activities must generate enough revenues to balance their own costs.

The mission and purpose of college unions will undoubtedly continue evolving and expanding as the future unfolds. While that future is difficult to predict, college and university administrators must try to do so. College unions have become a basic and vital component in the campus environment. Campuses must be prepared to adapt their unions to cope with the changes and trends in society, and to meet the challenges of everchanging student enrollments. Instead of waiting for the future to happen, higher education leaders must be proactive in their approaches to student life in the $21^{\text {st }}$ century. They "must be innovators who are unafraid to take risks, and they must be catalytic agents who facilitate educational change" (Bailey, Owens, \& Witten, 1982, p. 346).

\section{Components of Campus Environment}

An understanding of the significance of the student union's role in the campus community deepens with a holistic look at the components of campus environments. A common misconception, the college faculty and curricular programs are not the only important elements of colleges. In truth, other components of the campus environment also directly influence student learning and satisfaction (Strange \& Banning, 2001). The literature surrounding campus planning in higher education is abundant and would be impossible to fully address in this review. Instead, this review focuses on the work of 
Strange and Banning (2001), who identified four components of the campus environment that influence effective person-environment interactions. These are: (a) the physical component; (b) the human aggregate component; (c) the organizational component; and (d) the constructed component (Strange \& Banning, 2001). An understanding of these components assists campus planners and student affairs professionals in designing student unions and building supportive learning communities within them.

\section{Physical Component}

The physical component of the campus environment refers to the physical condition, design, and layout of the campus. When a visitor arrives on a college campus, the physical features of the campus make a noticeable and powerful first impression that conveys a variety of nonverbal messages that may be welcoming and valuing, or discouraging and disrespecting (Strange, 2003; Strange \& Banning, 2001). The landscaping, buildings, artifacts and learning environments communicate the campus' purposes and values in overt and subtle ways. When combined, these elements “influence students' feelings of well-being, belonging, and identity” (Kuh, Kinzie, Schuh, $\&$ Whitt, 2005, p. 106) and contribute to student recruitment, retention and success.

First, well-designed landscaping fosters a sense of belonging, comfort and safety - requisites for student learning (Strange \& Banning, 2001). Campuses with plenty of open, green spaces and gathering spots promote interaction among community members; whereas campuses lacking such spaces may subliminally encourage students to leave when classes are not in session. Therefore, the campus landscape is important. Trees, bushes, and other plants should be well maintained. Even seemingly simple things such as trash disposal and campus parking should be well-managed, with parking conveniently 
available near campus facilities, and the grounds kept clean, welcoming, and free of litter (Strange \& Banning, 2001). More importantly, proper lighting and a natural flow for foot traffic between and within the buildings provides a safer and more secure environment (Strange \& Banning, 2001). Prospective students and their family need such assurances (Strange \& Banning, 2001), particularly in the wake of tragic campus shootings in recent years that have made national headlines.

The campus visit - the student's first physical introduction to the campus - has been described as the "golden walk" (Boyer, 1987). Boyer noted that, in students" college choice decisions, "It was the buildings, the trees, the walkways, and well-kept lawns that overwhelmingly won out. The appearance of campus is, by far, the most influential characteristic during campus visits" (1987, p. 17). In determining who is most influential in recruiting students, he further noted that the work of the campus facilities director may have a greater impact than that of the college dean (Boyer, 1987).

Second, buildings communicate strong identity messages. The campus facilities comprise the institution's self-image, "how it wishes to present itself to students, alumni, faculty members and the public" (Greenberg, 2007). Architecture projects messages in three ways: through symbols, plans and relationships (Greenberg, 2007). For example, a church prominently anchoring one end of the campus quadrangle tells visitors that the college or university is or was once faith-affiliated. This may be an attractor for students who seek that kind of environment. For other students, upscale, high-end looking buildings may be an attractor; or historic buildings that convey a sense of tradition and timelessness. 
The majority of US colleges and universities have campuses that developed over decades, and many have developed over centuries. Their architecture typically reflects a range of styles and eras, forming "a complex and vital living composition, part of a context of shared ideas and respect for differences" (Greenberg, 2007, p. B25). Regardless of their style, Strange and Banning (2001) recommend that campus buildings should be human-scale in design. Settings designed as human-scale are no more than three stories in height, which blends in better with their surroundings and the landscaping. Because they are smaller and accommodate fewer people, human-scaled buildings tend not to be overcrowded, are easier to navigate, and allow students to become familiar with and feel competent in their environment more quickly. This, in turn, encourages greater participation and involvement among people (Strange \& Banning, 2001).

Similarly, campus buildings should reflect a balance between old and new design. When building or renovating, the style and architectural element determines the physical appearance of the building. According to Dahlgren, Dougherty, and Goodno, (2013) many campuses seek to maintain a level of uniformity between building styles so that new construction or renovation of existing facilities blend into the larger campus environment. Others build or renovate structures that are completely different in style to communicate a unique aesthetic value (Dahlgren, Dougherty, \& Goodno, 2013).

Regardless of campus design, when visitors are on campus, one of the first things they notice is the physical condition of the buildings. Run down, dilapidated facades send a message to visitors that the college does not care about its purpose or the condition of its campus. Or worse yet, it may signal that the college lacks adequate resources to 
operate properly and is unable to keep the buildings in good condition. Michael McPherson, Morton Shapiro and Gordon Winston, noted scholars on the economics of higher education, observe that while students may not have access to or understand campus budgets, they can readily grasp a sense of the financial health of an institution by viewing the condition of the campus and its buildings (1993).

Building interiors are just as crucial. When students walk into a building, they should feel a sense of comfort, a sense of community, and maybe even a sense of home (Strange \& Banning, 2001). Interiors should be barrier-free and accessible to all students (Kuh, Kinzie, Schuh \& Whitt, 2005). Directions and signage should be clear and understandable (Evans \& McCoy, 1998). Offices and services should be conveniently located (Strange \& Banning, 2001). Students should not have to go to multiple locations on campus in order to conduct basic university business, get their questions answered, or have their problems addressed. Ideally, student services offices (e.g. registrar, admissions, health services, counseling) should be located in one central area on campus.

Third, physical artifacts across the campus communicate the organizational culture (Schein, 2010). Observable through senses such as sight, smell, touch and hearing, these artifacts take a variety of forms and can include artwork, signs, graffiti (Banning \& Bartels, 1997) and printed materials. For example, the representation of students, faculty and staff in admission brochures, advertising and campus websites communicates messages about which types of students belong there. More subtly, the pictures and artwork displayed in buildings set a tone and send a message of who is welcome on that campus. Therefore, it is important to portray different cultures, genders, races, and physical abilities within campus artifacts (Banning \& Bartels, 1997). 
Campuses need greater awareness of the messages being sent to their students through artifacts (Strange \& Banning, 2001) and should strive to be welcoming to all students and reflect a diversified student body.

Finally, the physical environment can either encourage or discourage student learning, development, and skill acquisition (Strange \& Banning, 2001). All learning spaces should encourage or facilitate student engagement and involvement (Astin, 1985; Evans, Forney \& Guido-DiBrito, 1998). Formal learning spaces such as classrooms and laboratories need to be appropriately designed and in good condition. Environmental attributes such as adequate lighting and physical attractiveness influence human motivation and efficiency (Strange \& Banning, 2001). Furthermore, all buildings should meet the technological needs of today's tech savvy students. This includes wireless internet access and smart classrooms that host an array of electronic devices used to enhance student learning (e.g. smart boards, clickers, video projectors, etc.). Location of learning spaces matters as well: students prefer classrooms that are a convenient distance from the building entrance (Strange and Banning, 2001).

Yet learning also takes place outside of classrooms and across the college campus, in places such as residence halls, lounges, the library, the student union, and in the offices of student organizations and student services. Therefore, building interiors should incorporate flexible environments that may be changed periodically to meet multiple needs (Temple \& Barnett, 2007). Lounges and study locations, for instance, may be transformed into temporary classrooms for individual and group learning experiences (Temple, 2008). Multi-purpose design layouts facilitate greater student interaction and involvement (Strange \& Banning, 2001). This is particularly important 
within multi-use buildings such as the student union. Prudent campus planners know this. They design new construction and renovations to allow for a mix of academic space, social space, and flexible, multi-use space (Temple \& Barnett, 2007). Unfortunately, not every campus can redesign its facilities to improve their design. To build new or alter existing spaces takes substantial funding (Temple \& Barnett, 2007). Across the various aspects of the physical environment, research suggests that the millennial generation - current, traditional-aged undergraduates - have new needs and tastes that differ from previous generations of students (Rickes, 2009). Perhaps the most striking difference in millennial students is that they are digital natives, born into and shaped by a world of ubiquitous information and communication technologies (Levine \& Dean, 2012). Conveniences described previously, such as high-quality Wi-Fi services and centralized student services, reflect millennial student preferences. Millennial students also differ from their predecessors in that they have greater concerns for their physical privacy and desire more home-like living quarters while at college, replete with private rooms and bathrooms or apartment-style living (Damon, Montefusco, Moriarty \& Hood, 2011; Rickes, 2009). Other conveniences, such as marché-style dining facilities and increased lounge and recreational spaces for rest and relaxation also appeal strongly to millennials, and these have the added benefit of promoting greater face-to-face social interaction between students (Damon, Montefusco, Moriarty \& Hood, 2011; Rickes, 2009). Furthermore, millennials are an environmentally conscious generation, expecting and sometimes demanding greater sustainability in campus buildings and services (Damon, Montefusco, Moriarty \& Hood, 2011; Rickes, 2009). 
The physical component of the campus environment "elicit[s] appropriate emotions, interpretations, behaviors, and transactions by setting up [specific]... situations and contexts" (Rapaport, 1982, p. 81). Individual students will gravitate to, remain in, and thrive in environments that match their needs and preferences. This is the essence of person-environment fit. Therefore, a well-designed campus environment, including the student union, is important (Schuetz, 2005).

\section{Human Aggregate Component}

The human aggregate component of the campus environment refers to the characteristics of the people who inhabit the campus. This includes all of those who work at the university, such as faculty and staff, as well as all of those who study there, such as other students. Banning and Banning (1986) identify and define "studentinstitution fit...[ as]... the degree of congruency, or fit, between student characteristics and the ability of the institution to respond to those characteristics" (p. 1). This includes students' goals, needs and individual traits.

First, at the broadest and most basic level, students choose to attend colleges that will meet their educational goals (Strange \& Banning, 2001). Those goals may entail any of a number of outcomes such as completing remedial, transfer or continuing education courses; or earning program certificates, associate or baccalaureate degrees. Further, each of these outcomes is anchored to specific foci of study, such as academic majors or vocational curricula. Students' goals, therefore, encompass both the focus of study (e.g. major) and the intended outcome (e.g. degree), whether that is a program in English literature leading to a baccalaureate degree, or a course in automotive mechanics leading to a certificate of achievement. A college's or university's ability to deliver these 
programs is contingent upon an appropriately qualified faculty and staff. Thus, that collection of faculty and staff - the human aggregate - must fit prospective students' goals.

Second, while enrolled in college, students manifest an array of needs. Many needs, such as the need for advising, are universal to all students. Therefore, faculty should be available to students for questions and consultation, whether through scheduled office hours, staying after class to speak to students, or responding to email in a timely fashion (Kuh, Schuh, Whitt, Andreas, Strange, Krehbiel \& McKay, 1991). Preferably, faculty offices should be located near where classes are held (Rickes, 2009) to encourage students to meet with faculty. It is important for the faculty to be approachable to students. Sometimes students are afraid to ask for assistance, and those fears can be reinforced and magnified by experiences with faculty in which they are made to feel unwelcome, their questions are not answered, or they are given the wrong information.

Other students have particular needs relevant to their programs of study or their life situations. Prime examples of population-specific needs include those of nontraditional students, students with children, and millennial students. Non-traditional students who work full-time during traditional business hours will be attracted to colleges and universities who offer convenient evening, weekend, or online courses (Strange \& Banning, 2001). Yet colleges that provide such programs often forget that evening and weekend students also need flexible hours in campus services as well. Student service offices (e.g. registrar, financial aid, admissions, etc.) are commonly open only during daytime, weekday business hours. Similarly, faculty and staff commonly hold their office hours only during those times as well. Students who attend classes on evenings 
and weekends may encounter shuttered doors at food services, various student life or campus recreation offices, and other campus amenities. Campuses services and amenities should be accessible on a schedule that meets the attendance profile of all students.

Students who have children (student-parents) also have needs that differ from the mainstream student. Specifically, student-parents often need daycare or evening care services so that they may attend classes, study, or participate in college events. If this need cannot be met, student-parents may have to stop out, drop out, or slow down their college attendance until a later time in their lives. While working, non-student parents commonly use the services of daycare and early learning centers to care for their children, but this may not be a suitable option for student-parents. Such services may be too cost prohibitive, not offered in the hours or increments that student-parents need, or may require signing a contract or purchasing a membership that exceeds student-parents' financial means. College student-parents need childcare services that are affordable, manageable (Strange \& Banning, 2001), conveniently located, and offered on the days, times and increments that student-parents need them. Many colleges and universities are responding to this need, with childcare services becoming an essential part of their campuses (Lau, 2003). A college's capacity to meet student needs- whether those needs are universal or population specific - resides in its staff and faculty, the human aggregate.

Third, human beings tend to identify with others who have similar characteristics, and students are no exception. The extent to which students' individual characteristics mirror those of the staff, faculty and other students across the campus deeply influences student-institution fit. Students who share common characteristics with other people in 
the environment - including faculty, staff and other students - are more likely to be attracted to, feel welcome in, and remain in that environment (Strange, 2003; Strange \& Banning, 2001; Price, Matzdorf, Smith, \& Agahi, 2003). Being surrounded by others who share similar or familiar traits or characteristics fosters a sense of belonging or home to a student, reducing feelings of isolation or loneliness. While this phenomenon most overtly manifests concerning race, ethnicity, country of origin and gender/sexuality, other important commonalities include socio-economic status, patterns and habits of speech, manner of dress and behavioral norms. A high degree of person-environment fit across characteristics such as these correlates with higher degrees of satisfaction and stability, a greater desire to persist, and ultimately greater student retention (Smart, Feldman \& Ethington, 2000) and success.

The opposite can be inferred as well. A student will probably not be attracted to an environment in which the human aggregate - the composition of faculty, staff and other students - does not resemble, reflect or honor their own individual characteristics. This does not mean that a student should not enroll where there are fewer people like him or her, or that students who do so are doomed to failure. It does mean, however, that colleges and universities have an obligation to reflect, honor and achieve greater diversity in their human aggregate, and make efforts to support students whose characteristics are in a numerical minority. "[T]he character of an environment is implicitly dependent on the typical [aggregate] characteristics of its members" (Moos, 1986, p. 286).

\section{Organizational Component}

"[O]rganizations can be thought of as environments with a purpose" (Strange \& Banning, 2001, p. 61). For colleges and universities, that purpose is educating students, 
constructing and disseminating knowledge, and applying that knowledge to serve the community (Strange \& Banning, 2001). The organizational component of the campus environment refers to the structures that both embody and facilitate these purposes and goals. Individual colleges and universities are, in one sense, a single organization. Yet in another sense they are a confederation of numerous smaller organizations with decentralized control, serving an array of parallel, overlapping or competing constituencies and functions (Kerr, 2001). Many in academe have grown accustomed to such overlapping and confusing structures. Yet what makes sense to long-time inhabitants such as faculty and staff can be difficult for college students to understand and navigate.

When looking at the organizational component of the campus environment, a student will most often see a set of complex structures that make it difficult to identify: (a) who is in charge; (b) who makes the decisions about distributing resources; (c) who creates the rules for how the college should function; and (d) what must be accomplished when (Strange \& Banning, 2001). Many colleges and universities lack the ability to assist students in their understanding of and navigation through the organizational structure of the campus environment (Deil-Amen \& Rosenbaum, 2003). Specifically, seven specific organizational obstacles often impede student success: (a) bureaucratic hurdles; (b) confusing choices; (c) student initiated rather than college initiated guidance; (d) limited counseling availability; (e) poor advice from staff; (f) delayed detection of mistakes; and (g) poor handling of conflicting demands (Deil-Amen \& Rosenbaum, 2003). 
To explain further, a college's bureaucratic hierarchy often exceeds that of any organization within students' realm of prior experience and knowledge. Due to the organizational complexity of a college campus, students often do not know where to turn for the help or services they need. Those who have questions or concerns are often shuffled or sent all around the campus to visit multiple offices and speak with multiple staff in order to get the assistance they request. Research such as that of Godwin and Markham (as cited in Kuh, Kinzie, Buckley, Bridges \& Hayek, 2007), demonstrates that bureaucratic organizational structures frustrate college students and impede new students' socialization. While higher education institutions often have maddeningly bureaucratic policies and procedures in place (Bolman \& Deal, 2003), this bureaucracy should be tamed or mitigated so as not to impede students' opportunity for success.

Academic advising and learning support services offer a concrete example of organizational structures that often pose challenges for students. These services are vital to college success. Students need academic support and guidance right from the start (Deil-Amen \& Rosenbaum, 2002), offered flexibly to meet their scheduling needs. This is especially true for underrepresented or at-risk students who often need additional advising and support services to help them achieve their academic goals (Deil-Amen \& Rosenbaum, 2002). Yet all too often, challenges in the organizational structure prohibit students from benefitting fully from these services. For example, on some campuses academic advising and learning support services are offered passively, available for those students who seek them out, instead of being offered equally, directly, and actively to all students. As a result, some students obtain necessary advising while others do not. On other campuses, students navigate through multiple layers of advisors: pre-major, within- 
major, and program-specific advisors such as those for students in federal TRIO programs. Transitioning across or shuffling between multiple advisors diminishes the opportunity for students to build relationships with their advisors and increases the risk of inconsistent or ineffective advising. An opposite problem, for some students, guidance comes too late in their program to be beneficial, if it occurs at all.

\section{Constructed Component}

The constructed component of the campus environment refers to the inhabitants' perceptions of the college's context and culture. When students arrive at a college campus, the physical, human aggregate and organizational components of the environment collectively send out messages that shape students' expectations and experiences. By themselves, these three components form the campus' objective reality. However, at the same time, students co-create their own subjective reality based upon how they interpret what they see, hear and experience in the campus environment. The processes through which students construct, evaluate and internalize these perceptions form the dynamics of the constructed component of the environment (Strange, 2003; Strange \& Banning, 2001).

It works like this: two students walk onto a campus at the same time, experience the same objective physical, human aggregate and organizational components of the environment, and yet evaluate these differently, arriving at two varying subjective experiences. Within a campus' physical environment, for example, one student may feel at ease and at home; while another feels alienated and uncomfortable. There are myriad college campuses in this country, each with varying physical attributes. Some are rural, some urban and many in-between. Whereas some students may perceive rural colleges as 
backwater places possessing few positive attributes and inferior to urban colleges; conversely, others may perceive urban colleges as imposing, impersonal and threatening places, and long instead for the smaller communities often found in rural settings. Similarly, some students may perceive public universities as less prestigious - and therefore less desirable - than private institutions; whereas others may perceive private institutions as cold, elitist places that are rife with cliques. Likewise, campus artifacts may give one student a sense of belonging and familiarity; and leave another feeling isolated or devalued. In each of these examples, the objective elements are the same, but students subjectively experience and evaluate them differently.

Similarly, within the human aggregate component of the campus environment, one student may deem that his or her goals and needs have been adequately met (e.g. degree offerings, student services, faculty/staff accessibility, friendliness, etc.), and thus feel satisfied; whereas another student may feel dissatisfied. Even when students have the same goals and needs, one may feel assisted and supported in his or her encounters with staff, while another who is treated exactly the same may still feel ignored and unsupported, or may dislike a faculty member's advising style. Each student has different expectations and evaluations of their experiences.

In the organizational component of the campus environment, one student may be at ease with the college's rules and regulations, whereas another student feels confused and uncertain about what is permissible. Similarly, campus expectations might seem reasonable to one student, and restrictive to another. In such instances, all students are subject to the same rules, regulations and expectations, but their subjective, constructed experiences differ. 
Constructed environments are potent for the individual. When a student steps on campus, his or her perceptions can enhance or impede his/her opportunity for success. However, colleges can intervene and influence the constructed environment. Specifically, colleges can positively influence students' perceptions by intentionally creating relationships between the students and various components of the campus environment (Strange \& Banning, 2001), thereby fostering student engagement (Astin, 1985; Evans, Forney, \& Guido-DiBrito, 1998; Kuh, Schuh, Whitt, Andreas, Strange, Krehbiel \& McKay, 1991). For instance, involvement with informal student groups and formal student organizations assists students with "making meaning of the college experience" and interpreting the organizational culture (Schein, 2010, p. 104).

\section{Environmental Psychology and Campus Ecology}

The work of Strange and Banning (2001) in the preceding section focuses on how various elements of the campus environment influence college students. Theories supporting the connection between human behavior and the environment trace back to the rise of behaviorism in the early twentieth century (Skinner, 1938; Watson, 1930). Behaviorism, a field of psychology that focuses on observable actions, maintains that human behavior is influenced by stimuli in the environment. This forms the core of theories such as operant conditioning (Skinner, 1938), through which behavior is learned or trained in response to environmental stimuli; and in theories such as applied behavioral analysis (behavior modification), though which undesirable behaviors are changed or unlearned in response to changes in environmental stimuli. 


\section{Environmental Psychology}

A modern outgrowth of behaviorism, environmental psychology "examines the interrelationship between environments and human behavior" and offers a theoretical framework to guide campus planning (De Young, 1999, p. 1). Psychologists broadly use the term 'environment' to include natural, man-made, and socially constructed elements (De Young, 2013). Unlike the one-directional relationship in behaviorism, environmental psychology takes a symbiotic view, holding that human behavior shapes the environments, just as the environment influences human behavior (Bechtel, 1997; Kopec, 2006). Given that environmental stimuli invoke human behavior, "understanding the relationship between stimulation and human responses is an important component of good [environmental] design" (Kopec, 2006, p. xv). To investigate that relationship, the field of environmental psychology has six subsets of study: (a) attention, (b) perception and cognitive maps, (c) preferred environments, (d) environmental stress and coping, (e) participation, and (f) conservation behavior (De Young, 1999). Each is defined below.

Attention. Environmental psychologists are concerned with "understanding how people notice the environment" (DeYoung, 1999, p. 223). This includes both directed and undirected attention. Directed attention refers to people's intentional efforts to focus on and maintain awareness of elements in their environment; undirected attention refers to people's attention being unintentionally captured by, or distracted by elements in the environment which "command human notice" (DeYoung, 1999, p. 223). Campus planners can consciously shape and direct students' attention to the environment through campus design and interior building designs. Human-scaled design, for example, directs 
attention on the people within the environment and avoids directing attention to the building itself (e.g. towering height).

Perception and cognitive maps. Environmental psychologists further study how people retain and recall information about the environment. Although people may believe that they have total-recall capacity, able to fully recall memories of an environment with $100 \%$ accuracy, this is a fallacy. What people perceive, retain and recall is always a mixture of objective reality and subjective interpretation (De Young, 1999). “[C]ognitive maps...link one's recall of...[the environment] with perception of present events, ideas and emotions ... prior knowledge and expectations" (DeYoung, 1999, p. 223).

Preferred environments. Environmental psychologists take an interest in the factors that make an environment preferable among individuals. "People tend to seek out places where they feel competent and confident, places where they can make sense of the environment while also being engaged with it" (DeYoung, 1999, p. 223). Preferable environments strike a balance between being 'sensible' and 'engaging.' On one hand, the environment needs to be understandable and predictable so that people can make sense of it. "Purposive actions," Evans and McCoy note, "require legible interiors. Coherence enables users to make reasonable deductions about the identity, meaning and location of objects and spaces inside of buildings" (1998, p. 87). On the other hand, the environment must offer enough complexity, variety and newness to attract people's engagement (De Young, 1999). "Human beings function optimally with moderate levels of stimulation [such as intensity, variety, complexity, mystery and novelty]. Lack of stimulation leads to boredom... Too much stimulation causes distraction and overload which interfere with 
cognitive processes that demand effort or concentration" (Evans \& McCoy, 1998, p. 86). Although subjective interpretations of what is sensible and engaging will vary among individuals, people experience greater well-being and effectiveness when they are in their preferred environments (De Young, 1999).

Environmental stress and coping. Environments are not always preferable. Actually, the inverse is more likely to be true. People experience an array of environmental stressors on a daily basis. Some of these are physical stressors, causing discomfort to the senses (odors, noises, uncomfortable temperatures or humidity levels, inappropriate lighting). Others are cognitive stressors, such as "prolonged uncertainty, ...[un]predictability, and stimulus overload. Research has identified numerous ... [negative]... outcomes [from environmental stress,] including physical illness, diminished altruism, helplessness and attentional fatigue (DeYoung, 1999, p. 223). Environmental psychologists study both the cause of stress as well as people's responses to it. Although coping responses vary widely, they fall into four basic categories: (a) do nothing and endure the stressors; (b) leave or escape the setting; (c) change or alter the setting; and (d) change or alter one's thinking about the stressors, thereby diminishing or diffusing their effect (DeYoung, 1999).

Participation and conservation behavior. Both of these final two subsets of study in environmental psychology are closely related. They involve studying people's values and attitudes about their environments; educating people about the humanenvironment interrelationship; engaging people in designing, maintaining or restoring their environments; and promoting ecologically sustainable environments and behavior (De Young, 1999). The difference between the two subsets is that "participation" 
concerns itself with people's awareness of and involvement in environmental design, broadly; whereas "conservation behavior" strictly concerns itself with sustainability issues.

\section{Connections with Campus Ecology and Campus Design}

The principles and perspectives of environmental psychology are evident as an undercurrent in Strange and Banning's (2001) writing on campus environments, and in the work of other authors referenced in the preceding section. Components of the campus environment - the physical, human aggregate and organizational - capture students' attention and influence their behavior. When designed well and working effectively, campuses can create preferred environments for students that make sense, are easy to navigate, and promote engagement. Effective campus space configurations, for example, promote teaching, learning, research, communication and decision-making (Scott-Webber, 2004). Conversely, when poorly designed or neglected, campuses can pose environmental stressors for students that detract from their educational experience or influence attrition. For example, crowded, overheated spaces can lead to aggression or hostility between students and thwart classroom learning (Graetz \& Goliber, 2002).

Environmental psychology takes a two-way perspective, focusing on the interrelationship between people and their environment. Subsets of study examine how people act as influencers in that relationship either by (a) directly shaping the environment, (b) choosing their reaction to it, (c) filtering their experiences through perceptions, or (d) reframing their thinking about the environment. Likewise, the interrelationship between students and their campus environments was also evident as an undercurrent in Strange and Banning's (2001) work. Students directly and indirectly 
influence the campus environment - physical, human-aggregate, and organizational through their goals, needs and preferences. In response to students, campus faculty and staff (the human aggregate) initiate changes in the environment such renovations and reorganizations, new programs and services (physical component, organizational component, human aggregate component) with the intention of attracting, retaining, and serving students better.

A less visible but equally important influence, students also subjectively construct the campus environment through their perceptions (Strange \& Banning, 2001). The entire environmental psychology subset of perception and cognitive mapping addresses this phenomenon. This also relates to concerns such as attention (choosing where to give or withhold attention), coping (choosing how to cope or not cope), preferred environments (subjectively evaluating what constitutes sensible and engaging in determining preference), and participation (harboring preexisting values and attitudes about elements in the environment).

Scholars have called the intersection of environmental psychology and campus design, "campus ecology" (Banning \& Bryner, 2001). Just as living organisms thrive within specific ecological niches in the natural environment, campus ecology theory holds that students will thrive in particular niches in the campus environment. This too is the essence of person-environment fit. All components of the environment - physical, human aggregate, organizational and constructed - shape the campus ecology (Strange \& Banning, 2001). Following in the tradition of foundational student affairs research such as that of Astin (1968), it focuses specifically on the mutual influence between college students and the campus environment, and helps student affairs professionals better 
identify, assess, and build preferred environments that support student success. While "[c]ampus ecology is not a student development theory, ...[it is] a method of conceptualizing the [environmentally triggered] processes associated with student development (Banning \& Bryner, 2001, p. 15).

\section{The Role of Campus Facilities and the Student Union in Recruitment and Retention}

Recruitment and retention have become challenging problems for many institutions. Educational attainment and college completion are among the top legislative policy priorities across the United States, coupled with performance-based funding mechanisms that incentivize and reward institutions for meeting these goals (AASCU, 2014). Therefore, effective strategies should be implemented that not only encourage students to attend college but also provide the assistance needed in order to help them be successful.

\section{The Challenge of Recruitment and Retention}

Volumes of research have been written on the challenges of recruiting and retaining students, as have numerous publications that summarize such research. For example, regarding recruitment, Dean, Hunt and Smith (2006) categorize the major theoretical models underlying college choice and recruitment as: "[a] economic..., which views a student's decision to attend college as an investment decision, ... [b] status attainment ..., which views a student's decision to attend college as calculation of its impact on their social status ..., [c] psychological..., which looks at how college environments ... fit with a student's individual identity, ... [d] information processing..., in which students attempt to reduce the process of uncertainty when selecting a college, by processing college-related information socially through interaction with peers, family 
and their school ..., [and e] hybrid ..., which combines two or more of the aforementioned models in various ways" (p. 18). Each of these models reflects an evolving understanding of the phenomena-effecting enrollment, and encompasses a variety of assets and barriers that promote or deter college choice among prospective students.

Likewise, regarding retention, Vincent Tinto (2006) reviewed four decades' of research on student retention and revealed how steady advances in our understanding of student retention have led to an array of models that still fail to capture the full complexity of retention decisions. Whereas the earliest research on retention viewed it as a result of individual student "attributes, skills, and motivation ... [by the 1970s researchers better] understood the relationship between individuals and ... the institution, in student decisions to stay or leave. ...Central to this model was the concept of integration and the patterns of interaction between the student and other members of the institution..." (Tinto, 2006, p. 2-3). Retention research in the 1980s, "reinforce[d] the importance of student contact or involvement," particularly outside of the classroom in the extra-curriculum, and particularly during the first year or transition to college (Tinto, 2006, p. 3). From the 1990 s through the present, retention research has exploded as has our understanding of the influence and intersections of students' varying backgrounds, an array of "cultural, economic, social, and institutional" forces, and differences in institutional environments (Tinto, 1993, 2006, p 3-4). As with college choice, we now have an array of economic, psychological and social models to understand and predict student retention; what is clear, though, is that student engagement is among the strongest influences on retention and graduation (Tinto, 2006). 


\section{The Importance of Campus Facilities in Recruitment and Retention}

The previous section reviewed the influence that components of the campus environment and environmental psychology have on students and their decisions to enroll or remain at a college or university. Relatedly, research also directly links campus facilities with recruitment and retention. Reynolds and Cain (2006) in their extensive review of this research, cited the seminal work of the Carnegie Foundation, Survey of the Transition from High School to College (1984-1985), in which 1,000 college-bound high school seniors revealed "that campus visits were the most important and most frequently used source of information in deciding on a college ...suggest[ing] that the physical property of a school has a strong relationship to college choice and selection... [particularly the] appearance of the grounds and building[s]" (p.12).

In more recent research, Price, Matzdorf, and Smith (2001), in their study of 4,812 students in the United Kingdom, demonstrated that campus facilities had an important effect on college choice. Repeating their study again a year later with 3,980 students, they again "clearly and unambiguously confirmed" that campus facilities influence college choice and "can often differentiate a particular institution" (Price, Matzdorf, Smith \& Agahi, 2003, p. 220). Specifically, important campus environment influences in their study included:

- Availability of areas for independent or group study,

- Availably of quiet areas,

- Availability of computers,

- Availability of university-owned accommodations,

- Cleanliness of accommodations, 
- Diversity/range of shops at the university (banks, bookshops, travel agents, food),

- Prices at the catering outlets (food services),

- Quality of bars on campus,

- Quality of library facilities,

- Quality of the lecture \& theatre facilities,

- Quality of the university grounds,

- Student union social facilities, and

- A friendly attitude towards students

Based on both studies, the authors concluded, "There is evidence that where the [campus and facilities have] been treated as a strategic asset it figures more highly in students' perceived reasons for choosing a particular location" (Price, Matzdorf, Smith \& Agahi, 2003, p. 220).

Closer to home, Reynolds and Cain (2006) surveyed 16,153 students in the United States and Canada, seeking to understand the influence that campus facilities had on their choice of college and retention decisions. This robust and comprehensive study included a mix of full-time and part-time students, male and female, representing an array of races; hailing from across 1,013 large and small, four-year public and private colleges and universities in urban, suburban, small town and rural settings. Focusing on the results for the students from the United States, they found that the quality of campus facilities was in the top third of 18 college characteristics important to students in college choice decisions ( $6^{\text {th }}$ out of 18 ). The most important facilities that students considered in college choice were academic-oriented, although more than a third of students named residence halls, recreation and exercise facilities, open spaces and the bookstore as important; and 
one fifth or more named the student union, dining facilities, and the performing arts center as important. These were also the facilities students that students deemed most important for them to see during their college search process; and $50 \%$ of the students surveyed agreed or strongly agreed that the first impression of the physical campus (knowing it was the "right college" for them) influenced their college choice decisions. Conversely, more than one fourth of students (26\%) reported rejecting a potential college because of an array of missing or inadequate facilities that they deemed important to them; and twice as many reported rejecting a potential college because of poorly maintained facilities such as residence halls (69\%), classrooms (44\%), open spaces (30\%), student unions (25\%), the library (19\%) and recreation facilities (16\%). In fact, $64 \%$ of all students agreed or strongly agreed that the condition of campus facilities influenced their enrollment decisions, with $16 \%$ saying that they had rejected a potential college because of poor maintenance. Notably, for more than a fifth $(22 \%)$ of students participating in the study, their parents' perception of the campus facilities was also an influence.

Gender differences in the important of campus facilities. In the same study, Reynolds and Cain (2006) also examined gender differences among students in their views on the importance of campus facilities. Generally, women were more influenced by and satisfied with campus facilities overall, but most differences were slight. Statistically significant differences $(\mathrm{p}=0.05)$ were evident, however, concerning the influence of specific facilities. For example, women deemed residential facilities, open spaces, the student union/center, the library, classrooms and facilities related to their majors as more important to see in a campus visit than men did, and women were significantly more 
likely to report rejecting a college because these facilities were either missing, inadequate and/or poorly maintained. In contrast, men deemed the computer and technology facilities and research/lab facilities significantly more important $(p=0.05)$ to see in a campus visit than women did, and were more likely to reject a campus when these were deemed inadequate.

Racial differences in the importance of campus facilities. Probing their data further for statistically significant differences in students' views according to their race, Reynolds and Cain (2006) found that all racial groups in the study held an attractive campus as equally important. Caucasians and Hispanics had significantly more overall positive feelings about their campuses $(\mathrm{p}=0.000)$ than students of other races, though, while Native Americans were generally less satisfied with their campus facilities than students of other races $(\mathrm{p}=0.010)$. While there were some differences among student racial groups in the perceived importance of various campus facilities, the differences were not statistically significant. However, looking at barriers to college choice, most minority races (Asians, Native Americans, African-Americans, and students of mixedrace) were significantly more likely $(\mathrm{p}=0.000)$, to have rejected a prospective college because of inadequate residential facilities; Asian students were also more likely to have rejected a college due to inadequate libraries and research/laboratory facilities; and African-American students were more likely to have rejected a college because of poorly maintained facilities.

\section{Differences in the importance of campus facilities by institutional type.}

Reynolds and Cain (2006) noted several statistically significant differences between students at public and private institutions in their views on the importance of campus 
facilities. For students in public colleges and universities, the condition of campus facilities was significantly more important in their college choice decisions; they were significantly more likely to know that the campus was "right for them" based on their first visual impression; and they were significantly more satisfied overall with their campus facilities than students at private institutions were $(p=0.000)$. For students at private colleges and universities, their parents were significantly more likely to be concerned with campus facilities in the college choice decision, and they were more likely to have rejected a prospective college for missing, inadequate or poorly maintained facilities $(p=0.000)$.

Reynolds and Cain's work (2006) clearly demonstrates that although the appropriateness and quality of academic programs were the most important influences on college choice, the presence, adequacy and proper maintenance of various physical components of the campus environment also had a strong role, with a significant number of students rejecting prospective colleges and universities based on missing, inadequate or poorly maintained facilities. Furthermore, these findings held true across gender, race, and institutional type; although there were some statistically significant differences evident in these demographic variables. As the authors note the research indicates that the built environment is fundamentally related to recruitment and retention of students. This relationship suggests that campus planning and operations of the built environment should be an integral part of the recruitment and retention strategy. Long-range planning for new construction and the repair and replacement of existing 
facilities and infrastructure should be an integral part of the institution's strategic plans in support of the academic mission (p.6).

\section{The Importance of Community in Recruitment and Retention}

Students have high expectations that universities, and more importantly student unions, are going to meet all their needs. As consumers of higher education, they expect numerous amenities within the student union. According to Dahlgren, Dougherty, and Goodno (2013) the amount of services provided can increase recruitment and retention efforts. The examination of the literature in regards to recruitment and retention also reveals the need for a sense of community. Student engagement is among the strongest influences on retention and graduation (Tinto, 2006), and that engagement cannot happen in isolation. It necessitates community. Along these lines, Alexander Astin's (1985) theory of involvement notes that "students learn by becoming involved" (p. 133). Astin's work (1985) emphasizes the need for campuses to create involvement opportunities for students both inside and outside the classroom, across the campus.

David Boren (2008), past President of the University of Oklahoma, in an excerpt from his book A Letter to America noted that all colleges (two or four-year) need to rebuild their spirit of community to basically create a sense or feeling of a small town

community. Creating a place that feels like home can increase the likelihood of a student staying on campus (Boren, 2008). He further commented that every decision made on a campus should reflect the goal of increasing community. However, one problem with Boren's suggestion is that, as Cheng (2006) noted, we "lack ... an agreed-upon framework for [defining] community. Pointing to the work of Ernie Boyer (1990), Campus life: In search of community, Cheng (2006) reviewed multiple nuances that can 
be used to define community. Cheng's qualitative research on definitions, experiences and indicators of community among college students (2006) demonstrated that community continues to be an individualized concept; students come to campus with varying expectations, and experience and interpret the environment in different ways. His findings resonate with Strange and Banning's (2001) conceptualization of the constructed component of the campus environment, and with environmental psychology's symbiotic, co-constructed relationship between people and their environments (De Young, 1999).

The role of facilities design in fostering campus community. Nevertheless, despite different conceptualizations of community and subjective interpretations of it, in order for students to be involved, environments must be created in colleges that encourage and facilitate such involvement. Scholars agree that campus facilities have a role in fostering campus community (Boren, 2008; Henry, 2004). Strange and Banning (2001) posit that the relationship between students' behavior and the campus facilities can be either direct, one of cause and effect (determinism); probable, with the environment likely to influence behavior (probabilism); or possible, with the environment encouraging or inhibiting behaviors (possibilism). As campuses have expanded over decades and centuries in response to steady growth in mission and enrollments, many have lost that sense of community through haphazard campus development (Greenberg, 2007). New campus facility designs, renovations or redesigns must therefore reverse the trend and encourage engagement, opportunities for involvement and a sense of community. Because capital improvements are costly and permanent, campus planners must make wise design decisions that address these goals. According to Strange and 
Banning (2001), the most salient environmental factors in the campus environment related to the purpose and development of community are campus location, human-scale design, layout, and flexibility.

Campus location. Campus location is perhaps the most obvious factor when considering how to foster community development in colleges and universities. Locations create opportunities for involvement. Cheng (2006), for example, found that the students in his study were eager for more intermixing of the campus and the surrounding New York City in the creation of campus community. While nearly all colleges and universities are not in a position to change their campus location, they can change their built and human relationship with that location.

A college or university whose built architecture "ignores its surroundings may suggest superiority, lack of interest, or even contempt. The same may be true of the human relationships or lack thereof, between the campus and its adjacent town" (Greenberg, 2007, p. B25). One need look no further than the ongoing contentious relationship between Columbia University and neighboring Harlem to see how campus communities can embrace location or isolate themselves from it (Lee, 2003; Shapiro, 1968; Sugar Hill Harlem Inn, n.d.). In the case of Columbia University, the institution has a history of holding itself intentionally apart from the local community, while attempting to use local resources to its advantage. In contrast, at other colleges, such as Farmingdale State University, Hampshire College, and San Jose State University the campus perceives itself as one community integral with the local town (David-Gaines, 2013; Kemp, 2013), and creates an array of initiatives that build town-gown community. 
Human-scale design. As reviewed in the preceding section, human-scale design refers to buildings that are three stories or less in height. This has the advantage of blending in better with the campus environment, an attribute that harmonizes campus design. Human-scale buildings are also easier to navigate, which diminishes environmental stress. Finally, their size is conducive only to smaller-sized human groupings and organizational arrangements, making overuse and overcrowding an improbability, and encouraging human interaction and involvement (Strange \& Banning, 2001).

Layout. The layout and design of the overall campus and the specific buildings within it facilitate the interaction of students, and can be seen as a precursor to involvement (Strange \& Banning, 2001). The term, layout, encompasses both specific elements within a building or campus, as well as the overall arrangement or design. Strange and Banning (2001) note that a building's specific features can encourage or discourage student development and learning. Torin Monahan (2002) calls this phenomenon 'built pedagogy.' He notes

the design of built spaces influences the behaviors and actions of individuals within those spaces. To a certain extent, these spaces embody the pedagogical philosophies of their designers ... Built pedagogies operate along a continuum between discipline and autonomy. On the disciplinary side, they can restrict learning possibilities by not allowing for certain movements or flows. For example, desks bolted to the ground make flexible interpretations of spatial use extremely difficult, and they impose directions for how space should be used. In the middle of the 
discipline/autonomy spectrum, there are built pedagogies that enable but do not require flexible behaviors: movable partitions and desks illustrate space left open to interpretative use. Finally, on the autonomy end, open classrooms invite and almost demand that individuals appropriate space to their perceived needs (p. 10).

While Monahan coined the term, built pedagogy, in 2002, Humphrey Osmond (1957) discovered these principles almost sixty years ago (as cited in Howard, 2008). He called the first, sociofugal, a grid-like system that keeps people separated; he called the second, sociopetal, a connecting system that brings people together (Howard, 2008).

The arrangement of the campus environment is the most influential factor for students (Moos, 1974). Chism (2006) notes the importance of achieving campus decenterness, turning the whole campus into a unified learning space. Rather than isolating, sociofugal layouts, campus buildings should be designed to encourage individuals to interact with each other. Rather than desks-in-rows seating arrangements, classroom seating should encourage greater student interaction. The purpose of campus facility design should be centered on the creation of areas/space for students to be engaged and involved (Astin, 1984; Evans, Forney et al., 1998; Schein, 2010). Central, sociopetal spaces that bring people together are essential. These are "[f]ocal points [that] provide socialization and small group interaction opportunities" (Evans \& McCoy, 1998, p.89). These spaces may be indoor, outdoor or identified as "personal space" that students' can call their own. Even a porch, Strange and Banning note (2001), can function as a sociopetal feature that encourages social interaction" (p. 198). 
"Legibility, the ease with which one can comprehend the spatial configuration of an interior space, is a critical component of building coherence" (Evans \& McCoy, 1998, p.87). Strange and Banning (2001) recommend behavioral zoning in campus buildings to help identify which areas are intended to serve which specific student needs, such as studying, eating, lounging, etc.. Behavioral zoning within campus buildings functions similarly to the way in which people zone specific behaviors within their homes (kitchen, bedroom, den, home office, etc.).

Flexibility. The layout should be predictable, which contributes to psychological comfort, and yet flexible for reconfiguring space as needed. Monahan (2002) identified five flexible properties of space. "Fluidity represents the design of space [to allow] for flows of individuals, sight, sound, and air;" and can be achieved thorough elements such as open spaces, windows and moveable partitions or screening (Monahan, 2002, p.2). "Versatility indicates the property of space that allows for multiple uses" (Monahan, 2002, p.2). For example, corridors can be used flexibly (Chism, 2006); given slender seating and tables they can function as passageways, coffee-break, study, and meeting spaces. "Convertibility designates the ease of adapting educational space for new uses," (Monahan, 2002, p.2), such as converting a single large classroom into smaller seminar rooms, or upgrading an older classroom with "smart" classroom technologies.

"Scalability describes a property of space for expansion or contraction" through annexes, additions, or converting entire buildings (Monahan, 2002, p.2). The final flexible property of space, "Modifiability is the spatial property which invites [quick and] active manipulation and appropriation...through mobile components such as walls, partitions, furniture, and equipment" (Monahan, 2002, p. 2). 
Innovative, flexible, and engaging educational environments best support student outcomes (Schuetz, 2005). To interact effectively with an interior space, individuals need a measure of control, or the ability to adjust lighting, climate, seating, privacy and the like (Evans \& McCoy, 1998). They need the versatility and modifiability as suggested by Monahan (2002). Modular seating arrangements, such as moveable chairs and tables, enable students to reconfigure spaces as needed, promoting eye contact, socializing and group interaction (Evans \& McCoy, 1998; Strange \& Banning, 2001). Increasing and enhancing student involvement and community requires flexibility by all constituents when creating spaces on campus for students.

“Third place." A "third place" is also needed on many university campuses and is related to student involvement (Oldenburg, 2001). Oldenburg noted that a "third place" is distinguished by its characteristic setting, "a place where one neither lives nor works, but where one goes to relax and enjoy the moment" (2001, p. 4). "Third places" can also become breakout spaces that students can use for studying after class has ended, or use to work together collaboratively on projects. This supports Astin's (1985) belief that learning can actually take place anywhere, not just in the classroom. Millennial students, in particular, seek spaces on campus where they can study or hang out in small groups (Rickes, 2009), or take time to use their technology such as cell phones, tablets and laptops. This experience, the "third place," would typically be facilitated in a student union.

Safety and security. In Strange and Banning's (2001) hierarchy of needs within campus facilities, basic safety and security - and with it a sense of inclusion and belonging - precede student involvement, engagement and community. Campus 
environments that promote community will inherently also provide for safety and security. Cheng's study (2006) of college students' perceptions and experiences of campus community revealed that while safety and security (adequate lighting, visible walkways, safe public places) were important, equally important was the respectfulness and efficiency of campus security staff interactions with students. Without efficient, effective and respectful services, students did not feel safe or secure. This also includes the services of maintenance staff, university bookstore vendors, and student health service providers. When students are in an environment that provides them opportunities to be safe, successful and satisfied, they will stay and thrive in that environment.

The role of the student union in fostering campus community. The initial section in this chapter presented the long history of student unions in American colleges and universities, and outlined the many ways in which these special facilities have supported and fostered community among students and the entire campus. Boren (2008) called the student union the "heart of campus" and encouraged colleges to create a small town feel in the student union as a way towards fostering campus community (p. A34). Wilma Henry (2004) echoed Boren's feelings when noting that the 21st century student center creates numerous opportunities for community building as well as collaboration.

Research continues to demonstrate the important role student unions hold on college and university campuses. For example, Henry (2004) emphasized the student center's critical role in the recruitment and retention of students, as it is often the first building on campus visited by parents and prospective students. Nearly two-fifths (38.7\%) of the 16,153 students in Reynolds and Cain's 2006 study of the role of facilities in student recruitment and retention, said that it was important for them to see the student 
union during the campus visit/college choice process; and one-fifth (21\%) said that the quality of the student union was important or very important to their enrollment decisions. Likewise, Romano and Hanish (2003) noted that the student union is one of the top eight most important characteristics used by a student to make their college choice.

The student union holds a deep symbolic value for students. Two-thirds (60\%) of the 16,153 students in Reynolds and Cain's study (2006) agreed or strongly agreed that a student center/union symbolizes a student-centered institution. Interestingly, students at private colleges and universities were significantly more likely to agree with that statement $(\mathrm{p}=0.000)$ than their counterparts at public institutions were, and significantly more likely to see the student union during their campus visits, factor the student union into their enrollment decisions, and reject a prospective college because of a lacking, inadequate, or poorly maintained student union. Puzzlingly, however, students at public colleges and universities were significantly more satisfied $(\mathrm{p}=0.000)$ with their campus student union than students at private colleges were.

Clearly, student unions make a difference in student recruitment and retention and can help attract and keep students on campus. Physical, human-aggregate, organizational and constructed components of the campus environment (Strange \& Banning, 2001) converge in the student union. These multi-purpose, flexible spaces house an array of services and spaces that meet a myriad of needs. They serve as sociopetal forces, a place in which students, faculty, staff, and community members interact with one another. Student unions are a unifying force, a community center that serves the whole of the campus community (ACUI, n.d.). 


\section{Barriers to Campus Facility and Student Union Design}

Components of campus environments, environmental psychology, and campus ecology provide insight as to the importance of key amenities and features in the campus built environment. We might reasonably expect that campus executives, facilities directors and student union directors would understand and value these theories, and articulate their inclusion into the design, redesign or renovations of campus facilities and student unions. Doing so could have a tremendous impact on the recruitment and retention of students, and the fostering of campus community. However, as Greenberg (2007) observed, many campus capital projects appear to have been accomplished with little regard for design and environmental theories. While the barriers to effective campus facility and student union design may be numerous, at least three stand out.

\section{Knowledge Constraints}

Campus leaders, key administrators, and campus constituencies may lack an understanding - or worse, lack an appreciation - of campus design and environmental psychology theories. They may not realize its importance. Environmental psychologists continue to advance their own understanding of people's values and attitudes about their environment (De Young, 1999). Chism (2006) notes that despite our knowledge about built pedagogies (Monahan, 2002), deeply entrenched facilities policies push capital planning and construction into a rut that ignores what we know about campus ecologies. Moreover, many faculty remain unwilling to make changes in their teaching practices and teaching environments (Chism, 2006), even when they are able to do so.

Greenberg (2007) goes further to suggest that campus leaders simply do not care. He laments 
“[B]eyond the elementary provision of space, campus planning and architecture are no longer considered important or worthy of serious attention....[N]ew buildings [are erected] with little or no relationship to each other or to their historic cores. Many of those buildings often seem interchangeable because their designs seldom consider differences in location, climate, topography, and culture. [We are] ... creating campuses that look like random collections of unrelated buildings" (2007, p. B25).

He challenges those in colleges and universities to "learn to read architecture again" (2007, p. B25). This too is a concern of environmental psychologists, who seek to expand people's awareness of and involvement in the design, maintenance or restoration of their built environments (De Young, 1999).

\section{Financial Constraints}

Where campuses have an appreciation of and desire for more effective campus facility and student union designs, limited finances especially in public and small private institutions, govern what may be accomplished (Chism, 2006). Colleges and universities will continue to experience financial constraints as funding at the national and state level continues to be reduced. While colleges and universities fund capital project (new construction and renovations) through a variety of means, such as direct state support (legislator or voter determined), bond issuance, student tuition and fees, and gifts and donations, each of these revenue sources is under pressure in the present economic climate. The amount and allocation of state appropriations for higher education remains a top ten policy issue in state legislatures, as does concerns for rising tuition and tuitionsetting policies (AASCU, 2014). 
In the meantime, costs continue to rise for new construction projects and renovations (Schroer \& Johnson, 2003). States simply may not be able to afford these projects and may have to make tough choices in capital outlays. "Aging campus facilities and diminished state monies due to the economic downturn has led to pent-up demand for significant state investment in campus construction needs," becoming yet another top ten policy issues for state legislatures (AASCU, 2014, p.4). While they may be unseen or unnoticed by many individuals on campus, critical infrastructure needs "such as roofs, power plant-affiliated equipment, and water and electrical substructures," have taken a beating from the combined effects of time and deferred maintenance (AASCU, 2014, p. 4) and need to be upgraded. Another large category of expenditure will be for technology upgrades, lab and research facilities improvements, and expanding classroom capacity (AASCU, 2014, p.4).

Academic and technology related facilities are vital assets in fierce competition for student enrollments and retention (Reynolds \& Cain, 2006; Schroer \& Johnson, 2003). As construction and renovation demand significant financial resources, placing a priority on academic and technology facilities leaves little money left over for building or renovating student unions. Although the unions are deeply important in student recruitment and retention as well, the importance of academic and technology facilities prevail (Reynolds \& Cain, 2006).

In the absence of appropriations, if colleges and universities place the burden on students directly for funding facility needs, it will inevitably lead to a tuition fee increase. In the current economic environment, this would most certainly be a difficult expense to cover for all but upper economic class students. For those students who lack fiscal 
means, fee increases translate into greater loan debt or greater out of pocket expenses. Given the public and political negative discourse on rising college costs, wise campus leaders are unlikely to take this course of action and opt not to fund facility needs through student fees. Likewise, in states where students vote on their special-use fee increases, such as California, support for a facilities-related fee increase is not likely to gain favor. Looking within the buildings, Chism (2006) noted other facility-related financial constraints,

"Many public campuses, for example, have no base funding allocations for furniture replacement. Furniture is generally funded with the construction of a new building or when major renovations take place, but routine replacement of furniture and updating of lighting and decor depend on the chance administrator with a little end-of-the-year cash. It is not unusual to see 40-year-old chairs in classroom buildings. In addition, universities often have no designated funding source for informal learning spaces" (p.1).

To help absorb some of their costs, some college unions derive a portion of revenue from the use of services located within the union, including auxiliary services like a college bookstore or campus dining center (Schroer \& Johnson, 2003). However, while these may help to offset operational expenses, they are insufficient for funding renovations and new construction.

\section{Political Constraints}

Bolman and Deal (2003) observed that politics are an important organizing framework in institutions. Politics often involve struggles for control over real or 
perceived limitations in key resources. As applied to campus facilities, both space and funding are key resources that have real limitations. They are often the focus of political disputes in colleges and universities. For example, Chism (2006) notes that part of the problem in funding facility refurbishments and maintenance is that organizational policies are often unclear concerning who has controlling authority over various spaces such as lobbies and hallways, and who is fiscally responsible for them. She challenges campuses to rethink how they finance space-related needs. On a larger scale, prioritizing among various campus capital construction, repair or renovation needs may happen more through politics than through prudent thought.

\section{Summary}

This chapter reviewed the stages of the historical development of student unions; the components of the campus environment; environmental psychology and its intersection with campus ecology; the role of campus facilities and the student union in student recruitment and retention; and several barriers to campus facilities and student union design.

College completion has become a top legislative priority across the United States (AASCU, 2014). Successful student recruitment and retention underlie this important policy priority as necessary first steps. While the research on the assets and barriers to student recruitment and retention are voluminous, we know that good personenvironment fit and student engagement strongly promote enrollment and success (Tinto, 2006). Both of these - fit and engagement - can be powerfully influenced by the campus environment (Astin, 1985; Evans, Forney, \& Guido-DiBrito, 1998; Kuh, Schuh, Whitt, Andreas, Strange, Krehbiel \& McKay, 1991; Strange \& Banning, 2001). 
Taking a broader view, the field of environmental psychology offers

understanding on how the environment influences human behavior. This field delves into how people notice aspects of, retain information about, and navigate their environments; and how certain aspects of the environment invoke stress and coping responses, while other aspects create preferred environments that invoke positive feelings and effective behaviors (DeYoung, 1999). Focusing on campus environments, the theory of campus ecology addresses how colleges and universities can create the conditions for effective person-environment fit by building an array of preferred environments - ecological niches - that meet the diverse needs of college students and contribute to their success (Banning \& Bryner, 2001). All components of the environment - physical, human aggregate, organizational and constructed - shape the campus ecology (Strange \& Banning, 2001).

Research demonstrates that campus facilities - the built environment within the campus ecology - are fundamentally related to student recruitment and retention (Price, Matzdorf, \& Smith, 2001; Price, Matzdorf, Smith \& Agahi, 2003; Reynolds \& Cain, 2006). First impressions of the campus matter; quality facilities influence enrollment decisions, while missing, inadequate or poorly maintained facilities lead students to reject potential colleges (Reynolds \& Cain, 2006). In particular, research consistently establishes the importance of student unions / student centers in attracting student enrollments and keeping students on campus (Henry, 2004; Reynolds \& Cain, 2006; Romano \& Hanish, 2003). The student union holds a deep value for students, symbolizing a student-centered institution (Reynolds \& Cain, 2006). These special 
places have been called the heart of the campus (Boren, 2008), the hearthstone or living room, and the unifying force for everyone on campus (ACUI, n.d.).

Within the campus ecology, that concept of community deserves particular attention for its influence on person-environment fit, student involvement, and engagement. The campus facilities - and specifically student unions / student centers have a clear role in fostering campus community (Boren, 2008; Henry, 2004). The purpose of campus facility (and student union/student center) design should be centered on the creation of areas/space for students to be engaged and involved (Astin, 1984; Evans, Forney et al., 1998; Schein, 2010). Certain building attributes are salient to that purpose, including campus location, human-scale design, layout, flexibility, a "third place" for student relaxation, and general safety and security (Strange \& Banning, 2001; Oldenburg, 2001). Specific features in buildings can encourage or discourage student development, learning and community (Howard, 2008; Monahan, 2002; Schuetz, 2005; Strange \& Banning, 2001).

Although the literature offers key elements and theories in facility design, gaps persist in our knowledge regarding the ever-changing needs of students and the actual relationship of the union and student retention. Humphreys' (1946) and Stevens' (1969) excellent works outlined the long history of student unions / student centers in American colleges and universities and the ways in which these special facilities have supported and fostered student and campus-wide community. Clearly the purposes, amenities and services of student unions have changed over time to reflect emerging needs of new generations of students, changes in society, and higher education's changing role within it. While we know a great deal about the history of these facilities, the present and future 
stages in student union development remain unnamed and uncertain. We do not know which purposes, services, amenities and attributes of student unions / student centers are likely to emerge as most important in the future.

Furthermore, despite what is known about environmental psychology, campus ecology, and components of the campus environment; colleges and universities do not always act on that knowledge. Many campus capital projects evidence little regard for design and theory (Greenberg, 2007). Knowledge constraints, financial constraints, and political constraints are potential barriers (AASCU, 2014; Bolman \& Deal, 2003; Chism, 2006). However, in truth, the barriers towards effective campus facility construction and renovation are not fully understood, as much published commentary is based on observation rather than empirical research.

Student recruitment, retention and success are key goals for all colleges and universities. The built environment, and specifically the college student union, is fundamentally related to these goals. The collection of literature reviewed in this chapter aids our understanding of the evolution of student unions and their importance, yet also points out how that literature is incomplete and insufficient to offer a current assessment of the changing and future role of student unions. This study addresses that knowledge gap. Its purpose is to understand and forecast the changing role of the student union in the modern era, investigating the most important purposes served by college and university student unions; the amenities and services that should exist in the student union based on these purposes; the barriers faced by student unions in meeting these purposes; and the most important influences that will shape the college and university student union of the future. The next chapter reviews the study's methodology. 


\section{CHAPTER III METHODOLOGY}

\section{Introduction}

The design of a college campus can play a critical role in a student's decision to attend or not attend a particular institution (Boyer, 1987). What a student sees when visiting campus - what the buildings look like, where different offices are located, the accessibility of services, and the general "feeling" a student has when walking around campus - can form a strong first impression. The messages communicated from that physical environment can influence students' feelings of well-being, belonging and identity (Kuh, Kinzie, Schuh \& Whitt, 2005) which not only influence enrollment decisions, but also may contribute to retention (Boyer, 1987). Yet the needs and preferences of students change with succeeding generations, as society and culture evolve. Colleges and universities seeking to attract and retain students must keep abreast of these changes.

One important component of the campus is the student union. Often called the "hearthstone" of the college campus, this important center of community life is integral to the educational and student development mission of colleges and universities (ACUI, n.d.2). As evident, though, the mission, purpose and usage of the student union have evolved over time with successive generations of students (Humphreys, 1949; Rudolph, 1962; Stevens, 1969; Towns, 2005). The purpose of this study was to understand and 
forecast the changing role of the student union in the modern era. It harnesses the expertise of directors of student unions to identify and forecast that changing role, and draws upon the theoretical framework proposed by Strange and Banning (2001) to understand these changes according to four important environmental components of college campuses: (a) the physical condition, design, and layout; (b) the characteristics of the people who inhabit them; (c) the organizational structures related to their purposes and goals; and (d) the inhabitants' collective perceptions or constructions of the context and culture of the setting. This chapter describes the research methodology, as organized into the following sections: research questions, research design, study population and sample, data collection, data analysis, consideration of human subjects, limitations of the study, design issues, and a chapter summary.

\section{Research Questions}

The following research questions guided this study:

1. What are the most important purposes served by college and university student unions?

2. What amenities and services should exist in the student union based on these purposes?

3. What are the barriers faced by student unions in meeting these purposes?

4. What are the most important influences that will shape the college and university student union of the future?

\section{Research Design: The Delphi Method}

The study relied on the Delphi method to achieve its goal of understanding the changing role of the student union and predicting future directions for these central features of college and university campuses. The Delphi method is a "widely used and accepted method for achieving convergence of opinion concerning real-world knowledge 
solicited from experts within certain topic areas" (Hsu \& Sanford, 2007, p 1). It relies on a structured communication process involving multiple rounds of questionnaires and analyses to gain consensus from a panel of experts (Linstone \& Turoff, 2002, Romano, 2010). The process facilitates anonymity between participants and encourages the free and open exchange of opinions and information. Delphi differs from standard survey and questionnaire administration in that rather than seeking to assess a current situation; it endeavors to forecast future trends and scenarios (Hsu \& Sanford, 2007; Miller, 2006). The strength of this approach resides in harnessing the combined expertise of participants who are chosen for their depth of industry-specific knowledge and experience (Powell, 2003).

The Delphi method was first introduced in the 1950's by Dalkey and Helmler (1963) at the RAND Corporation as a way to collect data for strategic defense purposes and long range planning (Hsu \& Sanford, 2007; Romano, 2010). However, it has since evolved into a wide array of applications in strategic planning, policy development, and industry forecasting (Hsu \& Sanford, 2007), and is considered one of the most reliable approaches to gaining consensus of opinion from a group of experts (Romano, 2010).

There are many ways to conduct a Delphi study. The commonality is that all methods include a set of participants who agree to complete a series of questionnaires. The creation of the questionnaire can be accomplished by utilizing previous research to create closed questions, or the researcher may create open-ended questions about the research topic (Wolf, 2011) and build a subsequent closed-question survey based on that first round of responses. Closed questions most often utilize seven-point Likert-scale or rank order method (Hsu \& Sanford, 2007). 
Each series of survey administration is referred to as a round; and in each round questionnaires are collected, edited, and returned to every participant [with] summary of qualitative responses and numerical scores from the previous round in addition to the participant's own score, making "each participant aware of the range of opinions and the reasons underlying those opinions "(Ludwig, 1994, p. 55). Next, each participant then evaluates his/her previous response and, in the subsequent round, has an opportunity to revise his/her answer based upon other experts' responses (Hsu \& Sanford, 2007).

The analysis of each round of responses typically involves the use of statistics to describe and present quantitative scores for each question, and the use of summarizing strategies to present the qualitative comments that participants provide in support of their scoring decisions (Hsu \& Sanford, 2007). Descriptive statistics commonly presented include the calculated mean (the theoretical middle ground) as well as the range (the difference between the largest and smallest values), and the median and mode of actual responses. This technique accurately and objectively represents all responses, confidential to the researcher but anonymous among participants; which reduces the potential for conformity or groupthink "from obedience to social norms, customs, organizational culture, or standing within a profession," (Hsu \& Sanford, 2007) such as could result from non-anonymous data collection strategies such as focus groups.

Researchers differ on the number of suggested rounds needed for a robust study. In its purest form, the process should be completed until achieving consensus among the participants (Hsu \& Sanford, 2007). However, depending on the nature of the study and the participants involved, it may take varying amounts of time to reach consensus; and, depending on the purpose of the study, varying degrees of consensus may be sufficient. 
According to Edwards (2001) the process can involve two or more rounds. While several methodologists recommend four rounds as standard (Hsu \& Sanford, 2007; Vogt, Gardner \& Haeffele, 2012), other research has demonstrated that conducting more than two rounds does not garner a considerable amount of new knowledge or consensus and can be time consuming and cost prohibitive (Romano, 2010). Many methodologists who use and study the Delphi method concur that three rounds usually provide the insight and consensus sufficient to address most types of research (Hsu \& Sanford, 2007).

This study used the Delphi method to understand and forecast the changing role of the student union in the modern era, harnessing the expertise of directors of student unions. It sought to identify the purposes served by student unions, the amenities and services that should exist based on those purposes, and how those purposes and their embodiment reflect campus context or culture. It further sought to identify the barriers student unions often face in meeting those purposes, as well as the most important influences that will shape student unions in the future. Colleges and universities need these valuable insights and information to inform their resource allocation and planning decisions.

There are hundreds of student unions in the country with numerous staff and various opinions about what services should be available to students in their campus facility. In this study, relying on the consensus from an expert panel - directors of student unions - minimized the dissonance and assisted in identifying and forecasting that changing role. The Delphi method allowed for an asynchronous group discussion while reaching consensus in a timely fashion. It offered more interaction among members than a simple survey would have accomplished, and less peer influence or group-think than a 
focus group method would have enabled. Delphi studies have proven a reliable and effective method upon which to base decisions (Griffin, 2005).

\section{Study Population \& Sample}

The strength of the Delphi method relied upon the consensus of expert opinion. Ironically, methodologists themselves lack consensus on how to define or select experts to participate in Delphi studies (Hsu \& Sanford, 2007). Generally, researchers agree that the population and sample must have requisite knowledge and expertise relevant to the subject (Hsu \& Sanford, 2007). However, Klee (1972) and Oh (1974) as cited in Hsu and Sanford (2007, p.1) caution that expert knowledge alone is not a sufficient criterion; the use of participants from key positions within industries - positional leaders such as senior level administrators or managers who would subsequently use the results of the study - is a better approach. Willingness to participate is also a key consideration, as the success of Delphi studies necessitate a commitment to respond to multiple rounds of questionnaires (Hsu \& Sanford, 2007).

\section{Study Population}

This study focused on student unions in US colleges and universities. The administrators responsible for managing or directing student unions or student centers, therefore, comprise the population for the study. These individuals have direct experience and knowledge with the study's subject and are accountable for ensuring the success of student unions. The exact number of student unions in US colleges and universities is not known, and attempts to identify such a listing proved elusive. Instead, this study relies on identifying administrators through the primary, international professional organization for such individuals: the Association of College Unions 
International (ACUI). ACUI is a 100 year-old association of college union / student center professionals in the United States and abroad, with a membership of 3,252 professionals representing 492 US colleges and universities (ACUI, n.d.). ACUI maintains a database that identifies its members by institutional type, position/title and an array of other demographic information.

\section{Study Sample}

The study relied on nested, purposive sampling strategies, including homogenizing and criterion strategies to gather information-rich participants (Patton, 2002) suitable for a Delphi study.

Homogenizing sampling strategies focus on a particular strata or subpopulation in order to control or reduce distracting variations (Patton, 2002). Specifically, this study delimited its investigation according to institutional type. It focused on public and private, non-profit, non-specialized, four year colleges and universities in the US. This reduced the differences in various aspects of the campus environment that would have been more pronounced with the inclusion of two-year colleges, for-profit institutions, and specialized colleges and universities, which have different enrollment profiles and organizational missions

Within the selected subpopulation, the researcher used criterion sampling (Patton, 2002) to identify a pool of experts to invite for panel participation based on predetermined criteria. Specifically, the criteria included (a) being a professional with the title of Director of the Student Union, Student Center, or Student Activities, and (b) having a minimum of five years' work experience in union center management. These 
criteria - job title and years on the job - served as a proxy for demonstrated knowledge and experience.

Just as methodologists differ on the procedures for recruiting a Delphi panel and the optimal number of rounds of questionnaire administration, they differ on the sufficient number of panel participants. Hsu and Sanford (2007), reviewing the literature on Delphi methods, encountered recommendations that ranged from ten to fifteen participants up to 50 participants, with a mode of 15 to 20 panelists. Consistent with purposive sampling strategies, fewer panelists may be used when the experts and subject of focus have a high degree of homogeneity (Hsu \& Sanford, 2007). For the purposes of this study of student unions, the intentional degree of homogeneity resultant from the sampling strategy enabled the study to draw upon a target panel size of 200 participants.

\section{Sampling Procedure}

The researcher relied on the assistance of the Association of College Unions International (ACUI) to identify members of the study population, select the study sample, and recruit participants. The researcher contacted the executive director and membership director of ACUI, explaining the study and sampling procedures, and asked for their assistance in identifying a roster of members that met the sampling criteria (Appendix A).

The ACUI provided the researcher with a copy of the resulting roster and contact information. The researcher then randomly sampled 80 individuals from the roster, 10 from each of ACUI's 8 geographical regions, to be invited to participate in the study, with a goal of achieving a panel size of 20 willing participants. The researcher then provided ACUI with the selected names and contact information, along with a digital 
copy of the initial letter of invitation to these individuals that explained the study and invited their participation (Appendix B). This letter was sent out directly from ACUI to potential participants via email. A link to the online first round of questionnaire administration and informed consent information accompanied the letter of invitation.

The researcher conducted two rounds of email follow up with those prospective participants who had neither completed the survey nor opted out, to enhance the legitimacy of the study and reduce the potential for ignored email. These follow ups were conducted at one week (Appendix C) and two week (Appendix D) intervals. Completion of the online questionnaire verified an individual's willingness to participate.

Sampling was conducted in two waves. The initial wave, described above, yielded 15 participants out of a pool of 80 invited potential participants. Working again through ACUI, a second pool of 80 potential participants was sampled (10 from each of ACUI's 8 regions), invited to participate, and sent two rounds of follow up. The second wave yielded 9 additional participants, for a total of 24 Round I participants. Of these, 22 participants continued to complete Rounds II and III. This resultant pool of respondents constituted the study sample, herein after referred to alternately as either the Delphi panel, participants, or the study sample. Patton (2002) notes that random purposive sampling strategies such as that used in this study can reduce subjectivity and add credibility to the research, although they do not enhance generalizability in the same way that a purely random sample would. 


\section{Data Collection Procedures}

The study involved administering three-rounds of survey questionnaires to the Delphi panel to determine expert consensus regarding the changing role of the student union in the modern era. The procedures used in collecting the data are described below.

\section{Round I}

Although some researchers launch their Delphi studies with a structured questionnaire derived from a literature review, Hsu and Sanford (2007) note that "the first round [of] the Delphi process traditionally begins with an open-ended questionnaire" that targets insights and information about the subject (p.2). The resultant baseline information is then analyzed and used to develop surveys for subsequent rounds, featuring primarily closed-ended, Likert-scaled questions.

Following this recommendation, the Round I questionnaire (Appendix E) included ten open-ended questions, the results of which were used to create closed-ended questions for subsequent rounds of the study. The following questions comprised the Round I questionnaire:

1. What is the central mission of a college or university student union?

2. What purposes are served by the union?

3. How important are these purposes, and why?

4. What amenities and services should exist within the union, based on these purposes?

5. What are the barriers faced by college and university student unions in meeting these purposes?

6. How may the location of the union on campus serve as an asset or a barrier in meeting its purposes? 
7. How may the design of the union serve as an asset or barrier in meeting its purposes?

8. How do student unions relate, if at all, to student recruitment and retention?

9. What do you think are the most important influences or forces that will shape the college and university student union of the future?

10. What do you think are the biggest influences or determinants on facility directors' decisions for new construction or renovations to student unions?

These open-ended survey questions (SQ) corresponded to the research questions (RQ) as follows:

1. RQ1: What are the most important purposes served by college and university student unions?
a. SQ1: central mission of the union
b. SQ2: purposes served by the union
c. SQ3: importance of these purposes
d. SQ8: relationship to recruitment and retention

2. RQ2: What amenities and services should exist in the student union based on these purposes?

a. SQ4: amenities and services

3. RQ3: What are the barriers faced by student unions in meeting these purposes?
a. SQ5: barriers
b. SQ6: location
c. SQ7: design

4. RQ4: What are the most important influences that will shape the college and university student union of the future

a. SQ9: influences on the future

b. SQ10: determinants for new construction or renovations

Participants were asked to be as specific as possible in their responses, providing examples and justifying their rationale within a minimum of two paragraphs. A 2000 character maximum response was imposed to assist the participant in creating concise, thoughtful, responses. 
The targeted questionnaire administration time for Round I was two weeks, with two rounds of follow up and resampling as needed (described previously) to assure a continued target panel size.

\section{Round II}

Round II (Appendix I) built upon the results of Round I and provided the foundation for the consensus-building process (Hsu \& Sanford, 2007). The results from Round I were used to develop a 26 question survey with 21 closed-ended questions and 5 open comment questions. The closed-ended questions included a matrix of response items. For example, the open question from Round I, "What amenities and services should exist...?" was rewritten as, "Which of the following amenities and services are most important in the student union?" This was followed by a matrix of items as provided in Round I responses. In some instances, the matrices were supplemented with items suggested through the review of literature. Participants were asked to review the questions and make prioritizing responses using a seven-point Likert scale as recommended by Vogt, Gardner \& Haeffele (2012), rating the importance of each item in the matrix as either "1." very important, "2," important, "3"” somewhat important, “4," neutral, "5," somewhat unimportant, "6" unimportant, or “7” very unimportant.

Similar procedures were used for administering Round II. Participants who responded to Round I received a letter thanking them for their participation in Round I, reminding them of the purpose of the study and requesting their continued participation in Round II (Appendix F). Instructions for completing the second questionnaire and a link to the survey administration site accompanied the letter. As in the previous round, 
participants were contacted via email, and the surveys were administered online through SurveyMonkey.

The targeted questionnaire administration time for Round II was also two weeks, with two rounds of follow up spaced at one week intervals, with continued follow up as needed to assure a continued target panel size (Appendices $\mathrm{G}, \mathrm{H}$ ).

\section{Round III}

Round III further refined the consensus-building process. Participants received another emailed letter, thanking them for their contributions in Round II, and requesting their continued participation, along with instructions for Round III (Appendix J). The third questionnaire was modeled after the second questionnaire, featuring closed-ended questions with a seven-point Likert-scaled response that asked participants to re-rate the extent of their agreement with or the importance of the item (Appendix N). The questionnaire provided participants with descriptive statistics of the Round II responses (mean, median, mode and range).A summary of qualitative comments and rationales was also provided upon request. Each participant was asked to review and consider the results of Round II, then complete the final survey, re-rating each item and taking into account the previous results provided. The targeted questionnaire administration time for Round III was two weeks, with two rounds of follow up conducted at one week intervals (Appendix K, L). A third follow up was made (Appendix M) in week three to assure a continued target panel size.

As noted previously, methodologists vary on the number of rounds recommended in the study depending on issues such as homogeneity/heterogeneity within the panelist and the level of consensus desired to declare study completion (Hsu \& Sanford, 2007). 
Generally, though, methodologists agree that repeated rounds of questionnaire administration yields only minimal increases in consensus (Romano, 2010). Because it involved a purposefully homogenous sample, data collection for this study concluded after the third round. At the conclusion of the study, all panelists received a thank you letter with information for how to obtain the study's results (Appendix O).

\section{Data Analysis Procedures}

Inherent to a Delphi study, formative data analysis occurred throughout the data collection period to develop and administer successive rounds of surveys, and a summative data analysis of the final results occurred at the end to address the research questions. This section describes the procedures that were used for data analysis. The actual results of the analysis are presented in Chapter IV, "Results."

\section{Formative Data Analyses}

Two rounds of formative data analysis occurred during the data collection period to develop and administer the questionnaires.

Round I analysis. The first questionnaire involved a series of ten open-ended questions intended to gather baseline information and insights corresponding with the study's four research questions. Basic categorizing and summarizing techniques were used to review the open-ended responses. Data were coded into major categories using the environmental components of college campuses (a) the physical condition, design, and layout; (b) the characteristics of the people who inhabit them; (c) the organizational structures related to their purposes and goals; and (d) the inhabitants' collective perceptions or constructions of the context and culture of the setting (Strange \& Banning, 2001). The results were used create items for the closed-ended questions featured in the 
second survey. All responses were used without regard to the frequency with which they appeared in the Round I results, permitting the Delphi panelists to make judgments as to the relative importance of each item. This yielded a resulting Round II survey with 26 questions divided into five sections, and corresponding matrices with a combined total of 257 response items.

Round II analysis. The second questionnaire involved 21 closed-ended questions with seven-point Likert scaled response options, and five comment fields for open-ended supporting information. The closed-ended responses were analyzed with basic descriptive statistics including the number of respondents; and the mean, median, mode and range. This information was then embedded into the questionnaire to create the resulting Round III questionnaire.

\section{Summative Data Analyses}

The third questionnaire built towards consensus among the expert panelists, addressing the purpose of the study: to understand and forecast the changing role of the student union in the modern era. Summative data analysis occurred with the analysis of the final, Round III results.

As with other major elements of Delphi studies, methodologists employ a variety of approaches in analyzing study results, such as those described by Hsu \& Sanford (2007) including: analyzing the percentage of responses occurring within a targeted range; analyzing the stability of responses over multiple rounds; and the same basic descriptive statistics used formatively in the survey administration. Because this study employed a modest number of rounds of questionnaire administration, it was unlikely that strategies such as analyzing the stability of responses over time would be meaningful 
to the study. Therefore, the results from Round III were analyzed and described using the basic descriptive statistical techniques and qualitative strategies described above.

Quantitative techniques. The responses to closed-ended questions were analyzed using basic descriptive statistics including the number of respondents; and the mean, median, mode and range. Delphi methodologists recommend using these basic strategies - measures of central tendency and level of dispersion - in order to best present the summative consensus of the panelists (Hsu \& Sanford, 2007). As the intention of this study is to derive knowledge and understanding from the panel as to what are the most important purposes, amenities and services of unions, and the most important barriers and influences, careful attention was given to rank-ordering the means. Analyzing the rank ordering of items revealed their relative importance as rated collectively by panelists.

However, averaging the responses of what panelists say is not the same thing as achieving consensus, or agreement, around a question. For example, if a number of panelists said, "very important," and an equal number said, "very unimportant," the mean response, "neutral," does not reflect an agreement or consensus of the panel. A hallmark of the Delphi methodology is its focus on gaining consensus from a group. A variety of methods have been used to identify consensus in Delphi studies, including: (a) response rate percentages, (b) percentages for each level of agreement for each statement, (c) median, range and their respective rankings, and (d) the mean of the standard deviations and their associated group rankings using the importance ratings (Holey, Freely, Dixon, \& Whitaker, 2007). This study relied upon the percentages of agreement strategy. Yet "a key question in any Delphi study is what percentage agreement [sh]ould a researcher accept as synonymous with consensus" (Keeny, Hasson \& McKenna, 2006, p. 210). 
Keeny, Hasson \& McKenna's (2006) review of Delphi studies found a wide variety of threshold levels of agreement accepted as 'consensus',' ranging from as low as $51 \%$ to as high as $80 \%$. They determined that "There are no recognized guidelines on appropriate level of consensus ... 75\% appears to be the minimal level,” (p. 210), but establishing intervals to present gradations of consensus is also a valuable practice.

In this study, gradations of consensus were used in the analysis. Specifically, general consensus about the importance of an item was reached if $75 \%$ or more of panelists selected response one of two adjacent response choices on the seven-point Likert scale: "1, very important," and "2, important." A stronger level of consensus or "true consensus" about the importance of an item was reached if $75 \%$ or more of panelists selected the same single response choice on the seven-point Likert scale: "1, very important." Conversely, if fewer than $75 \%$ of panelists selected response choices "1" or " 2, " then the item was deemed to lack consensus about it regardless of the actual mean score for that item. Combined, these quantitative techniques revealed (a) the panelists overall judgment concerning the importance of the item (mean, median), (b) the relative importance of items compared to each other, (c) whether consensus about the item's importance was present, and (d) the strength of that consensus was (mode and percent response rates).

Qualitative techniques. The qualitative data provided in the questionnaires' comment fields was further refined and analyzed using the coding strategies developed for Round I analysis. Major themes and exemplar quotes are presented and explored to illuminate the rationale underlying the questionnaire responses, and panelists' consensus or lack thereof. 
Research questions. Combined, the results of the questionnaire administration and consensus-building process were used to address the major research questions of the study intended to understand and forecast the changing role of the student union in the modern era:

1. What are the most important purposes served by college and university student unions?

2. What amenities and services should exist in the student union based on these purposes?

3. What are the barriers faced by student unions in meeting these purposes?

4. What are the most important influences that will shape the college and university student union of the future?

\section{Consideration of Human Subjects}

The study complied with the policies and procedures of the Illinois State University Institutional Review Board (IRB), to ensure that the rights and welfare of the prospective and participating panelists were protected. This included considerations for the safe and secure collection, handling and storage of all data; and for the confidentiality of the names and identifying information of all participants. IRB approval was sought and obtained prior to the study's implementation.

\section{Limitations of the Study}

The researcher acknowledges and addressed several limitations to the study inherent to the Delphi method, as discussed below.

\section{Response Rates}

The choice of the Delphi method as the research design placed the study at greater than normal risk for low response rates. Any survey administration carries with it the risk of non-respondents. However, the Delphi method asks prospective participants to 
commit to several repeated rounds of questionnaires. This reiterative process is vital for the consensus-building goal of the Delphi method. Yet the repetition of surveys increases the likelihood for non-response with each round of administration.

Purposeful selection of prospective participants addressed this limitation. The study intentionally recruited those experts from the study population who will potentially benefit from knowledge of the study's findings (Hsu \& Sanford, 2007), with the aim of increasing participants' interest, commitment and response rates. As a result, the study benefited from a strong retention rate among participants: 24 individuals participated in Round I and 22 continued to Round II and the same 22 completed the entire study in Round III. Demographic information on the individual participants, beyond meeting sampling criteria, was not salient to the study and therefore not collected.

\section{Response Quality}

The study relied on the quality of the participants' responses. Adequately descriptive information was needed from the open-ended questions in Round I in developing the questionnaire for Round II. The study assumed that individuals who agreed to participate would be sufficiently motivated to provide adequately descriptive responses. As a result, Round I responses were robust enough to develop the Round II and III surveys. In only a few instances, response choices for Round II were supplemented with items suggested by the literature review.

\section{Panelists' Expertise}

Hsu and Sanford (2007) note that despite attempts to recruit an expert panel, the actual expertise of Delphi panelists cannot be guaranteed. Although the researcher attempted to ensure a baseline level of expertise by delimiting prospective participants to 
those with five years or more of experience in student union / student center management, the institutional conditions or environment of that employment, the actual range and quality of that experience, as well as the range and quality of the individual's performance could not be ascertained and controlled in the sampling procedures.

The researcher addressed the potential for uneven expertise of participants by recruiting an adequately sized panel that exceeded the ranges of recommended size. Through this strategy, a critical mass of expert panelists helped smooth any effects of any panelists who may have inadvertently had lower expertise.

\section{Biases and Subjectivities}

As Creswell (2009) explained, qualitative research is interpretative research. Thus, describing my own background and perspectives is relevant for establishing possible subjectivities in the study.

In my professional role as a director of student activities, my daily work involves working directly with students, faculty, and staff. In addition, my work is conducted in a college student union where I see and hear about the struggles and frustrations students have and hear the multiple complaints about what exists and does not exist in the facility.

In addition to working directly in a student union, I was a member of a student union renovation project team at two prior institutions. I was fascinated by the renovation process but found myself struggling with ways to include students in the decision making process in addition to meeting their wide range of needs and wants. It was also difficult to balance these needs and wants with the fiscal outlook occurring at that time in higher education. With few to no state dollars for the renovation project, I found it challenging for the team to prioritize what amenities needed to be in the facility 
and which would have to be scrapped or planned for at a later date. As a member of the team, I also was asked to represent the students' voice during the project as they were not physically at the planning table. I had to gather information via small group discussions or with brief student surveys and then interpret the data and report back to the team. I felt a tremendous amount of pressure to correctly hear and be able to interpret not only what current students wanted but also predict what future students would want and need.

These experiences influenced my interest in this study. If I would have had prior research data that supported or argued for certain amenities, I could have used that information in conjunction with what the students were telling me and propose a more thorough analysis of needs.

Fortunately, the potential for any influence resulting from my own subjectivities is diminished in the Delphi method. The Delphi method relies upon the baseline input and reiterative feedback and refinement of participants' responses. This heavily participant-based process diminishes the potential distortions from the researcher. In contrast, my own experiences with student unions should prove to be an asset to the study, one that will enable me to better understand the panelists' comments.

\section{Summary}

This study employed the Delphi method to collect and explore the knowledge and insights of experts in student union management, with the goal of understanding and forecasting the changing role of the student union in the modern era. A review of the history of college and university student unions, the components of campus environments, the role of student unions in student recruitment and retention, and the influences of environmental psychology anchored the research. The administrators 
responsible for managing or directing student unions or student centers, who were members of the Association of College Unions International, comprised the study population. The procedures for, sampling, data collection, and data analysis were described in this chapter, and reflect accepted strategies for conducting research of this design. The limitations of the study were presented, as were considerations for research with human subjects. The results of the research and a discussion of the findings are presented in the next two chapters. 


\section{CHAPTER IV}

\section{RESULTS}

\section{Introduction}

As outlined in prior chapters, this study was designed to understand and forecast the changing role of the student union. More specifically, the research project explored four interrelated research questions: (RQ1) the most important purposes served by student unions, (RQ2) the amenities and services that contribute to serving those purposes, (RQ3) the barriers student unions face in meeting these purposes, and (RQ4) the most important influences that will shape the college and university student union of the future. The study employed three rounds of questionnaires in a Delphi method to collect experts' knowledge and seek consensus or convergence of their opinion about the importance of a series of items related to the research questions. This chapter presents an analysis of the formative results of Rounds I and II of the study, and the summative results of Round III.

\section{Round I Results}

In Round I, participants were asked to answer ten open-ended questions based upon their knowledge, experiences and perceptions:

1. What is the central mission of a college or university student union?

2. What purposes are served by the unions?

3. How important are these purposes, and why? 
4. What amenities and services should exist within the union, based upon these purposes?

5. What are the barriers faced by college and university student unions in meeting these purposes?

6. How may the location of the union on campus serve as an asset or barrier in meeting its purposes?

7. How may the design of the union serve as an asset or barrier in meeting its purposes?

8. How do student unions relate, if at all, to recruitment and retention?

9. What do you think are the most important influences or forces that will shape the college and university student union of the future?

10. What do you think are the biggest influences or determinants on facility directors' decisions for new construction or renovation to student unions?

The questionnaire yielded 24 usable panelist responses, which were analyzed using an open-coding method. Five distinct themes were identified based upon participant responses and included: (a) purpose \& mission of the student union; (b) services, programs \& amenities of the student union; (c) attributes of student unions; (d) barriers \& constraints for student unions; and (e) the student union of the future. Each theme is further described below.

\section{Purpose and Mission of Student Unions}

In Round I, panelist responses indicated that student unions serve an array of purposes, missions, and populations. Terms such as "purpose" and "mission" are often used interchangeably and distinctions between the two can be slight. Responses were coded as a "purpose" of the student union if they answered the "why unions exist?" question. The purpose of the student union explains why it exists as part of a college campus and the primary roles it fills. Responses were coded as a "mission" of the student union if they answered the "how unions fulfill the mission?" question. The mission of 
the student union explains how its purposes are fulfilled, or how the union fulfills its

roles.

Purpose. Round I responses identified four distinct themes in the purposes of student unions: (a) building, creating or fostering community, (b) supporting student success, (c) serving as the "welcome center" for the campus, and (d) serving as the "living room" for the campus. Table 1 offers a sample of supporting survey responses.

Table 1

\section{Round I Comments - Purpose and Mission}

\begin{tabular}{|c|c|}
\hline Purpose of the Union & Sample Supporting Comments \\
\hline $\begin{array}{l}\text { Building, Creating or Fostering } \\
\text { Community }\end{array}$ & $\begin{array}{l}\text { We are the community center of the campus. } \\
\text { - We are the central gathering place for building community. } \\
\text { - While each union may be different in the programs and } \\
\text { community building. } \\
\text { - The college union is a catalyst for community } \\
\text { - The union is central to the building of community }\end{array}$ \\
\hline Supporting Student Success & $\begin{array}{l}\text { The experiences and opportunities provided in a union } \\
\text { through leadership, employment, and activities all provide } \\
\text { direct educational development and support the mission of } \\
\text { the university in holistic student development. } \\
\text { We hope that students feel that the Union is their home } \\
\text { away from home and as a comfortable place to visit, work, } \\
\text { and get what they need to be successful. } \\
\text { [The union provides the]...Offices and services that } \\
\text { directly support students as individuals and student } \\
\text { organizations }\end{array}$ \\
\hline
\end{tabular}

Serving As The "Welcome Center" for The Campus
- On many campuses the union serves as the welcome center for the campus. ... the first stop for almost all of the guests to campus

Serving As The "Living Room" for
The Campus

- A place to relax and socialize.

- Heart of the campus.

- Living room of the campus providing any and all with a place to relax, meet, eat, unwind, study and play.

- Home away from home-comfortable space for socializing, relaxing, communicating with friends, etc.

- It is often described as the "kitchen or living room" of the campus. 
Mission. Student unions pursue a variety of missions as a means to fulfill their central purposes. Round I responses identified the following 11 missions, or ways in which the union fosters community, supports student success, and serves as both a welcome center and a living room for the campus:

1. Support co-curricular student development \& learning

2. Support curricular / classroom student learning

3. Support student recruitment

4. Support student retention

5. Provide informal spaces (e.g. lounge space, study space, socializing space)

6. Provide formal spaces (e.g. for meetings and events)

7. Offer food services (e.g. food courts, cafeterias, restaurants)

8. Offer retail services (e.g. book store, computer/technology store, post office)

9. Offer recreation \& entertainment opportunities (e.g. bowling, movies)

10. Offer cultural opportunities (e.g. art gallery, music or dance performances)

11. Offer student employment opportunities

Populations served. Inherently implied by the purposes and missions as identified by the panelists, student unions serve an array of populations. The following populations were specifically cited within Round I responses:

1. Residential students

2. Commuter students

3. Prospective students

4. Alumni

5. Families of current students or alumni 
6. Campus faculty and staff (as individuals)

7. Academic departments

8. Administrative departments

9. Visitors to the campus

In the process of developing the Round II survey, these responses were expanded to include four additional subgroups of students commonly discussed in the literature on higher education, even though they were not expressly named by panelists. Additionally, the category "visitors to campus" was expanded to distinguish between those visitors who come for college-related purposes (e.g. attending a lecture or conference), and those who come for non-college related purposes (e.g. attending the movies or a concert). This resulted in the following additional populations for use in the Round II survey:

10. Evening students

11. Virtual / online students

12. Traditional age undergraduates

13. Non-traditional age undergraduates

14. Graduate students

15. Visitors to the campus for other college-related business/purposes

16. Visitors to the campus for non-college related purposes.

Panelists' responses in subsequent Rounds II and III tested the appropriateness or salience of including these additional categories.

\section{Services, Programs, and Amenities of Student Unions}

In this study, "services, programs and amenities" of the student union answer the "what?" question. They are the specific means or strategies through which the union 
enacts its missions to fulfill its purposes. For example, the union may offer food courts (a specific amenity) as a means of providing food services (a mission), which brings people together and ultimately fosters community (its larger purpose).

Services and amenities. Round I participants named an array of amenities and services that should be located in student unions (Table 2). Many of the services that they named seemed related to the purpose of fostering student success, and the missions of student retention, co-curricular development, and academic support. A few, such as the Admissions office and information desks and kiosks, seemed related to the "welcome center" purpose. In contrast, the amenities that panelists named seemed related to the purposes of fostering community and serving as a campus "living room," and related to the missions of providing spaces, conveniences and opportunities.

Programming. Round I participants also noted various types of programming that should be located or offered within the student union. These included for-credit and co-curricular programs, as well as active and passive programs. When commenting on student union programming, panelists referred to different roles the union might have in these endeavors. For example, at a minimum the union might serve simply as the place where these things occur. Others across the campus put together the programming, which is then hosted in the union. At the other end of the continuum, the union staff might take full responsibility for designing and offering the programming. In the middle, the union might serve as an active partner with other campus organizations in co-designing and sponsoring programming. Thus, "the role of the union in programming" emerged as a tangential theme equally important as "specific types of programming," and gave greater dimensionality to the study. These are listed in Table 3 
Table 2

\section{Round I Comments - Services and Amenities}

Services Located in Student Unions

- Admissions, financial aid, and registrar's offices

- Dean of Students and leadership \& service offices

- Student activities, student government, student newspaper, student organization, and student programming board offices

- Counseling services, health \& wellness services, and victim advocacy offices

- Multicultural Center

- Academic support \& tutoring services, library services, and career services

- Homecoming/Alumni Relations Office

- Event / conference planning and production / audio-visual services, ticket outlet / office (e.g. athletics, cultural events)

- ID Card / university card and parking services

- Information desk services (staffed), information kiosk (unstaffed), and room reservations office
Amenities Located in Student Unions

- Food court, cafeteria, fast-service and fullservice restaurants, coffee shop, pub serving alcohol, internet café, and catering services

- Bookstore, convenience store (C-Store)

- Banking services, ATM machine, post office or mailing services, travel agency, barber / beauty shop

- Lounge Spaces with TV's

- Bowling, billiards, table-tennis, electronic / video and non-electronic gaming centers, movie theatres, craft centers, outdoor recreation equipment rental

- Wireless internet service, phone \& device charging stations

- Computer labs, computer stations / kiosks (not in lab), copy-print services, printer stations / kiosks (not in a copy/print shop)

- Showers, gender-neutral bathrooms, locker rentals

- Art galleries and art dispersed throughout the building

- Hotel Connected to the Union

Table 3

Round I Comments - Programming Types and Roles of Student Unions

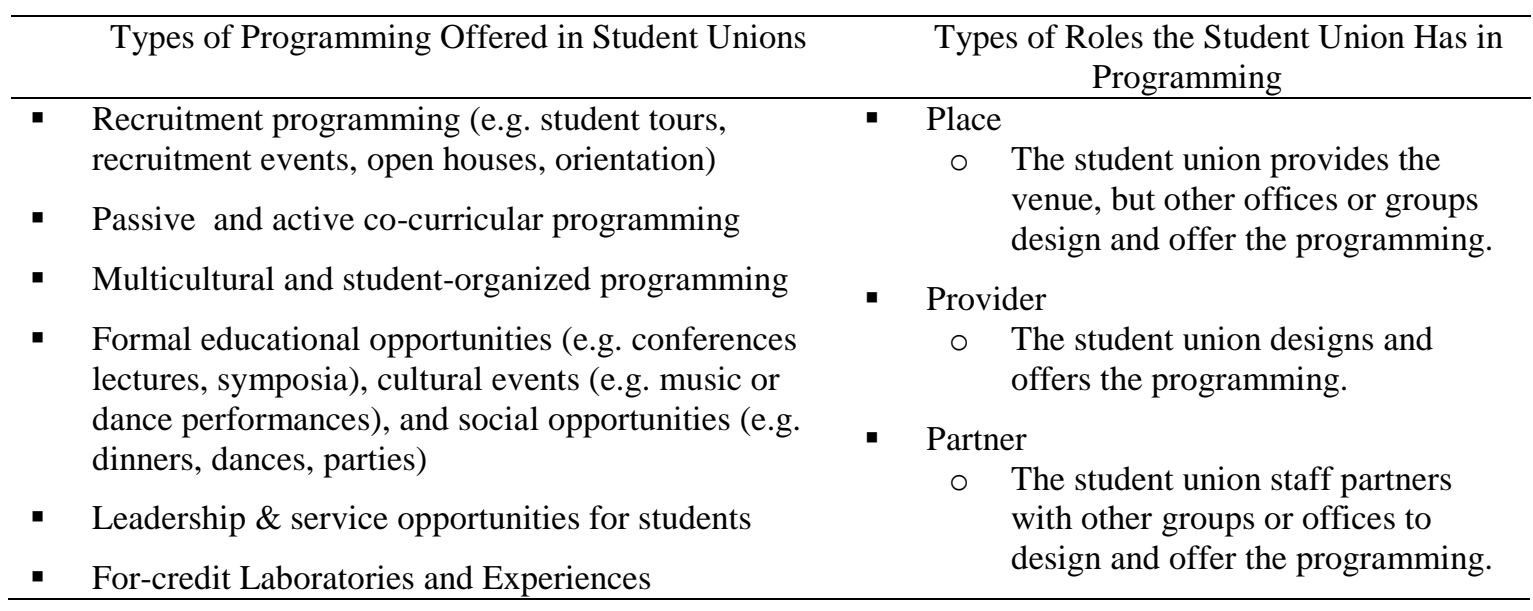


Spaces. In addition to identifying specific amenities, services and programming that should be located or offered in the union, panelists identified an array of types of spaces that should be located or offered within the union (Table 4). These included types of spaces according to physical characteristics, such as formal and informal, large and small, indoor and outdoor, open and quiet; and also types of spaces according to their usage, such as studying, sleeping, meeting and gathering.

Table 4

Round I Comments - Types of Spaces in Student Unions

Types of Spaces

- Large-scale and small-scale formal gathering Spaces (e.g. performance halls, ballrooms, banquet $\&$ multi-purpose rooms, and classrooms, meetings rooms)Large-scale and small-scale informal gathering places (e.g. lounge spaces, nooks)

- Large-group, small-group, and individual study spaces

- Open spaces and atrium

- Outdoor Spaces / Areas (for eating, studying, socializing, etc.)

- Quiet spaces, sleeping spaces, and spiritual / prayer spaces

\section{Attributes of Student Unions}

The third theme that emerged from participant comments in Round I was the desirable attributes of the student union (Tables 5, 6). In this study, the "attributes" of the student union refers to characteristics which may influence the union's effectiveness in providing the specific amenities and services, (the "what"), through which it enacts its missions (the "how") to fulfill its purposes (the "why"). Round I responses identified two clearly distinguishable types of attributes: (a) physical, and (b) human. Physical attributes include characteristics such as the union's location on campus, and the design and condition of building interiors and exteriors. Human attributes include a wide array 
of people-related characteristics, such as the people who work within the union, and the degree of fit between union offerings and student needs.

\section{Table 5}

\section{Round I Comments - Physical Attributes of Student Unions}

\begin{tabular}{|c|c|}
\hline $\begin{array}{l}\text { Physical Attributes } \\
\text { of Student Unions }\end{array}$ & Desirable Characteristics \\
\hline Location & $\begin{array}{l}\text { Located close to the physical center of campus } \\
\text { Located in a high-traffic area / pedestrian crossroads of the campus } \\
\text { Located close to the residence halls } \\
\text { Located close to the library } \\
\text { Located close to mass transit }\end{array}$ \\
\hline Building Exteriors & $\begin{array}{l}\text { Attractive exterior landscaping } \\
\text { Attractive exterior building design } \\
\text { Condition / maintenance of exterior } \\
\text { Cleanliness of exterior } \\
\text { Clearly defined entrance }\end{array}$ \\
\hline Building Interiors & $\begin{array}{l}\text { Attractive interior design } \\
\text { Condition / maintenance of interior } \\
\text { Cleanliness of interior } \\
\text { ADA Accessible } \\
\text { Lots of windows / natural lighting } \\
\text { "Open" feel to interior } \\
\text { Adequate lighting fixtures } \\
\text { Adequate technology infrastructure } \\
\text { Adequate space for various functions } \\
\text { Conveniently clustered functions (one stop shopping) } \\
\text { Good traffic flow between functions } \\
\text { Zoning /defined spaces for various functions } \\
\text { Focal point that brings people together, like a lounge or porch } \\
\text { "Sticky spaces" where people want to come and stay } \\
\text { Seating that encourages interaction } \\
\text { Seating / tables that can be moved around } \\
\text { Flexible design } \\
\text { Comfortable interiors and furnishings } \\
\text { Engaging environment } \\
\text { "Fun" or playful environment } \\
\text { Interior plantings / greenery } \\
\text { Noise-proofing }\end{array}$ \\
\hline
\end{tabular}


Table 6

Round I Comments - Human Attributes of Student Unions

\begin{tabular}{ll}
\hline $\begin{array}{l}\text { Human Attributes } \\
\text { of Student Unions }\end{array}$ & Desirable Characteristics \\
\hline Union Staff & Knowledgeable, well-trained \\
& $\begin{array}{l}\text { Friendly, student focused, committed } \\
\text { Diverse } \\
\text { Adequate staff size / number, includes student employees } \\
\text { Partnerships with admissions/ enrollment services, core academics }\end{array}$ \\
\hline Service & Essential / destination services that students need \\
& Late /weekend hours for student services, retail, food, recreation and \\
entertainment & Variety and options in dining, services, spaces, with affordable prices \\
& High quality, fast \\
\hline Psychological Climate & Welcoming \& inviting \\
& Safe place, physically and psychologically \\
Conveys to students that they matter
\end{tabular}

In the process of developing the Round II survey, these responses were expanded to include seven additional physical and human attributes discussed in the literature on campus environments (Strange and Banning, 2001), even though they were not expressly named by panelists. These included: exterior and interior signage, human-scaled design, climate control and stylistically modern interiors (physical attributes); and artifacts that communicate school spirit, school history, and human diversity (human attributes).

\section{Barriers and Constraints for Student Unions}

Barriers and constraints refer to specific issues or concerns that may prohibit or impede the union's ability or effectiveness in fulfilling its purpose or mission. This is the fourth theme that emerged from the participant responses in Round I. While a lack or absence of any desirable attribute, amenity or service can be considered as a barrier or constraint, this theme refers to the specific issues or challenges that respondents named in 
the Round 1 survey. Four categories emerged: (a) physical constraints, (b) knowledge constraints, (d) financial constraints, and political constraints (Tables 7, 8, 9).

Physical constraints refer to specific concerns or issues that the campus may face regarding the student union building, such as its location, design, or infrastructure needs. Architectural preservation requirements that often constrain what can be done with a building or dictate what must be done, also fell into this category. Knowledge constraints refer to specific concerns or issues related to the professional knowledge needed to run unions successfully or engage in student development. Financial constraints refer to specific issues or concerns with revenues and expenses related to the union. Political constraints, the last category, refer to organizational issues or concerns related to power and limited resources that have an impact on union operations.

Table 7

Round I Comments - Physical Constraints for Student Unions

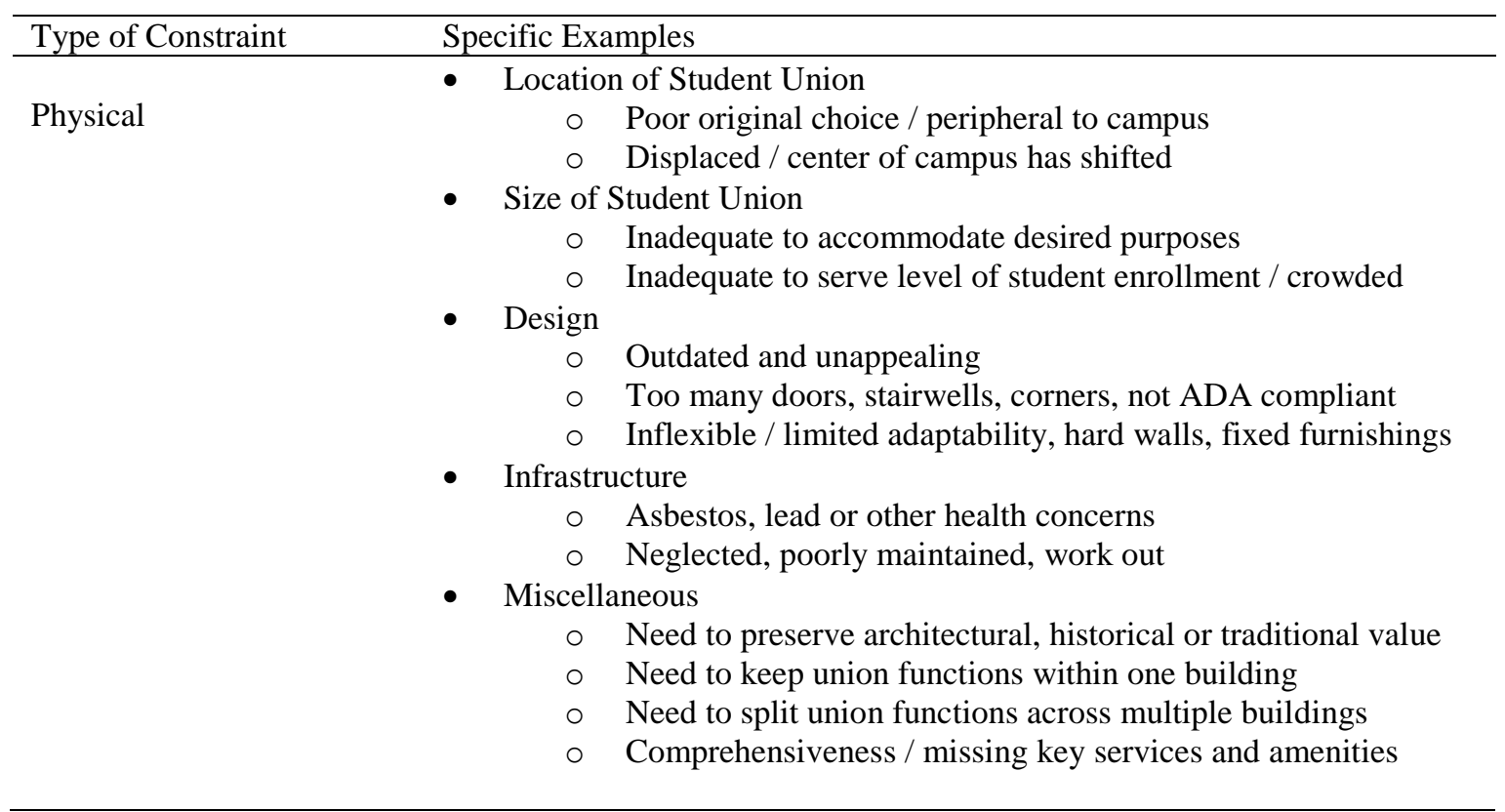




\section{Table 8}

\section{Round I Comments - Knowledge Constraints for Student Unions}

Type of Constraint $\quad$ Specific Examples

Knowledge

- Assessments

- need to identify current

- Satisfaction - need to measure union's effectiveness in meeting student \& community needs.

- Outcomes - need to measure and prove the union's contribution to educational and co-curricular purposes

- User input - need to seek input from multiple consumers \& populations served by the union

- Student union staff

- Insufficient awareness of their role in student development as educators

○ Insufficient knowledge about student development theory

- Insufficient knowledge about student learning outcomes \& assessment

○ Difficulty in recruiting and retaining student-focused staff

- General management

○ Insufficient understanding of the "whole enterprise" of the union

○ Use inappropriate administrative paradigms (e.g. a "facilities" framework instead of a "student development" framework)

- Space is used inefficiently

- Student union has lost its focus on students

- Need more student involvement in union programming and management

- Miscellaneous

○ Outsourced service providers do not understand or value student employment as a developmental process

- Campus leaders and academic affairs lack understanding and appreciation of student development \& the union 
Table 9

\section{Round I Comments -Financial and Political Constraints for Student Unions}

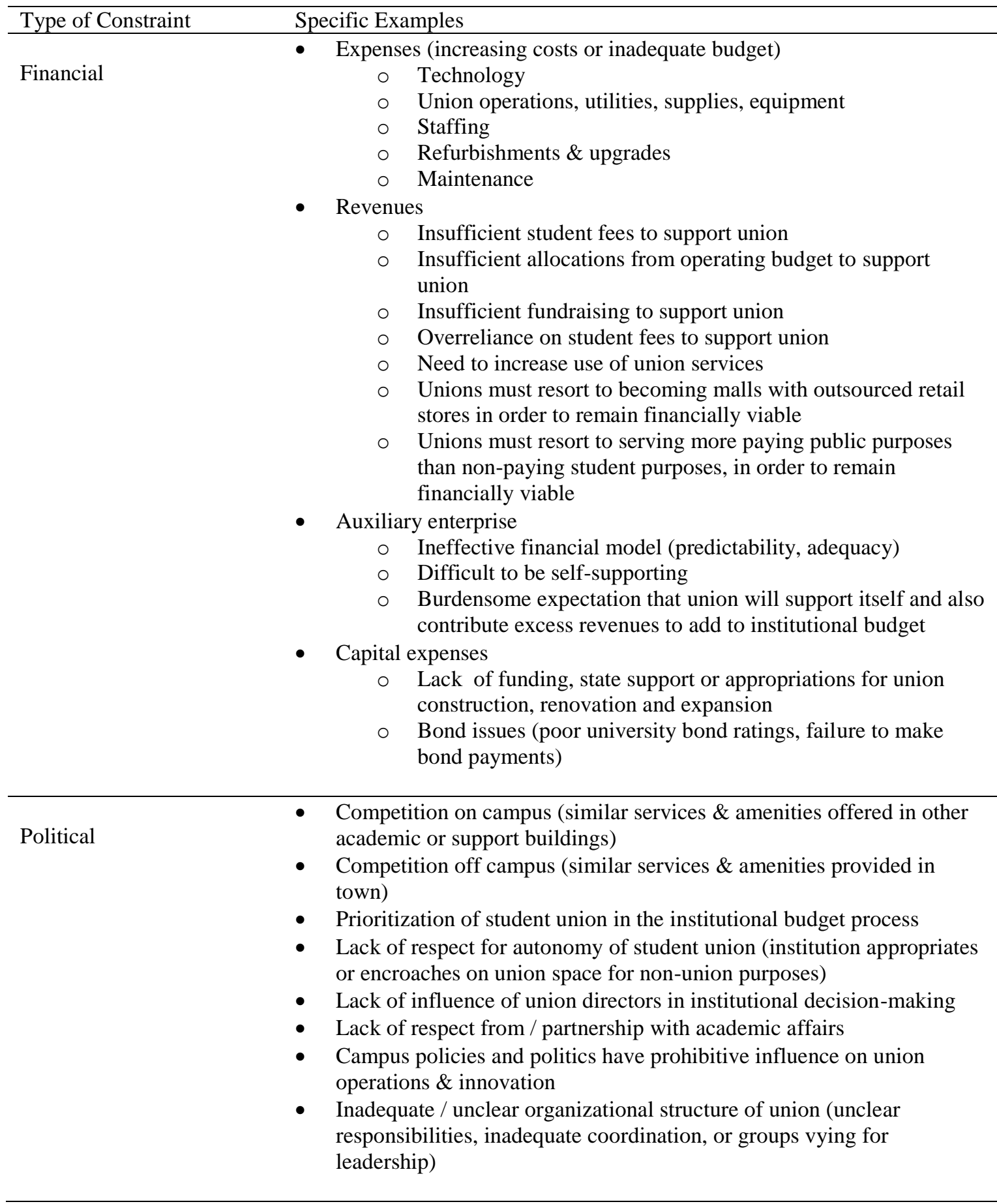




\section{Influences on the Student Union of the Future}

The final theme emerging from Round I identified influences or forces that participants believe will shape the college and university student union of the future, including considerations that might go into renovation or construction decisions. Three types of responses emerged: (a) sustaining forces, (b) changing forces, and (c) challenging forces (Table 10).

Sustaining forces are those things that support the core purposes of and a continued need for the student union. For example, many respondents indicated that the campus would always need a welcome center, a place to foster community, and a place that functions as a "living room" where students can relax. Additionally, colleges and universities will remain committed to ensuring student success, which will in turn sustain a continued need for the student union and its array of functions.

Changing forces are those things that may introduce new missions, alter current missions, or modify the ways in which the union fulfills its purposes. Changing student demographics and the impact of technological innovations appeared frequently in participants' responses.

Challenging forces are those things that create barriers or constraints for the union in meeting its purposes and fulfilling its missions. For the most part, "challenging forces" overlapped and reflected the same issues and concerns enumerated previously in the fourth theme, "barriers and constraints." Therefore, as Round I data were analyzed and used to develop the subsequent questionnaires, "challenging forces" was folded into the "barriers and constraints" category to avoid duplication; and the section on shaping the student union of the future focused on the sustaining and changing forces. 
Table 10

Round I Comments - Influences on the Student Union of the Future

\begin{tabular}{|c|c|}
\hline Type of Force / Influence & Specific Examples \\
\hline Sustaining & $\begin{array}{l}\text { - The basic human / student need to connect and belong to the campus } \\
\text { community } \\
\text { - The continued need for students to have a "living room," and a place to } \\
\text { feel "at home" on campus. } \\
\text { - The continued need for co-curricular skill building (e.g. responsibility, } \\
\text { leadership, communication) } \\
\text { - The continued need for a "welcome center" that makes an impression } \\
\text { for students, alumni and visitors, and conveys the campus identity and } \\
\text { instills loyalty } \\
\text { - The importance of student development in the institution's mission and } \\
\text { strategic plan } \\
\text { - The importance of providing a human, high-touch location on campus, } \\
\text { as human interactions are increasingly mediated through technology } \\
\text { - The importance of the union's services and amenities to the campus } \\
\text { community } \\
\text { - The institutional commitment to the student union concept }\end{array}$ \\
\hline Changing & $\begin{array}{l}\text { - } \begin{array}{l}\text { Globalization } \\
\text { - }\end{array} \text { Chanainability / eco-awareness } \\
\text { future students will need) } \\
\text { - Online classes (e.g. keeping more students off campus, diminishing } \\
\text { primacy of a residential college experience) } \\
\text { Evening \& weekend classes (e.g. changing needs for union's operating } \\
\text { hours) } \\
\text { - Finding new ways to create a sense of community } \\
\text { Finding new ways to engage students / compete for their time and } \\
\text { attention } \\
\text { Technology-mediated human interaction (e.g. social media \& virtual } \\
\text { services threaten the need for a physical student union; virtual vs } \\
\text { physical union) } \\
\text { Pace of technological change (e.g. difficult to forecast, keep pace with, } \\
\text { and afford) }\end{array}$ \\
\hline
\end{tabular}

\section{Round II and Round III Results}

As described in Chapter III, "Methodology," the resulting themes and responses

from the open-ended Round I questionnaire were used to develop a closed-ended

questionnaire for use in Rounds II and III. This second questionnaire involved 21 closed-

ended questions, with corresponding matrices of 257 specific response items. 
Respondents were asked to rate the importance of each item on a seven-point Likert scale with choices ranging from 1 (very important) to 7 (very unimportant). The questionnaire also included five comment fields for open-ended supporting information.

Of the 24 panelists who completed Round I, 22 of these remained in the study and completed Rounds II and III, for a 91.6\% retention rate within the study. The resulting data for Rounds II and III were analyzed through three methods consistent with those commonly employed in Delphi studies. These are detailed in Chapter III. First measures of central tendency were calculated (i.e. mean, mode, median) along with the range of participants' ratings for each of the items in the questions. These are reported in detail in Appendix P, and selected data are reported below in corresponding sections. Within each table, scores for both Round II and Round III are provided to allow the reader to see any changes in the descriptive statistics from one round to the next. Although there were slight changes in participants' responses between Rounds II and III, no significant differences emerged that are worth noting.

Second, the means from each item in the Round III results were ranked in order of importance (highest to lowest), and are reported in that order within the Chapter IV and appendix tables. Third, and finally, the level of consensus among the participants' rating of the different items in each question was examined using strategies suggested by Keeney, Hasson \& McKenna (2006). The analysis distinguished between two gradations of consensus: general consensus, and true consensus. True consensus was reached when a critical mass of $75 \%$ or more of participants selected a single response - either "1" (very important), or "2" (important) - in their Likert scale rankings of items within the 
questions. A general consensus was reached when a combined total of $75 \%$ or more of participants selected either of these two adjacent points on the Likert scale.

The analysis of consensus focused specifically on panelist agreement for ratings "1" (very important), and "2" (important), because this study focused on identifying the most important purposes, amenities, barriers, and influences for college unions. Thus, it was salient to the research to measure degrees of consensus concerning importance. Conversely, it was not salient to measure consensus on degrees of unimportance.

This section presents the results of the Round II and Round III questionnaires according to the five themes identified in Round I.

\section{Purpose and Mission of Student Unions}

The first three questions of the Round II and III questionnaires addressed the purposes, missions, and populations served by student unions, as identified by panelists through the Round I questionnaire (Tables P1, P2, P3).

Purpose. The purpose of the student union explains why it exists as part of a college campus and what primary roles it fills. Four purposes of student unions emerged from Round I: building, creating or fostering community; supporting student success; serving as a "welcome center" for the campus; and serving as the "living room" for the campus. Overall, the panelists' responses in Rounds II and III achieved consensus that each of the above four purposes is important or very important for student unions, with mean scores in Round III ranging between 1.14 and 1.64 (Tables 11, P1).

Analyzing the means, the two most important purposes served by the union, according to participants' ratings (i.e. the mean closest to 1.0), were building, creating or fostering community ( $M=1.14)$, and supporting student success $(M=1.38)$. Panelists 
achieved a $100 \%$ consensus that both of these items were important or very important. Although the differences in the mean scores for the two items were slight, "building, creating or fostering community" emerged as the most important purpose of all, with $86.4 \%$ of panelists achieving a true consensus and rating it as very important.

Serving as the "living room" for the campus ranked third $(\mathrm{M}=1.38$, consensus $=$ 95.5\%), and serving as the "welcome center" for the campus ranked fourth $(\mathrm{M}=1.64$, consensus $=86.4 \%)$. Although, as one participant noted in the comment field, "The 'living room of the campus' is actually becoming old terminology. Living rooms even in houses have changed purpose."

\section{Table 11}

\section{Round II and III Results - Purposes of Student Unions}

Q1: How important is it for the student union to serve each of the following purposes (roles)?

\begin{tabular}{|c|c|c|c|c|}
\hline \multirow{5}{*}{$\begin{array}{l}\text { Building, creating or } \\
\text { fostering community }\end{array}$} & & Round II & Round III & Agreement \\
\hline & Mean & 1.00 & 1.14 & $86.4 \%=1$ \\
\hline & Range & 0 & $1-2$ & $13.6 \%=2$ \\
\hline & Median & 1 & 1 & $\therefore 100 \%=1,2$ \\
\hline & Mode & 1 & 1 & $\sqrt{ }$ True Consensus \\
\hline \multirow[t]{5}{*}{ Supporting student success } & & Round II & Round III & Agreement \\
\hline & Mean & 1.23 & 1.38 & $61.9 \%=1$ \\
\hline & Range & $1-2$ & $1-2$ & $38.1 \%=2$ \\
\hline & Median & 1 & 1 & $\therefore 100 \%=1,2$ \\
\hline & Mode & 1 & 1 & $\sqrt{ }$ Consensus \\
\hline \multirow{5}{*}{$\begin{array}{l}\text { Serving as the "living room" } \\
\text { for the campus }\end{array}$} & & Round II & Round III & Agreement \\
\hline & Mean & 1.27 & 1.45 & $68.2 \%=1$ \\
\hline & Range & $1-3$ & $1-5$ & $27.3 \%=2$ \\
\hline & Median & 1 & 1 & $\therefore 95.5 \%=1,2$ \\
\hline & Mode & 1 & 1 & $\sqrt{ }$ Consensus \\
\hline \multirow{5}{*}{$\begin{array}{l}\text { Serving as the "welcome } \\
\text { center" for the campus }\end{array}$} & & Round II & Round III & Agreement \\
\hline & Mean & 1.55 & 1.64 & $50.0 \%=1$ \\
\hline & Range & $1-3$ & $1-3$ & $36.4 \%=2$ \\
\hline & Median & 1 & 1.5 & $\therefore 86.4 \%=1,2$ \\
\hline & Mode & 1 & 1 & $\sqrt{ }$ Consensus \\
\hline
\end{tabular}

$\mathrm{N}=2$ 
Taken as a whole, the experts achieved consensus that each of these are important purposes for unions, and reached a true consensus that building, creating, or fostering community is the most important purpose of all.

Mission. The mission of the student union explains how it fulfills its purposes or roles. According to the participant responses in the Round I survey, the student union can serve a variety of missions, and 11 distinct items were included on this question. As with the preceding analysis, almost all were rated as either important or very important by participants. When analyzing the rank ordering of mean responses and the degrees of consensus, a few distinctions can be made.

First, providing students informal spaces for studying, lounging, or socializing $(M=1.14$, consensus $=100 \%)$ emerged as the most important mission. This was also the only item on the list for which panelists reached true consensus, with $86.4 \%$ rating it as very important. However, five other items also rated very high, with general consensus above $90 \%$. These were: providing formal spaces for meetings and events $(M=1.27$, consensus $=100 \%)$; supporting co-curricular student learning and development $(\mathrm{M}=1.32$, consensus $=95.4 \%)$; offering food services $(M=1.36$, consensus $100 \%)$; offering student employment opportunities ( $\mathrm{M}=1.36$, consensus $=95.5 \%)$; and supporting student retention $(\mathrm{M}=1.59$, consensus $=96.4 \%)$.

Clearly, however, four additional missions were also important to panelists as indicated by their means, which ranged from 1.59 to 2.00 , and their level of agreement, which ranged from $77.2 \%$ to $96.4 \%$ consensus. These included offering cultural opportunities, supporting both student retention and recruitment, offering retail services such as a bookstore, computer/technology store and a post office, and offering recreation 
Table 12

\section{Round II and III Results - Top Six Missions of Student Unions}

Q2: How important is it for the union to serve each of the following missions?

\begin{tabular}{|c|c|c|c|c|}
\hline \multirow{5}{*}{$\begin{array}{l}\text { Provide informal spaces } \\
\text { (e.g. lounge space, study } \\
\text { space, socializing space) }\end{array}$} & & Round II & Round III & \multirow{5}{*}{$\begin{array}{l}\quad \text { Agreement } \\
86.4 \%=1 \\
13.6 \%=2 \\
\therefore 100 \%=1,2 \\
\sqrt{ } \text { True Consensus }\end{array}$} \\
\hline & Mean & 1.05 & 1.14 & \\
\hline & Range & $1-2$ & $1-2$ & \\
\hline & Median & 1 & 1 & \\
\hline & Mode & 1 & 1 & \\
\hline \multirow{5}{*}{$\begin{array}{l}\text { Provide formal spaces (e.g. } \\
\text { for meetings and events) }\end{array}$} & & Round II & Round III & \multirow{5}{*}{$\begin{array}{l}\quad \text { Agreement } \\
72.7 \%=1 \\
27.3 \%=2 \\
\therefore 100 \%=1,2 \\
\sqrt{ } \text { Consensus }\end{array}$} \\
\hline & Mean & 1.18 & 1.27 & \\
\hline & Range & $1-2$ & $1-2$ & \\
\hline & Median & 1 & 1 & \\
\hline & Mode & 1 & 1 & \\
\hline \multirow{5}{*}{$\begin{array}{l}\text { Support co-curricular } \\
\text { student development \& } \\
\text { learning }\end{array}$} & & Round II & Round III & \multirow{5}{*}{$\begin{array}{l}\quad \text { Agreement } \\
72.7 \%=1 \\
22.7 \%=2 \\
\therefore 95.4 \%=1,2 \\
\sqrt{ } \text { Consensus }\end{array}$} \\
\hline & Mean & 1.23 & 1.32 & \\
\hline & Range & $1-2$ & $1-3$ & \\
\hline & Median & 1 & 1 & \\
\hline & Mode & 1 & 1 & \\
\hline \multirow{5}{*}{$\begin{array}{l}\text { Offer food services (e.g. } \\
\text { food courts, cafeterias, } \\
\text { restaurants) }\end{array}$} & & Round II & Round III & Agreement \\
\hline & Mean & 1.41 & 1.36 & \multirow{4}{*}{$\begin{array}{l}63.6 \%=1 \\
36.4 \%=2 \\
\therefore 100 \%=1,2 \\
\sqrt{ } \text { Consensus }\end{array}$} \\
\hline & Range & $1-2$ & $1-2$ & \\
\hline & Median & 1 & 1 & \\
\hline & Mode & 1 & 1 & \\
\hline \multirow{5}{*}{$\begin{array}{l}\text { Offer student employment } \\
\text { opportunities }\end{array}$} & & Round II & Round III & Agreement \\
\hline & Mean & 1.18 & 1.36 & \multirow{4}{*}{$\begin{array}{l}68.2 \%=1 \\
27.3 \%=2 \\
\therefore 95.5 \%=1,2 \\
\sqrt{ } \text { Consensus }\end{array}$} \\
\hline & Range & $1-2$ & $1-3$ & \\
\hline & Median & 1 & 1 & \\
\hline & Mode & 1 & 1 & \\
\hline \multirow[t]{5}{*}{ Support student retention } & & Round II & Round III & \multirow{5}{*}{$\begin{array}{l}\text { Agreement } \\
59.1 \%=1 \\
27.3 \%=2 \\
\therefore 96.4 \%=1,2 \\
\sqrt{ } \text { Consensus }\end{array}$} \\
\hline & Mean & 1.55 & 1.59 & \\
\hline & Range & $1-3$ & $1-4$ & \\
\hline & Median & 1 & 1 & \\
\hline & Mode & 1 & 1 & \\
\hline
\end{tabular}

$\mathrm{N}=22$

and entertainment opportunities including bowling and movies. Although panelists agreed on the importance of these missions, "The type of campus will affect these answers," as one participant wrote in a comment field. Seemingly speaking in unison, another panelist wrote, "Each campus must determine the right blend of services and 
amenities. There is no right answer for these. However, the program, hangout, and meeting pieces are essential on every campus."

It is worth noting that the lowest ranked mission of the student union, "supporting curricular / classroom student learning," had an overall mean score of 2.45 (somewhat important), and failed to achieve consensus among panelists. This suggests that although panelists identified "supporting student success" as an important purpose of the union, there is disagreement among experts as to whether that should include supporting curricular learning as a mission of the union. The top six ranked missions are reported in Table 12, and the full results for this question are reported in Table P2 in the appendix.

Populations served. The student union serves a variety of populations. Round III presented panelists with 15 different types of populations on campus, and asked panelists to rate how important it was for the union to serve each. Not surprisingly, the results indicated that student populations have the most importance for student unions (Tables 13, P3). Two types of student populations emerged as the most important of all: traditional age undergraduates $(M=1.14$, consensus $=100 \%)$ and residential students $(M=1.32$, consensus $=90.7 \%)$. These were the only populations for which panelists reached a true consensus, with $86.4 \%$ agreeing that traditional aged students are a very important population served by unions, and $77.3 \%$ agreeing that residential students are a very important population served.

However, there was consensus that nearly all populations of current students are important .Interestingly, the rank order of the means suggested that panelists tended to negatively correlate age with importance, with traditional-aged and residential students having top priority, as aforementioned; and older populations of students, such as 
Table 13

Round II and III Results, Student Populations Served by Student Unions

Q3: How important is it for the union to serve each of the following populations?

\begin{tabular}{|c|c|c|c|c|}
\hline \multirow{5}{*}{$\begin{array}{l}\text { Traditional age } \\
\text { undergraduate }\end{array}$} & & Round II & Round III & Agreement \\
\hline & Mean & 1.32 & 1.14 & $86.4 \%=1$ \\
\hline & Range & $1-5$ & $1-2$ & $13.6 \%=2$ \\
\hline & Median & 1 & 1 & $\therefore 100.0 \%=1,2$ \\
\hline & Mode & 1 & 1 & $\sqrt{ }$ True Consensus \\
\hline \multirow[t]{5}{*}{ Residential students } & & Round II & Round III & Agreement \\
\hline & Mean & 1.27 & 1.32 & $77.3 \%=1$ \\
\hline & Range & $1-3$ & $1-3$ & $13.4 \%=2$ \\
\hline & Median & 1 & 1 & $\therefore 90.7 \%=1,2$ \\
\hline & Mode & 1 & 1 & $\sqrt{ }$ True Consensus \\
\hline \multirow[t]{5}{*}{ Commuter students } & & Round II & Round III & Agreement \\
\hline & Mean & 1.33 & 1.32 & $72.7 \%=1$ \\
\hline & Range & $1-3$ & $1-3$ & $22.7 \%=2$ \\
\hline & Median & 1 & 1 & $95.4 \%=1,2$ \\
\hline & Mode & 1 & 1 & $\sqrt{ }$ Consensus \\
\hline \multirow[t]{5}{*}{ Evening student } & & Round II & Round III & Agreement \\
\hline & Mean & 1.57 & 1.41 & $68.2 \%=1$ \\
\hline & Range & $1-3$ & $1-4$ & $22.7 \%=2$ \\
\hline & Median & 2 & 1 & $\therefore 90.9 \%=1,2$ \\
\hline & Mode & $1+2$ & 1 & $\sqrt{ }$ Consensus \\
\hline \multirow{5}{*}{$\begin{array}{l}\text { Nontraditional age } \\
\text { undergraduates }\end{array}$} & & Round II & Round III & Agreement \\
\hline & Mean & 1.50 & 1.59 & $40.9 \%=1$ \\
\hline & Range & $1-5$ & $1-2$ & $59.1 \%=2$ \\
\hline & Median & 1 & 1 & $\therefore 100.0 \%=1,2$ \\
\hline & Mode & 1 & 1 & $\sqrt{ }$ Consensus \\
\hline \multirow[t]{5}{*}{ Graduate students } & & Round II & Round III & Agreement \\
\hline & Mean & 1.73 & 1.68 & $45.5 \%=1$ \\
\hline & Range & $1-3$ & $1-3$ & $40.1 \%=2$ \\
\hline & Median & 2 & 2 & $\therefore 85.6 \%=1,2$ \\
\hline & Mode & 2 & 2 & $\sqrt{ }$ Consensus \\
\hline \multirow[t]{5}{*}{ Virtual/online student } & & Round II & Round III & Agreement \\
\hline & Mean & 3.10 & 3.14 & $9.1 \%=1$ \\
\hline & Range & $2-7$ & $1-6$ & $13.6 \%=2$ \\
\hline & Median & 3 & 3 & $22.7 \%=1,2$ \\
\hline & Mode & 3 & 3 & No Consensus \\
\hline $\mathrm{N}=22$ & & & & \\
\hline
\end{tabular}

non-traditional students $(\mathrm{M}=1.59$, consensus $100 \%)$ and graduate students $(\mathrm{M}=1.68$,

consensus $85.6 \%$ ) having slightly lesser priority. Populations that mix older and younger 
students, such as commuter students $(\mathrm{M}=1.32$, consensus $95.4 \%)$ and evening students $(\mathrm{M}=1.41$, consensus $=90.9 \%)$ ranked somewhere in between. It is important to stress that these differences were very slight. Only the population of virtual / online students was not rated as important for the union to serve $(M=3.14$, consensus $=22.7 \%)$.

When considering populations who either are not students or not currently students (Table 14), panelists identified prospective students $(\mathrm{M}=1.82$, consensus $=$ $81.9 \%)$ as the most important, followed by individual campus faculty and staff $(\mathrm{M}=1.86$, consensus $86.3 \%)$. Visitors to campus for either college related purposes $(\mathrm{M}=2.18$, consensus $=77.3 \%)$ and alumni $(\mathrm{M}=2.50$, consensus $81.9 \%)$ were also ranked as important, but not as high as the aforementioned. Conversely, panelists lacked agreement as to the primacy of the union serving groups such as visitors who were there for noncollege related purposes $(M=2.55$, consensus $=40.9 \%)$, academic departments $(M=2.59$, consensus $=40.9 \%)$, administrative departments $(M=2.64$, consensus $=45.5 \%)$, and families of students and alumni $(M=2.82$, consensus $=27.2 \%)$.

Panelists offered several write-in comments about the rationale behind their rankings. "The College Union seeks to serve all populations associated with a University / College," one participant noted. Two others added, "We try to serve as broad a population and purpose as possible," and "I perceive the need to serve all students equally." Other panelists, however, were more pragmatic. In contrast to the all-serving viewpoint, one pointed out, "I imagine the level of importance could vary significantly from campus to campus. What is important on one campus may be very unimportant on another campus." Another wrote quite simply, "I really do not know how we could be 
Table 14

Round II and III Results - Other Populations Served by Student Unions

Q3: How important is it for the union to serve each of the following populations?

\begin{tabular}{|c|c|c|c|c|}
\hline \multirow[t]{5}{*}{ Prospective students } & & Round II & Round III & Agreement \\
\hline & Mean & 1.68 & 1.82 & $36.4 \%=1$ \\
\hline & Range & $1-4$ & $1-3$ & $45.5 \%=2$ \\
\hline & Median & 1 & 2 & $\therefore 81.9 \%=1,2$ \\
\hline & Mode & 1 & 2 & $\sqrt{ }$ Consensus \\
\hline \multirow{5}{*}{$\begin{array}{l}\text { Campus staff and faculty (as } \\
\text { individuals) }\end{array}$} & & Round II & Round III & Agreement \\
\hline & Mean & 1.95 & 1.86 & $31.8 \%=1$ \\
\hline & Range & $1-4$ & $1-4$ & $54.5 \%=2$ \\
\hline & Median & 2 & 2 & $\therefore 86.3 \%=1,2$ \\
\hline & Mode & 2 & 2 & $\sqrt{ }$ Consensus \\
\hline \multirow{5}{*}{$\begin{array}{l}\text { Visitors to the campus for } \\
\text { other college-related } \\
\text { business/purposes }\end{array}$} & & Round II & Round III & Agreement \\
\hline & Mean & 1.91 & 2.18 & $18.2 \%=1$ \\
\hline & Range & $1-3$ & $1-5$ & $59.1 \%=2$ \\
\hline & Median & 2 & 2 & $\therefore 77.3 \%=1,2$ \\
\hline & Mode & $1+2$ & 2 & $\sqrt{ }$ Consensus \\
\hline \multirow[t]{5}{*}{ Alumni } & & Round II & Round III & Agreement \\
\hline & Mean & 2.45 & 2.50 & $45.5 \%=1$ \\
\hline & Range & $1-5$ & $1-5$ & $36.4 \%=2$ \\
\hline & Median & 2.5 & 2 & $\therefore 81.9 \%=1,2$ \\
\hline & Mode & 3 & 2 & $\sqrt{ }$ Consensus \\
\hline \multirow{5}{*}{$\begin{array}{l}\text { Visitors to the campus for } \\
\text { non-college related purposes }\end{array}$} & & Round II & Round III & Agreement \\
\hline & Mean & 2.43 & 2.55 & $9.1 \%=1$ \\
\hline & Range & $1-4$ & $1-4$ & $31.8 \%=2$ \\
\hline & Median & 3 & 3 & $\therefore 40.9 \%=1,2$ \\
\hline & Mode & 3 & 3 & No Consensus \\
\hline \multirow[t]{5}{*}{ Academic departments } & & Round II & Round III & Agreement \\
\hline & Mean & 2.45 & 2.59 & $18.2 \%=1$ \\
\hline & Range & $1-4$ & $1-4$ & $22.7 \%=2$ \\
\hline & Median & 2 & 3 & $\therefore 40.9 \%=1,2$ \\
\hline & Mode & 2 & 3 & No Consensus \\
\hline \multirow[t]{5}{*}{ Administrative departments } & & Round II & Round III & Agreement \\
\hline & Mean & 2.36 & 2.64 & $9.1 \%=1$ \\
\hline & Range & $1-4$ & $1-4$ & $36.4 \%=2$ \\
\hline & Median & 2 & 3 & $\therefore 45.5 \%=1,2$ \\
\hline & Mode & 2 & 2.5 & No Consensus \\
\hline \multirow{5}{*}{$\begin{array}{l}\text { Families of current students } \\
\text { or alumni }\end{array}$} & & Round II & Round III & Agreement \\
\hline & Mean & 2.59 & 2.82 & $4.5 \%=1$ \\
\hline & Range & $1-4$ & $1-5$ & $22.7 \%=2$ \\
\hline & Median & 2.5 & 3 & $\therefore 27.2 \%=1,2$ \\
\hline & Mode & 2 & 3 & No Consensus \\
\hline
\end{tabular}


able to serve virtual or on-line students.” These comments illuminated why nearly all populations were ranked highly, yet not equally.

Taken as a whole, experts agreed that students are the most important population served by unions. Among current students, clearly residential and traditional age students were deemed the most important populations served by unions. One panelist explained, “...the needs and lifestyles of commuter, virtual and evening students are very different than residential students and thus they are a less important constituency given limited resources....unions owe more to current students than prospective students who may or may not attend."

\section{Services, Programs, Spaces and Amenities of Student Unions}

In this study, "services, programs and amenities" of the student union refers to the specific means or strategies through which the union enacts its missions to fulfill its purposes and serve its target populations. This section considers these elements, the nature of the student unions' role in providing them, and the spaces in the union used for these purposes.

Services. Panelists evaluated the importance of 26 different types of services identified in the Round I questionnaire as commonly offered in student unions. Participants' ratings ranged widely on these items, covering a six point spread from "1 very important" to "5 somewhat unimportant" (Tables $15,16, \mathrm{P} 4)$. Three clear categories emerged: (a) those for which panelists reached true consensus and deemed very important; (b) those for which panelists reached general consensus and deemed as either important or very important; and (c) those for which no consensus was reached and panelists deemed with varying degrees of importance. In the highest category, the four 
top ranked services that should be located within the union included the offices of student activities $(\mathrm{M}=1.18$, consensus $=95.4 \%)$, student government $(\mathrm{M}=1.18$, consensus $=$ 95.4\%), student programming board $(\mathrm{M}=1.23$, consensus $=95.4 \%)$, and student organizations $(M=1.27$, consensus $=95.4 \%)$. Each of these services focuses on cocurricular student development and community building - highly ranked purposes and missions identified in previous questions - and panelists reached true consensus with $77.3 \%$ to $86.4 \%$ agreeing uniformly that it was very important for these to be located in the union.

Table 15

Round II and III Results - Top Four Services in Student Unions

Q5: How important is for each of the following services to be located within the student union?

\begin{tabular}{|c|c|c|c|c|}
\hline \multirow[t]{5}{*}{ Student Activities Office } & & Round II & Round III & Agreement \\
\hline & Mean & 1.18 & 1.18 & $86.4 \%=1$ \\
\hline & Range & $1-3$ & $1-3$ & $9.0 \%=2$ \\
\hline & Median & 1 & 1 & $\therefore 95.4 \%=1,2$ \\
\hline & Mode & 1 & 1 & $\sqrt{ }$ True Consensus \\
\hline \multirow[t]{5}{*}{ Student Government Office } & & Round II & Round III & Agreement \\
\hline & Mean & 1.36 & 1.18 & $86.4 \%=1$ \\
\hline & Range & $1-4$ & $1-3$ & $9.0 \%=2$ \\
\hline & Median & 1 & 1 & $\therefore 95.4 \%=1,2$ \\
\hline & Mode & 1 & 1 & $\sqrt{ }$ True Consensus \\
\hline \multirow{5}{*}{$\begin{array}{l}\text { Student Programming Board } \\
\text { Office }\end{array}$} & & Round II & Round III & Agreement \\
\hline & Mean & 1.18 & 1.23 & $81.8 \%=1$ \\
\hline & Range & $1-3$ & $1-3$ & $13.6 \%=2$ \\
\hline & Median & 1 & 1 & $95.4 \therefore \%=1,2$ \\
\hline & Mode & 1 & 1 & $\sqrt{ }$ True Consensus \\
\hline \multirow[t]{5}{*}{ Student Organization Office } & & Round II & Round III & Agreement \\
\hline & Mean & 1.18 & 1.27 & $77.3 \%=1$ \\
\hline & Range & $1-3$ & $1-3$ & $18.1 \%=2$ \\
\hline & Median & 1 & 1 & $\therefore 95.4 \%=1,2$ \\
\hline & Mode & 1 & 1 & $\sqrt{ }$ True Consensus \\
\hline $\mathrm{N}=22$ & & & & \\
\hline
\end{tabular}


There were five additional services for which panelists reached general consensus (Table 16). Among these, four focused on the coordination and production of internal and external activities and events. These included a staffed information desk service $(\mathrm{M}=1.41$, consensus $=90.9 \%)$, the room reservation office $(\mathrm{M}=1.45$, consensus $=95.5 \%)$, event planning services $(M=2.05$, consensus $=77.3 \%)$ and event production services $(M=2.05$, consensus $=81.8 \%)$. The student leadership and service office $(M=2.18$, consensus $=77.3 \%)$ rounded out the list.

Table 16

Round II and III Results - Other Important Services in Student Unions

\begin{tabular}{|c|c|c|c|c|}
\hline \multirow{5}{*}{$\begin{array}{l}\text { Information Desk Services } \\
\text { (staffed) }\end{array}$} & & Round II & Round III & Agreement \\
\hline & Mean & 1.18 & 1.41 & \multirow{4}{*}{$\begin{array}{l}72.7 \%=1 \\
18.2 \%=2 \\
\therefore 90.9 \%=1,2 \\
\sqrt{ } \text { Consensus }\end{array}$} \\
\hline & Range & $1-2$ & $1-4$ & \\
\hline & Median & 1 & 1 & \\
\hline & Mode & 1 & 1 & \\
\hline \multirow[t]{5}{*}{ Room Reservations Office } & & Round II & Round III & Agreement \\
\hline & Mean & 1.29 & 1.45 & \multirow{4}{*}{$\begin{array}{l}59.1 \%=1 \\
36.4 \%=2 \\
\therefore 95.5 \%=1,2 \\
\sqrt{ } \text { Consensus }\end{array}$} \\
\hline & Range & $1-3$ & $1-3$ & \\
\hline & Median & 1 & 1 & \\
\hline & Mode & 2 & 3 & \\
\hline \multirow{5}{*}{$\begin{array}{l}\text { Event/Conference Planning } \\
\text { Services }\end{array}$} & & Round II & \multicolumn{2}{|l|}{ Round III } \\
\hline & Mean & 1.82 & 2.05 & $31.8 \%=1$ \\
\hline & Range & $1-3$ & $1-5$ & $45.5 \%=2$ \\
\hline & Median & 2 & 2 & $\therefore 77.3 \%=1,2$ \\
\hline & Mode & 2 & 2 & $\sqrt{ }$ Consensus \\
\hline \multirow{5}{*}{$\begin{array}{l}\text { Event Production/Audio- } \\
\text { visual Services }\end{array}$} & & Round II & Round III & Agreement \\
\hline & Mean & 1.73 & 2.05 & $31.8 \%=1$ \\
\hline & Range & $1-5$ & $1-5$ & $50.0 \%=2$ \\
\hline & Median & 1.5 & 2 & $\therefore 81.8 \%=1,2$ \\
\hline & Mode & 1 & 2 & $\sqrt{ }$ Consensus \\
\hline \multirow{5}{*}{$\begin{array}{l}\text { Leadership \& Service } \\
\text { Office }\end{array}$} & & Round II & Round III & Agreement \\
\hline & Mean & 1.57 & 2.18 & $18.2 \%=1$ \\
\hline & Range & $1-3$ & $1-6$ & $59.1 \%=2$ \\
\hline & Median & 1.5 & 2 & $\therefore 77.3 \%=1,2$ \\
\hline & Mode & 1 & 2 & $\sqrt{ }$ Consensus \\
\hline
\end{tabular}

$\mathrm{N}=22$ 
Beyond these, panelists rated seven other kinds of services as "neutral" to "somewhat important." These included unstaffed information kiosks, multicultural centers, ID / University card services, ticket outlet / offices, student newspaper offices, the dean of student's office and career services. There were also several services that panelists deemed as not belonging in the union, rating them between neutral and unimportant. These included: the victim advocacy office, health \& wellness, homecoming/alumni relations, admissions, counselling services, academic and support services, parking, financial aid, the registrar, and the library. The full results for each of these items are reported in Appendix P, Table P4.

It is important to clarify that panelists were not evaluating the importance of each service, per se, but rather the importance of its being located specifically within the union. As two panelists wrote in the Round III questionnaire comment field, "It's hard to minimize the importance of any of the measures, but there is some relative importance...," and "Everything listed has value. I am just trying to propose the idea that we can't be all things to all people, and should put most of our efforts towards our prime purpose." Thus, while many of these services are mission critical to the college or university as a whole, responses suggested that they may be more appropriately located elsewhere on campus.

Programming. The Round I questionnaire generated a list of ten types of student union programming (Tables 17, P5). Among these, participants agreed that it is most important for student-organized programming $(\mathrm{M}=1.18$, consensus $=100 \%)$ and active co-curricular programming $(\mathrm{M}=1.36$, consensus $=90.9 \%$. $)$ to be located or offered within the student union. Panelists achieved true consensus on these two items, with $77.3 \%$ to 
$81.8 \%$ ranking them as very important. They also reached general consensus about the importance of five additional types of programming offered in unions: formal social opportunities such as dinners, dances, and parties $(M=1.41$, consensus $=90.9 \%)$; formal cultural events such as music or dance performances $(M=1.41$, consensus $=95.2 \%)$; leadership and service opportunities for students $(\mathrm{M}=1.45$, consensus $=90.9 \%)$; multicultural programming $(\mathrm{M}=1.48$, consensus $=95.2 \%)$ and passive co-curricular programming $(\mathrm{M}=1.95$, consensus $=77.3 \%)($ Table 16$)$.

Participants did not reach consensus on the importance of three other types of programming: recruitment (e.g. student tours, recruitment events, open houses and orientation); formal educational opportunities (e.g. conferences, lectures and symposia) and for-credit laboratories and experiences (Table P5).

As described previously, the Round III questionnaire further asked the participants to rank how important the student union's involvement is in three distinct roles in programming: place, provider, and partner. Responses indicated that experts deem all roles to be equally important (Tables 18, P6). The "partner" role, in which union staff partners with other groups or offices to design and offer programming, garnered the highest consensus and mean score $(M=1.36$, consensus $=95.5 \%)$. However, differences were slight. The "place"-role, in which the union provides a venue for programming that others design and offer, scored a mean of $M=1.52$, with a $90.4 \%$ consensus. The "provider" role, in which the union staff designs and offers programming, scored a mean of 1.73 , with an $89.4 \%$ consensus. 
Table 17

\section{Round II and III Results - Programming Offered in Student Unions}

Q6: How important is it for each of the following types of programming to be located or offered within the student union?

\begin{tabular}{|c|c|c|c|c|}
\hline \multirow{5}{*}{$\begin{array}{l}\text { Student organized } \\
\text { programming }\end{array}$} & & Round II & Round III & Agreement \\
\hline & Mean & 1.00 & 1.18 & $81.8 \%=1$ \\
\hline & Range & 0 & $1-2$ & $18.2 \%=2$ \\
\hline & Median & 1 & 1 & $\therefore 100 \%=1,2$ \\
\hline & Mode & 1 & 1 & $\sqrt{\text { True Consensus }}$ \\
\hline \multirow{5}{*}{$\begin{array}{l}\text { Active co-curricular } \\
\text { programming }\end{array}$} & & Round II & Round III & Agreement \\
\hline & Mean & 1.23 & 1.36 & $77.3 \%=1$ \\
\hline & Range & $1-2$ & $1-4$ & $13.6 \%=2$ \\
\hline & Median & 1 & 1 & $\therefore 90.9 \%=1,2$ \\
\hline & Mode & 1 & 1 & $\sqrt{\text { True Consensus }}$ \\
\hline \multirow{5}{*}{$\begin{array}{l}\text { Formal social opportunities } \\
\text { (e.g. dinners, dances, } \\
\text { parties) }\end{array}$} & & Round II & Round III & Agreement \\
\hline & Mean & 1.23 & 1.41 & $68.2 \%=1$ \\
\hline & Range & $1-3$ & $1-3$ & $22.7 \%=2$ \\
\hline & Median & 1 & 1 & $\therefore 90.9 \%=1,2$ \\
\hline & Mode & 1 & 1 & $\sqrt{ }$ Consensus \\
\hline \multirow{5}{*}{$\begin{array}{l}\text { Formal cultural events (e.g. } \\
\text { music or dance } \\
\text { performances) }\end{array}$} & & Round II & Round III & Agreement \\
\hline & Mean & 1.27 & 1.43 & $71.4 \%=1$ \\
\hline & Range & $1-3$ & $1-5$ & $23.8 \%=2$ \\
\hline & Median & 1 & 1 & $95.2 \%=1,2$ \\
\hline & Mode & 1 & 1 & $\sqrt{ }$ Consensus \\
\hline \multirow{5}{*}{$\begin{array}{l}\text { Leadership \& service } \\
\text { opportunities for students }\end{array}$} & & Round II & Round III & Agreement \\
\hline & Mean & 1.23 & 1.45 & $68.2 \%=1$ \\
\hline & Range & $1-2$ & $1-4$ & $22.7 \%=2$ \\
\hline & Median & 1 & 1 & $\therefore 90.9 \%=1,2$ \\
\hline & Mode & 1 & 1 & $\sqrt{ }$ Consensus \\
\hline \multirow[t]{5}{*}{ Multicultural programming } & & Round II & Round III & Agreement \\
\hline & Mean & 1.36 & 1.48 & $57.1 \%=1$ \\
\hline & Range & $1-3$ & $1-3$ & $38.1 \%=2$ \\
\hline & Median & 1 & 1 & $95.2 \%=1,2$ \\
\hline & Mode & 1 & 1 & $\sqrt{ }$ Consensus \\
\hline \multirow{5}{*}{$\begin{array}{l}\text { Passive co-curricular } \\
\text { programming }\end{array}$} & & Round II & Round III & Agreement \\
\hline & Mean & 1.68 & 1.95 & $31.8 \%=1$ \\
\hline & Range & $1-3$ & $1-4$ & $45.5 \%=2$ \\
\hline & Median & 1.5 & 2 & $\therefore 77.3 \%=1,2$ \\
\hline & Mode & 1 & 2 & $\sqrt{ }$ Consensus \\
\hline $\mathrm{N}=22$ & & & & \\
\hline
\end{tabular}


Table 18

Round II and III Results - Roles of Student Unions

Q7: How important the student union's involvement is in each of the following roles in programming?

\begin{tabular}{|c|c|c|c|c|}
\hline \multirow{5}{*}{$\begin{array}{l}\text { Partner } \\
\text { (The student union staff } \\
\text { partner with other groups or } \\
\text { offices to design and offer } \\
\text { the programming) }\end{array}$} & & Round II & Round III & Agreement \\
\hline & Mean & 1.45 & 1.36 & \multirow{4}{*}{$\begin{array}{l}68.2 \%=1 \\
27.3 \%=2 \\
\therefore 95.5 \%=1,2 \\
\sqrt{\text { Consensus }}\end{array}$} \\
\hline & Range & $1-3$ & $1-3$ & \\
\hline & Median & 1 & 1 & \\
\hline & Mode & 1 & 1 & \\
\hline \multirow{5}{*}{$\begin{array}{l}\text { Place } \\
\text { (The student union provides } \\
\text { a venue or place, but other } \\
\text { offices or groups design and } \\
\text { offer the programming) }\end{array}$} & & Round II & Round III & Agreement \\
\hline & Mean & 1.27 & 1.52 & $71.4 \%=1$ \\
\hline & Range & $1-5$ & $1-5$ & $19.0 \%=2$ \\
\hline & Median & 1 & 1 & $\therefore 90.4 \%=1,2$ \\
\hline & Mode & 1 & 1 & $\sqrt{ }$ Consensus \\
\hline \multirow{5}{*}{$\begin{array}{l}\text { Provider } \\
\text { (The student union staff } \\
\text { designs and offers the } \\
\text { programming) }\end{array}$} & & Round II & Round III & Agreement \\
\hline & Mean & 1.82 & 1.73 & $50.0 \%=1$ \\
\hline & Range & $1-5$ & $1-5$ & $36.4 \%=2$ \\
\hline & Median & 1 & 1.5 & $\therefore 86.4 \%=1,2$ \\
\hline & Mode & 1 & 1 & $\sqrt{ }$ Consensus \\
\hline \multicolumn{5}{|l|}{$\mathrm{N}=22$} \\
\hline
\end{tabular}

Spaces. A clear trend running through the responses reported thus far is the student union's importance in providing a place or venue for various purposes, missions, services, and programming to occur. Question eight asked participants to rank the importance of 11 different types of spaces that should be located or offered within the union (Tables 19, 20, P7). Among these, panelists rated four the highest, achieving a true consensus with $81 \%$ or more rating each as very important (Table 18). These included, in order of ranking, large-scale formal gathering spaces such as performance halls, ballrooms, banquet and multi-purpose rooms $(M=1.05$, consensus $=100 \%)$; small-scale formal gathering spaces like classrooms and meeting rooms $(\mathrm{M}=1.14$, consensus $=$ $100 \%)$; small-scale informal gathering places such as nooks $(M=1.19$, consensus $=$ $100 \%)$, and large-scale informal gathering places such as lounge spaces $(M=1.27$, consensus $=90.1 \%$. 
Table 19

\section{Round II and III Results: Top Four Spaces in Student Unions}

Q8: How important is it for the following types of spaces to be located or offered within the union?

\begin{tabular}{lllll}
\hline Large-scale formal & & Round II & Round III & \multicolumn{1}{c}{ Agreement } \\
\cline { 2 - 5 } $\begin{array}{l}\text { gathering spaces (e.g. } \\
\text { performance halls, }\end{array}$ ballrooms, banquet \& multi- & Mean & 1.00 & 1.05 & $95.4 \%=1$ \\
purpose rooms) & Range & 0 & $1-2$ & $4.6 \%=2$ \\
& Median & 1 & 1 & $\therefore 100 \%=1,2$ \\
& Mode & 1 & 1 & V True Consensus \\
\hline Small-scale formal & & Round II & Round III & Agreement \\
gathering spaces (e.g. & Mean & 1.14 & 1.14 & $86.4 \%=1$ \\
classrooms, meeting rooms) & Range & $1-3$ & $1-2$ & $13.6 \%=2$ \\
& Median & 1 & 1 & $\therefore 100 \%=1,2$ \\
& Mode & 1 & 1 & $\sqrt{ }$ True Consensus \\
\hline Small-scale informal & & Round II & Round III & Agreement \\
gathering places (e.g. & Mean & 1.09 & 1.19 & $81.0 \%=1$ \\
nooks) & Range & $1-2$ & $1-2$ & $19.0 \%=2$ \\
& Median & 1 & 1 & $\therefore 100 \%=1,2$ \\
& Mode & 1 & 1 & $\sqrt{ }$ True Consensus \\
\hline Large-scale informal & & Round II & Round III & Agreement \\
gathering places (e.g. & Mean & 1.14 & 1.27 & $81.1 \%=1$ \\
lounge spaces) & Range & $1-3$ & $1-3$ & $9.0 \%=2$ \\
& Median & 1 & 1 & $\therefore 90.1 \%=1,2$ \\
& Mode & 1 & 1 & $\sqrt{ }$ True Consensus \\
\hline \multirow{2}{*}{ N=22 } & & & & \\
\hline
\end{tabular}

Panelists also reached general consensus that three other types of spaces were important. These included open spaces $(M=1.45$, consensus $=86.4 \%)$; outdoor spaces for eating, studying and socializing $(\mathrm{M}=1.73$, consensus $=90.9 \%)$; and quiet areas $(\mathrm{M}=2.05$, consensus $=77.3 \%)($ Table 19$)$. For the remaining three spaces - an atrium, spiritual or prayer spaces and sleeping spaces - panelists did not reach consensus (Table P7). Responses on these items ranged widely from very important to very unimportant, demonstrating that while a space may have value on one campus, it may not be needed on another. This may reflect differences in student bodies and populations served, as well as 
differences in the range of spaces available on specific campuses, and the geographic location of campuses.

Table 20

Round II and III Results - Other Important Spaces in Student Unions

Q8: How important is it for the following types of spaces to be located or offered within the union?

\begin{tabular}{lllll}
\hline Open spaces & & Round II & Round III & Agreement \\
\cline { 2 - 5 } & Mean & 1.41 & 1.45 & $68.2 \%=1$ \\
& Range & $1-3$ & $1-3$ & $18.2 \%=2$ \\
& Median & 1 & 1 & $\therefore 86.4 \%=1,2$ \\
& Mode & 1 & 1 & $\sqrt{ }$ Consensus \\
\hline Outdoor spaces/areas (for & & Round II & Round III & Agreement \\
eating, studying, socializing, & Mean & 1.86 & 1.73 & $36.4 \%=1$ \\
etc.) & Range & $1-4$ & $1-3$ & $54.5 \%=2$ \\
& Median & 2 & 2 & $\therefore 90.9 \%=1,2$ \\
& Mode & $1+2$ & 2 & $\sqrt{ }$ Consensus \\
\hline Quiet areas & & Round II & Round III & Agreement \\
\cline { 2 - 5 } & Mean & 2.27 & 2.05 & $27.3 \%=1$ \\
& Range & $1-5$ & $1-5$ & $50.0 \%=2$ \\
& Median & 2 & 2 & $\therefore 77.3 \%=1,2$ \\
& Mode & 2 & 2 & $\sqrt{ }$ Consensus \\
\hline
\end{tabular}

$\mathrm{N}=22$

Amenities. Because so many amenities were identified in Round I it was necessary to split the amenities into two survey questions that asked participants to rate 34 different amenities based upon their importance in the student union. The combined results are presented and discussed here (Tables 21, P8). Interestingly, true consensus emerged for only one item: wireless internet service $(M=1.14$, consensus $=95.4 \%)$, with $90.9 \%$ of panelists rating this as a very important amenity to have in the student union. General consensus was reached on eight more items, with a majority of panelists rating them as important or very important to have in the union. For one of these, ATM machines $(M=1.27)$, there was $100 \%$ consensus. Food courts $(M=1.45$, consensus $=$ 
95.5\%) and art (dispersed through the building) $(\mathrm{M}=1.68$, consensus $=90.9 \%)$ rounded out the top four.

The remaining five amenities most agreed-upon included a coffee shop $(\mathrm{M}=1.68$, consensus $=90.9 \%)$, catering services for events and meetings $(M=1.77$, consensus $=$ $85.7 \%)$ a convenience store $(M=1.73$, consensus $=96.4 \%)$; phone and device charging stations $(M=1.95$, consensus $=86.3 \%)$, and lounge space with televisions $(M=2.05$, consensus $=81.8 \%$ ) (Table 20). Panelists rated the remaining 25 amenities with varying degrees of importance and without achieving consensus. These are reported in Table P8.

\section{Attributes of Student Unions}

Attributes of the student union refer to distinguishing characteristics of either the building's physical location, its exteriors or interiors, or the characteristics of the people who work in and use the union.

Physical attributes. Physical attributes include those characteristics that relate to the building's location, exterior or interior.

Building locations. First, participants were asked to identify the importance of various physical attributes of student union locations, and achieved consensus on four of the six items (Tables 21, P9). These included: located in a high-traffic area/pedestrian crossroads of the campus $(M=1.32$, consensus $=93.0 \%)$, located close to the physical center of campus $(M=1.43$, consensus $=95.2 \%)$, located close to parking $(M=2.00$, consensus $=91.8 \%)$, and located close to residence halls $(\mathrm{M}=2.18$, consensus $=77.3 \%)$. Finding an ideal spot on campus that meets each of these considerations may prove difficult, which may partly explain that no true consensus was reached on any single 
Table 21

\section{Round II and III Results - Important Amenities in Student Unions}

Q9 \& Q10: How important is it for each of the following amenities to be in the student union?

\begin{tabular}{|c|c|c|c|c|}
\hline \multirow[t]{5}{*}{ Wireless Internet service } & & Round II & Round III & Agreement \\
\hline & Mean & 1.00 & 1.14 & $90.9 \%=1$ \\
\hline & Range & 0 & $1-3$ & $4.5 \%=2$ \\
\hline & Median & 1 & 1 & $\therefore 95.4 \%=1,2$ \\
\hline & Mode & 1 & 1 & $\sqrt{\text { True Consensus }}$ \\
\hline \multirow[t]{5}{*}{ ATM Machine } & & Round II & Round III & Agreement \\
\hline & Mean & 1.45 & 1.27 & $72.7 \%=1$ \\
\hline & Range & $1-2$ & $1-2$ & $27.3 \%=2$ \\
\hline & Median & 1 & 1 & $\therefore 100.0 \%=1,2$ \\
\hline & Mode & 1 & 1 & $\sqrt{ }$ Consensus \\
\hline \multirow[t]{5}{*}{ Food court } & & Round II & Round III & Agreement \\
\hline & Mean & 1.50 & 1.45 & $59.1 \%=1$ \\
\hline & Range & $1-3$ & $1-3$ & $36.4 \%=2$ \\
\hline & Median & 1 & 1 & $\therefore 95.5 \%=1,2$ \\
\hline & Mode & 1 & 1 & $\sqrt{ }$ Consensus \\
\hline \multirow{5}{*}{$\begin{array}{l}\text { Art (dispersed throughout } \\
\text { building) }\end{array}$} & & Round II & Round III & Agreement \\
\hline & Mean & 1.77 & 1.68 & $40.9 \%=1$ \\
\hline & Range & $1-3$ & $1-3$ & $50.0 \%=2$ \\
\hline & Median & 2 & 2 & $\therefore 90.9 \%=1,2$ \\
\hline & Mode & 1 & 2 & $\sqrt{ }$ Consensus \\
\hline \multirow[t]{5}{*}{ Coffee Shop } & & Round II & Round III & Agreement \\
\hline & Mean & 1.59 & 1.68 & $40.9 \%=1$ \\
\hline & Range & $1-3$ & $1-3$ & $50.0 \%=2$ \\
\hline & Median & 2 & 2 & $\therefore 90.9 \%=1,2$ \\
\hline & Mode & 2 & 2 & $\sqrt{ }$ Consensus \\
\hline \multirow{5}{*}{$\begin{array}{l}\text { Catering services for events } \\
\text { and meetings }\end{array}$} & & Round II & Round III & Agreement \\
\hline & Mean & 1.77 & 1.71 & $57.1 \%=1$ \\
\hline & Range & $1-5$ & $1-4$ & $28.6 \%=2$ \\
\hline & Median & 1 & 1 & $\therefore 85.7 \%=1,2$ \\
\hline & Mode & 1 & 1 & $\sqrt{ }$ Consensus \\
\hline \multirow[t]{5}{*}{ Convenience Store } & & Round II & Round III & Agreement \\
\hline & Mean & 1.86 & 1.73 & $32.8 \%=1$ \\
\hline & Range & $1-4$ & $1-3$ & $63.6 \%=2$ \\
\hline & Median & 2 & 2 & $\therefore 96.4 \%=1,2$ \\
\hline & Mode & 1 & 2 & $\sqrt{ }$ Consensus \\
\hline \multirow{5}{*}{$\begin{array}{l}\text { Phone \& device Charging } \\
\text { stations }\end{array}$} & & Round II & Round III & Agreement \\
\hline & Mean & 1.82 & 1.95 & $22.7 \%=1$ \\
\hline & Range & $1-4$ & $1-4$ & $63.6 \%=2$ \\
\hline & Median & 2 & 2 & $\therefore 86.3 \%=1,2$ \\
\hline & Mode & $2+4$ & 2 & $\sqrt{ }$ Consensus \\
\hline \multirow{5}{*}{$\begin{array}{l}\text { Lounge spaces with } \\
\text { televisions }\end{array}$} & & Round II & Round III & Agreement \\
\hline & Mean & 2.00 & 2.05 & $18.2 \%=1$ \\
\hline & Range & $1-5$ & $1-4$ & $63.6 \%=2$ \\
\hline & Median & 2 & 2 & $\therefore 81.8 \%=1,2$ \\
\hline & Mode & 2 & 2 & $\sqrt{ }$ Consensus \\
\hline
\end{tabular}


item, although panelists agreed that they are each important. Only two attributes did not generate consensus: being close to mass transit $(M=2.64$, consensus $=45.5 \%)$, and being close to the library ( $\mathrm{M}=2.91$, consensus 36.3\%) (Tables 22, P9)

Table 22

Round II and III Results - Physical Attributes of Student Union Locations

Q12: How important are each of the following physical attributes of student union locations?

\begin{tabular}{|c|c|c|c|c|}
\hline \multirow{5}{*}{$\begin{array}{l}\text { Located in a high-traffic } \\
\text { area/pedestrian crossroads } \\
\text { of the campus }\end{array}$} & & Round II & Round III & Agreement \\
\hline & Mean & 1.48 & 1.32 & $61.2 \%=1$ \\
\hline & Range & $1-4$ & $1-2$ & $31.8 \%=2$ \\
\hline & Median & 1 & 1 & $\therefore 93.0 \%=1,2$ \\
\hline & Mode & 1 & 1 & $\sqrt{ }$ Consensus \\
\hline \multirow{5}{*}{$\begin{array}{l}\text { Located close to the } \\
\text { physical center of campus }\end{array}$} & & Round II & Round III & Agreement \\
\hline & Mean & 1.64 & 1.43 & $61.9 \%=1$ \\
\hline & Range & $1-3$ & $1-3$ & $33.3 \%=2$ \\
\hline & Median & 1 & 1 & $\therefore 95.2 \%=1,2$ \\
\hline & Mode & 1 & 1 & $\sqrt{\text { Consensus }}$ \\
\hline \multirow[t]{5}{*}{ Located close to parking } & & Round II & Round III & Agreement \\
\hline & Mean & 1.86 & 2.00 & $27.3 \%=1$ \\
\hline & Range & $1-5$ & $1-5$ & $54.5 \%=2$ \\
\hline & Median & 2 & 2 & $\therefore 91.8 \%=1,2$ \\
\hline & Mode & 2 & 2 & $\sqrt{ }$ Consensus \\
\hline \multirow{5}{*}{$\begin{array}{l}\text { Located close to residence } \\
\text { halls }\end{array}$} & & Round II & Round III & Agreement \\
\hline & Mean & 2.18 & 2.18 & $18.2 \%=1$ \\
\hline & Range & $1-5$ & $1-5$ & $59.1 \%=2$ \\
\hline & Median & 2 & 2 & $\therefore 77.3 \%=1,2$ \\
\hline & Mode & 2 & 2 & $\sqrt{\text { Consensus }}$ \\
\hline $\mathrm{N}=22$ & & & & \\
\hline
\end{tabular}

Building exteriors. Second, after consideration of student union locations, panelists were asked to rate the importance of seven physical attributes of student union exteriors. While no attribute generated a true consensus, panelists reached agreement that six of the seven are important to unions (Tables 23, P10). These include, in ranked order: cleanliness of the building exterior $(M=1.36$, consensus $=95.5 \%)$, a clearly defined entrance $(M=1.41$, consensus $=90.9 \%)$, along with clear exterior signage $(M=1.41$, 
consensus $=95.4 \%)$, and a well-maintained building exterior $(\mathrm{M}=1.50$, consensus $=90.0 \%)$. An attractive design of both the building exterior $(M=1.59$, consensus $=86.3 \%)$ and landscaping $(M=1.68$, consensus $=91.0 \%)$ completed the list. Only the attribute of having a human-scale design (no more than three stories high) did not generate consensus, although it was rated as somewhat important overall $(\mathrm{M}=2.73$, consensus $=45.5 \%$,

Building interiors. Because 25 physical attributes of the interior for a student union were identified in Round I, it was necessary to split the physical attributes of the interior into two questions, \#14 and \#15, in subsequent survey rounds. The full results for these questions are presented in Table P11.

Panelists achieved consensus on a majority (22) of the items. Among these, true consensus was achieved for six (Tables 24, P11). Adequate \& appropriate technological capability/infrastructure was most highly ranked item $(M=1.05$, consensus $=100 \%)$, which is not surprising, given that wireless internet service had been named as the most highly ranked amenity. The other most agreed-upon attributes included: adequate and appropriate space for all the various union functions $(M=1.14$, consensus $=100 \%)$, a well-maintained building interior $(M=1.14$, consensus $=95.4 \%)$, seating styles that encourage interaction $(M=1.18$, consensus $=100 \%)$, an attractive interior design $(\mathrm{M}=1.23$, consensus $=95.4 \%)$, and ADA accessibility $(M=1.23$, consensus $=100 \%)$.

The next sixteen items also achieved strong levels of consensus and high mean scores, despite falling short of the "true consensus" designation. Appendix P, Table P11 presents these in rank order, but this section clusters them in terms of three themes: interior infrastructures, interior design, and furnishings (Tables, 25, 26, 27). 
Table 23

Round II and III Results - Physical Attributes of Student Union Exteriors

Q13: How important is it for each of the following physical attributes of student union exteriors?

\begin{tabular}{|c|c|c|c|c|}
\hline \multirow{5}{*}{$\begin{array}{l}\text { Cleanliness of building } \\
\text { exterior }\end{array}$} & & Round II & Round III & Agreement \\
\hline & Mean & 1.41 & 1.36 & $68.2 \%=1$ \\
\hline & Range & $1-2$ & $1-3$ & $27.3 \%=2$ \\
\hline & Median & 1 & 1 & $\therefore 95.5 \%=1,2$ \\
\hline & Mode & 1 & 1 & $\sqrt{ }$ Consensus \\
\hline \multirow[t]{5}{*}{ Clearly defined entrance } & & Round II & Round III & Agreement \\
\hline & Mean & 1.27 & 1.41 & $68.2 \%=1$ \\
\hline & Range & $1-3$ & $1-3$ & $22.7 \%=2$ \\
\hline & Median & 1 & 1 & $\therefore 90.9 \%=1,2$ \\
\hline & Mode & 1 & 1 & $\sqrt{ }$ Consensus \\
\hline \multirow[t]{5}{*}{ Clear exterior signage } & & Round II & Round III & Agreement \\
\hline & Mean & 1.45 & 1.41 & $63.6 \%=1$ \\
\hline & Range & $1-3$ & $1-3$ & $31.8 \%=2$ \\
\hline & Median & 1 & 1 & $\therefore 95.4 \%=1,2$ \\
\hline & Mode & 1 & 1 & $\sqrt{ }$ Consensus \\
\hline \multirow{5}{*}{$\begin{array}{l}\text { Physical condition of the } \\
\text { building exterior (well- } \\
\text { maintained) }\end{array}$} & & Round II & Round III & Agreement \\
\hline & Mean & 1.36 & 1.50 & $59.1 \%=1$ \\
\hline & Range & $1-2$ & $1-3$ & $31.8 \%=2$ \\
\hline & Median & 1 & 1 & $\therefore 90.0 \%=1,2$ \\
\hline & Mode & 1 & 1 & $\sqrt{ }$ Consensus \\
\hline \multirow{5}{*}{$\begin{array}{l}\text { Attractive design of } \\
\text { building exterior }\end{array}$} & & Round II & Round III & Agreement \\
\hline & Mean & 1.55 & 1.59 & $54.5 \%=1$ \\
\hline & Range & $1-3$ & $1-3$ & $31.8 \%=2$ \\
\hline & Median & 1 & 1 & $\therefore 86.3 \%=1,2$ \\
\hline & Mode & 1 & 1 & $\sqrt{ }$ Consensus \\
\hline \multirow{5}{*}{$\begin{array}{l}\text { Attractive design of exterior } \\
\text { landscaping }\end{array}$} & & Round II & Round III & Agreement \\
\hline & Mean & 1.73 & 1.68 & $45.5 \%=1$ \\
\hline & Range & $1-3$ & $1-4$ & $45.5 \%=2$ \\
\hline & Median & 1 & 2 & $\therefore 91.0 \%=1,2$ \\
\hline & Mode & 1 & $1+2$ & $\sqrt{ }$ Consensus \\
\hline \multirow{5}{*}{$\begin{array}{l}\text { Human scale design (no } \\
\text { more than } 3 \text { stories high) }\end{array}$} & & Round II & Round III & Agreement \\
\hline & Mean & 3.23 & 2.73 & $9.1 \%=1$ \\
\hline & Range & $1-5$ & $1-5$ & $36.4 \%=2$ \\
\hline & Median & 3.5 & 3 & $\therefore 45.5 \%=1,2$ \\
\hline & Mode & 4 & $2+3$ & No Consensus \\
\hline
\end{tabular}


Table 24

Round II and III Results - Top Five Physical Attributes of Student Union Interiors

\begin{tabular}{|c|c|c|c|c|}
\hline \multicolumn{5}{|c|}{ Q14 \& Q15: How important is each of the following physical attributes of student union interiors? } \\
\hline \multirow{5}{*}{$\begin{array}{l}\text { Adequate \& appropriate } \\
\text { technological capability / } \\
\text { infrastructure }\end{array}$} & & Round II & Round III & Agreement \\
\hline & Mean & 1.27 & 1.05 & $95.5 \%=1$ \\
\hline & Range & $1-2$ & $1-2$ & $4.5 \%=2$ \\
\hline & Median & 1 & 1 & $\therefore 100 \%=1,2$ \\
\hline & Mode & 1 & 1 & $\sqrt{ }$ True Consensus \\
\hline \multirow{5}{*}{$\begin{array}{l}\text { Adequate \& appropriate } \\
\text { space for all the various } \\
\text { functions/usage of the union }\end{array}$} & & Round II & Round III & Agreement \\
\hline & Mean & 1.18 & 1.14 & $86.4 \%=1$ \\
\hline & Range & $1-2$ & $1-2$ & $13.6 \%=2$ \\
\hline & Median & 1 & 1 & $\therefore 100 \%=1,2$ \\
\hline & Mode & 1 & 1 & $\sqrt{ }$ True Consensus \\
\hline \multirow{5}{*}{$\begin{array}{l}\text { Physical condition of the } \\
\text { building interior (well- } \\
\text { maintained) }\end{array}$} & & Round II & Round III & Agreement \\
\hline & Mean & 1.14 & 1.14 & $90.9 \%=1$ \\
\hline & Range & $1-2$ & $1-3$ & $4.5 \%=2$ \\
\hline & Median & 1 & 1 & $\therefore 95.4 \%=1,2$ \\
\hline & Mode & 1 & 1 & $\sqrt{ }$ True Consensus \\
\hline \multirow{5}{*}{$\begin{array}{l}\text { Seating styles/types } \\
\text { encourage interaction }\end{array}$} & & Round II & Round III & Agreement \\
\hline & Mean & 1.36 & 1.18 & $81.8 \%=1$ \\
\hline & Range & $1-2$ & $1-2$ & $18.2 \%=2$ \\
\hline & Median & 1 & 1 & $\therefore 100 \%=1,2$ \\
\hline & Mode & 1 & 1 & $\ddot{\sqrt{ }}$ True Consensus \\
\hline \multirow{5}{*}{$\begin{array}{l}\text { Attractive design of } \\
\text { building interior }\end{array}$} & & Round II & Round III & Agreement \\
\hline & Mean & 1.23 & 1.23 & $81.8 \%=1$ \\
\hline & Range & $1-3$ & $1-3$ & $13.6 \%=2$ \\
\hline & Median & 1 & 1 & $\therefore 95.4 \%=1,2$ \\
\hline & Mode & 1 & 1 & $\sqrt{ }$ True Consensus \\
\hline \multirow[t]{5}{*}{ ADA Accessible } & & Round II & Round III & Agreement \\
\hline & Mean & 1.18 & 1.23 & $77.3 \%=1$ \\
\hline & Range & $1-2$ & $1-2$ & $22.7 \%=2$ \\
\hline & Median & 1 & 1 & $\therefore 100 \%=1,2$ \\
\hline & Mode & 1 & 1 & $\sqrt{ }$ True Consensus \\
\hline
\end{tabular}

Important infrastructure attributes included: the cleanliness of the building interior $(\mathrm{M}=1.09$, consensus $=90.9 \%)$ clear interior directions and signage $(\mathrm{M}=1.32$, consensus $=100 \%)$, adequate lighting fixtures $(M=1.32$, consensus $=93.0 \%)$, noise- 
proofing or sound-proofing that reduces the sound transfer between areas $(\mathrm{M}=1.91$, consensus $=81.8 \%)$, and movable walls that allow for flexible use of space $(M=1.91$, consensus $=77.2 \%)($ Table 25$)$.

Important design attributes included: "sticky spaces" where people want to come and stay, regardless of their transaction needs $(M=1.41$, consensus $=95.4 \%)$, lots of windows with natural lighting $(M=1.41$, consensus $=90.9 \%)$, an "open" feel to the building interior $(M=1.45$, consensus $=90.9 \%)$, a good flow for traffic patterns between services and amenities $(M=1.50$, consensus $=95.4 \%)$, a focal point that brings people together, such as a lounge or a front porch $(\mathrm{M}=1.55$, consensus $=95.5 \%)$, and conveniently clustered offices and services that create a "one stop shopping" experience $(M=1.73$, consensus $=94.4 \%)$. The characteristics of the interior design should create an engaging $(M=1.32$, consensus $=100 \%)$, and fun, or playful $(M=1.55$, consensus $=$ 95.5\%) environment (Table 26).

In regards to student union seating, tables and furnishings, important attributes include: comfortable $(\mathrm{M}=1.27$, consensus $=100 \%)$, modular and able to be moved around $(\mathrm{M}=1.50$, consensus $=100 \%)$, and stylistically modern or timeless, without being obviously dated $(M=1.81$, consensus $=81.0 \%)($ Table 27$)$.

In summary, the interior of the union and its physical attributes as seen by the participants needs to: have the infrastructure for student technology needs, be clean and appealing to the student, and have the space to meet the multiple needs of students. 
Table 25

Round II and III Results - Physical Attributes of Student Union Infrastructures

\begin{tabular}{llllc}
\hline Q14 \& Q15: How important is each of the following physical attributes of student union interiors? \\
\hline Cleanliness of building & & Round II & Round III & Agreement \\
\cline { 2 - 5 } interior & Mean & 1.14 & 1.09 & $68.2 \%=1$ \\
& Range & $1-2$ & $1-2$ & $22.7 \%=2$ \\
& Median & 1 & 1 & $\therefore 90.9 \%=1,2$ \\
& Mode & 1 & 1 & V Consensus \\
\hline Clear interior signage \& & & Round II & Round III & Agreement \\
directions & Mean & 1.32 & 1.32 & $68.2 \%=1$ \\
& Range & $1-2$ & $1-2$ & $31.8 \%=2$ \\
& Median & 1 & 1 & $\therefore 100 \%=1,2$ \\
& Mode & 1 & 1 & $\sqrt{ }$ Consensus \\
\hline Adequate lighting fixtures & & Round II & Round III & Agreement \\
\cline { 2 - 5 } & Mean & 1.41 & 1.32 & $61.2 \%=1$ \\
& Range & $1-2$ & $1-2$ & $31.8 \%=2$ \\
& Median & 1 & 1 & $\therefore 93.0 \%=1,2$ \\
& Mode & 1 & 1 & $\sqrt{ }$ Consensus \\
\hline Noise-proofing/Sound- & & Round II & Round III & Agreement \\
proofing (reduce sound & Mean & 2.23 & 1.91 & $27.3 \%=1$ \\
transfer between areas) & Range & $1-4$ & $1-3$ & $54.5 \%=2$ \\
& Median & 2 & 2 & $\therefore 81.8 \%=1,2$ \\
& Mode & 2 & 2 & $\sqrt{ }$ Consensus \\
\hline Flexible multipurpose & & Round II & Round III & Agreement \\
design/moveable walls & Mean & 1.91 & 1.91 & $31.8 \%=1$ \\
& Range & $1-5$ & 2 & $45.5 \%=2$ \\
& Median & 2 & 2 & $\sqrt{ }$ Consensus \\
\hline & Mode & 2 & &
\end{tabular}

$\mathrm{N}=22$ 
Table 26

Round II and III Results -Physical Attributes of Student Union Interior Designs

\begin{tabular}{|c|c|c|c|c|}
\hline \multirow[t]{5}{*}{ Engaging environment } & & Round II & Round III & Agreement \\
\hline & Mean & 1.36 & 1.32 & $68.2 \%=1$ \\
\hline & Range & $1-3$ & $1-2$ & $31.8 \%=2$ \\
\hline & Median & 1 & 1 & $\therefore 100 \%=1,2$ \\
\hline & Mode & 1 & 1 & $\sqrt{ }$ Consensus \\
\hline \multirow{5}{*}{$\begin{array}{l}\text { Has "sticky-spaces" where } \\
\text { people want to come and } \\
\text { stay (regardless of } \\
\text { transaction needs) }\end{array}$} & & Round II & Round III & Agreement \\
\hline & Mean & 1.55 & 1.41 & $63.6 \%=1$ \\
\hline & Range & $1-3$ & $1-3$ & $31.8 \%=2$ \\
\hline & Median & 1 & 1 & $\therefore 95.4 \%=1,2$ \\
\hline & Mode & 1 & 1 & $\sqrt{ }$ Consensus \\
\hline \multirow{5}{*}{$\begin{array}{l}\text { Lots of windows/Natural } \\
\text { lighting }\end{array}$} & & Round II & Round III & Agreement \\
\hline & Mean & 1.41 & 1.41 & $68.2 \%=1$ \\
\hline & Range & $1-2$ & $1-3$ & $22.7 \%=2$ \\
\hline & Median & 1 & 1 & $\therefore 90.9 \%=1,2$ \\
\hline & Mode & 1 & 1 & $\sqrt{ }$ Consensus \\
\hline \multirow{5}{*}{$\begin{array}{l}\text { "Open feel" to the building } \\
\text { interior }\end{array}$} & & Round II & Round III & Agreement \\
\hline & Mean & 1.41 & 1.45 & $63.6 \%=1$ \\
\hline & Range & $1-2$ & $1-3$ & $27.3 \%=2$ \\
\hline & Median & 1 & 1 & $\therefore 90.9 \%=1,2$ \\
\hline & Mode & 1 & 1 & $\sqrt{ }$ Consensus \\
\hline \multirow{5}{*}{$\begin{array}{l}\text { Good flow/traffic pattern } \\
\text { between services and } \\
\text { amenities }\end{array}$} & & Round II & Round III & Agreement \\
\hline & Mean & 1.50 & 1.50 & $54.5 \%=1$ \\
\hline & Range & $1-3$ & $1-3$ & $40.9 \%=2$ \\
\hline & Median & 1 & 1 & $\therefore 95.4 \%=1,2$ \\
\hline & Mode & 1 & 1 & $\sqrt{ }$ Consensus \\
\hline \multirow{5}{*}{$\begin{array}{l}\text { Has a focal point that brings } \\
\text { people together (e.g. lounge, } \\
\text { porch) }\end{array}$} & & Round II & Round III & Agreement \\
\hline & Mean & 1.59 & 1.55 & $50.0 \%=1$ \\
\hline & Range & $1-3$ & $1-3$ & $45.5 \%=2$ \\
\hline & Median & 1 & 1 & $\therefore 95.5 \%=1,2$ \\
\hline & Mode & 1 & 1 & $\sqrt{ }$ Consensus \\
\hline \multirow[t]{5}{*}{ Fun," playful environment } & & Round II & Round III & Agreement \\
\hline & Mean & 1.68 & 1.55 & $50.0 \%=1$ \\
\hline & Range & $1-4$ & $1-3$ & $45.5 \%=2$ \\
\hline & Median & 1 & 1.5 & $\therefore 95.5 \%=1,2$ \\
\hline & Mode & 1 & 1 & $\sqrt{ }$ Consensus \\
\hline \multirow{5}{*}{$\begin{array}{l}\text { Conveniently clustered } \\
\text { offices and services ("one- } \\
\text { stop shop") }\end{array}$} & & Round II & Round III & Agreement \\
\hline & Mean & 2.14 & 1.73 & $31.8 \%=1$ \\
\hline & Range & $1-3$ & $1-3$ & $63.6 \%=2$ \\
\hline & Median & 2 & 2 & $\therefore 94.4 \%=1,2$ \\
\hline & Mode & 2 & 2 & $\sqrt{ }$ Consensus \\
\hline $\mathrm{N}=22$ & & & & \\
\hline
\end{tabular}


Table 27

Round II and III Results - Important Attributes of Student Union Furnishings

\begin{tabular}{lllll}
\hline \multicolumn{4}{l}{ Q14 \& Q15: How important is each of the following physical attributes of student union interiors? } \\
\hline Comfortable interiors and & & Round II & Round III & Agreement \\
\cline { 2 - 5 } furnishings & Mean & 1.32 & 1.27 & $72.7 \%=1$ \\
& Range & $1-2$ & $1-2$ & $27.3 \%=2$ \\
& Median & 1 & 1 & $\therefore 100 \%=1,2$ \\
& Mode & 1 & 1 & V Consensus \\
\hline Seating \& tables can be & & Round II & Round III & Agreement \\
moved around (modular) & Mean & 1.59 & 1.50 & $50.0 \%=1$ \\
& Range & $1-3$ & $1-2$ & $50.0 \%=2$ \\
& Median & 2 & 1.5 & $\therefore 100 \%=1,2$ \\
& Mode & 2 & $1+2$ & $\sqrt{ }$ Consensus \\
\hline Stylistically modern or & & Round II & Round III & Agreement \\
timeless interiors and & Mean & 1.82 & 1.81 & $38.1 \%=1$ \\
furnishings (not obviously & Range & $1-3$ & $1-3$ & $42.9 \%=2$ \\
dated) & Median & 2 & 2 & $\therefore 81.0 \%=1,2$ \\
& Mode & 2 & 2 & $\sqrt{ }$ Consensus \\
\hline $\mathrm{N}=22$ & & & & \\
\hline
\end{tabular}

Human attributes. Human attributes refers to the characteristics of the people who work in or use the union. As explained in the review of literature in Chapter II, this includes 'the degree of congruency, or fit, between ... [an individual's] characteristics and the ability of the institution to respond to those characteristics" (Banning \& Banning, 1986, p. 1). As applied to attributes of student unions, this would include the extent to which the union is meeting the goals, needs and preferences of the populations that it serves. Responses from Round I created 25 different human attributes. Appendix P, Table P12 reports these in rank order of the mean scores. In this section they are further broken down and discussed in terms of attributes of student union staff (Table 28), and attributes of how populations experience their interaction with the union (Tables 29, P12).

Union staff. Panelists reached true consensus on four attributes of student union staff, including giving a unanimous "very important" rating to two of these (Table 28). 
Table 28

Round II and III Results - Important Attributes of Student Union Staff

Q16 \& Q17: How important is each of the following human attributes of student unions?

\begin{tabular}{|c|c|c|c|c|}
\hline \multirow{5}{*}{$\begin{array}{l}\text { Staff is student } \\
\text { focused/committed }\end{array}$} & & Round II & Round III & Agreement \\
\hline & Mean & 1.09 & 1.00 & $100.0 \%=1$ \\
\hline & Range & $1-2$ & 0 & $0.0 \%=2$ \\
\hline & Median & 1 & 1 & $\therefore 100.0 \%=1,2$ \\
\hline & Mode & 1 & 1 & $\sqrt{ }$ True Consensus \\
\hline \multirow{5}{*}{$\begin{array}{l}\text { Staff includes student } \\
\text { employees }\end{array}$} & & Round II & Round III & Agreement \\
\hline & Mean & 1.09 & 1.00 & $100.0 \%=1$ \\
\hline & Range & $1-2$ & 0 & $0.0 \%=2$ \\
\hline & Median & 1 & 1 & $\therefore 100.0 \%=1,2$ \\
\hline & Mode & 1 & 1 & $\sqrt{ }$ True Consensus \\
\hline \multirow{5}{*}{$\begin{array}{l}\text { Staff is knowledgeable/well- } \\
\text { trained }\end{array}$} & & Round II & Round III & Agreement \\
\hline & Mean & 1.09 & 1.09 & $90.9 \%=1$ \\
\hline & Range & $1-2$ & $1-2$ & $9.1 \%=2$ \\
\hline & Median & 1 & 1 & $\therefore 100.0 \%=1,2$ \\
\hline & Mode & 1 & 1 & $\sqrt{ }$ True Consensus \\
\hline \multirow[t]{5}{*}{ Staff is friendly } & & Round II & Round III & Agreement \\
\hline & Mean & 1.00 & 1.09 & $90.9 \%=1$ \\
\hline & Range & 0 & $1-2$ & $9.1 \%=2$ \\
\hline & Median & 1 & 1 & $\therefore 100.0 \%=1,2$ \\
\hline & Mode & 1 & 1 & $\sqrt{ }$ True Consensus \\
\hline \multirow[t]{5}{*}{ Staff size is adequate } & & Round II & Round III & Agreement \\
\hline & Mean & 1.41 & 1.27 & $72.7 \%=1$ \\
\hline & Range & $1-3$ & $1-2$ & $27.3 \%=2$ \\
\hline & Median & 1 & 1 & $\therefore 100 \%=1,2$ \\
\hline & Mode & 1 & 1 & $\sqrt{ }$ Consensus \\
\hline \multirow[t]{5}{*}{ Staff is diverse } & & Round II & Round III & Agreement \\
\hline & Mean & 1.68 & 1.55 & $59.1 \%=1$ \\
\hline & Range & $1-7$ & $1-5$ & $36.4 \%=2$ \\
\hline & Median & 1 & 1 & $\therefore 95.5 \%=1,2$ \\
\hline & Mode & 1 & 1 & $\sqrt{ }$ Consensus \\
\hline
\end{tabular}

Staff attributes with a perfect score of "very important" included: being student focused and committed to serving students $(\mathrm{M}=1.0$, consensus $=100 \%)$, and including student employees in the union $(M=1.0$, consensus $=100 \%)$. Additional staff attributes that 
generated a true consensus included being knowledgeable and well-trained $(\mathrm{M}=1.09$, consensus $=100 \%)$, and being friendly $(M=1.09$, consensus $=100 \%)$. Other important attributes included having an adequate staff size $(M=1.27$, consensus $=100 \%)$, and diversity among staff members $(M=1.55$, consensus $=95.5 \%)$.

Union interactions. Panelists reached true consensus on six attributes of how populations experience their interactions with the union (Table 29). Among these, the most important attribute was conveying to students that they matter $(M=1.00$, consensus $=100 \%$ ). Panelists unanimously rated this as very important, yielding one of the few perfect 1.00 means in the study. Other attributes achieving true consensus included: feeling welcoming or inviting $(\mathrm{M}=1.09$, consensus $=100 \%)$, feeling like a safe place both physically $(\mathrm{M}=1.09$, consensus $=100 \%)$ and psychologically $(\mathrm{M}-1.14$, consensus $=$ $100 \%)$; and having high quality services $(M=1.14$, consensus $=100 \%)$, with variety and options in reasons or purposes for visiting the building (e.g. a mixed-use building) $(\mathrm{M}=1.23$, consensus $=100 \%)$.

Panelists reached consensus for ten additional human aspects of how populations experience their interactions with the union. These are presented in rank order of their mean scores in Table P12. Here, however, they are further broken down into three categories: meeting demands for multiple types of services and amenities, meeting needs for multiple types of conveniences, and meeting desires for inclusivity.

Three important human attributes center on meeting the demands for multiple types of services and amenities (Table 30). These include having variety and options in both dining services in the union $(\mathrm{M}=1.36$, consensus $=95.5 \%)$, and in types of lounge areas $(M=1.57$, consensus $=90.5 \%)$; and having essential, or destination services that 
students need and therefore must visit the union $(M=1.57$, consensus $=95.5 \%)$. Such

attributes ensure that students will visit the union, and will do so frequently.

Table 29

Round II and III Results - Top Attributes of Union Interactions

Q16 \& Q17: How important is each of the following human attributes of student unions?

\begin{tabular}{|c|c|c|c|c|}
\hline \multirow{5}{*}{$\begin{array}{l}\text { Union conveys to students } \\
\text { that they matter }\end{array}$} & & Round II & Round III & Agreement \\
\hline & Mean & 1.05 & 1.00 & $100.0 \%=1$ \\
\hline & Range & $1-2$ & 0 & $0.0 \%=2$ \\
\hline & Median & 1 & 1 & $\therefore 100.0 \%=1,2$ \\
\hline & Mode & 1 & 1 & $\sqrt{ }$ True Consensus \\
\hline \multirow{5}{*}{$\begin{array}{l}\text { Union feels } \\
\text { welcoming/inviting }\end{array}$} & & Round II & Round III & Agreement \\
\hline & Mean & 1.14 & 1.09 & $90.9 \%=1$ \\
\hline & Range & $1-2$ & $1-2$ & $9.1 \%=2$ \\
\hline & Median & 1 & 1 & $\therefore 100.0 \%=1,2$ \\
\hline & Mode & 1 & 1 & $\sqrt{ }$ True Consensus \\
\hline \multirow{5}{*}{$\begin{array}{l}\text { Union feels like a safe } \\
\text { place, physically }\end{array}$} & & Round II & Round III & Agreement \\
\hline & Mean & 1.20 & 1.09 & $90.9 \%=1$ \\
\hline & Range & $1-2$ & $1-2$ & $9.1 \%=2$ \\
\hline & Median & 1 & 1 & $\therefore 100.0 \%=1,2$ \\
\hline & Mode & 1 & 1 & $\sqrt{ }$ True Consensus \\
\hline \multirow{5}{*}{$\begin{array}{l}\text { Union feels like a safe } \\
\text { place, psychologically }\end{array}$} & & Round II & Round III & Agreement \\
\hline & Mean & 1.14 & 1.14 & $86.4 \%=1$ \\
\hline & Range & $1-2$ & $1-2$ & $13.6 \%=2$ \\
\hline & Median & 1 & 1 & $\therefore 100 \%=1,2$ \\
\hline & Mode & 1 & 1 & $\sqrt{ }$ True Consensus \\
\hline \multirow{5}{*}{ Services are high quality } & & Round II & Round III & Agreement \\
\hline & Mean & 1.09 & 1.14 & $86.4 \%=1$ \\
\hline & Range & $1-2$ & $1-2$ & $13.6 \%=2$ \\
\hline & Median & 1 & 1 & $\therefore 100 \%=1,2$ \\
\hline & Mode & 1 & 1 & $\sqrt{ }$ True Consensus \\
\hline \multirow{5}{*}{$\begin{array}{l}\text { Variety and options in } \\
\text { purposes for visiting the } \\
\text { building (e.g. mixed use } \\
\text { building) }\end{array}$} & & Round II & Round III & Agreement \\
\hline & Mean & 1.45 & 1.23 & $77.3 \%=1$ \\
\hline & Range & $1-3$ & $1-2$ & $22.7 \%=2$ \\
\hline & Median & 1 & 1 & $\therefore 100 \%=1,2$ \\
\hline & Mode & 1 & 1 & $\sqrt{ }$ True Consensus \\
\hline
\end{tabular}


Table 30

Round II and III Results - Important Attributes that Address Service Demands

Q16 \& Q17: How important is each of the following human attributes of student unions?

\begin{tabular}{|c|c|c|c|c|}
\hline \multirow{5}{*}{$\begin{array}{l}\text { Variety and options in } \\
\text { purposes for visiting the } \\
\text { building (e.g. mixed use } \\
\text { building) }\end{array}$} & & Round II & Round III & Agreement \\
\hline & Mean & 1.45 & 1.23 & $77.3 \%=1$ \\
\hline & Range & $1-3$ & $1-2$ & $22.7 \%=2$ \\
\hline & Median & 1 & 1 & $\therefore 100 \%=1,2$ \\
\hline & Mode & 1 & 1 & $\sqrt{ }$ True Consensus \\
\hline \multirow{5}{*}{$\begin{array}{l}\text { Variety and options in } \\
\text { dining }\end{array}$} & & Round II & Round III & Agreement \\
\hline & Mean & 1.41 & 1.36 & $68.2 \%=1$ \\
\hline & Range & $1-2$ & $1-3$ & $27.3 \%=2$ \\
\hline & Median & 1 & 1 & $\therefore 95.5 \%=1,2$ \\
\hline & Mode & 1 & 1 & $\sqrt{ }$ Consensus \\
\hline \multirow{5}{*}{$\begin{array}{l}\text { Variety and options in } \\
\text { lounge areas }\end{array}$} & & Round II & Round III & Agreement \\
\hline & Mean & 1.73 & 1.57 & $52.4 \%=1$ \\
\hline & Range & $1-3$ & $1-3$ & $38.1 \%=2$ \\
\hline & Median & 2 & 1 & $\therefore 90.5 \%=1,2$ \\
\hline & Mode & 2 & 1 & $\sqrt{ }$ Consensus \\
\hline \multirow{5}{*}{$\begin{array}{l}\text { Services are } \\
\text { essential/destination } \\
\text { services that students need } \\
\text { (must visit) }\end{array}$} & & Round II & Round III & Agreement \\
\hline & Mean & 1.64 & 1.57 & $47.6 \%=1$ \\
\hline & Range & $1-3$ & $1-3$ & $47.6 \%=2$ \\
\hline & Median & 2 & 2 & $\therefore 95.2 \%=1,2$ \\
\hline & Mode & 2 & $1+2$ & $\sqrt{ }$ Consensus \\
\hline
\end{tabular}

Panelists reached consensus on five attributes that meet the need for convenience among the populations served by student unions (Table 31). Having prices at the various food and retail outlets that are affordable for students $(M=1.59$, consensus $=90.9 \%)$ tops the list, which reflects earlier panelists rankings that students are indeed the most important population served by the union. Among the remaining attributes, offering late and weekend hours for entertainment and recreation offerings $(\mathrm{M}=1.59$, consensus $=$ 95.5\%), for student services in the building $(M=1.91$, consensus $=77.1 \%)$ and for food services $(M=2.00$, consensus $=81.0 \%)$, further reflects that the union serves an array of 
student populations who use the campus at all hours daily. The last item, fast services, $(\mathrm{M}=1.91$, consensus $90.9 \%)$ rounds out the list.

Table 31

Round II and III Results -Important Attributes that Address Convenience Needs

Q16 \& Q17: How important is each of the following human attributes of student unions?

\begin{tabular}{|c|c|c|c|c|}
\hline \multirow{5}{*}{$\begin{array}{l}\text { Prices at the various food } \\
\text { and retail outlets are } \\
\text { affordable for students }\end{array}$} & & Round II & Round III & Agreement \\
\hline & Mean & 1.55 & 1.59 & $50.0 \%=1$ \\
\hline & Range & $1-3$ & $1-3$ & $40.9 \%=2$ \\
\hline & Median & 1 & 1.5 & $\therefore 90.9 \%=1,2$ \\
\hline & Mode & 1 & 1 & $\sqrt{ }$ Consensus \\
\hline \multirow{5}{*}{$\begin{array}{l}\text { Late/weekend hours for } \\
\text { entertainment/recreation } \\
\text { offerings }\end{array}$} & & Round II & Round III & Agreement \\
\hline & Mean & 1.76 & 1.59 & $45.5 \%=1$ \\
\hline & Range & $1-5$ & $1-3$ & $50.0 \%=2$ \\
\hline & Median & 1 & 2 & $\therefore 95.5 \%=1,2$ \\
\hline & Mode & 1 & 2 & $\sqrt{ }$ Consensus \\
\hline \multirow{5}{*}{$\begin{array}{l}\text { Late/weekend hours for } \\
\text { student services in the } \\
\text { building }\end{array}$} & & Round II & Round III & Agreement \\
\hline & Mean & 2.00 & 1.91 & $36.4 \%=1$ \\
\hline & Range & $1-4$ & $1-4$ & $40.9 \%=2$ \\
\hline & Median & 2 & 2 & $\therefore 77.3 \%=1,2$ \\
\hline & Mode & 2 & 2 & $\sqrt{ }$ Consensus \\
\hline \multirow{5}{*}{ Services are fast } & & Round II & Round III & Agreement \\
\hline & Mean & 1.86 & 1.91 & $22.7 \%=1$ \\
\hline & Range & $1-4$ & $1-4$ & $68.2 \%=2$ \\
\hline & Median & 2 & 2 & $\therefore 90.9 \%=1,2$ \\
\hline & Mode & 1 & 2 & $\sqrt{ }$ Consensus \\
\hline \multirow{5}{*}{$\begin{array}{l}\text { Late/weekend hours for } \\
\text { food services }\end{array}$} & & Round II & Round III & Agreement \\
\hline & Mean & 2.00 & 2.00 & $28.6 \%=1$ \\
\hline & Range & $1-4$ & $1-5$ & $52.4 \%=2$ \\
\hline & Median & 2 & 2 & $\therefore 81.0 \%=1,2$ \\
\hline & Mode & 1 & 2 & $\sqrt{ }$ Consensus \\
\hline
\end{tabular}

$\mathrm{N}=22$

The two remaining human attributes that panelists rated as important in student unions addressed the need or desire for inclusivity (Table 32). These took the form of artifacts within the student union building that communicate messages to populations who use the building, and thus have an impact on their experiences in interacting with the 
Table 32

\section{Round II and III Results -Important Attributes that Address Inclusivity}

Q16 \& Q17: How important is each of the following human attributes of student unions?

\begin{tabular}{|c|c|c|c|c|}
\hline \multirow{5}{*}{$\begin{array}{l}\text { Late/weekend hours for } \\
\text { entertainment/recreation } \\
\text { offerings }\end{array}$} & & Round II & Round III & Agreement \\
\hline & Mean & 1.76 & 1.59 & $45.5 \%=1$ \\
\hline & Range & $1-5$ & $1-3$ & $50.0 \%=2$ \\
\hline & Median & 1 & 2 & $\therefore 95.5 \%=1,2$ \\
\hline & Mode & 1 & 2 & $\sqrt{ }$ Consensus \\
\hline \multirow{5}{*}{$\begin{array}{l}\text { Artifacts communicate } \\
\text { school spirit/history }\end{array}$} & & Round II & Round III & Agreement \\
\hline & Mean & 1.82 & 1.64 & $45.5 \%=1$ \\
\hline & Range & $1-3$ & $1-3$ & $45.5 \%=2$ \\
\hline & Median & 2 & 2 & $\therefore 91.0 \%=1,2$ \\
\hline & Mode & 2 & $1+2$ & $\sqrt{ }$ Consensus \\
\hline \multirow{5}{*}{$\begin{array}{l}\text { Artifacts communicate } \\
\text { human diversity }\end{array}$} & & Round II & Round III & Agreement \\
\hline & Mean & 2.05 & 1.82 & $31.8 \%=1$ \\
\hline & Range & $1-6$ & $1-3$ & $54.5 \%=2$ \\
\hline & Median & 2 & 2 & $\therefore 96.3 \%=1,2$ \\
\hline & Mode & 2 & 2 & $\sqrt{ }$ Consensus \\
\hline \multirow{5}{*}{$\begin{array}{l}\text { Late/weekend hours for } \\
\text { student services in the } \\
\text { building }\end{array}$} & & Round II & Round III & Agreement \\
\hline & Mean & 2.00 & 1.91 & $36.4 \%=1$ \\
\hline & Range & $1-4$ & $1-4$ & $40.9 \%=2$ \\
\hline & Median & 2 & 2 & $\therefore 77.3 \%=1,2$ \\
\hline & Mode & 2 & 2 & $\sqrt{ }$ Consensus \\
\hline \multirow{5}{*}{ Services are fast } & & Round II & Round III & Agreement \\
\hline & Mean & 1.86 & 1.91 & $22.7 \%=1$ \\
\hline & Range & $1-4$ & $1-4$ & $68.2 \%=2$ \\
\hline & Median & 2 & 2 & $\therefore 90.9 \%=1,2$ \\
\hline & Mode & 1 & 2 & $\sqrt{ }$ Consensus \\
\hline \multirow{5}{*}{$\begin{array}{l}\text { Late/weekend hours for } \\
\text { food services }\end{array}$} & & Round II & Round III & Agreement \\
\hline & Mean & 2.00 & 2.00 & $28.6 \%=1$ \\
\hline & Range & $1-4$ & $1-5$ & $52.4 \%=2$ \\
\hline & Median & 2 & 2 & $\therefore 81.0 \%=1,2$ \\
\hline & Mode & 1 & 2 & $\sqrt{ }$ Consensus \\
\hline \multirow{5}{*}{$\begin{array}{l}\text { Student union has strong } \\
\text { partnerships with } \\
\text { admissions/enrollment } \\
\text { services }\end{array}$} & & Round II & Round III & Agreement \\
\hline & Mean & 2.23 & 2.36 & $13.6 \%=1$ \\
\hline & Range & $1-4$ & $1-5$ & $54.5 \%=2$ \\
\hline & Median & 2 & 2 & $\therefore 68.1 \%=1,2$ \\
\hline & Mode & 2 & 2 & No Consensus \\
\hline \multirow{5}{*}{$\begin{array}{l}\text { Late/weekend hours for } \\
\text { retail services }\end{array}$} & & Round II & Round III & Agreement \\
\hline & Mean & 2.59 & 2.45 & $9.1 \%=1$ \\
\hline & Range & $1-5$ & $1-5$ & $45.5 \%=2$ \\
\hline & Median & 3 & 2 & $\therefore 54.6 \%=1,2$ \\
\hline & Mode & 3 & 2 & No Consensus \\
\hline
\end{tabular}


union. They addressed inclusivity in two forms: being included as part of the campus and its history $(\mathrm{M}=1.64$, consensus $=91.0 \%)$, and being included as part of human diversity $(\mathrm{M}=1.82$, consensus $=96.3 \%)$.

In summary, the participants agreed that the human attributes of the student union need to be convey to students that they matter, making them and other populations who use the union feel welcome and safe. This is achieved through a staff that is studentfocused, committed to the needs of students, knowledgeable, and well-trained.

Populations served by the union should experience the union as meeting their individual and varying needs for services and conveniences. Having an adequate sized staff is important. Finally, the union should have human attributes that foster inclusivity, which includes student staff, a diverse staff, and artifacts that communicate the campus history and human diversity. As one panelist commented, "Making sure the space is welcoming is critical. Having displays of school spirit that help create a deep connection between the campus and the students are essential for engaging students, but for some the union just needs to be a clean place where they can receive the services they most desire."

\section{Barriers and Constraints for the Student Union}

Thus far, the study's results have reported on the purposes and missions of the union; all the populations it should serve; all the union should offer in terms of services, amenities and programming, and the union's role within those; and specific physical and human attributes or characteristics for how these should be achieved. Yet as several panelists noted, the union cannot be all things to all people. Beyond the sheer impossibility of attempting to do it all, this section focuses on barriers and constraints that panelists identified in Round I, which have an impact on the union's effectiveness. 
These were categorized into four emerging themes: physical constraints, knowledge constraints, financial constraints, and political constraints. Round III findings for each are reported below.

Physical constraints. The preceding section presented an array of physical attributes that panelists deemed were important to student unions. They reflect how important the physical environment is in influencing union effectiveness. In Round I, participants named 15 different potential physical constraints that could negatively impact student union effectiveness. In Round III, participants achieved consensus on ten concerns that could create barriers for unions. These are presented in rank order in Tables 33, 34 and P13.

At the apex of the top ten, panelists reached a true consensus on one item, agreeing that the most important constraint on the union's effectiveness is a neglected, poorly maintained, run down or worn out building $(\mathrm{M}=1.25$, consensus $=100 \%)$. The remaining nine included infrastructure concerns, such as an aging or poor infrastructure (e.g. plumbing, HVAC, wiring) (M=1.36, 100\% consensus), lack of ADA compliance $(M=1.59$, consensus $=91.8 \%)$, and the presence of asbestos, lead or other health concerns that need to be addressed $(\mathrm{M}=1.59$, consensus $=91.8 \%)$. Design issues or concerns also made the list, including a building size that is inadequate to accommodate desired purposes $(\mathrm{M}=1.64,86.3 \%)$ or serve the level of usage and student enrollment $(\mathrm{M}=1.64$, $90.9 \%$ consensus $)$, and having an outdated and unappealing design $(\mathrm{M}=1.73$, consensus $=$ 86.4\%).Relatedly, lack of comprehensiveness (missing key services and amenities that should be present in the union) was another constraint $(M=1.73$, consensus $=91.9 \%)$. Finally, issues with the student union location, such as being poorly located on campus 
either through an original construction site choice peripheral to campus ( $M=1.73,86.4 \%)$, or through displacement as the center of campus has shifted over time $(\mathrm{M}=2.09$,

consensus $=81.8 \%$.

Table 33

\section{Round II and III Results - Top Five Physical Constraints}

Q19: How important is each of the following physical constraints, in influencing student union effectiveness?

\begin{tabular}{|c|c|c|c|c|}
\hline \multirow{5}{*}{$\begin{array}{l}\text { Building - neglected, poorly } \\
\text { maintained, run down, worn } \\
\text { out }\end{array}$} & & Round II & Round III & Agreement \\
\hline & Mean & 1.29 & 1.25 & $75.0 \%=1$ \\
\hline & Range & $1-2$ & $1-2$ & $25.0 \%=2$ \\
\hline & Median & 1 & 1 & $\therefore 100 \%=1,2$ \\
\hline & Mode & 1 & 1 & $\sqrt{ }$ True Consensus \\
\hline \multirow{5}{*}{$\begin{array}{l}\text { Infrastructure-aging/poor } \\
\text { infrastructure (e.g. HVAC, } \\
\text { plumbing, wiring) }\end{array}$} & & Round II & Round III & Agreement \\
\hline & Mean & 1.41 & 1.36 & $63.6 \%=1$ \\
\hline & Range & $1-3$ & $1-2$ & $36.4 \%=2$ \\
\hline & Median & 1 & 1 & $\therefore 100 \%=1,2$ \\
\hline & Mode & 1 & 1 & $\sqrt{ }$ Consensus \\
\hline \multirow{5}{*}{$\begin{array}{l}\text { Design-not ADA } \\
\text { compliant/accessible }\end{array}$} & & Round II & Round III & Agreement \\
\hline & Mean & 1.50 & 1.48 & $61.9 \%=1$ \\
\hline & Range & $1-3$ & $1-3$ & $28.6 \%=2$ \\
\hline & Median & 1 & 1 & $\therefore 90.4 \%=1,2$ \\
\hline & Mode & 1 & 1 & $\sqrt{\text { Consensus }}$ \\
\hline \multirow{5}{*}{$\begin{array}{l}\text { Infrastructure-asbestos, } \\
\text { lead, or other health } \\
\text { concerns must be addressed }\end{array}$} & & Round II & Round III & Agreement \\
\hline & Mean & 1.41 & 1.59 & $59.1 \%=1$ \\
\hline & Range & $1-3$ & $1-3$ & $22.7 \%=2$ \\
\hline & Median & 1 & 1 & $\therefore 91.8 \%=1,2$ \\
\hline & Mode & 1 & 1 & $\sqrt{\text { Consensus }}$ \\
\hline \multirow{5}{*}{$\begin{array}{l}\text { Size-inadequate to } \\
\text { accommodate desired } \\
\text { purposes (can't fit all the } \\
\text { functions in) }\end{array}$} & & Round II & Round III & Agreement \\
\hline & Mean & 1.55 & 1.64 & $54.5 \%=1$ \\
\hline & Range & $1-4$ & $1-4$ & $31.8 \%=2$ \\
\hline & Median & 1 & 1 & $\therefore 86.3 \%=1,2$ \\
\hline & Mode & 1 & 1 & $\sqrt{ }$ Consensus \\
\hline
\end{tabular}

$\mathrm{N}=22$

Five additional physical constraints named in Round I did not generate enough consensus in Round III to be deemed important, and are presented in Table P13. These included additional design issues such as multiple doors, stairwells and corners; and hard 
walls with limited adaptability; a need to preserve the desired, architectural, historic or traditional value of the union, and the need to either keep the union within one building or to split it across multiple buildings. The range of responses suggested that these might be salient issues on selected campuses, but not universal among student union experts.

Table 34

Round II and III Results - Other Important Physical Constraints

Q19: How important is each of the following physical constraints, in influencing student union effectiveness?

\begin{tabular}{lllll}
\hline Size-inadequate to serve & & Round II & Round III & Agreement \\
\cline { 2 - 5 } $\begin{array}{l}\text { level of usage/student } \\
\text { enrollment (crowded usage) }\end{array}$ & Mean & 1.48 & 1.64 & $50.0 \%=1$ \\
& Range & $1-3$ & $1-4$ & $40.9 \%=2$ \\
& Median & 1 & 1.5 & $\therefore 90.9 \%=1,2$ \\
& Mode & 1 & 1 & V Consensus \\
\hline Comprehensiveness-missing & & Round II & Round III & Agreement \\
\cline { 2 - 5 } $\begin{array}{l}\text { key services \& amenities } \\
\text { that should be in the union }\end{array}$ & Mean & 1.86 & 1.73 & $45.5 \%=1$ \\
& Range & $1-3$ & $1-3$ & $36.4 \%=2$ \\
& Median & 2 & 2 & $\therefore 91.9 \%=1,2$ \\
\hline Location-poor original & Mode & 2 & 1 & $\sqrt{ }$ Consensus \\
choice/peripheral to campus & & Round II & Round III & Agreement \\
\cline { 2 - 5 } & Mean & 1.50 & 1.73 & $40.9 \%=1$ \\
& Range & $1-3$ & $1-3$ & $45.5 \%=2$ \\
& Median & 1 & 2 & $\therefore 86.4 \%=1,2$ \\
\hline Design-outdated and & Mode & 1 & 2 & $\sqrt{ }$ Consensus \\
\cline { 2 - 5 } unappealing & Mean & 1.64 & 1.73 & Agreement \\
\cline { 2 - 5 } & Range & $1-3$ & $1-3$ & $40.9 \%=1$ \\
& Median & 1.5 & 2 & $45.5 \%=2$ \\
& Mode & 1 & 2 & $\therefore 86.4 \%=1,2$ \\
\hline Location-displaced/center of \\
campus has shifted as & & Round II & Round III & Agreement \\
\cline { 2 - 5 } campus grew & Mean & 2.09 & 2.09 & $13.6 \%=1$ \\
& Range & $1-5$ & $1-4$ & $68.2 \%=2$ \\
& Median & 2 & 2 & $\therefore 81.8 \%=1,2$ \\
& Mode & 2 & 2 & $\sqrt{ }$ Consensus \\
\hline
\end{tabular}

$\mathrm{N}=22$

In summary, the physical constraint that appears to have the greatest influence on the effectiveness of the student union is the building not being well kept. Fortunately for campuses, this one can be more easily addressed than some of the larger infrastructure or design issues. 
Knowledge constraints. In Round I, participants named 15 different potential knowledge constraints that could negatively impact student union effectiveness. In Round III, participants achieved consensus on all of these except for one. These are presented in Tables 35, 36, 37 and P14. There were five issues for which panelists achieved $100 \%$ consensus regarding their importance, including two for which they achieved a true consensus, rating those as very important (Table 35). The top two knowledge constraints were the need to seek input from multiple consumers or populations served by the union $(M=1.23$, consensus $100 \%)$, and a lost focus on students $(M=1.24$, consensus $=100 \%)$. Completing the top five include: the need to measure the union's effectiveness in meeting student and community needs $(M=1.32$, consensus $=100 \%)$, the need to clarify current and future student needs for the union $(M=1.45$, consensus $=100 \%)$, and an insufficient understanding of the "whole enterprise" of the union $(M=1.50$, consensus $=100 \%)$.

Three additional important knowledge constraints related to issues or concerns with union staff (Table 36). These included staff having an insufficient awareness of their role in student development as educators $(M=1.59$, consensus $=95.5 \%)$, difficulty in recruiting and retaining union staff who are student-focused $(\mathrm{M}=1.77$, consensus $=$ $86.4 \%$ ), and staff having insufficient knowledge about student learning outcomes and assessments $(\mathrm{M}=1.95$, consensus $=86.4 \%)$.

The remaining six knowledge constraints rated by participants as important (Table 37) included three management concerns: an inappropriate management paradigm for the union, that focuses on a facilities framework instead of a student development framework $(\mathrm{M}=1.64$, consensus $=95.4 \%)$; lack of understanding or appreciation about student development and the union among campus leaders $(M=1.81$, consensus $=90.5 \%)$ and 
academic affairs $(M=2.16$, consensus $=79 \%)$; and the inefficient use of space $(M=1.90$, consensus $=95.2 \%)$. Issues of outcomes assessment, specifically the need for the union to measure and prove its contribution to the educational and co-curricular process (assessment $=1.73$, consensus $=81.9 \%$ ); and having outsourced service providers who do not understand or uphold the importance of student employment as a developmental process $(M=2.05$, consensus $=86.4 \%)$ completed the list.

Table 35

\section{Round II and III Results - Top Five Knowledge Constraints}

Q20: How important is each of the following knowledge constraints, in influencing student union effectiveness?

\begin{tabular}{|c|c|c|c|c|}
\hline \multirow{5}{*}{$\begin{array}{l}\text { User input-need to seek } \\
\text { input from multiple } \\
\text { consumers/populations } \\
\text { served by the union }\end{array}$} & & Round II & Round III & Agreement \\
\hline & Mean & 1.33 & 1.23 & $77.3 \%=1$ \\
\hline & Range & $1-2$ & $1-2$ & $22.7 \%=2$ \\
\hline & Median & 1 & 1 & $\therefore 100 \%=1,2$ \\
\hline & Mode & 1 & 1 & $\sqrt{ }$ True Consensus \\
\hline \multirow{5}{*}{$\begin{array}{l}\text { General management- } \\
\text { student union has lost its } \\
\text { focus on students }\end{array}$} & & Round II & Round III & Agreement \\
\hline & Mean & 1.64 & 1.24 & $76.2 \%=1$ \\
\hline & Range & $1-6$ & $1-2$ & $23.8 \%=2$ \\
\hline & Median & 1 & 1 & $\therefore 100 \%=1,2$ \\
\hline & Mode & 1 & 1 & $\sqrt{ }$ True Consensus \\
\hline \multirow{5}{*}{$\begin{array}{l}\text { Satisfaction assessment- } \\
\text { need to measure union's } \\
\text { effectiveness in meeting } \\
\text { student \& community needs }\end{array}$} & & Round II & Round III & Agreement \\
\hline & Mean & 1.45 & 1.32 & $68.2 \%=1$ \\
\hline & Range & $1-3$ & $1-2$ & $31.8 \%=2$ \\
\hline & Median & 1 & 1 & $\therefore 100 \%=1,2$ \\
\hline & Mode & 1 & 1 & $\sqrt{\text { Consensus }}$ \\
\hline \multirow{5}{*}{$\begin{array}{l}\text { Needs assessment-need to } \\
\text { identify current \& future } \\
\text { student needs for the union }\end{array}$} & & Round II & Round III & Agreement \\
\hline & Mean & 1.59 & 1.45 & $54.5 \%=1$ \\
\hline & Range & $1-3$ & $1-2$ & $45.5 \%=2$ \\
\hline & Median & 1.5 & 1 & $\therefore 100 \%=1,2$ \\
\hline & Mode & 1 & 1 & $\sqrt{ }$ Consensus \\
\hline \multirow{5}{*}{$\begin{array}{l}\text { General management- } \\
\text { insufficient understanding } \\
\text { of "whole enterprise" of the } \\
\text { union }\end{array}$} & & Round II & Round III & Agreement \\
\hline & Mean & 1.52 & 1.50 & $50.0 \%=1$ \\
\hline & Range & $1-4$ & $1-2$ & $50.0 \%=2$ \\
\hline & Median & 1 & 1.5 & $\therefore 100 \%=1,2$ \\
\hline & Mode & 1 & $1+2$ & $\sqrt{ }$ Consensus \\
\hline
\end{tabular}

$\mathrm{N}=22$ 
Table 36

Round II and III Results - Additional Knowledge Constraints

Q20: How important is each of the following knowledge constraints, in influencing student union effectiveness?

\begin{tabular}{lllll}
\hline Staff-have insufficient & & Round II & Round III & Agreement \\
\cline { 2 - 5 } $\begin{array}{llll}\text { awareness of their role in } \\
\text { student development as }\end{array}$ & Mean & 1.59 & 1.59 & $45.5 \%=1$ \\
& Range & $1-2$ & $1-3$ & $50.0 \%=2$ \\
& Median & 2 & 2 & $\therefore 95.5 \%=1,2$ \\
& Mode & 2 & 2 & $\sqrt{ }$ Consensus \\
\hline Staff-have difficulty in & & Round II & Round III & Agreement \\
recruiting and retaining & Mean & 1.55 & 1.77 & $45.5 \%=1$ \\
student-focused union staff & Range & $1-2$ & $1-5$ & $40.9 \%=2$ \\
& Median & 2 & 2 & $\therefore 86.4 \%=1,2$ \\
& Mode & 2 & 1 & $\sqrt{ }$ Consensus \\
\hline Staff-have insufficient & & Round II & Round III & Agreement \\
knowledge about student & Mean & 2.05 & 1.95 & $18.2 \%=1$ \\
learning outcomes \& & Range & $1-3$ & $1-3$ & $68.2 \%=2$ \\
assessment & Median & 2 & 2 & $\therefore 86.4 \%=1,2$ \\
& Mode & 2 & 2 & $\sqrt{ }$ Consensus \\
\hline
\end{tabular}

$\mathrm{N}=22$

In summary, it appears that the most important knowledge constraints that effect the success of the student union center on promoting an understanding of and focus on student development and the union's role within that; and then engaging in an array of assessments to identify current and future student needs, measure success in meeting those needs, and prove the union's contribution to the educational and co-curricular processes. 
Table 37

\section{Round II and III Results - Other Important Knowledge Constraints}

Q20: How important is each of the following knowledge constraints, in influencing student union effectiveness?

\begin{tabular}{|c|c|c|c|c|}
\hline \multirow{5}{*}{$\begin{array}{l}\text { General management-use } \\
\text { inappropriate administrative } \\
\text { paradigms (e.g. "facilities" } \\
\text { framework vs. "student } \\
\text { development" framework }\end{array}$} & & Round II & Round III & Agreement \\
\hline & Mean & 1.68 & 1.64 & $40.9 \%=1$ \\
\hline & Range & $1-3$ & $1-3$ & $54.6 \%=2$ \\
\hline & Median & 2 & 2 & $\therefore 95.4 \%=1,2$ \\
\hline & Mode & 2 & 2 & $\sqrt{ }$ Consensus \\
\hline \multirow{5}{*}{$\begin{array}{l}\text { Outcomes assessment-need } \\
\text { to measure and prove the } \\
\text { union's contribution to the } \\
\text { educational \& co-curricular } \\
\text { process }\end{array}$} & & Round II & Round III & Agreement \\
\hline & Mean & 1.73 & 1.73 & $45.5 \%=1$ \\
\hline & Range & $1-5$ & $1-3$ & $36.4 \%=2$ \\
\hline & Median & 1.5 & 2 & $\therefore 81.9 \%=1,2$ \\
\hline & Mode & 1 & 1 & $\sqrt{ }$ Consensus \\
\hline \multirow{5}{*}{$\begin{array}{l}\text { Campus leaders-lack } \\
\text { understanding or } \\
\text { appreciation of student } \\
\text { development \& the union }\end{array}$} & & Round II & Round III & Agreement \\
\hline & Mean & 1.68 & 1.81 & $28.6 \%=1$ \\
\hline & Range & $1-3$ & $1-3$ & $61.9 \%=2$ \\
\hline & Median & 2 & 2 & $\therefore 90.5 \%=1,2$ \\
\hline & Mode & 2 & 2 & $\sqrt{ }$ Consensus \\
\hline \multirow{5}{*}{$\begin{array}{l}\text { General management-space } \\
\text { is used inefficiently }\end{array}$} & & Round II & Round III & Agreement \\
\hline & Mean & 2.00 & 1.90 & $14.3 \%=1$ \\
\hline & Range & $1-3$ & $1-3$ & $80.9 \%=2$ \\
\hline & Median & 2 & 2 & $\therefore 95.2 \%=1,2$ \\
\hline & Mode & 2 & 2 & $\sqrt{ }$ Consensus \\
\hline \multirow{5}{*}{$\begin{array}{l}\text { Outsourced service } \\
\text { providers-do not understand } \\
\text { / value / uphold importance } \\
\text { of student employment as a } \\
\text { developmental process }\end{array}$} & & Round II & Round III & Agreement \\
\hline & Mean & 2.09 & 2.05 & $18.2 \%=1$ \\
\hline & Range & $1-4$ & $1-4$ & $68.2 \%=2$ \\
\hline & Median & 2 & 2 & $\therefore 86.4 \%=1,2$ \\
\hline & Mode & 2 & 2 & $\sqrt{ }$ Consensus \\
\hline \multirow{5}{*}{$\begin{array}{l}\text { Academic affairs-lack } \\
\text { understanding or } \\
\text { appreciation of student } \\
\text { development \& the union }\end{array}$} & & Round II & Round III & Agreement \\
\hline & Mean & 2.00 & 2.16 & $15.8 \%=1$ \\
\hline & Range & $1-3$ & $1-5$ & $63.2 \%=2$ \\
\hline & Median & 2 & 2 & $\therefore 79.0 \%=1,2$ \\
\hline & Mode & 2 & 2 & $\sqrt{ }$ Consensus \\
\hline
\end{tabular}

Financial constraints. In Round I, participants named 18 different potential

financial constraints that could negatively impact student union effectiveness, and in

Round III, they achieved general consensus on 13. These are presented in Tables 38, 39, 
40 and P15, and may be categorized according to expenses, revenues, and the general auxiliary budget model.

Expenses were the largest subcategory of financial constraints, with panelists ranking six different issues as important (Table 38). Recurring expenses such as increased utilities, supplies and equipment costs in union operations $(M=1.45$, consensus $=90.0 \%)$ topped the list, followed by needed maintenance expenses $(M=1.50$, consensus 95.5\%). Differences between these and other expense constraints were slight. Capital expenses for union construction, renovation and expansion. $(\mathrm{M}=1.64$, consensus $=$ $86.3 \%)$, and more recurring expenses for staffing $(M=1.64$, consensus $=91.0 \%)$, technology $(M=1.64$, consensus $=95.5 \%)$, and basic refurbishments and upgrades such as furniture and lighting replacement $(\mathrm{M}=1.77$, consensus $=86.4 \%)$ completed the list.

In revenue constraints, four stood out as important (Table 39). Overreliance on student fees to support student unions $(M=1.50$, consensus $=86.5 \%)$ topped the list, reflecting a concern for and need to reduce overall college costs and student debt. However, curiously panelists indicated that insufficient student fee support $(\mathrm{M}=1.91$, consensus $=77.3 \%)$ was also an important issue. While this contradiction seems paradoxical, it is important to remember that the ranking of constraints reflects issues that could affect student union effectiveness, and does not necessarily indicate that participants were presently experiencing these on their campuses. Thus insufficient student fees can present a problem, but also can overreliance upon them. The subsequent two items reflected that student unions have multiple revenue streams that they rely upon and inadequacy in any could present a problem, such as insufficient allocations from the 
institution's general operating budget $(\mathrm{M}=1.95$, consensus $=85.7 \%)$, or the need to increase revenues from the use of union services $(\mathrm{M}=1.82$, consensus $=85.3 \%)$.

Table 38

\section{Round II and III Results - Expense Constraints}

Q21: How important is each of the following financial constraints, in influencing student union effectiveness?

\begin{tabular}{|c|c|c|c|c|}
\hline Expenses-union operations & & Round II & Round III & Agreement \\
\hline (e.g. increasing costs or & Mean & 1.50 & 1.45 & $63.6 \%=1$ \\
\hline inadequate budget for utilities, & Range & $1-2$ & $1-3$ & $27.3 \%=2$ \\
\hline & Median & 1.5 & 1 & $\therefore 90.0 \%=1,2$ \\
\hline & Mode & $1+2$ & 1 & $\sqrt{ }$ Consensus \\
\hline Expenses-needed maintenance & & Round II & Round III & Agreement \\
\hline (e.g. increasing costs or & Mean & 1.52 & 1.50 & $54.6 \%=1$ \\
\hline & Range & $1-2$ & $1-3$ & $40.9 \%=2$ \\
\hline & Median & 2 & 1 & $\therefore 95.5 \%=1,2$ \\
\hline & Mode & 2 & 1 & $\ddot{\sqrt{ } \text { Consensus }}$ \\
\hline Capital expenses-lack of funding & & Round II & Round III & Agreement \\
\hline for union construction, & Mean & 1.73 & 1.64 & $54.5 \%=1$ \\
\hline & Range & $1-4$ & $1-4$ & $31.8 \%=2$ \\
\hline & Median & 2 & 1 & $\therefore 86.3 \%=1,2$ \\
\hline & Mode & 1 & 1 & $\sqrt{ }$ Consensus \\
\hline Expenses-staffing & & Round II & Round III & Agreement \\
\hline (e.g. increasing costs or & Mean & 1.50 & 1.64 & $45.5 \%=1$ \\
\hline inadequate budget ror number of & Range & $1-2$ & $1-3$ & $45.5 \%=2$ \\
\hline & Median & 1.5 & & $\therefore 91.0 \%=1,2$ \\
\hline & Mode & $1+2$ & $1+2$ & $\sqrt{ }$ Consensus \\
\hline Expenses-technology & & Round II & Round III & Agreement \\
\hline (e.g. increasing costs or & Mean & 1.62 & 1.64 & $40.9 \%=1$ \\
\hline inadequate budget) & Range & $1-3$ & $1-3$ & $54.6 \%=2$ \\
\hline & Median & 2 & 2 & $\therefore 95.5 \%=1,2$ \\
\hline & Mode & 2 & 2 & $\sqrt{ }$ Consensus \\
\hline Expenses-basic refurbishments & & Round II & Round III & Agreement \\
\hline$\&$ upgrades & Mean & 1.59 & 1.77 & $36.4 \%=1$ \\
\hline (e.g. increasing costs or & Range & $1-2$ & $1-3$ & $50.0 \%=2$ \\
\hline inadequate budget for furniture & Median & 2 & 2 & $\therefore 86.4 \%=1,2$ \\
\hline \& lighting replacement) & Mode & 2 & 2 & $\sqrt{ }$ Consensus \\
\hline
\end{tabular}

$\mathrm{N}=22$ 
Table 39

\section{Round II and III Results - Revenue Constraints}

Q21: How important is each of the following financial constraints, in influencing student union effectiveness?

\begin{tabular}{|c|c|c|c|c|}
\hline \multirow{5}{*}{$\begin{array}{l}\text { Revenues-overreliance on } \\
\text { student fee support } \\
\text { (e.g. need to reduce, concern for } \\
\text { college costs \& student debt }\end{array}$} & & Round II & Round III & Agreement \\
\hline & Mean & 1.82 & 1.50 & $50.1 \%=1$ \\
\hline & Range & $1-3$ & $1-4$ & $36.4 \%=2$ \\
\hline & Median & 2 & 1 & $\therefore 86.5 \%=1,2$ \\
\hline & Mode & 1 & 1 & $\sqrt{ }$ Consensus \\
\hline \multirow{5}{*}{$\begin{array}{l}\text { Revenues-need to increase use } \\
\text { of the union service }\end{array}$} & & Round II & Round III & Agreement \\
\hline & Mean & 1.95 & 1.82 & $31.8 \%=1$ \\
\hline & Range & $1-4$ & $1-3$ & $54.5 \%=2$ \\
\hline & Median & 2 & 2 & $\therefore 85.3 \%=1,2$ \\
\hline & Mode & 2 & 2 & $\sqrt{ }$ Consensus \\
\hline \multirow{5}{*}{$\begin{array}{l}\text { Revenues-insufficient student } \\
\text { fees to support union }\end{array}$} & & Round II & Round III & \\
\hline & Mean & 1.82 & 1.91 & $40.9 \%=1$ \\
\hline & Range & $1-5$ & $1-5$ & $36.4 \%=2$ \\
\hline & Median & 2 & 2 & $\therefore 77.3 \%=1,2$ \\
\hline & Mode & 1 & 1 & $\sqrt{ }$ Consensus \\
\hline \multirow{5}{*}{$\begin{array}{l}\text { Revenues-insufficient } \\
\text { allocations from institution's } \\
\text { general operating budget to } \\
\text { support union }\end{array}$} & & Round II & Round III & Agreement \\
\hline & Mean & 2.27 & 1.95 & $33.3 \%=1$ \\
\hline & Range & $1-6$ & $1-5$ & $52.4 \%=2$ \\
\hline & Median & 2 & 2 & $\therefore 85.7 \%=1,2$ \\
\hline & Mode & 1 & 2 & $\sqrt{ }$ Consensus \\
\hline
\end{tabular}

$\mathrm{N}=22$

On some campuses, student unions function as auxiliary enterprises. When they do, this poses the potential for additional financial constraints. In this study, three such emerged as important (Table 40). Specifically, panelists agreed that the burdensome expectation that the union will make and contribute excess revenues to add to the institutions budget $(\mathrm{M}=2.00$, consensus $=76.2 \%)$ was an important concern, as were the difficulty for the union in being a self-supported entity $(\mathrm{M}=2 . .09$, consensus $=81.8 \%)$, and the general ineffectiveness of the union's budget model $(\mathrm{M}=2.09$, consensus $=$ $77.3 \%$ ), in terms of its predictability and adequacy was also an important concern. 
Table 40

\section{Round II and III Results - Auxiliary Financial Model Constraints}

Q21: How important is each of the following financial constraints, in influencing student union effectiveness?

\begin{tabular}{|c|c|c|c|c|}
\hline \multirow{5}{*}{$\begin{array}{l}\text { Auxiliary enterprise-burdensome } \\
\text { expectation that union will make } \\
\text { and contribute excess revenues } \\
\text { to add to institutional budget }\end{array}$} & & Round II & Round III & Agreement \\
\hline & Mean & 2.18 & 2.00 & $33.3 \%=1$ \\
\hline & Range & $1-6$ & $1-4$ & $42.9 \%=2$ \\
\hline & Median & 2 & 2 & $\therefore 76.2 \%=1,2$ \\
\hline & Mode & $1+2$ & 2 & $\sqrt{ }$ Consensus \\
\hline \multirow{5}{*}{$\begin{array}{l}\text { Auxiliary enterprise-difficult to } \\
\text { be self-supporting }\end{array}$} & & Round II & Round III & Agreement \\
\hline & Mean & 2.23 & 2.09 & $18.2 \%=1$ \\
\hline & Range & $1-5$ & $1-4$ & $63.6 \%=2$ \\
\hline & Median & 2 & 2 & $\therefore 81,8 \%=1,2$ \\
\hline & Mode & 2 & 2 & $\sqrt{ }$ Consensus \\
\hline \multirow{5}{*}{$\begin{array}{l}\text { Auxiliary enterprise-ineffective } \\
\text { financial model supporting union } \\
\text { (e.g. predictability, adequacy) }\end{array}$} & & Round II & Round III & Agreement \\
\hline & Mean & 2.41 & 2.09 & $18.2 \%=1$ \\
\hline & Range & $1-6$ & $1-4$ & $59.1 \%=2$ \\
\hline & Median & 2 & 2 & $\therefore 77.3 \%=1,2$ \\
\hline & Mode & 2 & 2 & $\sqrt{ }$ Consensus \\
\hline $\mathrm{N}=22$ & & & & \\
\hline
\end{tabular}

Participants did not reach consensus on the importance of five financial constraints originally named in Round I. These included additional revenue concerns such as insufficient fundraising, the pressure to function more like shopping malls, or serve resort to serving the paying public purpose more than the non-paying student purpose in order to remain financially viable; and capital expense concerns, such as a poor bond rating or lack of state support for union construction, renovation and expansion. Scores on these items ranged widely, from very important to very unimportant. This reflects that financial constraints can differ by institutional type. For example, a private college or university might place greater importance on fundraising than a public institution would; whereas conversely, the public institution may place greater importance on state appropriations than private colleges and universities do. 
In summary, participants agreed upon the importance of a number of financial constraints addressing expenses, revenues, and the general auxiliary financial model. Although there was not true consensus about which is most important or influential to the effectiveness of the student union, the range of responses may be more reflective of the variances in financing evidenced between public and private colleges and universities.

Political constraints. In Round I, participants named 8 political constraints that could negatively impact student union effectiveness. From these, four emerged in Round III as attaining general consensus (Tables 41, P16). The top two, ranked between important and very important, included respect for the autonomy of the student union $(\mathrm{M}=1.59$, consensus $=95.5 \%)$ when the institution appropriates union space for nonunion purposes such as storage or administrative offices, and union directors' lack of influence in institutional decisions making $(\mathrm{M}=1.77$, consensus $=81.9 \%)$. The second two were ranked slightly lower, as simply important. These included campus policies and politics $(\mathrm{M}=2.00$, consensus $=77.2 \%)$ that have a prohibitive influence on union operations and innovation; and the low prioritization of the student union in the institutional budget process $(\mathrm{M}=2.05$, consensus $=81.8 \%)$.

In the Round I questionnaire, panelists identified 56 different barriers and constraints, that can impede student union effectiveness. In Round III, panelists agreed that nearly three fourths $(73 \%)$ of these were important concerns. Variances in the importance of individual physical, knowledge, financial, or political constraints may be attributable to differences in institutional type. However, tracking such information was beyond the scope of this study., Looking across the section, however only three barriers achieved a true consensus: A building in poor condition through neglected maintenance 
ranked as the highest barrier overall (physical constraint), followed closely by the barriers created by not having user input and needing to seek input from multiple constituencies (knowledge constraint), or by management losing its focus on students (knowledge constraint).

Table 41

Round II and III Results - Political Constraints

Q22: How important is each of the following political constraints, in influencing student union effectiveness?

\begin{tabular}{llllc}
\hline Respect for/autonomy of student & & Round II & Round III & Agreement \\
\cline { 2 - 5 } $\begin{array}{l}\text { union (e.g. institution } \\
\text { appropriates union space for non- }\end{array}$ Mnion purposes such as storage or & Mean & 1.50 & 1.59 & $45.5 \%=1$ \\
administrative offices) & Range & $1-3$ & $1-3$ & $50.0 \%=2$ \\
& Median & 1 & 2 & $\therefore 95.5 \%=1,2$ \\
& Mode & 1 & 2 & V Consensus \\
\hline Lack of influence of union & & Round II & Round III & Agreement \\
\cline { 2 - 5 } $\begin{array}{l}\text { directors in institutional decision } \\
\text { making }\end{array}$ & Mean & 1.73 & 1.77 & $45.5 \%=1$ \\
& Range & $1-3$ & $1-4$ & $36.4 \%=2$ \\
& Median & 2 & 2 & $\therefore 81.9 \%=1,2$ \\
& Mode & 2 & 1 & $\sqrt{ }$ Consensus \\
\hline Campus policies and politics (e.g. & & Round II & Round III & Agreement \\
\cline { 2 - 5 } prohibitive influence on union & Mean & 2.14 & 2.00 & $31.8 \%=1$ \\
operations \& innovation) & Range & $1-3$ & $1-4$ & $45.5 \%=2$ \\
& Median & 2 & 2 & $\therefore 77.2 \%=1,2$ \\
& Mode & 2 & 2 & $\sqrt{ }$ Consensus \\
\hline Prioritization of student union in & & Round II & Round III & Agreement \\
\cline { 2 - 5 } the institutional budget process & Mean & 1.95 & 2.05 & $22.7 \%=1$ \\
& Range & $1-4$ & $1-5$ & $59.1 \%=2$ \\
& Median & 2 & 2 & $\therefore 81.8 \%=1,2$ \\
& Mode & 2 & 2 & $\sqrt{ }$ Consensus \\
\hline N=22 & & & & \\
\hline
\end{tabular}

\section{Influences on the Student Union of the Future}

In the final section of Round III, participants addressed the importance of a variety of forces that can influence the student union of the future. These were categorized into two types. Sustaining forces referred to things that will continue to support the core purposes of student unions and the continued need for these entities on 
campus. Eight sustaining forces emerged from the analysis of the Round 1 questionnaire responses. Changing forces referred to things that may introduce new missions, change some of the ways that union fulfills its purposes), and nine emerged from the analysis of Round 1.

Sustaining forces. Panelists reached consensus that all of the eight sustaining forces were important towards influencing the student union of the future (Tables 42 , P17). However, four of these garnered a true consensus of opinion, ranking as very important. The highest ranked sustaining forces was the importance of the union's services and amenities to the campus community $(\mathrm{M}=1.18$, consensus $=100 \%)$. The next two highest ranked forces were closely related: students' basic human need to connect and belong to the campus community $(\mathrm{M}=1.18$, consensus $=100 \%)$, and the importance of providing a human, high-touch location on campus $(\mathrm{M}=1.27$, consensus $=95.5 \%)$, as human interactions become increasingly mediated through technology. The continued need for co-curricular skill building $(\mathrm{M}=1.27$, consensus $=95.4 \%)$ in areas such as responsibility, leadership and communication anchored the list of the highest ranked items.

Looking at the rest of the list, the institutional commitment to the union concept and a continued need for students to have a "living room" and a place to feel at home each scored means of 1.32, and consensus of $95.4 \%$. The general importance of student development in colleges' and universities' strategic plans $(\mathrm{M}=1.50$, consensus $=94.5 \%)$ was also rated highly important, as well as the continued need for a "welcome center" $(\mathrm{M}=1.55$, consensus $=86.4 \%)$ that makes an impression for students, alumni, and visitors, while conveying the campus' identity story and instills loyalty $(\mathrm{M}=1.55)$. 
Table 42

\section{Round II and III Results - Sustaining Influences on the Student Union of the Future}

Q24: How important is each of the following sustaining forces, in influencing the student union of the future?

\begin{tabular}{|c|c|c|c|c|}
\hline \multirow{5}{*}{$\begin{array}{l}\text { Importance of the union's } \\
\text { services \& amenities to the } \\
\text { campus community }\end{array}$} & & Round II & Round III & Agreement \\
\hline & Mean & 1.36 & 1.14 & $86.4 \%=1$ \\
\hline & Range & $1-3$ & $1-2$ & $13.6 \%=2$ \\
\hline & Median & 1 & 1 & $\therefore 100 \%=1,2$ \\
\hline & Mode & 1 & 1 & $\sqrt{ }$ True Consensus \\
\hline \multirow{5}{*}{$\begin{array}{l}\text { Basic human/student need to } \\
\text { connect and belong to the } \\
\text { campus community }\end{array}$} & & Round II & Round III & Agreement \\
\hline & Mean & 1.27 & 1.18 & $81.8 \%=1$ \\
\hline & Range & $1-2$ & $1-2$ & $18.2 \%=2$ \\
\hline & Median & 1 & 1 & $\therefore 100 \%=1,2$ \\
\hline & Mode & 1 & 1 & $\sqrt{ }$ True Consensus \\
\hline \multirow{5}{*}{$\begin{array}{l}\text { Continued need for students to } \\
\text { have a "living room," a place to } \\
\text { feel "at home." }\end{array}$} & & Round II & Round III & Agreement \\
\hline & Mean & 1.32 & 1.32 & $72.7 \%=1$ \\
\hline & Range & $1-3$ & $1-3$ & $22.7 \%=2$ \\
\hline & Median & 1 & 1 & $\therefore 95.4 \%=1,2$ \\
\hline & Mode & 1 & 1 & $\sqrt{ }$ Consensus \\
\hline \multirow{5}{*}{$\begin{array}{l}\text { Institutional commitment to the } \\
\text { union concept }\end{array}$} & & Round II & Round III & Agreement \\
\hline & Mean & 1.52 & 1.32 & $72.7 \%=1$ \\
\hline & Range & $1-3$ & $1-3$ & $22.7 \%=2$ \\
\hline & Median & 1 & 1 & $\therefore 95.4 \%=1,2$ \\
\hline & Mode & 1 & 1 & $\sqrt{ }$ Consensus \\
\hline \multirow{5}{*}{$\begin{array}{l}\text { Importance of providing a } \\
\text { human, high-touch location on } \\
\text { campus, as human interactions } \\
\text { are increasingly mediated } \\
\text { through technology }\end{array}$} & & Round II & Round III & Agreement \\
\hline & Mean & 1.41 & 1.27 & $77.3 \%=1$ \\
\hline & Range & $1-3$ & $1-3$ & $18.2 \%=2$ \\
\hline & Median & 1 & 1 & $\therefore 95.5 \%=1,2$ \\
\hline & Mode & 1 & 1 & $\ddot{V}$ True Consensus \\
\hline \multirow{5}{*}{$\begin{array}{l}\text { Continued need for co-curricular } \\
\text { skill building (e.g. responsibility, } \\
\text { leadership, communication) }\end{array}$} & & Round II & Round III & Agreement \\
\hline & Mean & 1.45 & 1.27 & $77.2 \%=1$ \\
\hline & Range & $1-3$ & $1-3$ & $18.2 \%=2$ \\
\hline & Median & 1 & 1 & $\therefore 95.4 \%=1,2$ \\
\hline & Mode & 1 & 1 & V True Consensus \\
\hline \multirow{5}{*}{$\begin{array}{l}\text { Importance of student } \\
\text { development in institution's } \\
\text { mission and strategic plan }\end{array}$} & & Round II & Round III & Agreement \\
\hline & Mean & 1.50 & 1.50 & $59.1 \%=1$ \\
\hline & Range & $1-3$ & $1-4$ & $36.4 \%=2$ \\
\hline & Median & 1 & 1 & $\therefore 94.5 \%=1,2$ \\
\hline & Mode & 1 & 1 & $\sqrt{ }$ Consensus \\
\hline \multirow{5}{*}{$\begin{array}{l}\text { Continued need for a "welcome } \\
\text { center" that makes an impression } \\
\text { for students, alumni and visitors, } \\
\text { and conveys the campus' } \\
\text { identity story, instills loyalty }\end{array}$} & & Round II & Round III & Agreement \\
\hline & Mean & 1.55 & 1.55 & $59.1 \%=1$ \\
\hline & Range & $1-3$ & $1-3$ & $27.3 \%=2$ \\
\hline & Median & 1 & 1 & $\therefore 86.4 \%=1,2$ \\
\hline & Mode & 1 & 1 & $\sqrt{ }$ Consensus \\
\hline $\mathrm{N}=22$ & & & & \\
\hline
\end{tabular}


Combined, panelists responses drew upon basic human needs and student development theory, underscoring the centrality of the student union to both student life and the institutional mission.

Changing forces. Of the nine different forces of change that emerged from the Round I analysis, only six were ranked as important in the Round III consensus-building process (Tables 43, P18). The difficulty in forecasting the needs of changing student populations $(M=1.50$, consensus $=95.4 \%)$ neared the top of the list, situated between finding new ways to engage students $(\mathrm{M}=1.45$, consensus $=100 \%)$ amid competition for their time and attention, and finding new ways to create a sense of community $(\mathrm{M}=1.52$, consensus $=97.9 \%$ ). In many respects, these reflect the forces of change that have shaped student unions since their inception. Unions continually evolve with changing society and changing students.

In contrast, the other three high ranking forces of change reflect unique developments and trends for our time. For example, the sustainability movement $(\mathrm{M}=1.73$, consensus $=90.9 \%)$ and accompanying eco-awareness are fairly recent trends that shape student and societal preferences and will likely have an impact on unions. Recycling programs within unions were a forerunner of such change, as were water bottle refilling stations. Contemporary trends in construction and building management have yielded an array of approaches towards reducing, reusing and recycling, all intended to boost sustainability and reduce carbon footprints. Technology, including the pace of technological change $(\mathrm{M}=1.82$, consensus $=81.8 \%)$ and the explosive growth of technology mediated human interaction $(\mathrm{M}=2.05$, consensus $=81.8 \%)$ are reshaping 
human society. For student unions, technological changes are difficult to forecast, keep pace with, and afford.

However one technology-driven force - online classes - did not generate panelist consensus. While a few rated this as an important force, one likely to keep more students off campus and change the primacy of a residential college, other panelists rated this as very unimportant. This viewpoint was best expressed in the comments of one panelist who wrote, "No matter what technology does, there will always be a need for the third space, high-touch, community building.”

Similarly, the force of globalization failed to generate consensus, despite its growing influence in shaping college curricula. Perhaps this may be attributed to the fact that the union's purposes and missions are place-bound endeavors that cannot be outsourced. At best, globalization may drive changes in the needs and preferences of populations served by student unions resulting, for example, in new dining offerings. Or it may bring new populations to campus and, in turn, to the union.

The increase in evening and weekend classes and the potential for a resulting need to change union operating hours failed to generate consensus. The range of responses (important to unimportant) may reflect the diversity of institutional types represented in the study. 
Table 43

\section{Round II and III Results - Changing Influences on the Student Union of the Future}

Q25: How important is each of the following changing forces, in influencing the student union of the future?

\begin{tabular}{|c|c|c|c|c|}
\hline \multirow{5}{*}{$\begin{array}{l}\text { Finding new ways to engage } \\
\text { students/compete for their time } \\
\text { and attention }\end{array}$} & & Round II & Round III & Agreement \\
\hline & Mean & 1.50 & 1.45 & $54.5 \%=1$ \\
\hline & Range & $1-4$ & $1-2$ & $45.5 \%=2$ \\
\hline & Median & 1 & 1 & $\therefore 100 \%=1,2$ \\
\hline & Mode & 1 & 1 & $\sqrt{ }$ Consensus \\
\hline \multirow{5}{*}{$\begin{array}{l}\text { Changing student } \\
\text { populations/needs (e.g. difficult } \\
\text { to forecast what future students } \\
\text { will need) }\end{array}$} & & Round II & Round III & Agreement \\
\hline & Mean & 1.77 & 1.50 & $54.5 \%=1$ \\
\hline & Range & $1-3$ & $1-3$ & $40.9 \%=2$ \\
\hline & Median & 2 & 1 & $\therefore 95.4 \%=1,2$ \\
\hline & Mode & 2 & 1 & $\sqrt{ }$ Consensus \\
\hline \multirow{5}{*}{$\begin{array}{l}\text { Finding new ways to create a } \\
\text { sense of community }\end{array}$} & & Round II & Round III & Agreement \\
\hline & Mean & 1.59 & 1.52 & $52.4 \%=1$ \\
\hline & Range & $1-5$ & $1-3$ & $45.5 \%=2$ \\
\hline & Median & 1 & 1 & $\therefore 97.9 \%=1,2$ \\
\hline & Mode & 1 & 1 & $\sqrt{ }$ Consensus \\
\hline \multirow[t]{5}{*}{ Sustainability/Eco-awareness } & & Round II & Round III & Agreement \\
\hline & Mean & 1.91 & 1.73 & $36.4 \%=1$ \\
\hline & Range & $1-3$ & $1-3$ & $54.5 \%=2$ \\
\hline & Median & 2 & 2 & $\therefore 90.9 \%=1,2$ \\
\hline & Mode & 2 & 2 & $\sqrt{\text { Consensus }}$ \\
\hline \multirow{5}{*}{$\begin{array}{l}\text { Pace of technological change } \\
\text { (e.g. difficult to forecast, keep } \\
\text { pace with, and afford) }\end{array}$} & & Round II & Round III & Agreement \\
\hline & Mean & 1.71 & 1.82 & $36.4 \%=1$ \\
\hline & Range & $1-3$ & $1-3$ & $45.4 \%=2$ \\
\hline & Median & 2 & 2 & $\therefore 81.8 \%=1,2$ \\
\hline & Mode & 1 & 2 & $\sqrt{ }$ Consensus \\
\hline \multirow{5}{*}{$\begin{array}{l}\text { Technology-mediated human } \\
\text { interaction (e.g. social media \& } \\
\text { virtual vs. physical union) }\end{array}$} & & Round II & Round III & Agreement \\
\hline & Mean & 1.95 & 2.05 & $18.2 \%=1$ \\
\hline & Range & $1-5$ & $1-4$ & $63.6 \%=2$ \\
\hline & Median & 2 & 2 & $\therefore 81.8 \%=1,2$ \\
\hline & Mode & 2 & 2 & $\sqrt{ }$ Consensus \\
\hline \multirow[t]{5}{*}{ Globalization } & & Round II & Round III & Agreement \\
\hline & Mean & 2.36 & 2.09 & $31.8 \%=1$ \\
\hline & Range & $1-5$ & $1-5$ & $36.4 \%=2$ \\
\hline & Median & 2 & 2 & $\therefore 68.2 \%=1,2$ \\
\hline & Mode & 2 & 2 & No Consensus \\
\hline \multirow{5}{*}{$\begin{array}{l}\text { Online classes (e.g. keeping more } \\
\text { students off of campus, changing } \\
\text { primacy of a residential college) }\end{array}$} & & Round II & Round III & Agreement \\
\hline & Mean & 2.59 & 2.82 & $0.0 \%=1$ \\
\hline & Range & $1-6$ & $2-7$ & $40.9 \%=2$ \\
\hline & Median & 2.5 & 3 & $\therefore 40.9 \%=1,2$ \\
\hline & Mode & 3 & 3 & No Consensus \\
\hline
\end{tabular}




\section{Summary}

This chapter presented the results of this Delphi study, designed to understand and forecast the changing role of the student union in the modern era. Five themes were addressed in the chapter: the purpose and mission of student unions; the services, programs and amenities that they offer; physical and human attributes of student unions that contribute to their success; and the physical, knowledge, financial and political constraints that can create barriers to union effectiveness. Influences that will shape the student union of the future were also addressed. For each of these themes, the chapter reviewed both the formative findings from Round I and the summative findings from Round III, focusing on presenting the expert consensus generated by the study. The full results, including those items that failed to achieve consensus, are provided in Appendix P. The following chapter will discuss these findings as they answer the research questions posed at the study's outset, draw conclusions from previous research and literature about student unions, and offer recommendations associated with this study. 


\section{CHAPTER V \\ DISCUSSION, CONCLUSIONS, AND RECOMMENDATIONS}

\section{Introduction}

The purpose of this study was to understand and forecast the changing role of the student union in the modern era as an approach towards addressing the problems of student recruitment, retention and success. The Delphi methodology was used to collect and explore the knowledge and insights from 22 experts in student union management as they relate to the following research questions:

1. What are the most important purposes served by college and university student unions?

2. What amenities and services should exist in the student union based on these purposes?

3. What are the barriers faced by student unions in meeting these purposes?

4. What are the most important influences that will shape the college and university student union in the future?

This chapter will review the key results presented in Chapter IV and explore the findings as they align with the research questions and relate to the literature about student unions presented in Chapter II. The implications of the findings for theory, practice and future research will be addressed. 


\section{Applying the Results to Address the Research Questions}

The following section uses the findings to address the study's research questions.

\section{RQ1: Purposes Served by College and University Student Unions}

The first research question investigated what were the most important purposes served by college and university student unions. In the summative analysis following Round I, this question expanded to encompass the purposes, missions and populations served.

Purposes. The student union historically has served multiple purposes (Berry, 1989), and the concept of a student union has evolved over centuries. Expert panelists in this study identified "building, creating or fostering community" as the most important purpose served by the union today. This resonates with the views of the Association of College Unions-International (ACUI), which also identified the role of the student union as "fostering a sense of community and envisioning the union as the community center of the college" (ACUI, n.d.). Arguably, this has been the main purpose of student unions since their inception. However, the meaning of community has evolved, as have the strategies used to achieve it and the mosaic of the populations served. Subsequent questions in the study explored those aspects.

The results also identified three additional purposes of the student union: (a) supporting student success, and serving as the (b) "welcome center" or (c) "living room". These also trace their origins back to preceding eras in student union evolution. The Club Stage (Humphreys, 1946) at the turn of the $20^{\text {th }}$ century, for example, may be said to be the origins of conceptualizing the student union as a living room of sorts. Even today, lounges, billiards and writing rooms (which are today's study spaces) bear the vestiges of 
the earlier exclusive clubs that were frequented by privileged university students. Similarly, the origins of the union's designation as a welcome center may stem from the Democracy Stage and Educational Stage (Humphreys, 1946). At that time, student populations expanded, and colleges began seriously exploring their role in fostering education and the union's role in "contributing a supplementary form of education outside the classroom" (Stevens, 169, p.18). These purposes were subsequently deepened in the Personalization and Humanization Stages (Stevens, 1969).

Missions. Student unions engage in an array of missions in order to fulfill these central purposes. The expert panelists identified six important missions through the Delphi process. These included offering an array of the following: (a) food services, (b) informal spaces for lounging, studying, and socializing, (c) formal spaces for meetings and events, (d) supporting co-curricular student development and learning, (e) student employment, and (f) supporting retention. Each relates to the purposes for student unions identified in the study.

As scholars have noted, campus building design should create spaces that encourage students to be engaged and involved (Astin, 1984; Evans, Forney et al., 1998; Schein, 2010). Offering an array of spaces - plus the availability of dining options to enjoy - create an important context for human interaction and integration that Tinto (2006) identified as vital for student retention.

"Students learn by becoming involved" (Astin, 1985, p. 133). Accordingly, the union's missions in co-curricular student development, learning, and employment foster involvement. Panelists mirrored ACUI's views that the college union is an "integral part 
of the educational mission of the college" that should complement the academic experience through programming (ACUI, n.d.).

Populations served. Understanding the populations served by the union is foundational towards articulating the human aggregate component (Strange \& Banning, 2001) of the union. Panelists agreed that the union serves many distinct categories of students. Among those, residential students and traditional age undergraduates clearly emerged as the top two. Both likely spend most of their time on campus, particularly if they live there, and thus are typically away from the comforts of their homes and all the amenities that home provides. Historically, these are the populations most served by the student union.

However, student populations are constantly changing. The findings acknowledged the importance of commuter and evening students, non-traditional age undergraduates, and graduate students. Recent student union discourse has focused upon the needs of millennial students (Rickes, 2009). However, student union professionals are being challenged to learn more about growing student populations that differ from their historic base. The union needs to understand their needs, and strategize how to create a greater "degree of congruency, or fit, between student characteristics and the [union's] ability...to respond to those characteristics" (Banning \& Banning, 1986, p.1). For example, as one panelist aptly noted, "the needs and lifestyles of commuter and evening students are very different than residential students."

Meeting the needs of the populations served by the union also entails serving nonstudent populations. Panelists named four such groups: prospective students, campus staff and faculty, visitors to the campus, and alumni. While student populations should remain 
the highest priority, non-student populations contribute to the overall concept of campus community. Recognizing, understanding and serving those differences speaks to the heart of the human aggregate component of campus environments, as defined by Strange and Banning (2001).

\section{RQ2: Amenities and Services that Should Exist in Student Unions}

The second research question sought to identify which amenities and services should exist in the union based upon the primary purposes identified by the Delphi panel. Clearly, amenities matter. Students choose to enroll in or reject colleges based on the presence of, or a lack of amenities they need and desire (Reynolds \& Cain, 2006). Yet it can be very difficult for student union professionals to identify what amenities and services should exist within the union due to the variety of individuals they serve daily.

Services. Participants in this study identified and agreed upon four very important services that should be located within the student union. These are the: (a) student activities office, (b) student government office, (c) student programming board, and (c) student organization office. These responses resonated with the importance of the organizational component (Strange \& Banning, 2001) of the campus environment, which is defined as having the appropriate structures that embody and facilitate an organization's purposes and goals. Clearly, these four core student-centric offices manifest the union's purposes of fostering community and student success, and its related missions of supporting co-curricular student development, retention and employment.

However, the union also serves other populations in the larger community mosaic. Reflecting this, several of the most important services identified in the study are those that benefit everyone such as a: (a) staffed information desk, (b) room reservations office, 
(c) event/conference planning services, and (d) production/audio-visual services. All of these services provide assistance and support that make community events and programming possible, and flexibly responds to a variety of purposes.

Programming and roles. The investigation of services and amenities expanded to include an exploration of programming and the union's role within it. Participants reached the highest consensus that the two most important types of programming were: student organized programming and active co-curricular programming; followed by items such as passive programming, leadership and service opportunities for students' and an array of social, cultural and multicultural offerings that potentially benefit all populations served by the union. Panelists agreed that it was important for the union to take multiple types of roles in these endeavors, including: (a) serving as a partner to other groups that wish to design and offer programming; (b) providing a venue or place for holding programing; and (c) serving as a provider that designs and offers its own programs. The role of the student union staff is thus very much active in nature (not passive).

Spaces. Price, Matzdorf and Smith (2001) demonstrated that quality spaces on campus have a strong impact upon student recruitment and retention, which they "clearly and unambiguously confirmed" in a follow up study (Price, Matzdorf, Smiith \& Agahi, 2003, p. 220). In this study, participants identified seven types of spaces that should be a part of the union in order to create a place for its mission-related services and programming to occur. The four identified as most important comprised both large-scale informal and formal gathering spaces such as lounges, performance halls, ballrooms, banquet and multi-purpose rooms; as well as small-scale informal and formal spaces, including classrooms, meeting rooms, and nooks. Panelists further agreed it was 
important for the union to have open spaces, outdoor spaces, and quiet areas, all of which create what Oldenburg (2001) termed, "third spaces," places outside of one's home and work, where people can go to relax.

Amenities. Panelists considered 34 different amenities offered in student unions, and reached consensus on nine that they deemed important. Overwhelmingly, the strongest consensus favored wireless internet service. This was unsurprising, given today's students' reliance on technology and the necessity for them to be connected wherever they are (Strange \& Banning, 2001). The remaining amenities identified by participants as being important included: conveniences such as an ATM machine, convenience store, and phone and device charging stations; places to eat such as a food court and coffee shop; lounge spaces with televisions for students to relax and hang out; catering services to support events and meetings; and art dispersed throughout the building to create a pleasing and cultured atmosphere. This list of varied amenities supports Strange \& Banning's human aggregate component (2001) of campus environments, demonstrating that student unions must serve a myriad of needs that may differ according to distinct populations.

\section{Attributes that Enhance Student Unions}

Although this study did not intend to address the research question, "what attributes of student unions influence their effectiveness in meeting their purposes?" it should have. The importance of the physical and human attributes of student unions emerged in Round I as being deeply interconnected to all four of the research questions. Just as RQ 3 asks what barriers impede union effectiveness, this unasked - yet answered - question revealed what attributes can improve its effectiveness. The attributes emerging 
from the study may be categorized as (a) the location of unions on campus, (b) union building exteriors, (c) union interiors, and (d) human attributes such as union staff and community members' interactions with the union. Each is discussed below.

Location. The student union is often called the "heart" or "hearthstone" of the campus, implying a physical centrality. The union cannot function as the heart, however, if it is located on the periphery, inconvenient to daily campus traffic. Panelists named four essential attributes of student union locations: (a) being located in a high-traffic area or at the pedestrian crossroads of the campus; (b) being close to the physical center of the campus; (c) the proximity of parking; and (d) being located close to residence halls. Understandably, it may be impossible to meet each of these attributes - unless the campus has space to build right next to a parking lot and residential complex in the center of its academic quadrangle. Nevertheless, traditionally the student union has been centrally located on campus or at least close to the physical center of campus. More important than being in the exact center, however, is being in the path of the campus community's daily foot traffic. A location that students must pass daily to get from one place to another creates an opportunity for students to engage with the union (Strange \& Banning, 2001).

Building exteriors. Greenberg (2007) noted that campus facilities constitute the institution's self-image. Accordingly, attributes of the exteriors and interiors of campus union buildings communicate strong identity messages. The study identified six important attributes of building exteriors. These included simple things, such as the cleanliness and maintenance of the building exterior, a clearly defined entrance and clear signage, all of which contribute to a positive physical component of the campus 
environment (Evans \& McCoy, 1998). The lack of such things signals to students and the community that the institution is in poor financial health (McPherson, Shapiro, \& Winston, 1993).

Similarly, attractive landscaping and an attractive exterior building design matter. What students see when they first arrive or visit campus is a critical first impression. Student union professionals and other campus administrators should recognize that first impressions may be the catalyst for students' decisions to enroll or go elsewhere for college (Tinto, 1993; 2006). Old, outdated buildings in need of repair can also have an impact on students' persistence, (Tinto, 1993), if they instill a desire to transfer or leave college.

Building interiors. A testament to the importance of student union interiors, the experts on the panel reached consensus on 22 different attributes of building interiors that they deemed important. Many of these were very similar to those noted as important for building exteriors, such as attractiveness, cleanliness, and maintenance. The highest ranked attribute was the need for adequate and appropriate technological capability and infrastructure. As previously stated, students today are tech savvy and they want to make sure that whatever building they are in allows them the opportunity to connect wirelessly to a variety of sites for a variety of reasons. The need for an adequate technological infrastructure is important, as bandwidth and speed continue to be maxed out on college campuses. Student union professionals face the challenge of balancing how fast the students want to get on sites with an infrastructure that, in some cases, cannot support such speed. This challenge will likely increase, as people bring more devices to campus that have more powerful applications and consume greater speed and bandwidth. 
The need for adequate and appropriate space for the functions housed within the union, the physical condition of the building's interior, its attractiveness, and ADA accessibility were also in the top five ranked attributes; as was sociopetal seating styles that encourage interaction. Making sure the interior is ADA accessible/compliant remains an issue on many campuses. Although it is a federal law, older facilities have been "grandfathered" in and have not been required to have accessible or barrier free spaces until they renovate or build new construction. This study supports the need for barrierfree spaces as an important attribute in student unions (Kuh, Kinzie, Schuh \& Whitt, 2005).

Other important attributes of student union interiors related to infrastructure, design, and furnishings. Desirable infrastructure elements included cleanliness, clear signage, adequate lighting, noise-proofing and flexible design. Comfortable, modern and modular furnishings were rated highly. Interior designs that are engaging, open and fun were highly favored, as were "sticky spaces" and focal points that draw people in and encourage them to linger. Natural lighting, conveniently clustered offices and services, and good flow of traffic between them were all rated as important or highly important. Pleasing physical attributes of the building such as these create the context for positive experiences and interactions with the union, making it a desirable place.

Human attributes. The extent to which the union meets the goals, needs and preferences of the population it serves, form the foundation of the human aggregate component (Strange \& Banning, 2001) of unions. Human attributes of the union capture students' attention and influence their behavior. Participants identified 29 different human attributes that they deemed important for student unions. 
Having the right staff in the union is vital. Panelists fully agreed that it is very important to have staff that: (a) are student focused/committed, and (b) includes student employees. They further agreed that it is important that staff (c) are knowledgeable and well-trained, (d) friendly, (e) adequate in number, and (f) diverse. Having the right staff can shape the way students experience their interactions with the union.

In terms of human interactions with the union, panelists indicated the importance for the union to feel welcoming and inviting, and convey to students that they matter. "Mattering" is subjective and some students will feel as if staff care and others may think staff do not care. Regardless, this research supports, as does Reynolds \& Cain, (2006), that students should come first and decisions should be made with them in mind.

Lastly, the union should feel safe both physically and psychologically. Students subjectively construct the campus environments through their perceptions (Strange \& Banning, 2001). It should be a place where they want to be and belong.

\section{RQ3: Barriers Faced by Student Unions}

The third research question asked what barriers student union's face in meeting their purposes. Participants identified the importance of four different types of constraints that can influence student union effectiveness. They were: (a) physical constraints, (b) knowledge constraints, (c) financial constraints, and (d) political constraints. Results based on each of these areas are listed below.

Physical constraints. The appearance of campus facilities during campus tours is the most influential element for prospective students (Boyer, 1987) and communicates messages to students based upon their first impressions (Kuh, Kinzie, Schuh, \& Whitt, 2005; Strange, 2003; Strange \& Banning, 2001). The physical component of the campus 
environment (Strange \& Banning, 2001) “influence[s] students' feelings of well-being, belonging and identity (Kuh, Kinzie, Schuh, \& Whitt, 2005). Therefore, problems with the physical component of the campus environment can adversely impact the union's effectiveness in meeting its purposes.

The number one ranked physical constraint identified by participants was having a neglected, poorly maintained, run-down or worn out building. Other important physical constraints included infrastructure issues such as aging or poor mechanical systems such as HVAC, plumbing, or wiring, and health and safety concerns such as asbestos and lead. A lack of ADA compliance and accessibility, also named as a constraint, violates the law and undermines the student union purpose. As noted previously, the student union's purpose is to foster community. Therefore, it needs to be accessible for all students, regardless of physical limitation or disability (Kuh, Kinzie, Schuh, \& Whitt, 2005).

Finally, issues such as the size of the student union, the comprehensiveness of the services and amenities included, the location and design of the building can each be a barrier to its effectiveness. The union must be able to accommodate all the needed functions. It also must be an adequate size to serve the level of usage so it is not crowded. On many campuses, the academic enterprise and student enrollments have expanded beyond the size intended to be served by unions that were built in past decades. Locations that were once central or convenient have become displaced as campuses have grown, and campus foot traffic patterns may no longer routinely and conveniently bring campus community members within passing of the union. While physical components such as the size and location of the building are permanent attributes that cannot be 
changed without expensive new construction, other components such as maintenance, infrastructure and design issues may be addressed.

Flexibility in physical design and infrastructure is critical as the student body continues to fluctuate (Temple \& Barnett, 2007). The student union needs to be able to adapt to the changing purposes and varying usage by a variety of constituents. At some point, infrastructure updates to student unions will need to be made. Knowing this, campus leaders and student union directors should plan ahead for inevitable repair or replacement, as systems become outdated or worn out.

Knowledge constraints. Participants ranked the following items at the top of their list of knowledge constraints: (a) identifying current and future student needs for the union, (b) assessing the unions effectiveness or satisfaction with meeting those needs, and (c) having input from the various populations served by the union. They also named (d) management issues that are tied to an insufficient understanding of the whole enterprise of the union and (e) an overall feeling that the student union is losing its focus on students.

While those five were the most critical, nine other knowledge constraints were agreed-upon. Three of these related to staff. Specifically, union leaders have difficulty in recruiting and retaining a student-focused union staff. Staff who have insufficient knowledge or awareness of their role in student development as educators, or insufficient knowledge about student learning outcomes and assessments also impede the union's effectiveness. In the preceding section on human attributes of student unions, panelists identified various traits of student union staff as among their most important assets. 
Having a strong student-focused staff that creates positive interactions with students may compensate for having a lackluster facility.

Campus leaders further exacerbate problems when they lack an understanding or appreciation of student development and the union's role within that. This includes management who view the union with a facilities paradigm (focusing only on the building) rather than a student development paradigm (focusing on the important purposes and mission that happen within the building); and outsourced service providers who do not understand or value the importance of student employment as a developmental process. Yet despite this lack of understanding - or perhaps because of it - the need for the union to measure and prove its contribution to the educational and cocurricular process is paramount.

Identifying student needs and assessing student satisfaction relate back to the human aggregate and constructed components of the union, which Strange \& Banning (2001) identify as vital. Yet conducting such assessment can be difficult due to the variety of users and their unique needs. It can also be difficult if union staff do not know how to effectively conduct assessments that will provide useful or meaningful information. Therefore, this study's findings would support the need to better train all union staff in the area of assessment.

In hindsight, the importance of the union focusing on students appears obvious. However, many student unions across the country serve not only students; they provide a venue for the local and regional community. Spaces are used for weddings, graduations, and other sources of entertainment. In some communities, they provide the largest available venue. Balancing the current student need with the need of the surrounding 
community is challenging especially when tied to the tension between students' "free use of space" versus the public's "paid use for space."

Financial constraints. The study identified 18 different potential financial constraints that face student unions, categorized according to expenses, revenues, and the general auxiliary budget model. Participant responses indicated that unions face increased expenses for their basic union operations, such as utilities, supplies, and equipment; technology; staffing; general maintenance; and basic refurbishments and upgrades. Capital expenses for union construction, renovation and expansion were also rated important. Concerning revenues, participant consensus indicated that insufficient budget allocations and insufficient student fees are an important problem, as well as the overreliance of student fees generally, and the need to increase revenues from the use of union services. In part, these problems appear to relate to constraints imposed by the auxiliary budget model that requires unions to be self-supporting and, on some campuses, also to make and contribute excess revenues back to the institution. These aspects of the budget model, along with its general ineffectiveness, unpredictability and inadequacy, were ranked as important constraints.

Higher education is already under pressure to keep costs low. It is difficult to do so if students continue to want updated or new facilities and amenities. Some union professionals choose to increase student fees to cover the cost of newly constructed, renovated or expanded buildings. However, the costs for renovating student unions included in student fees is now being challenged by local and state leaders as placing an undue financial burden on students who are already debt ridden with the total cost of their 
education (Zumeta, 2005). Even if students agree to support the expenses and pay for them through their fees, it still remains a burden placed on students.

Many student union staffs are also being asked to do more with less. Positions are lost through attrition, as vacant positions remain vacant while the workload is redistributed among those still on the payroll. Inadequate funding for personnel challenges student unions to continue provide needed services to students while requiring a reduction in service hours. Unfortunately, this study's findings suggest that this constraint will only continue. The need for the student union to do more with less (money, staff, and students) will continue to be the norm. Overall, financial constraints will continue to be a barrier to improving campus facilities (Chism, 2006).

Political constraints. The experts in this study identified four political constraints that can impede student union effectiveness. These were: (a) a lack of respect for / autonomy of student union, (b) union directors' lack of influence in the institutional decision-making process, (c) campus policies and politics that have a prohibitive influence on union operations and innovation; and (d) how the student union is prioritized in the institutional budget process.

A lack of student union autonomy leads the union to being used for hodgepodge purposes such as storage or administrative offices, and not its intended purpose. Taken too far, this could inadvertently lead to one of the above mentioned knowledge constraints: a union that loses its focus on the student. Participants in this study likely understood how important it is for student union professionals to have some organizational political clout within the campus administration so they can influence change when necessary. Unfortunately, not all professionals have this clout. Although 
their knowledge and perspective could be valuable to planning, budgeting and other institutional leadership decisions, some are not invited to the table to discuss their priorities. This research would suggest that it is imperative for student union staff to know how to strategically play the game of organizational politics in order to influence student union effectiveness.

\section{RQ 4: Influences on the Student Union of the Future}

The final research question asked what are the most important influences that will shape the college and university union of the future. Eight sustaining forces will continue to drive a need for a student union on campus: (a) the basic human/student need to connect and belong to the campus community, (b), the importance of providing a human, high-touch location on campus, as humans continue to connect via technology, (c) the continued need for students to have a "living room" and a place to feel at home, (d) the continued need for co-curricular building of student skills such as leadership, communication, and responsibility, (e) the importance of union services and amenities to the campus community, (f) a continued need for a "welcome center" on campus, and (g) the institutional commitment to the union concept and the importance of student development in the institution's mission and strategic plan.

Every campus community includes multiple constituents. Students want to feel like they belong, and the opportunity for students to join various clubs and organizations located within the student union often provides this sense of community, as does just hanging out and enjoying the union as a living room. Opportunities for students to learn more about their own leadership or communication style can also be provided through various educational programs or even through student employment in the union. 
In addition to sustaining forces that will support a continued need for student unions, participants noted six forces of change that will influence or shape the union's future. As student populations expand and change over time, their needs will expand and change as well. This has been evidenced throughout the history of student unions, and will continue long into the future. This creates an impetus for unions to continually find new ways to engage students and create a sense of community, as they compete for students' attention and time. Larger societal trends, such as the sustainability movement, and the explosive and rapid growth of technology and technology-mediated human interactions will certainly have an impact, although the end result of that cannot be foretold.

\section{Intersections with Campus Environment Theory}

This study was informed by the work of Strange \& Banning (2001), and their research on how elements of campus environments influence college students. Their work is an outgrowth of studies on environmental psychology, and part of the growing field of campus ecology and campus design. The four-component framework of the campus environment - physical, human, organizational, and constructed (psychological) guided the data analysis of the Round I results and informed the analysis of the Round III results. This section pulls together the findings of this study according to the four components.

Physical component. The condition, design, and layout of a campus constitute the physical component of the campus environment. As applied to this study of student unions, the most immediate application of this framework is the fact that the student 
union is a place. On many campuses it is a distinct building or set of buildings. On other campuses, it may be an area within a building.

Among the four core purposes of the student union (RQ1), included being the "welcome center" and a "living room" for the campus, and its mission includes providing a variety of formal and informal, large and small spaces for ten primary populations. Chief among these are traditional age and residential undergraduates, but other important populations include commuter, evening, non-traditional and graduate students, as well as prospective students, staff and faculty, and alumni. Among the services and amenities provided in the union (RQ2) the study identified the union as a provider of a venue or place for programming to occur; and identified a specific list of types of space that should be in the union for those purposes. Furthermore, the study yielded lists of 32 key physical attributes that are desirable for student unions, including elements related to the building location, the interior and the exterior. Each of these reflected aspects of a good physical component of campus environments that foster a sense of belonging, comfort and safety, as recommended by Strange and Banning (2001). Conversely, the study also yielded barriers to union effectiveness, (RQ4). Ranking highly among them were neglected, poorly maintained building, problems with the building infrastructure, and the inadequacies with the building's design.

Human aggregate component. Translated for the purpose of this study, the human aggregate component comprises the characteristics of the people who inhabit the union. This study identified ten important populations served by the union. The human aggregate component includes each of these, plus the people who work in the union. 
The human component looks for the degree of congruency between people's goals, needs and individual traits and the ability of the union to respond. Findings in all research questions pointed to an overarching focus of the union in understanding and meeting the needs of those whom it serves. For example, "supporting student success" is a core purpose of the student union (RQ1), and "supporting student development and learning" is a critical mission. Exemplifying this, RQ2 identified over 30 amenities and a wide range of co-curricular, social and multicultural programming and events the union offerings as an approach towards fulfilling its mission and purpose.

A lack of focus on the human aggregate component is a major barrier for student unions. Specifically, when unions lose their focus on students, when they do not make efforts to understand their students' needs and assess how well they serve them, when the people involved - staff, union management, campus leaders, outsourced providers - fail to understand or care about their role in serving students; then the effectiveness of the union suffers. Having staff who are committed to including students is vital for union success.

The human aggregate component was also evident among the influences on the future of student unions (RQ4). Specifically, the value of services and amenities that the union provides to the campus community will sustain the student union of the future. While at the same time, changes in student populations will bring new individual goals, needs and traits to the doorstep of the student union. As it has for over a century, the union will adapt and find new ways of fostering good person-environment fit.

Organizational component. The organizational component refers to structures that embody and facilitate the purposes and goals of the institution. Although it did not 
manifest specifically in the purpose or mission of the union (RQ1), the organizational component was evident in the services provided within the union (RQ2). The study identified an array of offices within the union to help students navigate college (and life) and achieve success, such as student activities, student government, student programming, and student organizations. These structures embody and facilitate a purpose of the student union: supporting student success.

Among the barriers to student union effectiveness, two - financial and political constraints - stem directly from the organizational component of the campus. Conversely, another organizational component - the institutional commitment to the union concept and student development, embodied in organizational missions and strategic plans - will help sustain the future of the union.

Constructed component. The last of the four components of campus environments refers to how people psychologically construct their impressions of the student union and how their expectations are shaped. The constructed component is influenced heavily by both the physical and human aggregate components, and implied by their findings. For example, one of the most significant things about the union is how it makes students feel. In that regard, the study identified "building or fostering community" as the most important purpose of student unions (RQ1), and aiding student retention as an important mission. "Making students feel that they matter," and "making them feel safe psychologically and physically," stood out amid the many important attributes of student unions catalogued as part of RQ2.

Nearly everything the union does shapes students' constructed component of the college environment. The human need to connect and belong to the campus will sustain 
the student union of the future (RQ5). So too will the continued need for students to have a "living room" and feel "at home." The continued need for a "welcome center" makes a first impression to students, alumni and visitors, conveys the campus identity story, and instills loyalty - all psychologically constructed impressions of the environment.

\section{Implications and Recommendations}

The findings of this study have implications for literature and theory and considerations for practice. These, along with suggestions for future research, are offered below.

\section{Contributions to Literature and Theory}

This study makes three contributions to the research literature and theory. First, it makes an important contribution to the literature on college student unions and campus facilities. While there are several large studies of college facilities, there are few published studies specifically about college unions. The extant research focuses on the history of college unions broadly, or histories and case studies of unions on specific campuses. This study addressed that knowledge gap. The findings demonstrate the purposes and populations college unions serve, what matters in helping them fulfil those purposes and what barriers impede their effectiveness. The findings point to an array of influences that will sustain the role of campus unions well into the future, and also influences that will change the nature of what they do. This new literature will be of interest to anyone seeking to better understand college student unions specifically, or the importance of college and university facilities broadly.

Second, the study supports established theory in two ways. First, it supports the literature on environmental psychology and campus ecology. Specifically, it supports 
Strange \& Banning's work on the campus environment and its importance for effective person-environment interactions (2001) by demonstrating the theory's high applicability for studying student unions and, by extension, any individual building on campus. The study illuminated the importance of the physical, human, organizational, and psychologically constructed components of student unions have, as applied to the goals of fostering community and supporting student success.

Third, the study extends the literature on the history of college student unions by offering two more stages in student union development. Humphreys (1949) seminal work on the history of unions and stage theories of their development provided a foundation, but ended at the year of its publication in 1949. Stevens (1969) picked up the baton and carried it forward, examining twenty more years of student union history and conceptualizing new stages in its development. The final stage named in his book, which he identified as beginning just a few years before the book's publication, extend out for approximately a decade, although he put no specific ending on it. There is a gap in the literature on student union development from between when Stevens' last stage ended, approximately in 1979, and the present. In Chapter II, this gap was termed "the unnamed present."

This study offered valuable insights into the current developmental stage of student unions. The aforementioned works demonstrated how the student union changes its purposes and strategies to meet the changing needs presented by the new populations enrolling in college. During the period Stevens described, higher education was enjoying a steady increase in enrollments triggered by first the GI Bill and later the Baby Boom. Starting in the 1980s, however, enrollments began to decline. At the same time, state 
appropriations to higher education have steadily dwindled since about 1980 (State Higher Education Executive Officers, 2014). As a result, the field of enrollment management has boomed as colleges and universities increasingly compete for students. The literature review in Chapter II demonstrated the strong influence campus facilities have in students' enrollment and retention decisions. The student union - and the amenities and services it offers - is an asset in enrollment management.

To meet student needs, unions are providing an astonishing array of amenities, services, and programs well beyond those that were the focus of Chapter IV. This study found that having wireless internet service, phone / device charging stations, ATM machines, convenience stores, coffee shops and food courts were among some of the important amenities of unions, and fast service, affordable pricing, and late and weekend hours for services were important attributes of the union. These items - and others like them - address students' consumer needs.

The use of and demand for technology was the most common theme throughout this study. This echoes the patterns in the Personalization Stage (1957-1966) (Stevens, 1969). During that time, mass education was growing, and advances in technology led to more computerization and less face to face contact. We are experiencing the same dilemma, even though fifty plus years have passed. We now live in such a technologically advanced world that students would not know what to do if they did not have a cell phone, access to Internet on demand, or the ability to connect wirelessly to any number of websites and pages where information is provided. Also, because of this reliance on technology, some students may never learn to engage or communicate face to face in meaningful conversations. This is one area that differs from the original purpose 
of the first student union, which was that of gathering together and having debates (Berry, 1989; Parkinson, 2009; Towns, 2005).

Students in the modern era are juggling multiple responsibilities. Many attend school, have to work, and are involved in student organizations. Time is tight and there are only so many hours in the day. Having more services and conveniences available to them that will make their life easier are the hallmarks of the present age in student union development. Therefore, I suggest that present stage, unnamed until this point, now be identified as the Consumerism Stage (2000-2014).

Student unions will undoubtedly be a feature on college campuses for generations to come. However, as this study found, unions will need to keep pace with changing student populations and student technologies. They will need to find new ways to create community, which includes finding new ways to engage students and compete for their time and attention. However, populations who use the union are not comprised of just residential and traditional aged students. Commuter, evening and non-traditional students are growing populations on our campuses, and student union staff will need to determine how to serve these students who typically are on campus for only short periods of time. This means that student unions will need to continually reinvent themselves to meet the challenges and changes ahead. Exciting times await! The student union will need to be innovative, flexible, and adaptable in order to be effective. This is particularly, true, given both the physical and financial constraints that will likely continue to be concerns in the future. Subsequently, I suggest the next stage of student union development, unknown and also unnamed until this point, now be identified as the Innovation Stage (2015-??). 


\section{Considerations for Practice}

The findings in this study hold several implications for practice. First, the most important implication for practice concerns what purposes and populations the union serves. The findings demonstrate clearly that building, fostering or creating community and supporting student success are the highest purposes of the union, along with being a welcome center and living room for the campus. Students, overwhelmingly, are the primary population served, but this includes a number of distinctly different types of student populations. Non-student populations are also served by the union. Every single decision concerning the union should be evaluated against this knowledge. Questions such as, "Does this foster community?" and "How can this support student success?" should be routine phrases heard in everyday student union management and decisionmaking. Yet the findings also indicated that one barrier to student union effectiveness is an absence of assessment data that identifies student needs and gauges their satisfaction with the union, and data that evaluates and validates the union's contribution to the educational and co-curricular processes. Other critical barriers suggest that some unions have lost their focus on students; and some deal with staff, management, outsourced services, and campus leaders who lack an understanding of the union's purpose or do not understand their roles in student development as educators.

Campus administrators should find this information sobering, yet beneficial. It can be used to inform hiring and training decisions, to ensure that student union staff understand and can perform their roles as student development professionals. It can be used to inform contracting decisions with vendors of outsourced services, to ensure that the campus contracts only with those companies who are committed to a student 
development ethos. Student union directors can partner with university assessment offices to develop a means to collect and analyze data about union operations, the results of which can be used to inform management and planning.

Second, the findings from this study represent the consensus of expert opinion regarding what amenities, services and programs should exist in student unions, and the attributes that help a union successfully fulfill its purposes and missions. The findings from this study can be used to improve student union environments and student union planning, thus fostering good campus-student fit, and indirectly contributing towards recruitment and retention.

\section{Suggestions for Future Research}

The results of this study were informative regarding the changing role of college and university student unions. However, more research is warranted. Three suggestions for future research are offered below.

First, this study should be repeated examining the same basic research questions and using the same methods, but conducted as a series of studies that focus on specific institutional types. This study included both public and private four-year institutions in an array of levels of comprehensiveness and geographic locations. On some questionnaire items, consensus was not reached, which may reflect different response patterns according to institutional type. Replicating this study different times but each time involving participants only from the same institutional type could either confirm the findings and increase generalizability, or offer insight about the commonalities and differences of student unions on different types of campuses. The enrollment profiles of campuses should be included as a sampling criterion. 
Second, the study should be repeated examining the same basic research questions, but with different of populations of student union stakeholders as the participants. This should include, at a minimum, distinctly different categories of student populations identified in this study, such as residential / commuter; full-time / part-time; undergraduate / non-traditional undergraduate / and graduate. It should also include nonstudent populations served by the union, such as faculty and staff and alumni. As this study determined, student union leaders lack basic information from key populations including students - about what the union means to them and what services, amenities and attributes they want most in a union. The study also found that student union leaders lack basic "customer satisfaction" assessment information from the populations that use the union. This type of study could be conducted in-depth at participating campuses. The results would offer a direct benefit to participating campus, which can use the results to make management decisions. In conducting such a study, campuses would convey the message that students matter, and should have a say in what goes on in the student union and what services are provided.

Third, the same basic questions should be studied, but through a different means. Repeating the study with a different methodology focused on qualitative data, such as campus visits and observation of student unions, plus interviews and focus groups with a variety of campus individuals to gather institution specific information, would offer rich, thick data. Students, both residential and non-residential should be a part of the study.

Beyond the research suggestions made thus far which primarily extend the contributions of this study, the findings lend credence to new questions and avenues for research. For example, how will "community" be defined by college student unions as 
technological innovations impact students' interactions on a college campus? Does community necessitate the physical presence of students as we live in a world where a "virtual presence" is becoming more common? What role will globalization have on the various facilities and programs that take place in the student union? Student populations on college campus will continue to evolve and develop on our college campus, so how does the union keep up with this global change? What are the implications for staff using a facilities management model versus a student development model? How can student union staff continue to provide opportunities for student development while being challenged to financially supplement their own future success?

Finally, a special note should be made regarding the use of the online survey administration service, SurveyMonkey, for collecting the research data. The use of SurveyMonkey or another type of electronic database saved expenses and time. The survey software streamlined survey administration, allowing for the pre-loading and scheduled electronic delivery of invitations to participate, follow up messages to encourage completion, and thank you notes for participating. The program also has capacity to support data analyses of certain types. This process was much quicker than mailed surveys, or sending individual personalized emails to participants especially when time was of the essence.

\section{Conclusion}

This study explored the changing role of the student union, using the Delphi method to survey 22 student union experts and reach consensus about the purposes, missions and populations that student unions serve, and the amenities, services and 
programs through which they meet those purposes. It further explored what hinders student union effectiveness.

The analytical framework for the study relied on the work Strange and Banning (2001), whose four components of campus environments were used to analyze and understand what matters most in student unions. The study found evidence that the physical, human aggregate, organizational, and constructed components are each a part of all that the student union does. The physical and human aggregate components appeared to matter most, and influenced the other components.

The findings of the study thus support the literature in environmental psychology and campus ecology They also contribute to the literature on student unions, providing a needed addition to the scant literature on college unions, and suggesting an extension of the stages of union development to include the Consumerism Stage (1980-2014), and the Innovative Stage (2015 --?).

Higher education leaders, administrators, scholars and students comprise the primary audiences for this study. The findings will be of interest to them, as well as all those who are concerned with campus facilities and student recruitment, retention and success. With that in mind, this study concludes with remarks addressed to the key stakeholders of college and university student unions.

To academics and graduate students: The union is part of the total educational experience at college (Stevens, 1969). It can also serve as a partner and help complement the academic experience. Remember that the union provides a variety of services and amenities to the entire campus community, including you. 
To university facility planners and senior staff: Recognize the importance the student union holds for the entire campus, but especially for students. Make sure the union is being used for its intended purpose, and be strategic when deciding what services will be physically located in the union.

The student union is a valuable asset. First impressions matter! Also, the exterior is just as important as the interior and both need equal amounts of attention. Make building maintenance and periodic upgrades for the union a priority in campus budgets, and do not let the building get so worn down that repairs and renovations become unaffordable. Furthermore, long range-planning for union projects should be an integral part of the campus strategic plan. Make it a commitment to talk to the student union professional about specific needs for the student union when planning for the future. They are the best ones to know what is happening in their own building. Take their advice and information to heart.

If you are fortunate to have the chance to build a brand new facility, it will be important to make sure the union is centrally located within the campus landscape where students will need to pass on a regular basis, ideally in a location that is not likely to become peripheral over time.

To admissions and enrollment professionals: Colleges and universities will continue to compete for students, many of whom have multiple options to choose from when deciding where to attend college. Research has stated that campus facilities are important factors influencing not only recruitment but retention of students as well (Reynolds \& Cain, 2006; Tinto, 2006). Retention research also reinforces the importance of student involvement outside the classroom particularly during the first year (Tinto, 
2006). You can be an important partner in helping student union staff create the kind of environment students want and need. Communicate on a regular basis with union staff about what you see in the new student populations coming to the campus. Prospective and incoming student profiles will be valuable information for the student union, as well as any insights or information you can share concerning what students want from your particular campus.

Finally, to student union professionals: Continue putting students first, despite pressures or constraints that might detract from that.

Student employees are an important part of the student union. Many student unions have a history of providing students with employment opportunities. Ensure that this opportunity continues to exist.

Talk with students about what they want or need and conduct formal assessments. You will benefit from input provided. Undoubtedly, technology will be high on their list. Students want it, they demand it, and expect it. Be sure the student union has the infrastructure to support current and future technological advances.

With the influence of technology in our daily lives, however, human interactions are now occurring digitally or electronically. It is critical for the union to recognize this changing force, and identify ways to mediate its influence. Just as students constantly change, so should the student union. As such, it is my hope that the findings in this study will contribute to your valuable work, and inform your planning and practice.

And always remember that the important role of student unions involves building, creating or fostering community. 


\section{REFERENCES}

Amenities matter to some-but not all-prospective students. (2005, November). Recruitment and Retention in Higher Education, 19(11), 4-5.

American Association of State Colleges and Universities. (2014). Policy matters: A higher education policy brief. Washington, DC: Author.

Association of College Unions International. (n.d.1). Quickfacts. Retrieved from http://www.acui.org/membership/quick_facts.aspx?id=154

Association of College Unions International. (n.d.2). Role of the College Union. Retrieved from http://www.acui.org/content.aspx?menu_id=30\&id=296

Astin, A. W. (1968). The college environment. Washington, D.C.: American Council on Education.

Astin, A. W. (1985). Achieving educational excellence: A critical assessment of priorities and practices in higher education. San Francisco: Jossey-Bass.

Astin, A. W. (1993). Assessment for excellence: The philosophy and practice of assessment and evaluation in higher education. Phoenix, AZ: Oryx Press.

Bailey, W. R., Owens, H. F., \& Witten, C. H. (Eds.). (1982). College student personnel administration - An anthology. Springfield, IL: Charles C. Thomas.

Bailey, T., \& Morest, V. S. (Eds.). (2006). Defending the community college equity agenda. Baltimore: Johns Hopkins University Press.

Banning, C. S., \& Banning, J.H. (1986). Student-institution fit: Linking campus ecology to enrollment management. Campus Ecology, 4(4), 1-8.

Banning, J. H., \& Bartels, S. (1997). A taxonomy: Campus physical artifacts as communicators of campus multiculturalism. NASPA Journal, 35(1), 29-37.

Banning, J. H. \& Bryner, C. (2001). A Framework for organizing the scholarship of campus ecology. Journal of Student Affairs, 10, 9-20. Retrieved from: http://www.colostate.edu/Depts/SAHE/JOURNAL2/2001/Framework.htm 
Bechtel, R. B. (1997). Environment and behavior: An introduction. Thousand Oaks, CA: SAGE Publications.

Berry, C. A. (Ed.). (1964). College unions: Year fifty. Bloomington, IN: Association of College Unions.

Berry, C. A. (Ed.). (1989). College unions: Seventy-five years. Bloomington, IN: Association of College Unions.

Bolman, L. G., \& Deal, T. E. (2003). Reframing organizations: Artistry, choice, and leadership ( $3^{\text {rd }}$ ed.). San Francisco: Jossey-Bass.

Boren, D. (2008). The campus as hometown. Chronicle of Higher Education, 54(27), A34.

Boyer, E. (1987). College: The undergraduate experience in America. New York: Harper.

Boyer, E. (1990). Campus Life: In Search of Community: A Special Report of The Carnegie Foundation for the Advancement of Teaching. Princeton, NJ: Princeton University Press.

Butts, P., Beltramini, E., Bourassa, M., Connelly, P., Meyer, R., Mitchell, S., Smith, J., \& Willis, T. J. (Eds.). (2012). The College Union Idea (2 ${ }^{\text {nd }}$ ed.). Bloomington, IN: Association of College Unions International.

Cheng, D. (2006). In their own words: A focus group approach to understanding students' perceptions of campus community. Overseas Chinese Association for Institutional Research. Retrieved from http://www.ocair.org/files/presentations/paper2003_04/DavidCheng.pdf

Cohen, A. M. (1998). The shaping of American higher education: Emergence and growth of the contemporary system. San Francisco: Jossey-Bass.

Creswell, J. W. (2009). Research design: Qualitative, quantitative, and mixed methods approaches. Thousand Oaks, CA: SAGE Publications.

Dahlgren, M., Dougherty, K., \& Goodno, A. (2013). The role of physical space in establishing community. In D. M. Desawal and B. A. Jacobs (Eds.), 100 year perspective on the college union, (pp. 62-84). Bloomington: IN: Indiana University Student Personnel Journal.

Dalkey, N. \& Helmer, O. (1963). An experimental application of the Delphi method to the use of experts. Management Science 9(3), 458-467. 
Damon, D. L, Montefusco, T., Morairty, B., \& Hood, S. (2011). Trends in campus living. College Services (Fall 2011), 28-31. Retrieved from

http://www.nxtbook.com/nxtbooks/naylor/JILQ0311/index.php\#/32

David-Gaines, W. (2013, December 9). Town/gown corroboration benefits college and community. The Examiner. Retrieved from http://www.examiner.com/article/town-gown-corroboration-benefits-college-andcommunity

De Young, R. (2013). Environmental psychology overview. In S. R. Klein and A. H. Huffman (Eds.), Green Organizations: Driving Change with IO Psychology (pp. 17-33) New York: Routledge. Retrieved from http://www.personal.umich.edu/ rdeyoung/envtpsych.html

De Young, R. (1999). Environmental Psychology. Retrieved June 27, 2009 from http://www.personal.umich.edu/ rdeyoung/envtpsych.html

Dean, D. R., Hunt, E., \& Smith, R. (2006). Committing to keep Illinois students in state: Understanding college choice, student migration patterns, and retention strategies. Normal, IL: Center for the Study of Education Policy.

Deil-Amen, R., \& Rosenbaum, J. E. (2002). The unintended consequences of stigma-free remediation. Sociology of Education, 75, 249-268.

Deil-Amen R., \& Rosenbaum, J. E. (2003). The social prerequisites of success: Can college structure reduce the need for social know how? The ANNALS of the American Academy of Political and Social Science, 586(1), 120-143.

Edwards, S. (2001). The essential elements of multi-family group therapy: A Delphi study. Unpublished doctoral dissertation, Virginia Polytechnic Institute and State University, Blacksburg.

Ellis, M. E. (n.d.). The History of Student Unions at Weber State University. Retrieved from http://departments.weber.edu/sub/outline.htm\#Introduction

Evans, N. J., \& McCoy, J. M. (1998). When buildings don't work: The role of architecture in human health. Journal of Environmental Psychology, 18, 85-94.

Evans, N. J., Forney, D. S., \& Guido-DiBrito, F. (1998). Student development in college: Theory, research and practice. San Francisco: Jossey-Bass.

Graetz, K. A., \& Goliber, M. J. (2002). Designing collaborative learning places: Psychological foundations and new frontiers. In N.V.N. Chism \& D. J. Bickford, (Eds.), The Importance of Physical Space in Creating Supportive Learning Environments: New Directions in Teaching and Learning, 92(Winter 2002), (pp. 13-22). San Francisco: Jossey-Bass. 
Greenberg, A. (2007, February 23). Colleges have lost interest in designing campuses with meaning. Chronicle of Higher Education, 53(25), B25. Retrieved from http://chronicle.com/article/Colleges-Have-Lost-Interest-in/26811/

Griffin, R. (2005). Management. Boston, MA: Houghton Mifflin Company.

Henry, W. J. (2004). The contemporary student center: Challenges at metropolitan universities. NASPA Journal, 41(3), 500-517.

Holey, E. A., Freely, J. L., Dixon, J., \& Whittaker, V. J. (2007). An exploration of the use of simple statistics to measure consensus and stability in Delphi studies. Retrieved from http://www.biomedcentral.com/1471-22288/7/52

Howard, J. (2008). Sociofugal vs sociopetal space. Design for Service: Research, Patterns and Observations. Retrieved from http://designforservice.wordpress.com/2008/02/09/sociofugal-and-sociopetalspace/

Howe, N., \& Strauss, W. (2000). Millennials rising: The next great generation. New York: Vintage Books.

Hsu, C. \& Sanford, B. A. (2007, August). The Delphi Technique: Making sense of consensus. Practical Assessment, Research \& Evaluation, 12(10). Retrieved from http://pareonline.net/pdf/v12n10.pdf

Humphreys, E. O. (1946). College unions: A handbook on college community centers. Ithaca, NY: Association of College Unions.

June, A. W. (2006). Facilities can play key role in students' enrollment decisions, study finds. The Chronicle of Higher Education, 52(40), A27. Retrieved from http://chronicle.com/article/Facilities-Play-a-Key-Role-in/26924

Keeney, S., Hasson, F., \& McKenna, H. (2006). Consulting the oracle: ten lessons from using the Delphi technique in nursing research. Journal of Advanced Nursing, 53(2), 205-212.

Kemp, R. L. (2013). Town and gown relations: A handbook of best practices. Jefferson, NC: McFarland.

Kerr, C. (2001). The uses of the university. Cambridge, MA: Harvard University Press.

Kopec, D. A. (2006). Environmental psychology for design. New York: Fairchild Publications, Inc. 
Kuh, G. D., Kinzie, J., Buckley, J. A., Bridges, B. K., \& Hayek, J. C. (2007). Piecing together the student success puzzle: Research, propositions and recommendations. ASHE Higher Education Report, 32(5). San Francisco: Jossey Bass.

Kuh, G. D., Kinzie, J., Schuh, J. H., \& Whitt, E. (2005). Student success in college: Creating conditions that matter. San Francisco: Jossey-Bass.

Kuh, G. D., Schuh, J. H., Whitt, E. J., Andreas, R. E., Lyons, J. W., Strange, C. C., et al., (1991). Involving colleges: Successful approaches to fostering student learning and development outside the classroom. San Francisco: Jossey-Bass.

Lau, L. K. (2003). Institutional factors affecting student retention. Education, 124(1), 126-136.

Levine, A. \& Dean, D. (2012). Generation on a tightrope: A portrait of today's college student. San Francisco: Jossey Bass.

Linstone, H., \& Turoff, M. (2002). The Delphi method: Techniques and applications. Retrieved from http://is.njit.edu/pubs/delphibook/

Lee, D. (2003, September 14). On the Heights, a chill wind begins to blow. The New York Times. Retrieved from http://www.nytimes.com/2003/09/14/nyregion/onthe-heights-a-chill-wind-begins-to-blow.html

Ludwig, B. G. (1994). Internationalizing extension: An exploration of the characteristics evident in a state university extension system that achieves internationalization. Unpublished doctoral dissertation, The Ohio State University, Columbus.

McPherson, M. S., Schapiro, M. O., \& Winston, G. C. (1993). Introduction. In M. S. McPherson, M. O. Schapiro, \& G. C. Winston (Eds.), Paying the piper: Productivity, incentives, and financing in U.S. higher education (pp. 3-14). Ann Arbor, MI: University of Michigan Press.

Milner, L. E. (2006). Determining what could/should be: The Delphi technique and its application. Paper presented at the meeting of the 2006 annual meeting of the Mid-Western Educational Research Association, Columbus, $\mathrm{OH}$.

Monahan, T. (2002). Flexible space and built pedagogy: Emerging IT embodiments. Inventio, 4(1), 1-19. Retrieved from http://www.torinmonahan.com/papers/Inventio.html

Moos, R. (1974). Evaluating treatment environments: A social ecological approach. New York: Wiley Publications. 
Moos, R. (1986). The human context: Environmental determinants of behavior. Malabar, FL: Robert E. Krieger.

North Carolina State University. (n.d.). Trailwood: "City of trailers.” In Transforming Society: The GI Bill Experience at NC State. Retrieved from http://www.lib.ncsu.edu/archivedexhibits/gibill/eTrailwood.html

Oldenburg, R. (2001). Celebrating the third place: Inspiring stories about the "great good places" at the heart of our communities. New York: Marlow \& Company.

Olson, K. W. (1973). The G. I. Bill and higher education: Success and surprise. American Quarterly 25(5), 596-610.

Parkinson, S. (2009). Arena of ambition: A history of the Cambridge union. Crows Nest, Australia: Allen \& Unwin Pty Ltd.

Patton, M. Q. (2002). Qualitative research and evaluation methods ( $3^{\text {rd }}$ ed.). Thousand Oaks, CA: SAGE Publications.

Price, I., Matzdorf, F., \& Smith, L. (2001). Where to study: Understanding the importance of the physical environment to students in choosing their university. Sheffield, U.K.: Authors. Retrieved from www.aude.ac.uk/filegrab/StudentChoices.doc? $r e f=52$

Price, I., Matzdorf, F., Smith, L., \& Agahi, H. (2003). The impact of facilities on student choice of university. Facilities, 21(10), 212-222.

Powell, C. (2003). The Delphi technique: Myths and realities. Journal of Advanced Nursing, 41(4), 376-382.

Rapaport, A. (1982). The meaning of the built environment: Thousand Oaks, CA: SAGE Publications.

Reynolds, G. L. \& Cain, D. (2006). Final report on the impact of facilities on the recruitment and retention of students. Alexandria, VA: International Association of Higher Education Facilities Officers (APPA) / Center for Facilities Research

Rickes, P. C. (2009). Make way for millennials! How today's students' are shaping higher education space. Planning for Higher Education, 37(2), 7-17.

Romano, A. R. (2010). Malleable Delphi: Delphi research technique, its evolution, and business applications. International Review of Business Research Papers, 6(5), 235-243.

Romano, C. R., \& Hanish, J. (2003). Balancing multiple needs through innovative facility design. New Directions for Student Services, 101, 3-15. 
Rudolph, F. (1962). The American college and university: A history. New York: Alfred A. Knopf, Inc.

Schein, E. H. (2010). Organizational culture and leadership (4th ed.). San Francisco: Jossey-Bass.

Schroer, T., \& Johnson, C. J. (2003). Contemporary financial issues in student unions and campus activities. New Directions for Student Services, 103, 31-38.

Schuetz, P. (2005). UCLA community college review: Campus environment: A missing link in studies of community college attrition. Retrieved April 28, 2010 from http://crw.sagepub.com

Scott-Webber, L. (2004). In sync: Environment behavior research and the design of learning spaces. Ann Arbor, MI: Society for College and University Planning.

Shapiro, W. (1968, May 9). Ivory tower, ebony Harlem. The Michigan Daily. Retrieved from http://news.google.com/newspapers?nid=2706\&dat=19680509\&id=QgpbAAAAI BAJ\&sjid=KU4NAAAAIBAJ\&pg=4232,288165

Skinner, B. F. (1938). The behavior of organisms: An experimental analysis. New York: Appleton-Century.

Smart, J. C., Feldman, K. A., \& Ethington, C. A. (2000). Academic disciplines: Holland's theory and the study of college students and faculty. Nashville, TN: Vanderbilt University Press.

State Higher Education Executive Officers. (2014). State higher education finance, 2013. Boulder, CO: Author.

Stevens, G., (1969). The college union-past, present and future. National Association of Student Personnel Administrators Journal, 7, 16-21.

Strange, C. C. (2003). Dynamics of campus environments. In S. R Komives, D. B Woodward, \& Associates (Eds.), Student Services: A handbook for the profession (4 ${ }^{\text {th }}$ ed.) (pp. 297 - 316). San Francisco: Jossey-Bass.

Strange, C. C. \& Banning, J. H. (2001). Educating by design: Creating campus learning environments that work. San Francisco: Jossey-Bass.

Sugar Hill Harlem Inn. (n.d.). Columbia goose steps into Harlem. Retrieved from http://sugarhillharleminn.com/columbia-goose-steps-into-harlem/ Company, Inc.

Temple, P. (2008). Learning spaces in higher education: An under-researched topic. London Review of Education, 6(3), 229-241. 
Temple, P., \& Barnett, R. (2007). Higher education space: Future directions. Planning for Higher Education, 36(1), 5-15.

Thelin, J. R. (2004). A history of American higher education. Baltimore, MD: Johns Hopkins University Press.

Tinto, V. (1993). Leaving College: Rethinking the causes and cures of student attrition $\left(2^{\text {nd }} \mathrm{ed}\right)$. Chicago: University of Chicago Press.

Tinto, V. (2006). Research and practice of student retention: What next? Journal of College Student Retention, 8(1), 1-19.

Towns, W. C. (2005). The student union movement at the University of Kansas, 19131970. Unpublished doctoral dissertation, University of Kansas, Manhattan.

Vogt, W. P., Gardner, D. C., \& Haeffele, L. M. (2012). When to use what research design. New York: The Guilford Press.

Watson, J. B. (1930). Behaviorism (Revised edition). Chicago: University of Chicago Press.

Williamson, J. A. (1999). In defense of themselves: The black students struggle for success at predominately white colleges and universities. Journal of Negro Education, 68, 92-105.

Wolf, A. K. (2011). The knowledge, skills, practices and attributes that are necessary for leadership roles in counseling. Unpublished doctoral dissertation, University of North Carolina, Greensboro.

Zumeta, W. (2005). State Higher Education Financing. In E. P. St. John \& M. D. Parsons, (Eds.), Public funding of higher education: Changing contexts and new rationales, (pp.79-107). Baltimore: Johns Hopkins University Press. 
APPENDIX A

\title{
LETTER REQUESTING ASSISTANCE WITH POPULATION IDENTIFICATION
}

AND SAMPLING (ASSOCIATION OF COLLEGE UNIONS INTERNATIONAL)

\author{
Mr. Jason Cline, CAE \\ Director of Membership and Sales \\ Association of College Unions International \\ One City Centre, Suite 200 \\ 120 W. Seventh St. \\ Bloomington, IN 47404 \\ Dear Jason,
}

Greetings! My name is Michelle Janisz. I am a doctoral student at Illinois State University conducting a research study on College Union facilities and amenities under the supervision of Dr. Diane Dean in the College of Education. The purpose of this study is to understand and forecast the changing role of the student union in the modern era. I am seeking your assistance in identifying members of the Association of College Unions International (ACUI) as potential participants.

This study relies on the Delphi research method to assist in achieving its goal of understanding the changing role of the student union and predicting future directions for college and university campuses. The Delphi method is a widely used and accepted method for achieving opinion consensus concerning direct knowledge solicited from a panel of experts in a particular field of work.

Participants of this study will agree to complete a series of three questionnaires following the Delphi methodology. The potential participants must meet the following criteria: (a) are employed at public and private, non-profit, non-specialized, four year colleges and universities in the US; and (b) hold the position title of Union or Student Center Director and/or Director of Student Activities.

As per previous email correspondence you had indicated that ACUI will assist me in identifying institutional members who meet the above criteria, and provide me with a roster of potential participants that includes the following demographic information:

(a) first/last name; (b) institution name; (c) member contact address including email and phone number; (d) institutional size; (e) institutional type; and (e) ACUI Regional 
representation. From this roster, I will randomly select 50 individuals to participate in the study.

You also indicated that ACUI would send out the initial invitation to participate via email to those 50 sampled individuals. From that point, I will continue the process, sending the invitations and instructions to participate for subsequent rounds of the study, conducting follow up, and thanking individuals for their participation.

In the event that the number of sampled individuals who agree to participate is not large enough, I will work with you to repeat the process and sample more individuals for the study.

I am very excited about this project and look forward to sharing my results with the ACUI membership by writing an article for The Bulletin and presenting the findings at a future national conference.

If you have questions or concerns I can be reached at (309) 255-0449 or majanisz@wiu.edu, and my full mailing address is below. Or you may contact Dr. Dean at (309) 438-2028 or drdean@ilstu.edu.

Thank you again for supporting this research.

Sincerely,

Michelle A. Janisz

Doctoral Candidate, Educational Administrations and Foundations

Illinois State University

\section{Contact Information:}

Michelle A. Janisz

Western Illinois University

Office of Student Activities

University Union

1 University Circle

Macomb, IL 61455-1390

309-298-3232 (office)

309-255-0449 (cell)

ma-janisz@wiu.edu 


\section{APPENDIX B \\ INITIAL INVITATION TO PARTICIPATE SENT THROUGH ACUI}

Dear Director,

Greetings! My name is Michelle Janisz. I am a doctoral student at Illinois State University conducting a research study on college and university student union facilities and amenities. Based on your membership in the Association of College Unions International (ACUI), you have been randomly selected to be invited to participate in the study.

This study relies on the Delphi research method to assist in achieving its goal of understanding the changing role of the student union and predicting future directions for college and university campuses. The Delphi method is a widely used and accepted method for achieving opinion consensus concerning direct knowledge solicited from a panel of experts in a particular field of work. Your role as the Student Union, Student Center, or Director of Student Activities, acknowledges your direct experience and knowledge of student union facilities across the United States.

If you agree to participate, your participation in this study will involve completing three rounds of survey questionnaires in an effort to determine expert consensus regarding the changing role of the student union in the modern era.

The first questionnaire, Round I, includes a series of 10 open-ended questions for which you will be asked to write a brief (2000 characters or less) reply. In order to participate in this study, you must have a minimum of five years union center management experience Completion and return of this initial questionnaire will verify your willingness to participate in the study.

Rounds II and III build upon the results of Round I and facilitate consensus building. In each round, you will be asked to rate the extent of your agreement or disagreement with questions, using a seven-point scale. At times you may be asked to briefly explain their reasoning for your response. Additionally, with each new questionnaire you will receive a summary of participant responses from the preceding round. These will be presented in the aggregate, with no identifying information for the individuals who wrote them.

Completion time for each survey questionnaire will vary; however this research intends to provide insight about future planning and practices in union center management and will be of interest to all those who are concerned with campus facilities, student recruitment, retention and success. In addition, the results of the study will be shared 
with you and with all ACUI members through an article in The Bulletin and presenting the findings at a future ACUI national conference.

There are no foreseeable risks or inconvenience to participating in the study, beyond that encountered in a normal work day. Your participation will remain confidential at all times, and any information that might allow someone to identify you will not be disclosed.

You may decline to participate in the study, or withdraw from participating at any time without any penalty to you or your institution, simply by contacting me by email.

If you have questions or concerns, I can be reached at (309) 255-0449 or majanisz@wiu.edu, and my full mailing address is below. Or you may contact Dr. Dean at (309) 438-2028 or drdean@ilstu.edu. If you have questions about research participants' rights, you may contact the Illinois State University's Research Ethics \& Compliance Office at (309) 438-2529 or rec@ilstu.edu.

Thank you very much for your time and interest in this study. Your insights and opinions will be invaluable to the success of the study, and I hope you will consider participating.

To participate in the study and begin the questionnaire, please click on the following link: https://www.surveymonkey.com/s/FVG9FKZ

Sincerely,

Michelle A. Janisz

Doctoral Candidate, Educational Administrations and Foundations

Illinois State University

Contact information:

Michelle A. Janisz

Western Illinois University

Office of Student Activities

University Union

1 University Circle

Macomb, IL 61455-1390

309-298-3232 (office)

309-255-0449 (cell)

ma-janisz@wiu.edu 


\section{APPENDIX C \\ FIRST FOLLOW UP, ROUND I}

Dear Director,

Hello. My name is Michelle Janisz. Recently you received an email message from me, sent to you through the assistance of the Association of College Unions International (ACUI)

I am a doctoral student at Illinois State University conducting a research study on College Union facilities and amenities under the supervision of Dr. Diane Dean in the College of Education. You have been randomly selected through assistance from ACUI to be invited to participate in this study. The email message you received from me was an invitation to participate. I am writing to remind you about this invitation and to ask for your participation.

This study relies on the Delphi research method to assist in achieving its goal of understanding the changing role of the student union and predicting future directions for college and university campuses. The Delphi method is a widely used and accepted method for achieving opinion consensus concerning direct knowledge solicited from a panel of experts in a particular field of work. Your role as the Director of the Student Union, Student Center, or Student Activities acknowledges your direct experience and knowledge of student union facilities across the United States.

If you agree to participate, your participation in the study will involve completing three rounds of survey questionnaires in an effort to determine expert consensus regarding the changing role of the student union in the modern era.

This first questionnaire, Round I, includes a series of 10 open-ended questions for which you will be asked to write a brief (2000 characters or less) reply. In order to participate in the study, you must have a minimum of five years' union center management experience. Completion and return of this initial questionnaire will verify your willingness to participate in the study.

Rounds II and III build upon the results of Round I and facilitate consensus building. In each round, you will be asked to rate the extent of your agreement or disagreement with questions, using a seven-point scale. At times you may be asked to briefly explain the reasoning for your response. Additionally, with each new questionnaire you will receive a summary of participant responses from the preceding round. These will be presented in the aggregate, with no identifying information for the individuals who wrote them. 
Completion time for each survey questionnaire will vary; however this research intends to provide insight about future planning and practices in union center management and will be of interest to all those who are concerned with campus facilities, student recruitment, retention and success. In addition, the results of the study will be shared with you and with all ACUI members through an article in The Bulletin and presenting the findings at a future ACUI national conference.

There are no foreseeable risks or inconvenience to participating in the study. Your participation will remain confidential at all times, and any information that might allow someone to identify you will not be disclosed.

If you have questions or concerns, I can be reached at (309) 255-0449 or majanisz@wiu.edu, and my full mailing address is below. Or you may contact Dr. Dean at (309) 438-2028.

Thank you very much for your time and interest in this study. Your insights and opinions will be invaluable to the success of the study, and I hope you will consider participating.

To participate in the study and begin the questionnaire, please click on the following link: https://www.surveymonkey.com/s/FVG9FKZ. Please respond by Monday, April 28 ${ }^{\text {th }}$.

Alternately, if you wish to decline to participate and be removed from future follow up email, please reply to me at ma-janisz@wiu.edu and let me know.

Sincerely,

Michelle A. Janisz

Doctoral Candidate, Educational Administrations and Foundations

Illinois State University

Contact Information:

Michelle A. Janisz

Western Illinois University

Office of Student Activities

University Union

1 University Circle

Macomb, IL 61455-1390

309-298-3232 (office)

309-255-0449 (cell)

ma-janisz@wiu.edu 


\section{APPENDIX D \\ SECOND FOLLOW UP, ROUND I}

Dear Director,

Hello, my name is Michelle Janisz. Approximately two weeks ago, you received an email message from me inviting you to participate in a research study on College Unions, sent to you through the assistance of the Association of College Unions-International (ACUI). I hope you will consider participating.

Early last week I contacted you to remind you about this invitation. I am contacting you again because the survey period closes Wednesday, April $30^{\text {th }}$.

If you would like to participate in the study, please click on the following link to begin the questionnaire: https://www.surveymonkey.com/s/FVG9FKZ by Wednesday, April $30^{\text {th }}$.

Alternately, if you wish to decline to participate and be removed from future follow up email, please reply to me at ma-janisz@wiu.edu and let me know.

There were a number of individuals who started, but did not fully complete their surveys. If you are one of these individuals, would you please enter the survey site within the next two days to complete your survey so that your contributions can be used in the study?

As a reminder, this is a Delphi study on college unions. You were randomly sampled for participation with the assistance of the Association of College Unions-International (ACUI) based on your role as the Student Union, Student Center, or Director of Student Activities.

If you agree to participate, your participation in this study will involve completing threerounds of survey questionnaires (two more, beyond this initial survey) in an effort to determine expert consensus regarding the changing role of the student union in the modern era.

The initial invitation and first follow up email contained more detail about the study. If you would like for me to repeat that information, or if you have any questions or concerns, I can be reached at (309) 255-0449 or at ma-janisz@wiu.edu, and my full 
mailing address is below. Or you may contact Dr. Dean at (309) 438-2028 or at drdean@ilstu.edu.

Thank you very much for your time and interest in this study. Your insights and opinions will be invaluable to the success of the study and I hope you will consider participating.

Sincerely,

Michelle A. Janisz

Doctoral Candidate, Educational Administrations and Foundations

Illinois State University

Mailing Address:

Western Illinois University

Office of Student Activities

University Union

1 University Circle

Macomb, IL 61455-1390 


\section{APPENDIX E}

\section{ROUND I QUESTIONNAIRE ${ }^{3}$}

\section{Dear Director,}

My name is Michelle Janisz. I am a doctoral student at Illinois State University conducting a research study on College Unions under the supervision of Dr. Diane Dean in the College of Education. The purpose of this study is to understand and forecast the changing role of the student union in the modern era. I am requesting your participation which will involve completing a series of three questionnaires following the Delphi methodology.

In this first round of the study, Round I, you will be asked to complete a series of 10 open-ended questions by writing a brief (2000 characters or less) reply.

Your participation in this study is voluntary. If you choose not to participate or to withdraw from the study at any time, there will be no penalty, and it will not affect your work with student unions. Your responses are confidential and any information that might allow someone to identify you will not be disclosed.

There are no risks involved with your participation beyond those of everyday life. Although there may be no direct benefit to you, a possible benefit of your participation would advance the college union research agenda on purposes served, amenities and services to be provided, and any barriers to these purposes.

If you have any questions concerning the research study, please call me at (309) 2550449 or via email at ma-janisz@wiu.edu.

If you have any questions about your rights as a participant in this research, or if you feel you have been placed at risk, you can contact the Office of Research Ethics and Compliance at (309) 438-2529 or at rec@ilstu.edu.

Sincerely,

Michelle A. Janisz

Doctoral Candidate, Educational Administration and Foundations

Illinois State University

${ }^{3}$ The actual format / design of this survey appeared differently in SurveyMonkey. 
1. Do you consent to participate in the above study?

$\bigcirc$ Yes.

No.

\section{Round I Questionnaire}

Below is a series of 10 questions about college and university student unions. Please answer the following questions based upon your experiences and perceptions. Each question has a 2000 character response limit.

Please remember to hit DONE after you complete all questions so your responses are received.

1. What is the central mission of a college or university student union?

2. What purposes are served by the union?

3. How important are these purposes, and why?

4. What amenities and services should exist within the union, based on these purposes?

5. What are the barriers faced by college and university student unions in meeting these purposes? 
6. How may the location of the union on campus serve as an asset or a barrier in meeting its purposes?

7. How may the design of the union serve as an asset or barrier in meeting its purposes?

8. How do student unions relate, if at all, to student recruitment and retention?

9. What do you think are the most important influences or forces that will shape the college and university student union of the future?

10. What do you think are the biggest influences or determinants on facility directors' decisions for new construction or renovations to student unions?

Thank you for completing this survey! Your responses are important and appreciated.

The next survey, Round 2, will be sent to you soon.

Please click below on the "done" button to submit your responses. 


\section{APPENDIX F \\ INVITATION \& INSTRUCTIONS TO PARTICIPATE, ROUND II}

\section{Dear Director,}

Thank you for your recent participation in Round I for the Delphi study on student union amenities that matter. As a reminder, the purpose of this study is to understand and forecast the changing role of the student union in the modern era.

For Round II, you are asked to respond to questions using a seven-point Likert scale to rate the importance of each item. There are five parts to the survey:

1. Purpose \& Mission of the Student Union

2. Services, Programs \& Amenities of the Student Union

3. Attributes of the Student Union

4. Barriers \& Constraints for the Student Union

5. The Student Union of the Future

The questions in each part reflect a summary and synthesis of all responses from the initial questionnaire. Each part of the survey concludes with an optional opportunity to offer further comment on that section.

Survey completion times will vary. You may start, stop and return to the survey at any time. To save your work and finish it later, simply advance forward in the survey until you reach the end and select "done/submit results". Your partial results will be submitted. Then, when you are ready to complete the survey, simply click on the same web link that was provided and your partially completed survey will open for you. NOTE: this feature is based on IP address recognition. So you must complete the survey from the same device on which you started it.

When finished, again remember to click the "done/submit results" button so your final results are recorded.

If you would like a copy of the Round I raw responses, without participant identification information, please contact me. As a reminder of the overall Delphi process, there will be one final survey (Round III) shortly following the completion of this one. 
To begin Round II, follow the link https://www.surveymonkey.com/s/D2GTRCS. Please complete this Round by June 10, 2014.

Thank you in advance for your time. If you have any questions, please contact me at:

Western Illinois University

Office of Student Activities

University Union

1 University Circle

Macomb, IL 61455-1390

309-298-3232 (office)

309-255-0449 (cell)

ma-janisz@wiu.edu

Sincerely,

Michelle A. Janisz

Doctoral Candidate, Educational Administrations and Foundations

Illinois State University 


\section{APPENDIX G \\ FIRST FOLLOW UP, ROUND II}

Dear Director,

Approximately one week ago you received an invitation from me to complete Round II, of a Delphi Study on college unions. I am contacting you again because the survey period closes in one week (June 10, 2014). If you have already completed and submitted your survey, thank you. Your responses are greatly appreciated.

If you have not yet completed your survey, please click on the following link to begin: http://www.surveymonkey.com/s/D2GTRCS. It should take you an estimated 30 minutes to complete the survey. You may start, stop, and return to the survey at any time. Your answers will not be final until you submit the survey.

To save your work and finish it later, simply advance forward in the survey until you reach the end, and select "done / submit results." Your partial results will then be submitted. Then, when you are ready to complete the survey, simply click on the same web link that was provided above, and your partially completed survey will open for you. NOTE: This feature is based in IP address recognition, so you must complete the survey from the same device on which you started it. When you are finished, remember to click the "done / submit results" button so that your results will be recorded.

If you would like a copy of the Round I responses without participant identification information, please let me know. As a reminder of the overall Delphi process, there will be one final survey (Round III) shortly following the completion of this one.

Please complete the Round II by June 10, 2014. Thank you in advance for your time. If you have any questions, please contact me at:

Western Illinois University

Director, Office of Student Activities

University Union

1 University Circle

Macomb, IL 61455-1390

309-298-3232 (office)

309-255-0449 (cell)

ma-janisz@wiu.edu 
Sincerely,

Michelle A. Janisz

Doctoral Candidate, Educational Administrations and Foundations

Illinois State University 


\section{APPENDIX H \\ SECOND FOLLOW UP, ROUND II}

\section{Dear Director,}

Hello again. This is Michelle Janisz. Approximately one week ago you received an email message from me regarding my research on college student unions. I am sending you a final reminder because the survey period closes next Tuesday (June 10, 2014). If you have already completed and submitted your survey, thank you so very much!

If you have started and need to fully complete the survey, or have not started yet, please follow the link: http://www.surveymonkey.com/s/D2GTRCS. It should take you an estimated 30 minutes to complete the survey. As a reminder, you may start, stop, and return to the survey at any time.

To save your work and finish it later, simply advance forward in the survey until you reach the end, and select "done / submit results." Your partial results will then be submitted. Then, when you are ready to complete the survey, simply click on the same web link that was provided above, and your partially completed survey will open for you. NOTE: This feature is based in IP address recognition, so you must complete the survey from the same device on which you started it. When you are finished, remember to click the "done / submit results" button so that your results will be recorded.

If you would like a copy of the Round I responses without participant identification information, please let me know. As a reminder of the overall Delphi process, there will be one final survey (Round III) shortly following the completion of this one.

Please complete the Round II by June 10, 2014. About $75 \%$ of the participants have already completed, and your voice matters and is greatly appreciated! Thank you in advance for your time. If you have any questions, please contact me at:

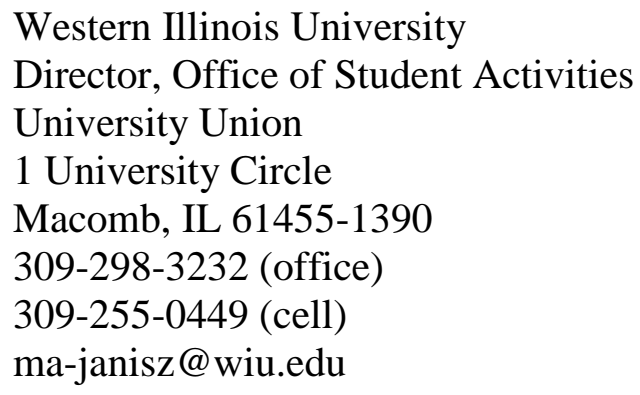


Sincerely,

Michelle A. Janisz

Doctoral Candidate, Educational Administrations and Foundations

Illinois State University 
APPENDIX I

ROUND II QUESTIONNAIRE ${ }^{4}$

\section{Delphi Study of College Unions - Round II}

\section{Part 1 - Purpose \& Mission of the Student Union}

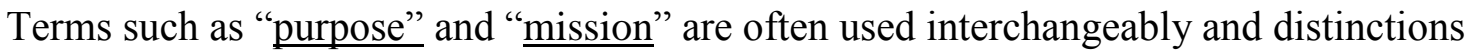
between the two can be slight.

In this study, the "purpose" of the student union answers the "why?" question. The purpose of the union explains why it exists as part of a college campus and the primary $\underline{\operatorname{role}(\mathrm{s})}$ it fills.

The "mission" of the student union answers the "how?" question. The mission of the union explains how those purposes are fulfilled, or how the union fulfills its role(s).

Round I responses indicated that the student union serves the following four distinct purposes:

1. Building, creating or fostering community

2. Supporting student success

3. Serving as the "welcome center" for the campus

4. Serving as the "living room" for the campus

Respondents named numerous ways that the union fulfills these roles. That is: student unions pursue a variety of missions as a means to fulfill these central purposes.

The questions in Part 1 ask you to rate the importance of various purposes, missions and populations being served by student unions.

${ }^{4}$ The actual format / design of this survey appeared differently in SurveyMonkey. 
1. How important is it for the student union to serve each of the following purposes (roles)?

\begin{tabular}{|c|c|c|c|c|c|c|c|}
\hline & $\begin{array}{c}\text { Very } \\
\text { Important }\end{array}$ & Important & $\begin{array}{l}\text { Somewhat } \\
\text { Important }\end{array}$ & Neutral & $\begin{array}{c}\text { Somewhat } \\
\text { Unimportant }\end{array}$ & Unimportant & $\begin{array}{c}\text { Very } \\
\text { Unimportant } \\
\end{array}$ \\
\hline $\begin{array}{l}\text { Building, creating or } \\
\text { fostering community }\end{array}$ & & & & & & & \\
\hline $\begin{array}{l}\text { Supporting student } \\
\text { success }\end{array}$ & & & & & & & \\
\hline $\begin{array}{l}\text { Serving as the } \\
\text { "welcome center" for } \\
\text { the campus }\end{array}$ & & & & & & & \\
\hline $\begin{array}{l}\text { Serving as the "living } \\
\text { room" for the campus }\end{array}$ & & & & & & & \\
\hline
\end{tabular}

\section{How important is it for the student union to serve each of the following missions?}

\begin{tabular}{|c|c|c|c|c|c|c|c|}
\hline & $\begin{array}{c}\text { Very } \\
\text { Important }\end{array}$ & Important & $\begin{array}{l}\text { Somewhat } \\
\text { Important }\end{array}$ & Neutral & $\begin{array}{c}\text { Somewhat } \\
\text { Unimportant }\end{array}$ & Unimportant & $\begin{array}{c}\text { Very } \\
\text { Unimportant }\end{array}$ \\
\hline $\begin{array}{l}\text { Support co-curricular } \\
\text { student development } \\
\text { \& learning }\end{array}$ & & & & & & & \\
\hline $\begin{array}{l}\text { Support curricular / } \\
\text { classroom student } \\
\text { learning }\end{array}$ & & & & & & & \\
\hline $\begin{array}{l}\text { Support student } \\
\text { recruitment }\end{array}$ & & & & & & & \\
\hline $\begin{array}{l}\text { Support student } \\
\text { retention }\end{array}$ & & & & & & & \\
\hline $\begin{array}{l}\text { Provide informal } \\
\text { spaces (e.g. lounge } \\
\text { space, study space, } \\
\text { socializing space) }\end{array}$ & & & & & & & \\
\hline $\begin{array}{l}\text { Provide formal } \\
\text { spaces (e.g. for } \\
\text { meetings and events) }\end{array}$ & & & & & & & \\
\hline $\begin{array}{l}\text { Offer food services } \\
\text { (e.g. food courts, } \\
\text { cafeterias, } \\
\text { restaurants) }\end{array}$ & & & & & & & \\
\hline $\begin{array}{l}\text { Offer retail services } \\
\text { (e.g. book store, } \\
\text { computer/technology } \\
\text { store, post office) }\end{array}$ & & & & & & & \\
\hline $\begin{array}{l}\text { Offer recreation \& } \\
\text { entertainment } \\
\text { opportunities (e.g. } \\
\text { bowling, movies) }\end{array}$ & & & & & & & \\
\hline $\begin{array}{l}\text { Offer cultural } \\
\text { opportunities (e.g. art } \\
\text { gallery, music or } \\
\text { dance performances) }\end{array}$ & & & & & & & \\
\hline $\begin{array}{l}\text { Offer student } \\
\text { employment } \\
\text { opportunities }\end{array}$ & & & & & & & \\
\hline
\end{tabular}


3. How important is it for the student union to serve each of the following populations?

\begin{tabular}{|c|c|c|c|c|c|c|c|}
\hline & $\begin{array}{c}\text { Very } \\
\text { Important }\end{array}$ & Important & $\begin{array}{l}\text { Somewhat } \\
\text { Important }\end{array}$ & Neutral & $\begin{array}{c}\text { Somewhat } \\
\text { Unimportant }\end{array}$ & Unimportant & $\begin{array}{c}\text { Very } \\
\text { Unimportant }\end{array}$ \\
\hline$\frac{\text { Residential }}{\text { students }}$ & 0 & O & 0 & 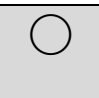 & & 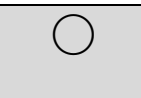 & \\
\hline Commuter students & 0 & 0 & 0 & O & 0 & $\int$ & O \\
\hline Evening students & O & O & 0 & 0 & 0 & & \\
\hline $\begin{array}{l}\text { Virtual / online } \\
\text { students }\end{array}$ & O & ? & $\bigcirc$ & 0 & $\curvearrowright$ & & \\
\hline $\begin{array}{l}\text { Traditional age } \\
\text { undergraduates }\end{array}$ & O & $\cap$ & O & O & O & & \\
\hline $\begin{array}{l}\text { Non-traditional age } \\
\text { undergraduates }\end{array}$ & O & $\cap$ & $\bigcirc$ & O & & & \\
\hline Graduate students & 0 & 0 & 0 & 0 & U & U & U \\
\hline $\begin{array}{l}\text { Prospective } \\
\text { students }\end{array}$ & & $\frown$ & O & O & & & \\
\hline Alumni & $\bigcirc$ & 0 & $\mathrm{O}$ & $\mathrm{O}$ & J & $\checkmark$ & 0 \\
\hline $\begin{array}{l}\text { Families of current } \\
\text { students or alumni }\end{array}$ & & & $\cap$ & & & & \\
\hline $\begin{array}{l}\text { Campus staff and } \\
\text { faculty (as } \\
\text { individuals) }\end{array}$ & 7 & 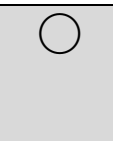 & $\bar{O}$ & D & & & $\cap$ \\
\hline $\begin{array}{l}\text { Academic } \\
\text { departments }\end{array}$ & $\bigcirc$ & ? & 0 & 0 & $\bigcirc$ & D & $\bigcirc$ \\
\hline $\begin{array}{l}\text { Administrative } \\
\text { departments }\end{array}$ & 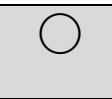 & $\cap$ & $\bigcirc$ & $\mathrm{O}$ & 0 & $\mathrm{O}$ & $\cap$ \\
\hline $\begin{array}{l}\text { Visitors to the } \\
\text { campus for other } \\
\text { college-related } \\
\text { business/purposes }\end{array}$ & O & O & $\bigcirc$ & $\bigcirc$ & ) & D & 0 \\
\hline $\begin{array}{l}\text { Visitors to the } \\
\text { campus for non- } \\
\text { college related } \\
\text { purposes }\end{array}$ & 0 & $\mathrm{O}$ & O & O & $\bigcirc$ & $\mathrm{O}$ & 0 \\
\hline
\end{tabular}

\section{Optional: If you would like to comment on the purposes, missions and populations} served by unions, please do so below. 


\section{Part 2 - Services, Programs \& Amenities of the Student Union}

In this study, the "amenities, programs \& services" of the student union answer the "what?" question. They are the specific means or strategies through which the union enacts its mission(s) to fulfill its purpose(s).

For example, the union may offer food courts (a specific amenity/service) as its means of providing food services (a mission), which ultimately fosters community (its larger purpose).

In Round I, respondents named a wide array of amenities and services offered in unions. However, unions have limits on what they can provide.

The questions in Part 2 ask you to rate how important it is for various services, programs and amenities to be located or offered within the student union.

\section{How important is it for each of the following services to be located within the student} union?

\begin{tabular}{|l|c|c|c|c|c|c|c|}
\hline Important & $\begin{array}{c}\text { Somewhat } \\
\text { Important }\end{array}$ & $\begin{array}{c}\text { Neutral } \\
\text { Important }\end{array}$ & $\begin{array}{c}\text { Somewhat } \\
\text { Unimportant }\end{array}$ & Unimportant & $\begin{array}{c}\text { Very } \\
\text { Unimportant }\end{array}$ \\
\hline Finissions office & $\bigcirc$ & $\bigcirc$ & $\bigcirc$ & $\bigcirc$ & $\bigcirc$ & $\bigcirc$ & $\bigcirc$ \\
\hline Registrar's office & $\bigcirc$ & $\bigcirc$ & $\bigcirc$ & $\bigcirc$ & $\bigcirc$ & $\bigcirc$ & $\bigcirc$ \\
\hline $\begin{array}{l}\text { Dean of Students } \\
\text { office }\end{array}$ & $\bigcirc$ & $\bigcirc$ & $\bigcirc$ & $\bigcirc$ & $\bigcirc$ & $\bigcirc$ & $\bigcirc$ \\
\hline $\begin{array}{l}\text { Career Services } \\
\text { office }\end{array}$ & $\bigcirc$ & $\bigcirc$ & $\bigcirc$ & $\bigcirc$ & $\bigcirc$ & $\bigcirc$ & $\bigcirc$ \\
\hline $\begin{array}{l}\text { Counselling Services } \\
\text { office }\end{array}$ & $\bigcirc$ & $\bigcirc$ & $\bigcirc$ & $\bigcirc$ & $\bigcirc$ & $\bigcirc$ & $\bigcirc$ \\
\hline $\begin{array}{l}\text { Health \& Wellness } \\
\text { Services office }\end{array}$ & $\bigcirc$ & $\bigcirc$ & $\bigcirc$ & $\bigcirc$ & $\bigcirc$ & $\bigcirc$ & $\bigcirc$ \\
\hline $\begin{array}{l}\text { Homecoming / } \\
\text { Alumni Relations } \\
\text { office }\end{array}$ & $\bigcirc$ & $\bigcirc$ & $\bigcirc$ & $\bigcirc$ & $\bigcirc$ & $\bigcirc$ & $\bigcirc$ \\
\hline $\begin{array}{l}\text { Leadership \& Service } \\
\text { office }\end{array}$ & $\bigcirc$ & $\bigcirc$ & $\bigcirc$ & $\bigcirc$ & $\bigcirc$ & $\bigcirc$ & $\bigcirc$ \\
\hline Multicultural Center & $\bigcirc$ & $\bigcirc$ & $\bigcirc$ & $\bigcirc$ & $\bigcirc$ & $\bigcirc$ & $\bigcirc$ \\
\hline $\begin{array}{l}\text { Student Activities } \\
\text { office }\end{array}$ & $\bigcirc$ & $\bigcirc$ & $\bigcirc$ & $\bigcirc$ & $\bigcirc$ & $\bigcirc$ & $\bigcirc$ \\
\hline $\begin{array}{l}\text { Student Government } \\
\text { office }\end{array}$ & $\bigcirc$ & $\bigcirc$ & $\bigcirc$ & $\bigcirc$ & $\bigcirc$ & $\bigcirc$ & $\bigcirc$ \\
\hline $\begin{array}{l}\text { Student Newspaper } \\
\text { office }\end{array}$ & $\bigcirc$ & $\bigcirc$ & $\bigcirc$ & $\bigcirc$ & $\bigcirc$ & $\bigcirc$ & $\bigcirc$ \\
\hline $\begin{array}{l}\text { Student Organization } \\
\text { office }\end{array}$ & $\bigcirc$ & $\bigcirc$ & $\bigcirc$ & $\bigcirc$ & $\bigcirc$ & $\bigcirc$ & $\bigcirc$ \\
\hline $\begin{array}{l}\text { Student } \\
\text { Programming Board } \\
\text { office }\end{array}$ & $\bigcirc$ & $\bigcirc$ & $\bigcirc$ & $\bigcirc$ & $\bigcirc$ & $\bigcirc$ & $\bigcirc$ \\
\hline $\begin{array}{l}\text { Victim Advocacy } \\
\text { office }\end{array}$ & $\bigcirc$ & $\bigcirc$ & $\bigcirc$ & $\bigcirc$ & $\bigcirc$ & $\bigcirc$ & $\bigcirc$ \\
\hline
\end{tabular}




\begin{tabular}{|c|c|c|c|c|c|c|c|}
\hline & $\begin{array}{c}\text { Very } \\
\text { Important }\end{array}$ & Important & $\begin{array}{l}\text { Somewhat } \\
\text { Important }\end{array}$ & Neutral & $\begin{array}{c}\text { Somewhat } \\
\text { Unimportant } \\
\end{array}$ & Unimportant & $\begin{array}{c}\text { Very } \\
\text { Unimportant }\end{array}$ \\
\hline Admissions office & 0 & 0 & 0 & 0 & 0 & & \\
\hline Financial Aid office & $\bigcirc$ & 0 & $\bigcirc$ & 0 & 0 & 0 & $\bigcirc$ \\
\hline Registrar's office & 0 & 0 & 0 & 0 & 0 & O & O \\
\hline $\begin{array}{l}\text { Dean of Students } \\
\text { office }\end{array}$ & & & & & & & \\
\hline $\begin{array}{l}\text { Career Services } \\
\text { office }\end{array}$ & & & & & & & \\
\hline $\begin{array}{l}\text { Counselling Services } \\
\text { office }\end{array}$ & & & & $\cap$ & & & \\
\hline $\begin{array}{l}\text { Health \& Wellness } \\
\text { Services office }\end{array}$ & & & & 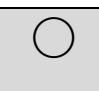 & & & \\
\hline $\begin{array}{l}\text { Homecoming / } \\
\text { Alumni Relations } \\
\text { office }\end{array}$ & & & & $\bigcirc$ & & & \\
\hline $\begin{array}{l}\text { Leadership \& Service } \\
\text { office }\end{array}$ & & & & D & & & \\
\hline Multicultural Center & & & & $\bigcirc$ & $\bigcirc$ & D & ) \\
\hline $\begin{array}{l}\text { Student Activities } \\
\text { office }\end{array}$ & & & & & & & \\
\hline $\begin{array}{l}\text { Student Government } \\
\text { office }\end{array}$ & & & & & & S & \\
\hline $\begin{array}{l}\text { Student Newspaper } \\
\text { office }\end{array}$ & & & & 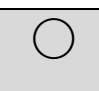 & & & \\
\hline $\begin{array}{l}\text { Student Organization } \\
\text { office }\end{array}$ & & & & & & & \\
\hline $\begin{array}{l}\text { Student } \\
\text { Programming Board } \\
\text { office }\end{array}$ & & & & & & & \\
\hline $\begin{array}{l}\text { Victim Advocacy } \\
\text { office }\end{array}$ & 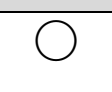 & & & & & & \\
\hline $\begin{array}{l}\text { Academic Support \& } \\
\text { Tutoring Services }\end{array}$ & & & & & & & \\
\hline Library Services & & & 0 & O & 0 & D & $U$ \\
\hline $\begin{array}{l}\text { Event / Conference } \\
\text { Planning Services }\end{array}$ & & & & & & & \\
\hline $\begin{array}{l}\text { Event Production / } \\
\text { Audio-visual } \\
\text { Services }\end{array}$ & 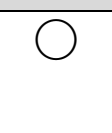 & & 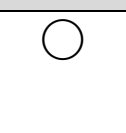 & & S & & \\
\hline $\begin{array}{l}\text { Room Reservations } \\
\text { office }\end{array}$ & $\cap$ & & $\frown$ & & 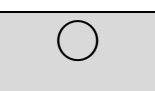 & ) & \\
\hline $\begin{array}{l}\text { ID Card / University } \\
\text { Card Services }\end{array}$ & $\cap$ & & $\Omega$ & 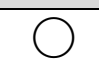 & ? & D & \\
\hline Parking Services & 0 & O & O & 0 & O & O & O \\
\hline $\begin{array}{l}\text { Ticket Outlet / Office } \\
\text { (e.g. athletics, } \\
\text { cultural events) }\end{array}$ & $\Omega$ & $\frown$ & ? & $\bigcirc$ & 0 & & 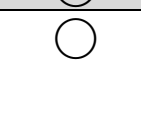 \\
\hline $\begin{array}{l}\text { Information desk } \\
\text { services (staffed) }\end{array}$ & O & $\bigcirc$ & $\mathrm{O}$ & $\mathrm{O}$ & $\mathrm{O}$ & 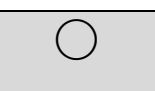 & $\bigcirc$ \\
\hline $\begin{array}{l}\text { Information kiosk } \\
\text { (unstaffed) }\end{array}$ & 0 & 0 & 0 & 0 & 0 & 0 & 0 \\
\hline
\end{tabular}




\section{How important is it for each of the following types of programming to be located or offered within the student union?}

\begin{tabular}{|c|c|c|c|c|c|c|c|}
\hline & $\begin{array}{c}\text { Very } \\
\text { Important }\end{array}$ & Important & $\begin{array}{l}\text { Somewhat } \\
\text { Important }\end{array}$ & Neutral & $\begin{array}{c}\text { Somewhat } \\
\text { Unimportant }\end{array}$ & Unimportant & $\begin{array}{c}\text { Very } \\
\text { Unimportant } \\
\end{array}$ \\
\hline $\begin{array}{l}\text { Recruitment } \\
\text { programming (e.g. } \\
\text { student tours, open } \\
\text { houses, recruitment } \\
\text { events, orientation) }\end{array}$ & & & & & & & \\
\hline $\begin{array}{l}\text { Passive co-curricular } \\
\text { programming }\end{array}$ & & & & & & & \\
\hline $\begin{array}{l}\text { Active co-curricular } \\
\text { programming }\end{array}$ & & & & & & & \\
\hline $\begin{array}{l}\text { Multicultural } \\
\text { programming }\end{array}$ & & & & & & & \\
\hline$\frac{\text { Student-organized }}{\text { programming }}$ & & & & & & & \\
\hline $\begin{array}{l}\text { Formal educational } \\
\text { opportunities (e.g. } \\
\text { conferences, lectures, } \\
\text { symposia) }\end{array}$ & & & & & & & \\
\hline $\begin{array}{l}\text { Formal social } \\
\text { opportunities (e.g. } \\
\text { dinners, dances, } \\
\text { parties) }\end{array}$ & & & & & & & \\
\hline $\begin{array}{l}\text { Formal cultural } \\
\text { events (e.g. music or } \\
\text { dance performances }\end{array}$ & & & & & & & \\
\hline $\begin{array}{l}\text { Leadership \& service } \\
\text { opportunities for } \\
\text { students }\end{array}$ & & & & & & & \\
\hline $\begin{array}{l}\text { For-credit } \\
\text { laboratories \& } \\
\text { experiences }\end{array}$ & & & & & & & \\
\hline
\end{tabular}

\section{How important is the student union's involvement in each of the following roles in programming?}

\begin{tabular}{|c|c|c|c|c|c|c|c|}
\hline & $\begin{array}{c}\text { Very } \\
\text { Important }\end{array}$ & Important & $\begin{array}{l}\text { Somewhat } \\
\text { Important }\end{array}$ & Neutral & $\begin{array}{c}\text { Somewhat } \\
\text { Unimportant }\end{array}$ & Unimportant & $\begin{array}{c}\text { Very } \\
\text { Unimportant }\end{array}$ \\
\hline $\begin{array}{l}\text { Place - (The union } \\
\text { provides a venue or } \\
\text { place, but other } \\
\text { offices or groups } \\
\text { design and offer the } \\
\text { programming.) }\end{array}$ & & & & & & & \\
\hline $\begin{array}{l}\text { Provider - (The } \\
\text { student union staff } \\
\text { designs and offers the } \\
\text { programming.) }\end{array}$ & & & & & & & \\
\hline $\begin{array}{l}\text { Partner - (The union } \\
\text { staff partners with } \\
\text { other groups or } \\
\text { offices to design and } \\
\text { offer the } \\
\text { programming.) }\end{array}$ & & & & & & & \\
\hline
\end{tabular}




\section{How important is it for the following types of spaces to be located or offered within the union?}

\begin{tabular}{|c|c|c|c|c|c|c|c|}
\hline & $\begin{array}{c}\text { Very } \\
\text { Important }\end{array}$ & Important & $\begin{array}{l}\text { Somewhat } \\
\text { Important }\end{array}$ & Neutral & $\begin{array}{c}\text { Somewhat } \\
\text { Unimportant }\end{array}$ & Unimportant & $\begin{array}{c}\text { Very } \\
\text { Unimportant } \\
\end{array}$ \\
\hline $\begin{array}{l}\text { Large-scale informal } \\
\text { gathering places (e.g. } \\
\text { lounge spaces) }\end{array}$ & & & & & & & \\
\hline $\begin{array}{l}\text { Small-scale informal } \\
\text { gathering places (e.g. } \\
\text { nooks) }\end{array}$ & & & & & & & \\
\hline $\begin{array}{l}\text { Large group study } \\
\text { spaces }\end{array}$ & & & & & & & \\
\hline $\begin{array}{l}\text { Small group / } \\
\text { individual study } \\
\text { spaces }\end{array}$ & & & & & & & \\
\hline Open spaces & & & & & & & 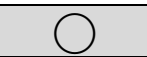 \\
\hline Atrium & & & & & & & \\
\hline $\begin{array}{l}\text { Outdoor spaces/areas } \\
\text { (for eating, studying, } \\
\text { socializing, etc) }\end{array}$ & & & & & & & \\
\hline Quiet areas & & & & & & & \\
\hline Sleeping spaces & & & & & & & ) \\
\hline$\frac{\text { Spiritual / prayer }}{\text { spaces }}$ & & & & & & & \\
\hline $\begin{array}{l}\text { Large-scale formal } \\
\text { gathering spaces (e.g. } \\
\text { performance halls, } \\
\text { ball rooms, banquet } \\
\& \text { multi-purpose } \\
\text { rooms) }\end{array}$ & & & & & & & \\
\hline $\begin{array}{l}\text { Small-scale formal } \\
\text { gathering spaces (e.g. } \\
\text { classrooms, meeting } \\
\text { rooms) }\end{array}$ & & & & & & & \\
\hline
\end{tabular}

\section{How important is it for each of the following amenities to be in the student union?}

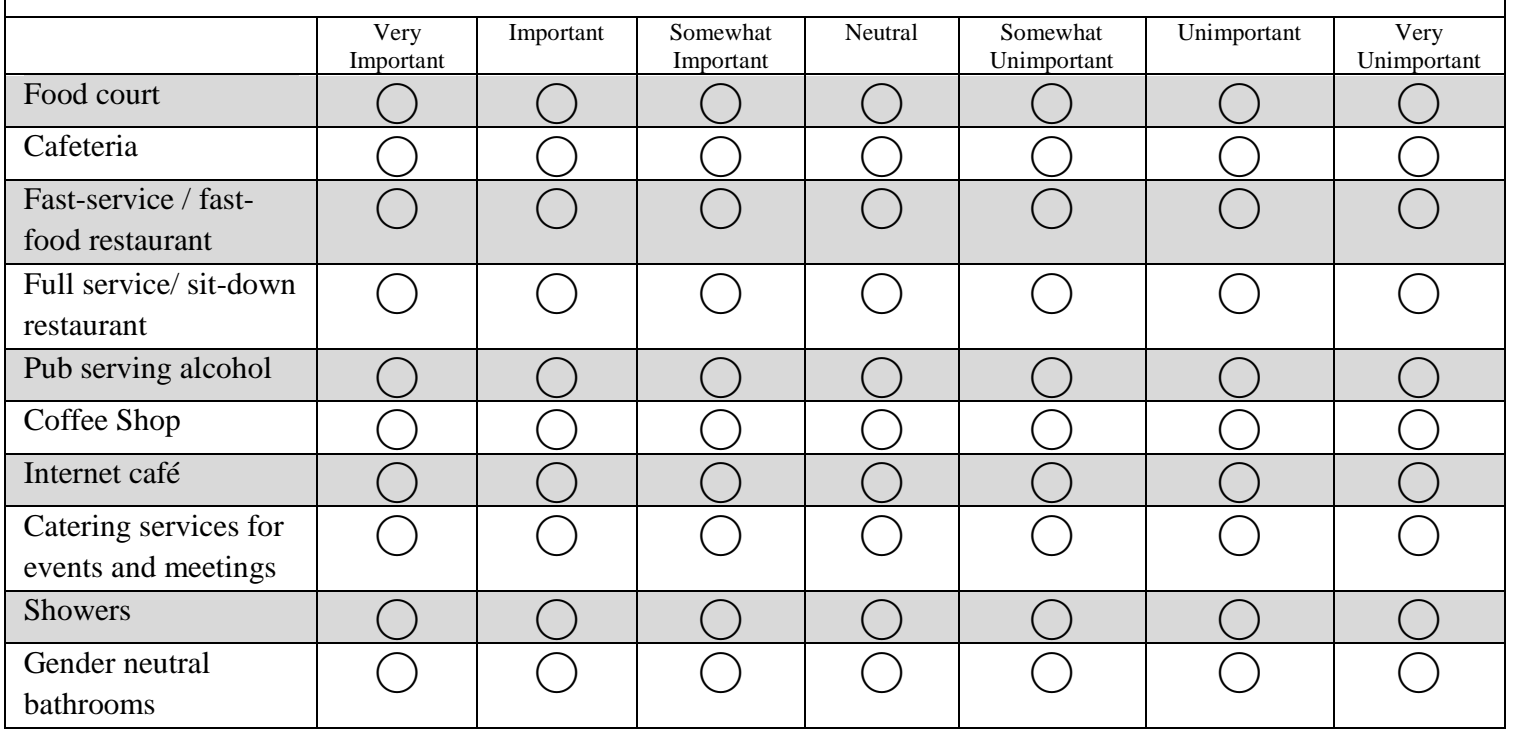




\begin{tabular}{|l|c|c|c|c|c|c|c|}
\hline & $\begin{array}{c}\text { Very } \\
\text { Important }\end{array}$ & Important & $\begin{array}{c}\text { Somewhat } \\
\text { Important }\end{array}$ & Neutral & $\begin{array}{c}\text { Somewhat } \\
\text { Unimportant }\end{array}$ & Unimportant & $\begin{array}{c}\text { Very } \\
\text { Unimportant }\end{array}$ \\
\hline $\begin{array}{l}\text { Lounge spaces with } \\
\text { televisions }\end{array}$ & $\bigcirc$ & $\bigcirc$ & $\bigcirc$ & $\bigcirc$ & $\bigcirc$ & $\bigcirc$ & $\bigcirc$ \\
\hline Locker rentals & $\bigcirc$ & $\bigcirc$ & $\bigcirc$ & $\bigcirc$ & $\bigcirc$ & $\bigcirc$ & $\bigcirc$ \\
\hline $\begin{array}{l}\text { Bowling, billiard, } \\
\text { table-tennis center }\end{array}$ & $\bigcirc$ & $\bigcirc$ & $\bigcirc$ & $\bigcirc$ & $\bigcirc$ & $\bigcirc$ & $\bigcirc$ \\
\hline $\begin{array}{l}\text { Gaming centers - } \\
\text { electronic / video }\end{array}$ & $\bigcirc$ & $\bigcirc$ & $\bigcirc$ & $\bigcirc$ & $\bigcirc$ & $\bigcirc$ & $\bigcirc$ \\
\hline $\begin{array}{l}\text { Gaming centers - } \\
\text { non-electronic (e.g. } \\
\text { table games) }\end{array}$ & $\bigcirc$ & $\bigcirc$ & $\bigcirc$ & $\bigcirc$ & $\bigcirc$ & $\bigcirc$ & $\bigcirc$ \\
\hline Movie theatres & $\bigcirc$ & $\bigcirc$ & $\bigcirc$ & $\bigcirc$ & $\bigcirc$ & $\bigcirc$ & $\bigcirc$ \\
\hline $\begin{array}{l}\text { Outdoor recreation } \\
\text { equipment rental }\end{array}$ & $\bigcirc$ & $\bigcirc$ & $\bigcirc$ & $\bigcirc$ & $\bigcirc$ & $\bigcirc$ & $\bigcirc$ \\
\hline Craft centers & $\bigcirc$ & $\bigcirc$ & $\bigcirc$ & $\bigcirc$ & $\bigcirc$ & $\bigcirc$ & $\bigcirc$ \\
\hline Art galleries & $\bigcirc$ & $\bigcirc$ & $\bigcirc$ & $\bigcirc$ & $\bigcirc$ & $\bigcirc$ & $\bigcirc$ \\
\hline $\begin{array}{l}\text { Art (dispersed } \\
\text { throughout building) }\end{array}$ & $\bigcirc$ & $\bigcirc$ & $\bigcirc$ & $\bigcirc$ & $\bigcirc$ & $\bigcirc$ & $\bigcirc$ \\
\hline
\end{tabular}

\section{0. (Amenities, continued) How important is it for each of the following amenities to be in the student union?}

\begin{tabular}{|l|c|c|c|c|c|c|c|}
\hline & $\begin{array}{c}\text { Very } \\
\text { Important }\end{array}$ & Important & $\begin{array}{c}\text { Somewhat } \\
\text { Important }\end{array}$ & Neutral & $\begin{array}{c}\text { Somewhat } \\
\text { Unimportant }\end{array}$ & Unimportant & $\begin{array}{c}\text { Very } \\
\text { Unimportant }\end{array}$ \\
\hline Book store & $\bigcirc$ & $\bigcirc$ & $\bigcirc$ & $\bigcirc$ & $\bigcirc$ & $\bigcirc$ & $\bigcirc$ \\
\hline Convenience store & $\bigcirc$ & $\bigcirc$ & $\bigcirc$ & $\bigcirc$ & $\bigcirc$ & $\bigcirc$ & $\bigcirc$ \\
\hline Banking services & $\bigcirc$ & $\bigcirc$ & $\bigcirc$ & $\bigcirc$ & $\bigcirc$ & $\bigcirc$ & $\bigcirc$ \\
\hline ATM machine & $\bigcirc$ & $\bigcirc$ & $\bigcirc$ & $\bigcirc$ & $\bigcirc$ & $\bigcirc$ & $\bigcirc$ \\
\hline $\begin{array}{l}\text { Post office / mailing } \\
\text { services }\end{array}$ & $\bigcirc$ & $\bigcirc$ & $\bigcirc$ & $\bigcirc$ & $\bigcirc$ & $\bigcirc$ & $\bigcirc$ \\
\hline $\begin{array}{l}\text { Travel agency } \\
\text { services }\end{array}$ & $\bigcirc$ & $\bigcirc$ & $\bigcirc$ & $\bigcirc$ & $\bigcirc$ & $\bigcirc$ & $\bigcirc$ \\
\hline $\begin{array}{l}\text { Barber / Beauty } \\
\text { shops }\end{array}$ & $\bigcirc$ & $\bigcirc$ & $\bigcirc$ & $\bigcirc$ & $\bigcirc$ & $\bigcirc$ & $\bigcirc$ \\
\hline Computer labs & $\bigcirc$ & $\bigcirc$ & $\bigcirc$ & $\bigcirc$ & $\bigcirc$ & $\bigcirc$ & $\bigcirc$ \\
\hline $\begin{array}{l}\text { Computer stations/ } \\
\text { kiosks (not in a lab } \\
\text { room) }\end{array}$ & $\bigcirc$ & $\bigcirc$ & $\bigcirc$ & $\bigcirc$ & $\bigcirc$ & $\bigcirc$ & $\bigcirc$ \\
\hline Copy / print services & $\bigcirc$ & $\bigcirc$ & $\bigcirc$ & $\bigcirc$ & $\bigcirc$ & $\bigcirc$ & $\bigcirc$ \\
\hline $\begin{array}{l}\text { Printer stations / } \\
\text { kiosks (not in a } \\
\text { copy/print shop) }\end{array}$ & $\bigcirc$ & $\bigcirc$ & $\bigcirc$ & $\bigcirc$ & $\bigcirc$ & $\bigcirc$ & $\bigcirc$ \\
\hline $\begin{array}{l}\text { Wireless internet } \\
\text { service }\end{array}$ & $\bigcirc$ & $\bigcirc$ & $\bigcirc$ & $\bigcirc$ & $\bigcirc$ & $\bigcirc$ & $\bigcirc$ \\
\hline $\begin{array}{l}\text { Phone \& device } \\
\text { charging stations }\end{array}$ & $\bigcirc$ & $\bigcirc$ & $\bigcirc$ & $\bigcirc$ & $\bigcirc$ & $\bigcirc$ & $\bigcirc$ \\
\hline $\begin{array}{l}\text { Hotel connected to } \\
\text { the union }\end{array}$ & $\bigcirc$ & $\bigcirc$ & $\bigcirc$ & $\bigcirc$ & $\bigcirc$ & $\bigcirc$ & $\bigcirc$ \\
\hline
\end{tabular}




\section{Optional: If you would like to comment on the services, programs \& amenities of}

unions, please do so below.

\section{Part 3 - Attributes of Student Unions}

In this study, the "attributes" of the student union refer to characteristics which may influence the union's effectiveness in providing the specific amenities \& services (the "what"), through which it enacts its missions (the "how"), to fulfill its purposes (the "why").

Round I responses identified two types of attributes:

1. Physical attributes (e.g. location, design, physical condition)

2. Human attributes (e.g. people-related characteristics)

Continuing the example offered previously: a union may offer a food court (a specific amenity) as a means of providing food services (a mission), which contributes to fostering community (a larger purpose). However, attributes such as the location of the union building and design of the food court may influence how frequently students use that amenity or satisfaction they derive from it.

\section{The questions in Part 3 ask you to rate the importance of various attributes of} student unions.

\section{How important is each of the following physical attributes of student union locations?}

\begin{tabular}{|l|c|c|c|c|c|c|c|}
\hline & $\begin{array}{c}\text { Very } \\
\text { Important }\end{array}$ & Important & $\begin{array}{c}\text { Somewhat } \\
\text { Important }\end{array}$ & Neutral & $\begin{array}{c}\text { Somewhat } \\
\text { Unimportant }\end{array}$ & Unimportant & $\begin{array}{c}\text { Very } \\
\text { Unimportant }\end{array}$ \\
\hline $\begin{array}{l}\text { Located close to the } \\
\text { physical center of } \\
\text { campus }\end{array}$ & $\bigcirc$ & $\bigcirc$ & $\bigcirc$ & $\bigcirc$ & $\bigcirc$ & $\bigcirc$ & $\bigcirc$ \\
\hline $\begin{array}{l}\text { Located in a high- } \\
\text { traffic area / } \\
\text { pedestrian crossroads } \\
\text { of the campus }\end{array}$ & $\bigcirc$ & $\bigcirc$ & $\bigcirc$ & $\bigcirc$ & $\bigcirc$ & $\bigcirc$ & $\bigcirc$ \\
\hline $\begin{array}{l}\text { Located close to } \\
\text { residence halls }\end{array}$ & $\bigcirc$ & $\bigcirc$ & $\bigcirc$ & $\bigcirc$ & $\bigcirc$ & $\bigcirc$ & $\bigcirc$ \\
\hline $\begin{array}{l}\text { Located close to the } \\
\text { library }\end{array}$ & $\bigcirc$ & $\bigcirc$ & $\bigcirc$ & $\bigcirc$ & $\bigcirc$ & $\bigcirc$ & $\bigcirc$ \\
\hline $\begin{array}{l}\text { Located close to } \\
\text { parking }\end{array}$ & $\bigcirc$ & $\bigcirc$ & $\bigcirc$ & $\bigcirc$ & $\bigcirc$ & $\bigcirc$ & $\bigcirc$ \\
\hline $\begin{array}{l}\text { Located close to } \\
\text { mass transit }\end{array}$ & $\bigcirc$ & $\bigcirc$ & $\bigcirc$ & $\bigcirc$ & $\bigcirc$ & $\bigcirc$ & $\bigcirc$ \\
\hline
\end{tabular}




\begin{tabular}{|l|c|c|c|c|c|c|c|}
\hline \multicolumn{7}{|c|}{ 13. How important is each of the following physical attributes of student union exteriors? } \\
\hline & $\begin{array}{c}\text { Very } \\
\text { Important }\end{array}$ & Important & $\begin{array}{c}\text { Somewhat } \\
\text { Important }\end{array}$ & Neutral & $\begin{array}{c}\text { Somewhat } \\
\text { Unimportant }\end{array}$ & Unimportant & $\begin{array}{c}\text { Very } \\
\text { Unimportant }\end{array}$ \\
\hline $\begin{array}{l}\text { Human scale design } \\
\text { (no more than 3 } \\
\text { stories high) }\end{array}$ & $\bigcirc$ & $\bigcirc$ & $\bigcirc$ & $\bigcirc$ & $\bigcirc$ & $\bigcirc$ & $\bigcirc$ \\
\hline $\begin{array}{l}\text { Attractive design of } \\
\text { exterior landscaping }\end{array}$ & $\bigcirc$ & $\bigcirc$ & $\bigcirc$ & $\bigcirc$ & $\bigcirc$ & $\bigcirc$ & $\bigcirc$ \\
\hline $\begin{array}{l}\text { Attractive design of } \\
\text { building exterior }\end{array}$ & $\bigcirc$ & $\bigcirc$ & $\bigcirc$ & $\bigcirc$ & $\bigcirc$ & $\bigcirc$ & $\bigcirc$ \\
\hline $\begin{array}{l}\text { Physical condition of } \\
\text { the building exterior } \\
\text { (Well -maintained) }\end{array}$ & $\bigcirc$ & $\bigcirc$ & $\bigcirc$ & $\bigcirc$ & $\bigcirc$ & $\bigcirc$ & $\bigcirc$ \\
\hline $\begin{array}{l}\text { Cleanliness of } \\
\text { building exterior }\end{array}$ & $\bigcirc$ & $\bigcirc$ & $\bigcirc$ & $\bigcirc$ & $\bigcirc$ & $\bigcirc$ & $\bigcirc$ \\
\hline $\begin{array}{l}\text { Clearly defined } \\
\text { entrance }\end{array}$ & $\bigcirc$ & $\bigcirc$ & $\bigcirc$ & $\bigcirc$ & $\bigcirc$ & $\bigcirc$ & $\bigcirc$ \\
\hline $\begin{array}{l}\text { Clear exterior } \\
\text { signage }\end{array}$ & $\bigcirc$ & $\bigcirc$ & $\bigcirc$ & $\bigcirc$ & $\bigcirc$ & $\bigcirc$ & $\bigcirc$ \\
\hline
\end{tabular}

\section{How important is each of the following physical attributes of student union interiors?}

\begin{tabular}{|l|c|c|c|c|c|c|c|}
\hline $\begin{array}{l}\text { Very } \\
\text { Important }\end{array}$ & Important & $\begin{array}{c}\text { Somewhat } \\
\text { Important }\end{array}$ & Neutral & $\begin{array}{c}\text { Somewhat } \\
\text { Unimportant }\end{array}$ & Unimportant & $\begin{array}{c}\text { Very } \\
\text { Unimportant }\end{array}$ \\
\hline $\begin{array}{l}\text { Physical condition of } \\
\text { the building interior } \\
\text { (well -maintained) }\end{array}$ & $\bigcirc$ & $\bigcirc$ & $\bigcirc$ & $\bigcirc$ & $\bigcirc$ & $\bigcirc$ & $\bigcirc$ \\
\hline $\begin{array}{l}\text { Cleanliness of } \\
\text { building interior }\end{array}$ & $\bigcirc$ & $\bigcirc$ & $\bigcirc$ & $\bigcirc$ & $\bigcirc$ & $\bigcirc$ & $\bigcirc$ \\
\hline $\begin{array}{l}\text { Clear interior signage } \\
\text { \& directions }\end{array}$ & $\bigcirc$ & $\bigcirc$ & $\bigcirc$ & $\bigcirc$ & $\bigcirc$ & $\bigcirc$ & $\bigcirc$ \\
\hline $\begin{array}{l}\text { ADA Accessible / } \\
\text { Barrier free }\end{array}$ & $\bigcirc$ & $\bigcirc$ & $\bigcirc$ & $\bigcirc$ & $\bigcirc$ & $\bigcirc$ & $\bigcirc$ \\
\hline $\begin{array}{l}\text { Lots of windows / } \\
\text { Natural lighting }\end{array}$ & $\bigcirc$ & $\bigcirc$ & $\bigcirc$ & $\bigcirc$ & $\bigcirc$ & $\bigcirc$ & $\bigcirc$ \\
\hline $\begin{array}{l}\text { "Open" feel to the } \\
\text { building interior }\end{array}$ & $\bigcirc$ & $\bigcirc$ & $\bigcirc$ & $\bigcirc$ & $\bigcirc$ & $\bigcirc$ & $\bigcirc$ \\
\hline $\begin{array}{l}\text { Adequate lighting } \\
\text { fixtures }\end{array}$ & $\bigcirc$ & $\bigcirc$ & $\bigcirc$ & $\bigcirc$ & $\bigcirc$ & $\bigcirc$ & $\bigcirc$ \\
\hline $\begin{array}{l}\text { Adequate \& } \\
\text { appropriate } \\
\text { technological } \\
\text { capability / } \\
\text { infrastructure }\end{array}$ & $\bigcirc$ & $\bigcirc$ & $\bigcirc$ & $\bigcirc$ & $\bigcirc$ & $\bigcirc$ & $\bigcirc$ \\
\hline $\begin{array}{l}\text { Adequate \& } \\
\text { appropriate space for } \\
\text { all the various } \\
\text { functions / usage of } \\
\text { the union }\end{array}$ & $\bigcirc$ & $\bigcirc$ & $\bigcirc$ & $\bigcirc$ & $\bigcirc$ & $\bigcirc$ & $\bigcirc$ \\
\hline
\end{tabular}




\begin{tabular}{|l|c|c|c|c|c|c|c|}
\hline & $\begin{array}{c}\text { Very } \\
\text { Important }\end{array}$ & Important & $\begin{array}{c}\text { Somewhat } \\
\text { Important }\end{array}$ & Neutral & $\begin{array}{c}\text { Somewhat } \\
\text { Unimportant }\end{array}$ & Unimportant & $\begin{array}{c}\text { Very } \\
\text { Unimportant }\end{array}$ \\
\hline $\begin{array}{l}\text { Interior plantings / } \\
\text { plant life within the } \\
\text { union }\end{array}$ & $\bigcirc$ & $\bigcirc$ & $\bigcirc$ & $\bigcirc$ & $\bigcirc$ & $\bigcirc$ & $\bigcirc$ \\
\hline $\begin{array}{l}\text { Noise-proofing/ } \\
\text { Sound-proofing } \\
\text { (reduce sound } \\
\text { transfer between } \\
\text { areas) }\end{array}$ & $\bigcirc$ & $\bigcirc$ & $\bigcirc$ & $\bigcirc$ & $\bigcirc$ & $\bigcirc$ & $\bigcirc$ \\
\hline
\end{tabular}

\section{5. (Interiors, continued) How important is each of the following physical attributes of student union interiors?}

\begin{tabular}{|c|c|c|c|c|c|c|c|}
\hline & $\begin{array}{c}\text { Very } \\
\text { Important }\end{array}$ & Important & $\begin{array}{l}\text { Somewhat } \\
\text { Important }\end{array}$ & Neutral & $\begin{array}{c}\text { Somewhat } \\
\text { Unimportant } \\
\end{array}$ & Unimportant & $\begin{array}{c}\text { Very } \\
\text { Unimportant }\end{array}$ \\
\hline $\begin{array}{l}\text { Behavioral zoning } \\
\text { (e.g. clearly defined } \\
\text { places for eating, } \\
\text { shopping, studying, } \\
\text { relaxing) }\end{array}$ & 0 & 0 & & 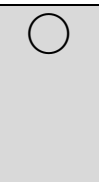 & & 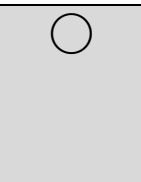 & 1 \\
\hline $\begin{array}{l}\text { Good flow / traffic } \\
\text { pattern between } \\
\text { services and } \\
\text { amenities }\end{array}$ & 0 & 0 & $\cap$ & 0 & $\bigcirc$ & $\cap$ & ) \\
\hline $\begin{array}{l}\text { Conveniently } \\
\text { clustered offices and } \\
\text { services ("one stop } \\
\text { shop") }\end{array}$ & 0 & 0 & & ) & & & ) \\
\hline $\begin{array}{l}\text { Has a focal point that } \\
\text { brings people } \\
\text { together (e.g. lounge, } \\
\text { porch) }\end{array}$ & 0 & 0 & & D & D & 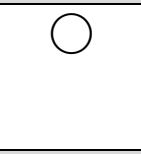 & D \\
\hline $\begin{array}{l}\text { Has "sticky spaces" } \\
\text { where people want to } \\
\text { come and stay } \\
\text { (regardless of } \\
\text { transaction needs) }\end{array}$ & $\cap$ & 0 & & & & 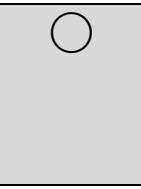 & $\cap$ \\
\hline $\begin{array}{l}\text { Seating styles / types } \\
\text { encourage interaction }\end{array}$ & 0 & 0 & & & ) & 0 & 0 \\
\hline $\begin{array}{l}\text { Seating \& tables can } \\
\text { be moved around } \\
\text { (modular) }\end{array}$ & 0 & 0 & & & & 0 & 0 \\
\hline $\begin{array}{l}\text { Flexible, } \\
\text { multipurpose design / } \\
\text { moveable walls }\end{array}$ & $\bigcirc$ & 0 & ( & & & 0 & \\
\hline $\begin{array}{l}\text { Individual climate } \\
\text { control in } \\
\text { rooms/areas } \\
\text { (heating/ac) }\end{array}$ & 0 & 0 & ( & & & O & 0 \\
\hline $\begin{array}{l}\text { Comfortable interiors } \\
\text { and furnishings }\end{array}$ & $\bigcirc$ & $\cap$ & 0 & & & $\cap$ & $\cap$ \\
\hline $\begin{array}{l}\text { Stylistically modern } \\
\text { or timeless interiors } \\
\text { and furnishings (not } \\
\text { obviously dated) }\end{array}$ & 0 & 0 & 0 & 0 & ( & O & O \\
\hline $\begin{array}{l}\text { Engaging } \\
\text { environment }\end{array}$ & 0 & 0 & $\cap$ & $\bigcirc$ & 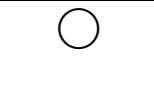 & 0 & 0 \\
\hline
\end{tabular}




\begin{tabular}{|l|c|c|c|c|c|c|c|}
\hline & $\begin{array}{c}\text { Very } \\
\text { Important }\end{array}$ & Important & $\begin{array}{c}\text { Somewhat } \\
\text { Important }\end{array}$ & Neutral & $\begin{array}{c}\text { Somewhat } \\
\text { Unimportant }\end{array}$ & Unimportant & $\begin{array}{c}\text { Very } \\
\text { Unimportant }\end{array}$ \\
\hline $\begin{array}{l}\text { "Fun," playful } \\
\text { environment }\end{array}$ & $\bigcirc$ & $\bigcirc$ & $\bigcirc$ & $\bigcirc$ & $\bigcirc$ & $\bigcirc$ & $\bigcirc$ \\
\hline
\end{tabular}

\section{How important is each of the following human attributes of student unions?}

\begin{tabular}{|c|c|c|c|c|c|c|c|}
\hline & $\begin{array}{c}\text { Very } \\
\text { Important }\end{array}$ & Important & $\begin{array}{l}\text { Somewhat } \\
\text { Important }\end{array}$ & Neutral & $\begin{array}{c}\text { Somewhat } \\
\text { Unimportant }\end{array}$ & Unimportant & $\begin{array}{c}\text { Very } \\
\text { Unimportant }\end{array}$ \\
\hline $\begin{array}{l}\text { Staff is } \\
\text { knowledgeable / } \\
\text { well-trained }\end{array}$ & 0 & Q & O & $\Omega$ & $\pi$ & D & 0 \\
\hline $\begin{array}{l}\text { Staff is student } \\
\text { focused / committed }\end{array}$ & $\bigcirc$ & $\frown$ & $\Omega$ & $\bigcirc$ & & & \\
\hline Staff is friendly & O & 0 & O & 0 & 0 & 0 & 0 \\
\hline Staff is diverse & O & O & 0 & D & O & & \\
\hline $\begin{array}{l}\text { Staff includes student } \\
\text { employees }\end{array}$ & & & & & & & \\
\hline Staff size is adequate & $\bigcirc$ & 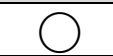 & 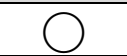 & O & 0 & 0 & 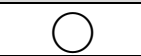 \\
\hline $\begin{array}{l}\text { Student union has } \\
\text { strong partnerships } \\
\text { with admissions / } \\
\text { enrollment services }\end{array}$ & & & $\curvearrowright$ & $\Omega$ & & & \\
\hline $\begin{array}{l}\text { Student union has } \\
\text { strong partnerships } \\
\text { with core academics }\end{array}$ & 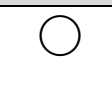 & & $\mathrm{O}$ & & & & \\
\hline $\begin{array}{l}\text { Artifacts } \\
\text { communicate school } \\
\text { spirit / history }\end{array}$ & O & ( & O & & & & \\
\hline $\begin{array}{l}\text { Artifacts } \\
\text { communicate human } \\
\text { diversity }\end{array}$ & $\Omega$ & $\Omega$ & 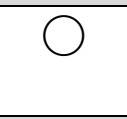 & & & & \\
\hline $\begin{array}{l}\text { Services are high } \\
\text { quality }\end{array}$ & O & O & ? & 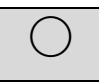 & ? & O & 0 \\
\hline Services are fast & $\bigcirc$ & $\bigcirc$ & $\bigcirc$ & 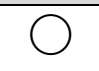 & $\bigcirc$ & $\Omega$ & $\Omega$ \\
\hline $\begin{array}{l}\text { Services are essential } \\
\text { I destination services } \\
\text { that students need } \\
\text { (must visit) }\end{array}$ & 0 & 0 & O & 0 & 0 & 0 & O \\
\hline
\end{tabular}

\section{7. (Human attributes, continued) How important is each of the following human attributes of student unions?}

\begin{tabular}{|c|c|c|c|c|c|c|c|}
\hline & $\begin{array}{c}\text { Very } \\
\text { Important }\end{array}$ & Important & $\begin{array}{l}\text { Somewhat } \\
\text { Important }\end{array}$ & Neutral & $\begin{array}{c}\text { Somewhat } \\
\text { Unimportant }\end{array}$ & Unimportant & $\begin{array}{c}\text { Very } \\
\text { Unimportan }\end{array}$ \\
\hline $\begin{array}{l}\text { Variety and options } \\
\text { in dining }\end{array}$ & & & & & & & \\
\hline $\begin{array}{l}\text { Variety and options } \\
\text { in lounge areas }\end{array}$ & & & & & & & \\
\hline $\begin{array}{l}\text { Variety and options } \\
\text { in purposes for } \\
\text { visiting the building } \\
\text { (e.g. mixed use } \\
\text { building) }\end{array}$ & & & & & & & \\
\hline $\begin{array}{l}\text { Late /weekend hours } \\
\text { for students services } \\
\text { in building }\end{array}$ & & & & & & & \\
\hline
\end{tabular}




\begin{tabular}{|c|c|c|c|c|c|c|c|}
\hline & $\begin{array}{c}\text { Very } \\
\text { Important }\end{array}$ & Important & $\begin{array}{l}\text { Somewhat } \\
\text { Important }\end{array}$ & Neutral & $\begin{array}{c}\text { Somewhat } \\
\text { Unimportant } \\
\end{array}$ & Unimportant & $\begin{array}{c}\text { Very } \\
\text { Unimportant }\end{array}$ \\
\hline $\begin{array}{l}\text { Late/weekend hours } \\
\text { for retail services }\end{array}$ & 0 & 0 & 0 & 0 & 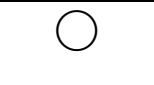 & ) & 0 \\
\hline $\begin{array}{l}\text { Late /weekend hours } \\
\text { for food services }\end{array}$ & 0 & 0 & 0 & O & ) & ) & ) \\
\hline $\begin{array}{l}\text { Late /weekend hours } \\
\text { for entertainment / } \\
\text { recreation offerings }\end{array}$ & 0 & $\bigcirc$ & $\bigcirc$ & Q & & 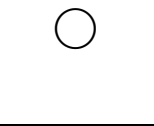 & \\
\hline $\begin{array}{l}\text { Prices at the various } \\
\text { food and retail outlets } \\
\text { are affordable for } \\
\text { students }\end{array}$ & 0 & 0 & 0 & 0 & & ) & \\
\hline $\begin{array}{l}\text { Union feels } \\
\text { welcoming / inviting }\end{array}$ & 0 & 0 & 0 & $\cap$ & $\cap$ & & \\
\hline $\begin{array}{l}\text { Union feels like a } \\
\text { safe place - } \\
\text { physically }\end{array}$ & 0 & O & 0 & C & ) & 0 & \\
\hline $\begin{array}{l}\text { Union feels like a } \\
\text { safe place- } \\
\text { psychologically }\end{array}$ & 0 & 0 & 0 & 0 & 0 & ) & 0 \\
\hline $\begin{array}{l}\text { Union conveys to } \\
\text { students that they } \\
\text { matter }\end{array}$ & 0 & 0 & 0 & 0 & 0 & 0 & 0 \\
\hline $\begin{array}{l}\text { 18. Optional: If y } \\
\text { unions, please }\end{array}$ & $\begin{array}{l}\text { woul } \\
\text { scrib }\end{array}$ & $\begin{array}{l}\text { to col } \\
\text { W. }\end{array}$ & nt & hh & or hum & tribute & \\
\hline
\end{tabular}

\section{Part 4 - Barriers \& Constraints for Student Unions}

In this study, "barriers \& constraints" refer to specific issues or concerns which may prohibit or impede the union's ability or effectiveness in fulfilling its purpose(s) and $\operatorname{mission}(\mathrm{s})$.

While a lack of any desirable attribute, amenity or service can be a barrier or constraint, this section refers to specific challenges respondents named in the Round I survey. Four categories of constraints emerged:

1. Physical constraints

2. Knowledge constraints

3. Financial constraints

4. Political constraints

The questions in Part 4 ask you to rate the importance of various barriers \& constraints facing student unions. 


\section{How important is each of the following physical constraints in influencing student union effectiveness?}

\begin{tabular}{|c|c|c|c|c|c|c|c|}
\hline & $\begin{array}{c}\text { Very } \\
\text { Important }\end{array}$ & Important & $\begin{array}{l}\text { Somewhat } \\
\text { Important }\end{array}$ & Neutral & $\begin{array}{c}\text { Somewhat } \\
\text { Unimportant }\end{array}$ & Unimportant & $\begin{array}{c}\text { Very } \\
\text { Unimportant } \\
\end{array}$ \\
\hline $\begin{array}{l}\text { Location - poor } \\
\text { original choice / } \\
\text { peripheral to campus }\end{array}$ & 0 & 0 & 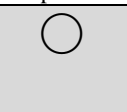 & 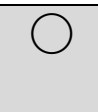 & & 0 & 0 \\
\hline $\begin{array}{l}\text { Location - displaced / } \\
\text { center of campus has } \\
\text { shifted as campus } \\
\text { grew }\end{array}$ & $\bigcirc$ & ? & $\cap$ & & & & D \\
\hline $\begin{array}{l}\underline{\text { Size }}-\text { Inadequate to } \\
\text { accommodate desired } \\
\text { purposes (can't fit all } \\
\text { the functions in) }\end{array}$ & $\bigcirc$ & O & & & & & \\
\hline $\begin{array}{l}\text { Size - Inadequate to } \\
\text { serve level of usage / } \\
\text { student enrollment } \\
\text { (crowded usage) }\end{array}$ & 0 & 0 & $\cap$ & ) & & 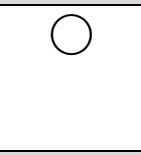 & ) \\
\hline $\begin{array}{l}\text { Comprehensiveness - } \\
\text { Missing key services } \\
\& \text { amenities that } \\
\text { should be in the } \\
\text { union }\end{array}$ & 0 & 0 & & & & $\bigcirc$ & O \\
\hline$\frac{\text { Design - outdated }}{\text { and unappealing }}$ & 0 & $\cap$ & & & & 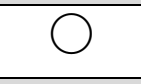 & $\cap$ \\
\hline $\begin{array}{l}\text { Design - poor } \\
\text { building design with } \\
\text { too many doors, } \\
\text { stairwells, corners } \\
\end{array}$ & 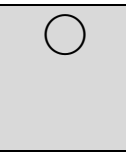 & ( & & & & & \\
\hline $\begin{array}{l}\text { Design - not ADA } \\
\text { compliant / } \\
\text { accessible }\end{array}$ & $\cap$ & $\cap$ & 0 & & & 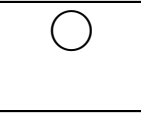 & $\cap$ \\
\hline $\begin{array}{l}\text { Design - hard walls } \\
\text { \& fixed equipment } \\
\text { with limited } \\
\text { adaptability / } \\
\text { flexibility }\end{array}$ & 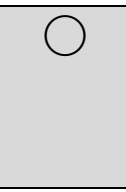 & 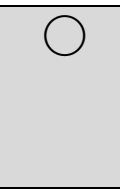 & & & & & \\
\hline $\begin{array}{l}\text { Infrastructure }- \text { aging } \\
\text { / poor infrastructure } \\
\text { (e.g. HVAC, } \\
\text { plumbing, wiring) }\end{array}$ & 7 & C & ( & & & & \\
\hline $\begin{array}{l}\text { Infrastructure - } \\
\text { asbestos, lead, or } \\
\text { other health concerns } \\
\text { must be addressed }\end{array}$ & $\cap$ & 0 & 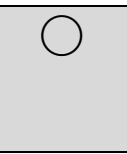 & & & & \\
\hline $\begin{array}{l}\text { Building - neglected, } \\
\text { poorly maintained, } \\
\text { run down, worn out }\end{array}$ & $\bigcirc$ & 0 & 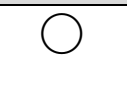 & & & 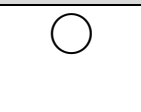 & ( \\
\hline $\begin{array}{l}\text { Building - need to } \\
\text { preserve desired } \\
\text { architectural, historic } \\
\text { or traditional value } \\
\end{array}$ & $\bigcirc$ & 0 & $\bigcirc$ & & & 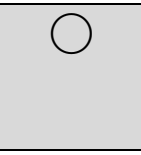 & \\
\hline $\begin{array}{l}\text { Building - need to } \\
\text { keep union within } \\
\text { one building }\end{array}$ & 0 & 0 & 0 & $\bigcirc$ & 0 & $\bigcirc$ & 0 \\
\hline $\begin{array}{l}\text { Building - need to } \\
\text { split union across } \\
\text { multiple buildings }\end{array}$ & 0 & 0 & 0 & 0 & 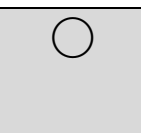 & 0 & 0 \\
\hline
\end{tabular}




\section{How important is each of the following knowledge constraints in influencing student union effectiveness?}

\begin{tabular}{|c|c|c|c|c|c|c|c|}
\hline & $\begin{array}{c}\text { Very } \\
\text { Important } \\
\end{array}$ & Important & $\begin{array}{l}\text { Somewhat } \\
\text { Important }\end{array}$ & Neutral & $\begin{array}{c}\text { Somewhat } \\
\text { Unimportant } \\
\end{array}$ & Unimportant & $\begin{array}{c}\text { Very } \\
\text { Unimportant } \\
\end{array}$ \\
\hline $\begin{array}{l}\text { Needs assessment - } \\
\text { need to identify } \\
\text { current \& future } \\
\text { student needs for the } \\
\text { union }\end{array}$ & 0 & 0 & O & O & & & $\bigcirc$ \\
\hline $\begin{array}{l}\text { User input - need to } \\
\text { seek input from } \\
\text { multiple consumers / } \\
\text { populations served by } \\
\text { the union }\end{array}$ & 0 & 0 & 0 & $\cap$ & 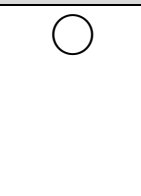 & 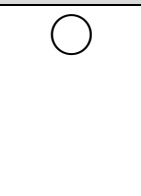 & ) \\
\hline $\begin{array}{l}\text { Satisfaction } \\
\text { assessment } \\
\text { measure union's } \\
\text { effectiveness in } \\
\text { meeting student \& } \\
\text { community needs }\end{array}$ & 0 & 0 & 0 & & & $\Omega$ & 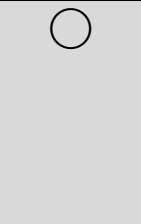 \\
\hline $\begin{array}{l}\text { Outcomes assessment } \\
\text { - need to measure } \\
\text { and prove the union's } \\
\text { contribution to the } \\
\text { educational \& co- } \\
\text { curricular process }\end{array}$ & $\bigcirc$ & $\frown$ & $\frown$ & & & & \\
\hline $\begin{array}{l}\text { Staff - have } \\
\text { insufficient } \\
\text { awareness of their } \\
\text { role in student } \\
\text { development as } \\
\text { educators }\end{array}$ & 0 & $\Omega$ & O & $\Omega$ & & & ) \\
\hline $\begin{array}{l}\text { Staff - have } \\
\text { insufficient } \\
\text { knowledge about } \\
\text { student development } \\
\text { theory }\end{array}$ & $\Omega$ & $\Omega$ & $\Omega$ & 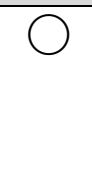 & & ( & ) \\
\hline $\begin{array}{l}\text { Staff - have } \\
\text { insufficient } \\
\text { knowledge about } \\
\text { student learning } \\
\text { outcomes \& } \\
\text { assessment }\end{array}$ & 0 & 0 & O & & & & \\
\hline $\begin{array}{l}\text { Staff - have } \\
\text { difficulty in } \\
\text { recruiting and } \\
\text { retaining student- } \\
\text { focused union staff }\end{array}$ & $\bigcirc$ & 0 & 0 & $\bigcirc$ & $\bigcirc$ & $\bigcirc$ & 0 \\
\hline $\begin{array}{l}\text { Staff - need more } \\
\text { student involvement } \\
\text { in union } \\
\text { programming and } \\
\text { management }\end{array}$ & 0 & 0 & 0 & 0 & 0 & 0 & 0 \\
\hline
\end{tabular}




\begin{tabular}{|c|c|c|c|c|c|c|c|}
\hline & $\begin{array}{c}\text { Very } \\
\text { Important }\end{array}$ & Important & $\begin{array}{l}\text { Somewhat } \\
\text { Important }\end{array}$ & Neutral & $\begin{array}{c}\text { Somewhat } \\
\text { Unimportant }\end{array}$ & Unimportant & $\begin{array}{c}\text { Very } \\
\text { Unimportant }\end{array}$ \\
\hline $\begin{array}{l}\text { Outsourced service } \\
\text { providers - do not } \\
\text { understand, value \& } \\
\text { uphold importance of } \\
\text { student employment } \\
\text { as a developmental } \\
\text { process }\end{array}$ & 0 & 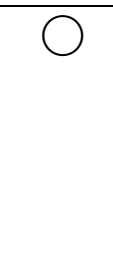 & $\frown$ & 0 & & & \\
\hline $\begin{array}{l}\text { Academic affairs - } \\
\text { lack understanding or } \\
\text { appreciation of } \\
\text { student development } \\
\& \text { the union }\end{array}$ & $\cap$ & & & & & & \\
\hline $\begin{array}{l}\text { Campus leaders - } \\
\text { lack understanding or } \\
\text { appreciation of } \\
\text { student development } \\
\text { \& the union }\end{array}$ & $\cap$ & 0 & 0 & $\cap$ & ) & & \\
\hline $\begin{array}{l}\text { General management } \\
\text { - insufficient } \\
\text { understanding of } \\
\text { "whole enterprise" of } \\
\text { the union }\end{array}$ & 0 & & 0 & $\cap$ & & & \\
\hline $\begin{array}{l}\text { General management } \\
\text { - use inappropriate } \\
\text { administrative } \\
\text { paradigms (e.g. } \\
\text { "facilities" } \\
\text { framework vs } \\
\text { "student } \\
\text { development" } \\
\text { framework }\end{array}$ & ? & & 0 & 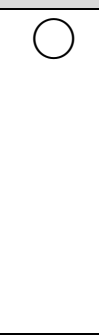 & 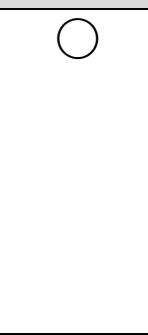 & & \\
\hline $\begin{array}{l}\text { General management } \\
\text { - } \text { space is used } \\
\text { inefficiently }\end{array}$ & 0 & 0 & O & O & 0 & D & 0 \\
\hline $\begin{array}{l}\text { General management } \\
\text { - } \text { student union has } \\
\text { lost its focus on } \\
\text { students }\end{array}$ & O & 0 & O & $\bigcirc$ & $\bigcirc$ & O & $\bigcirc$ \\
\hline
\end{tabular}

\section{How important is each of the following financial constraints in influencing student union effectiveness?}

\begin{tabular}{|c|c|c|c|c|c|c|c|}
\hline & $\begin{array}{c}\text { Very } \\
\text { Important }\end{array}$ & Important & $\begin{array}{l}\text { Somewhat } \\
\text { Important }\end{array}$ & Neutral & $\begin{array}{c}\text { Somewhat } \\
\text { Unimportant }\end{array}$ & Unimportant & $\begin{array}{c}\text { Very } \\
\text { Unimportant }\end{array}$ \\
\hline $\begin{array}{l}\text { Expenses - } \\
\text { technology (e.g. } \\
\text { increasing costs or } \\
\text { inadequate budget) }\end{array}$ & & & & & & & \\
\hline $\begin{array}{l}\text { Expenses - union } \\
\text { operations (e.g. } \\
\text { increasing costs or } \\
\text { inadequate budget for } \\
\text { utilities, supplies, } \\
\text { equipment) }\end{array}$ & & & & & & & \\
\hline
\end{tabular}




\begin{tabular}{|c|c|c|c|c|c|c|c|}
\hline & $\begin{array}{c}\text { Very } \\
\text { Important }\end{array}$ & Important & $\begin{array}{l}\text { Somewhat } \\
\text { Important }\end{array}$ & Neutral & $\begin{array}{c}\text { Somewhat } \\
\text { Unimportant }\end{array}$ & Unimportant & $\begin{array}{c}\text { Very } \\
\text { Unimportant }\end{array}$ \\
\hline $\begin{array}{l}\text { Expenses - staffing } \\
\text { (e.g. increasing costs } \\
\text { or inadequate budget } \\
\text { for number of staff; } \\
\text { operating hours) }\end{array}$ & 0 & $\cap$ & ר & $\cap$ & & & \\
\hline $\begin{array}{l}\text { Expenses - basic } \\
\text { refurbishments \& } \\
\text { upgrades (e.g. } \\
\text { increasing costs or } \\
\text { inadequate budget for } \\
\text { furniture \& lighting } \\
\text { replacement) }\end{array}$ & 0 & $\cap$ & $\bigcirc$ & 0 & $\cap$ & & \\
\hline $\begin{array}{l}\text { Expenses - needed } \\
\text { maintenance (e.g. } \\
\text { increasing costs or } \\
\text { inadequate budget) }\end{array}$ & 0 & 7 & 0 & 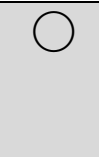 & & & \\
\hline $\begin{array}{l}\text { Revenues - } \\
\text { insufficient } \\
\text { allocations from } \\
\text { institution's general } \\
\text { operating budget to } \\
\text { support union }\end{array}$ & 0 & 0 & $\bigcirc$ & 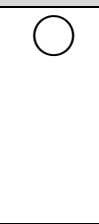 & & & \\
\hline $\begin{array}{l}\text { Revenues - } \\
\text { insufficient student } \\
\text { fees to support union }\end{array}$ & & & & & & & \\
\hline $\begin{array}{l}\text { Revenues - } \\
\text { insufficient } \\
\text { fundraising to } \\
\text { support union (e.g. } \\
\text { gifts, donations) }\end{array}$ & 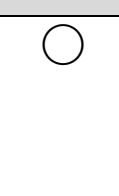 & & & ( & & & \\
\hline $\begin{array}{l}\text { Revenues - } \\
\text { overreliance on } \\
\text { student fee support } \\
\text { (e.g. need to reduce, } \\
\text { concerns for college } \\
\text { costs \& student debt) }\end{array}$ & $\cap$ & $\overline{7}$ & $\cap$ & & 0 & & \\
\hline $\begin{array}{l}\text { Revenues - need to } \\
\text { increase use of the } \\
\text { union service }\end{array}$ & 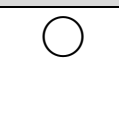 & 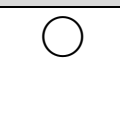 & C & 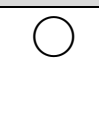 & C & & \\
\hline $\begin{array}{l}\text { Revenues - unions } \\
\text { must resort to } \\
\text { becoming malls with } \\
\text { outsourced retail } \\
\text { stores in order to } \\
\text { remain financially } \\
\text { viable. }\end{array}$ & 0 & 8 & 0 & $\bigcirc$ & $\cap$ & 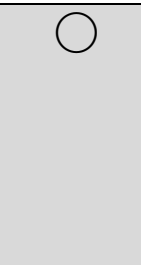 & 0 \\
\hline $\begin{array}{l}\text { Revenues - unions } \\
\text { must resort to serving } \\
\text { paying public } \\
\text { purposes more than } \\
\text { non-paying student } \\
\text { purposes in order to } \\
\text { remain financially } \\
\text { viable }\end{array}$ & 0 & 0 & 0 & O & ? & 0 & 0 \\
\hline
\end{tabular}




\begin{tabular}{|c|c|c|c|c|c|c|c|}
\hline & $\begin{array}{c}\text { Very } \\
\text { Important }\end{array}$ & Important & $\begin{array}{l}\text { Somewhat } \\
\text { Important }\end{array}$ & Neutral & $\begin{array}{c}\text { Somewhat } \\
\text { Unimportant }\end{array}$ & Unimportant & $\begin{array}{c}\text { Very } \\
\text { Unimportant }\end{array}$ \\
\hline $\begin{array}{l}\text { Auxiliary enterprise - } \\
\text { ineffective financial } \\
\text { model supporting } \\
\text { union (e.g. } \\
\text { predictability, } \\
\text { adequacy) }\end{array}$ & ( & $\cap$ & ( & $\Omega$ & & & \\
\hline $\begin{array}{l}\text { Auxiliary enterprise - } \\
\text { difficult to be self- } \\
\text { supporting }\end{array}$ & $\Omega$ & 7 & $\cap$ & $\Omega$ & ) & & D \\
\hline $\begin{array}{l}\text { Auxiliary enterprise - } \\
\text { burdensome } \\
\text { expectation that } \\
\text { union will make and } \\
\text { contribute excess } \\
\text { revenues to add to } \\
\text { institutional budget }\end{array}$ & 0 & 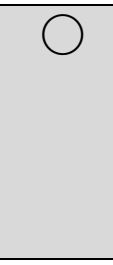 & $\bigcirc$ & $\cap$ & 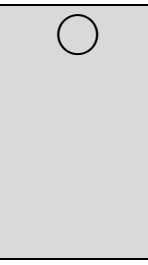 & & D \\
\hline $\begin{array}{l}\text { Capital expenses - } \\
\text { lack of funding for } \\
\text { union construction, } \\
\text { renovation and } \\
\text { expansion }\end{array}$ & ? & $\cap$ & $\mathrm{C}$ & 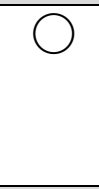 & ( & & 0 \\
\hline $\begin{array}{l}\text { Capital expenses - } \\
\text { lack of state support / } \\
\text { appropriations for } \\
\text { union construction, } \\
\text { renovation and } \\
\text { expansion }\end{array}$ & 0 & 0 & O & ? & 0 & ( & 0 \\
\hline $\begin{array}{l}\text { Capital expenses - } \\
\text { bond issues (e.g. poor } \\
\text { university bond } \\
\text { rating, failure to } \\
\text { make bond } \\
\text { payments) }\end{array}$ & $\bigcirc$ & $\bigcirc$ & $\bigcirc$ & $\bigcirc$ & $\bigcirc$ & $\bigcirc$ & C \\
\hline
\end{tabular}

\section{How important is each of the following political constraints in influencing student union effectiveness?}

\begin{tabular}{|c|c|c|c|c|c|c|c|}
\hline & $\begin{array}{c}\text { Very } \\
\text { Important }\end{array}$ & Important & $\begin{array}{l}\text { Somewhat } \\
\text { Important }\end{array}$ & Neutral & $\begin{array}{c}\text { Somewhat } \\
\text { Unimportant }\end{array}$ & Unimportant & $\begin{array}{c}\text { Very } \\
\text { Unimportant }\end{array}$ \\
\hline $\begin{array}{l}\text { Competition on } \\
\text { campus (e.g. similar } \\
\text { services \& amenities } \\
\text { offered in other } \\
\text { academic or support } \\
\text { buildings) }\end{array}$ & 0 & & & & & & \\
\hline $\begin{array}{l}\text { Competition off } \\
\text { campus (e.g. similar } \\
\text { service \& amenity } \\
\text { providers in town) }\end{array}$ & & & & & & & \\
\hline $\begin{array}{l}\text { Prioritization of } \\
\text { student union in the } \\
\text { institutional budget } \\
\text { process }\end{array}$ & & & & & & & \\
\hline
\end{tabular}




\begin{tabular}{|c|c|c|c|c|c|c|c|}
\hline & $\begin{array}{c}\text { Very } \\
\text { Important }\end{array}$ & Important & $\begin{array}{l}\text { Somewhat } \\
\text { Important }\end{array}$ & Neutral & $\begin{array}{c}\text { Somewhat } \\
\text { Unimportant }\end{array}$ & Unimportant & $\begin{array}{c}\text { Very } \\
\text { Unimportant }\end{array}$ \\
\hline $\begin{array}{l}\text { Respect for / } \\
\text { autonomy of student } \\
\text { union (e.g. institution } \\
\text { appropriates union } \\
\text { space for non-union } \\
\text { purposes such as } \\
\text { storage or } \\
\text { administrative } \\
\text { offices) }\end{array}$ & 0 & 0 & 0 & 0 & 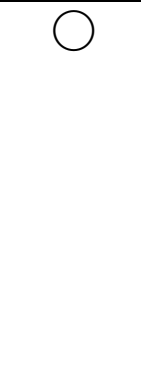 & 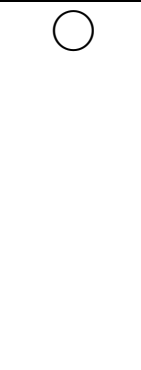 & 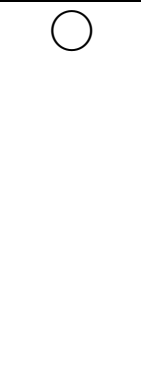 \\
\hline $\begin{array}{l}\text { Lack of influence of } \\
\text { union directors in } \\
\text { institutional decision- } \\
\text { making }\end{array}$ & 0 & 0 & O & 0 & 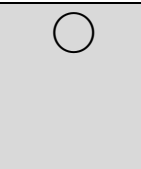 & 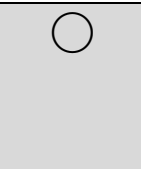 & 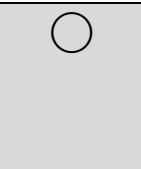 \\
\hline $\begin{array}{l}\text { Lack of respect from } \\
\text { / partnership with } \\
\text { academic affairs }\end{array}$ & 0 & 0 & 0 & $\bigcirc$ & 0 & $\bigcirc$ & R \\
\hline $\begin{array}{l}\text { Campus policies and } \\
\text { politics (e.g. } \\
\text { prohibitive influence } \\
\text { on union operations } \\
\& \text { innovation) }\end{array}$ & 0 & 0 & 0 & 0 & 0 & O & O \\
\hline $\begin{array}{l}\text { Inadequate / unclear } \\
\text { organizational } \\
\text { structure of union } \\
\text { (e.g. unclear } \\
\text { responsibilities, } \\
\text { inadequate } \\
\text { coordination, groups } \\
\text { vie for leadership) }\end{array}$ & 0 & 0 & $\bigcirc$ & $\bigcirc$ & $\bigcirc$ & $\bigcirc$ & $\bigcirc$ \\
\hline $\begin{array}{l}\text { 23. Optional: If } \\
\text { please descri }\end{array}$ & low. & 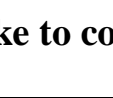 & 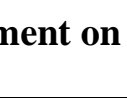 & & $\&_{-}$ & fac & ions, \\
\hline
\end{tabular}




\section{Part 5 - The Student Union of the Future}

The Round 1 survey asked about the student union of the future and what considerations might go into renovations or construction decisions. Three types of responses emerged:

1. Sustaining Forces (e.g. those that support the core purposes and a continued need for the student union)

2. Changing Forces (e.g. those that may introduce new missions, change some of the ways that union fulfills its purposes)

3. Challenging Forces (e.g. things that create barriers or constraints to the union in meeting its purposes and fulfilling its missions)

"Challenging forces" reflect the exact same types of barriers and constraints enumerated and addressed previously, in Part 4.

Therefore, the final questions here in Part 5 focus only on sustaining and challenging forces, and ask you to rate their importance in shaping the student union of the future.

\section{How important is each of the following sustaining forces in influencing the student union of the future?}

\begin{tabular}{|c|c|c|c|c|c|c|c|}
\hline & $\begin{array}{c}\text { Very } \\
\text { Important }\end{array}$ & Important & $\begin{array}{l}\text { Somewhat } \\
\text { Important }\end{array}$ & Neutral & $\begin{array}{l}\text { Somewhat } \\
\text { Unimportant }\end{array}$ & Unimportant & $\begin{array}{c}\text { Very } \\
\text { Unimportant }\end{array}$ \\
\hline $\begin{array}{l}\text { Basic human / } \\
\text { student need to } \\
\text { connect and belong } \\
\text { to the campus } \\
\text { community }\end{array}$ & & & & & & & \\
\hline $\begin{array}{l}\text { Continued need for } \\
\text { students to have a } \\
\text { "living room," a } \\
\text { place to feel "at } \\
\text { home." }\end{array}$ & & & & & & & \\
\hline $\begin{array}{l}\text { Continued need for } \\
\text { co-curricular skill } \\
\text { building (e.g. } \\
\text { responsibility, } \\
\text { leadership, } \\
\text { communication) }\end{array}$ & & & & & & & \\
\hline $\begin{array}{l}\text { Continued need for a } \\
\text { "welcome center" } \\
\text { that makes an } \\
\text { impression for } \\
\text { students, alumni and } \\
\text { visitors, and conveys } \\
\text { the campus' identity } \\
\text { story, instills loyalty. }\end{array}$ & & & & & & & \\
\hline $\begin{array}{l}\text { Importance of student } \\
\text { development in } \\
\text { institution's mission } \\
\text { and strategic plan }\end{array}$ & & & & & & & \\
\hline
\end{tabular}




\begin{tabular}{|l|c|c|c|c|c|c|c|}
\hline $\begin{array}{l}\text { Very } \\
\text { Important }\end{array}$ & Important & $\begin{array}{c}\text { Somewhat } \\
\text { Important }\end{array}$ & Neutral & $\begin{array}{c}\text { Somewhat } \\
\text { Unimportant }\end{array}$ & Unimportant & $\begin{array}{c}\text { Very } \\
\text { Unimportant }\end{array}$ \\
\hline $\begin{array}{l}\text { high-touch a location } \\
\text { on campus, as human } \\
\text { interactions are } \\
\text { increasingly } \\
\text { mediated through } \\
\text { technology }\end{array}$ & $\bigcirc$ & $\bigcirc$ & $\bigcirc$ & $\bigcirc$ & $\bigcirc$ & $\bigcirc$ & $\bigcirc$ \\
\hline $\begin{array}{l}\text { Importance of the } \\
\text { union's services \& } \\
\text { amenities to the } \\
\text { campus community }\end{array}$ & $\bigcirc$ & $\bigcirc$ & $\bigcirc$ & $\bigcirc$ & $\bigcirc$ & $\bigcirc$ & $\bigcirc$ \\
\hline $\begin{array}{l}\text { Institutional } \\
\text { commitment to the } \\
\text { union concept }\end{array}$ & $\bigcirc$ & $\bigcirc$ & $\bigcirc$ & $\bigcirc$ & $\bigcirc$ & $\bigcirc$ & $\bigcirc$ \\
\hline
\end{tabular}

\section{How important is each of the following changing forces in influencing the student union of the future?}

\begin{tabular}{|c|c|c|c|c|c|c|c|}
\hline & $\begin{array}{c}\text { Very } \\
\text { Important }\end{array}$ & Important & $\begin{array}{l}\text { Somewhat } \\
\text { Important }\end{array}$ & Neutral & $\begin{array}{c}\text { Somewhat } \\
\text { Unimportant }\end{array}$ & Unimportant & $\begin{array}{c}\text { Very } \\
\text { Unimportant } \\
\end{array}$ \\
\hline Globalization & & & & & & & \\
\hline $\begin{array}{l}\text { Sustainability / Eco- } \\
\text { awareness }\end{array}$ & & & & & & & \\
\hline $\begin{array}{l}\text { Changing student } \\
\text { populations / needs } \\
\text { (e.g. difficult to } \\
\text { forecast what future } \\
\text { students will need) }\end{array}$ & & & & & & & \\
\hline $\begin{array}{l}\text { Online classes (e.g. } \\
\text { keeping more } \\
\text { students off of } \\
\text { campus, changing } \\
\text { primacy of a } \\
\text { residential college } \\
\text { experience) }\end{array}$ & & & & & & & \\
\hline $\begin{array}{l}\text { Evening \& weekend } \\
\text { classes (e.g. changing } \\
\text { needs for union's } \\
\text { operating hours) }\end{array}$ & & & & & & & \\
\hline $\begin{array}{l}\text { Finding new ways to } \\
\text { create a sense of } \\
\text { community }\end{array}$ & & & & & & & \\
\hline $\begin{array}{l}\text { Finding new ways to } \\
\text { engage students / } \\
\text { compete for their } \\
\text { time and attention }\end{array}$ & & & & & & & \\
\hline $\begin{array}{l}\text { Technology-mediated } \\
\text { human interaction } \\
\text { (e.g. virtual vs. } \\
\text { physical union, social } \\
\text { media \& virtual } \\
\text { services threaten } \\
\text { need for unions) }\end{array}$ & & & & & & & \\
\hline $\begin{array}{l}\text { Pace of technological } \\
\text { change (e.g. difficult } \\
\text { to forecast, keep pace } \\
\text { with, and afford) }\end{array}$ & & & & & & & \\
\hline
\end{tabular}


26. Optional: If you would like to comment on the sustaining \& changing forces influencing the future of the student union, please describe below.

Thank you for completing this survey! Your responses are important and appreciated.

The final survey, Round 3, will be sent to you soon.

Please click below on the "done" button to submit your responses.

You may wish to print your survey responses, if you would like to have a copy to compare how you responded with aggregate results that will accompany the final survey. 


\section{APPENDIX J \\ INVITATION \& INSTRUCTIONS TO PARTICIPATE, ROUND III}

\section{Dear Director,}

Thank you for your recent participation in Round II of the Delphi study on Student Union Amenities that Matter. As a reminder, the purpose of this study is to understand and forecast the changing role of the student union in the modern era.

This is the third and final round of the study.

This survey presents the same questions as Round II, along with descriptive statistics that show how you and your national peers responded (e.g. mean, mode, median and range.) This information offers you a consensus of the opinion among your national peers.

For Round III, please complete the survey again, taking into account the consensus information provided.

At the end of each section, an optional comment box is provided. Please use this box if your responses differed from the apparent consensus (means) in that section, or if they changed substantially from the way you responded in Round II. You may also use this box if you simply wish to offer additional comments or insights relevant to each section.

To begin Round III, follow this link https://www.surveymonkey.com/s.aspx.

As a reminder, you may start, stop and return to the survey at any time. To save your work and finish it later:

- Simply advance forward in the survey until you reach the end

- Select "done/submit results". Your partial results will be submitted.

- Then, when you are ready to complete the survey, simply reopen the same web link that was provided above, and your partially completed survey will open for you.

- When finished, please remember to click the "done/submit results" button again so your final results are recorded.

NOTE: this feature is based on IP address recognition. So you must complete the survey from the same device on which you started it.

Please complete this final survey by July 11. 
I hope you will be willing to complete this final round. However, if you wish to drop out of the study and not complete this survey or receive any follow up emails, please click on this link, https://www.surveymonkey.com/optout.aspx , and you will be automatically removed from the contact list.

As in previous rounds, if you would like a summary of the responses of your fellow experts, please let me know.

Thank you in advance for your time. If you have any questions, please contact me at:

Western Illinois University

Office of Student Activities

University Union

1 University Circle

Macomb, IL 61455-1390

309-298-3232 (office)

309-255-0449 (cell)

ma-janisz@wiu.edu

Sincerely,

Michelle A. Janisz

Doctoral Candidate

Educational Administrations and Foundations

Illinois State University 


\section{APPENDIX K \\ FIRST FOLLOW UP, ROUND III}

\section{(Version A: For participants who had not yet started the survey)}

\section{Dear Director,}

Hello. This is Michelle Janisz. Approximately one week ago you received an email message from me inviting you to complete Round III (final round) of my research study on College Unions.

I am contacting you because the survey period closes in one week (July 11, 2014), and I have not yet received your completed response.

You may access the survey at: https://www.surveymonkey.com/s.aspx .

As a reminder, you may start, stop and return to the survey at any time. To save your work and finish it later:

- Simply advance forward in the survey until you reach the end

- Select “done/submit results". Your partial results will be submitted.

- Then, when you are ready to complete the survey, simply reopen the same web link that was provided above, and your partially completed survey will open for you.

- When finished, please remember to click the "done/submit results" button again so your final results are recorded.

NOTE: this feature is based on IP address recognition. So you must complete the survey from the same device on which you started it.

Please complete this final survey by July 11.

I hope you will be willing to complete this final round. However, if you wish to drop out of the study and not complete this survey or receive any follow up emails, please click on this link, https://www.surveymonkey.com/optout.aspx , and you will be automatically removed from the contact list.

Thank you in advance for your time. If you have any questions, please contact me at: Western Illinois University 
Director, Office of Student Activities

University Union

1 University Circle

Macomb, IL 61455-1390

309-298-3232 (office)

309-255-0449 (cell)

ma-janisz@wiu.edu

Sincerely,

Michelle A. Janisz

Doctoral Candidate

Educational Administrations and Foundations

Illinois State University

\section{(Version B: For participants who had started, but not yet completed the survey).}

Dear Director,

Hello. This is Michelle Janisz. Approximately one week ago you received an email message from me inviting you to complete Round III (final round) of my research study on College Unions.

I am contacting you because you have started but not yet completed the survey.

The survey period closes in one week (July 11, 2014), I would be grateful if you could please complete the remainder of your survey before that date.

To access and finish completing your survey, simply follow the link at: https://www.surveymonkey.com/s.aspx .

- Advance forward in the survey until you reach the parts you have not yet completed.

- Enter your responses

- When finished, please remember to click the "done/submit results" button again so your final results are recorded.

NOTE: this feature is based on IP address recognition. So you must complete the survey from the same device on which you started it.

I hope you will be willing to complete this final round. However, if you wish to drop out of the study and not complete this survey or receive any follow up emails, please click on this link, https://www.surveymonkey.com/optout.aspx , and you will be automatically removed from the contact list. 
Thank you in advance for your time. If you have any questions, please contact me at:

\author{
Western Illinois University \\ Director, Office of Student Activities \\ University Union \\ 1 University Circle \\ Macomb, IL 61455-1390 \\ 309-298-3232 (office) \\ 309-255-0449 (cell) \\ ma-janisz@wiu.edu
}

Sincerely,

Michelle A. Janisz

Doctoral Candidate

Educational Administrations and Foundations

Illinois State University 


\section{APPENDIX L \\ SECOND FOLLOW UP, ROUND III}

\section{(Version A: For participants who had not yet started the survey.)}

Dear Director,

Hello. This is Michelle Janisz. Recently you received an email message from me inviting you to complete Round III (final round) of my research study on College Unions.

I am contacting you because the survey period closes in three days (July 11, 2014), and I have not yet received your completed response.

You may access the survey at: https://www.surveymonkey.com/s.aspx .

As a reminder, you may start, stop and return to the survey at any time. To save your work and finish it later:

- Simply advance forward in the survey until you reach the end

- Select "done/submit results". Your partial results will be submitted.

- Then, when you are ready to complete the survey, simply reopen the same web link that was provided above, and your partially completed survey will open for you.

- When finished, please remember to click the "done/submit results" button again so your final results are recorded.

NOTE: this feature is based on IP address recognition. So you must complete the survey from the same device on which you started it.

Please complete this final survey by July 11.

I hope you will be willing to complete this final round. However, if you wish to drop out of the study and not complete this survey or receive any follow up emails, please click on this link, https://www.surveymonkey.com/optout.aspx , and you will be automatically removed from the contact list.

Thank you in advance for your time. If you have any questions, please contact me at:

Western Illinois University

Director, Office of Student Activities 
University Union

1 University Circle

Macomb, IL 61455-1390

309-298-3232 (office)

309-255-0449 (cell)

ma-janisz@wiu.edu

Sincerely,

Michelle A. Janisz

Doctoral Candidate

Educational Administrations and Foundations

Illinois State University

\section{(Version B: For participants who had started, but not yet completed, the survey.)}

Dear Director,

Hello. This is Michelle Janisz. Recently you received an email message from me inviting you to complete Round III (final round) of my research study on College Unions.

I am contacting you because you have started but not yet completed the survey.

The survey period closes in three days (July 11, 2014), I would be grateful if you could please complete the remainder of your survey before that date.

To access and finish completing your survey, simply follow the link at: https://www.surveymonkey.com/s.aspx .

- Advance forward in the survey until you reach the parts you have not yet completed.

- Enter your responses

- When finished, please remember to click the "done/submit results" button again so your final results are recorded.

NOTE: this feature is based on IP address recognition. So you must complete the survey from the same device on which you started it.

I hope you will be willing to complete this final round. However, if you wish to drop out of the study and not complete this survey or receive any follow up emails, please click on this link, https://www.surveymonkey.com/optout.aspx , and you will be automatically removed from the contact list.

Thank you in advance for your time. If you have any questions, please contact me at: 


\author{
Western Illinois University \\ Director, Office of Student Activities \\ University Union \\ 1 University Circle \\ Macomb, IL 61455-1390 \\ 309-298-3232 (office) \\ 309-255-0449 (cell) \\ ma-janisz@wiu.edu
}

Sincerely,

Michelle A. Janisz

Doctoral Candidate

Educational Administrations and Foundations

Illinois State University 


\section{APPENDIX M \\ THIRD FOLLOW UP, ROUND III}

Dear Director,

Hello. This is Michelle Janisz. Recently you received an email message from me inviting you to complete Round III (final round) of my research study on College Unions.

I am contacting you because the survey deadline has passed. However, I have not yet received your response. Therefore, I have re-opened the survey and ask if possible that you complete no later than end of day July 14, 2014.

You may access the survey at: https://www.surveymonkey.com/s.aspx .

I hope you will be willing to complete this final round. However, if you wish to drop out of the study and not complete this survey or receive any follow up emails, please click on this link, https://www.surveymonkey.com/optout.aspx , and you will be automatically removed from the contact list.

As a reminder, you may start, stop and return to the survey at any time. To save your work and finish it later:

- Simply advance forward in the survey until you reach the end

- Select “done/submit results". Your partial results will be submitted.

- Then, when you are ready to complete the survey, simply reopen the same web link that was provided above, and your partially completed survey will open for you.

- When finished, please remember to click the "done/submit results" button again so your final results are recorded.

NOTE: this feature is based on IP address recognition. So you must complete the survey from the same device on which you started it.

Please complete this final survey by end of day July 14 .

Thank you in advance for your time. If you have any questions, please contact me at:

Western Illinois University

Director, Office of Student Activities

University Union

1 University Circle 
Macomb, IL 61455-1390

309-298-3232 (office)

309-255-0449 (cell)

ma-janisz@wiu.edu

Sincerely,

Michelle A. Janisz

Doctoral Candidate

Educational Administrations and Foundations

Illinois State University 


\section{APPENDIX N \\ ROUND III QUESTIONNAIRE 5}

\section{Delphi Study of College Unions - Round III}

\section{Part 1 - Purpose \& Mission of the Student Union}

The questions in Part 1 ask you to rate the importance of various purposes, missions and populations being served by student unions.

\section{How important is it for the student union to serve each of the following purposes (roles)?}

\begin{tabular}{|c|c|c|c|c|c|c|c|}
\hline & $\begin{array}{c}\text { Very } \\
\text { Important }\end{array}$ & Important & $\begin{array}{l}\text { Somewhat } \\
\text { Important }\end{array}$ & Neutral & $\begin{array}{c}\text { Somewhat } \\
\text { Unimportant }\end{array}$ & Unimportant & $\begin{array}{c}\text { Very } \\
\text { Unimportant }\end{array}$ \\
\hline $\begin{array}{l}\text { Building, creating or } \\
\text { fostering community } \\
\text { Mean }=1.00, \text { Range }=0 \text {, } \\
\text { Median }=1, \text { Mode }=1\end{array}$ & & & & & & & \\
\hline $\begin{array}{l}\text { Supporting student } \\
\text { success } \\
\begin{array}{l}\text { Mean }=1.23, \text { Range }=1-2, \\
\text { Median }=1, \text { Mode }=1\end{array}\end{array}$ & & & & & & & \\
\hline $\begin{array}{l}\text { Serving as the } \\
\text { "welcome center" for } \\
\text { the campus } \\
\text { Mean }=1.55, \text { Range }=1-3 \text {, } \\
\text { Median }=1, \text { Mode }=1\end{array}$ & & & & & & & \\
\hline $\begin{array}{l}\text { Serving as the "living } \\
\text { room" for the campus } \\
\text { Mean }=1.27, \text { Range }=1-3 \text {, } \\
\text { Median }=1, \text { Mode }=1\end{array}$ & & & & & & & \\
\hline
\end{tabular}

\section{How important is it for the student union to serve each of the following missions?}

\begin{tabular}{|l|c|c|c|c|c|c|c|}
\hline & $\begin{array}{c}\text { Very } \\
\text { Important }\end{array}$ & Important & $\begin{array}{c}\text { Somewhat } \\
\text { Important }\end{array}$ & Neutral & $\begin{array}{c}\text { Somewhat } \\
\text { Unimportant }\end{array}$ & Unimportant & $\begin{array}{c}\text { Very } \\
\text { Unimportant }\end{array}$ \\
\hline $\begin{array}{l}\text { Support co-curricular } \\
\text { student development } \\
\& \text { learning } \\
\text { Mean=1.23, Range=1-2, } \\
\text { Median=1, Mode=1 }\end{array}$ & $\bigcirc$ & $\bigcirc$ & $\bigcirc$ & $\bigcirc$ & $\bigcirc$ & $\bigcirc$ & $\bigcirc$ \\
\hline
\end{tabular}

${ }^{5}$ The actual format / design of this survey appeared differently in SurveyMonkey. 


\begin{tabular}{|c|c|c|c|c|c|c|c|}
\hline & $\begin{array}{c}\text { Very } \\
\text { Important }\end{array}$ & Important & $\begin{array}{l}\text { Somewhat } \\
\text { Important }\end{array}$ & Neutral & $\begin{array}{c}\text { Somewhat } \\
\text { Unimportant }\end{array}$ & Unimportant & $\begin{array}{c}\text { Very } \\
\text { Unimportant }\end{array}$ \\
\hline $\begin{array}{l}\text { Support curricular / } \\
\text { classroom student } \\
\text { learning } \\
\text { Mean }=2.59, \text { Range }=1-5 \text {, } \\
\text { Median }=2.5, \text { Mode }=2\end{array}$ & 0 & 0 & $O$ & $\cap$ & $\frown$ & & \\
\hline $\begin{array}{l}\begin{array}{l}\text { Support student } \\
\text { recruitment } \\
\text { Mean }=1.77, \text { Range }=1-4 \text {, } \\
\text { Median }=2, \text { Mode }=2\end{array} \\
\end{array}$ & $\cap$ & 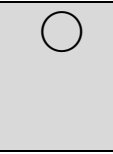 & $\cap$ & $\cap$ & & & \\
\hline $\begin{array}{l}\text { Support student } \\
\text { retention } \\
\text { Mean }=1.55, \text { Range }=1-3 \text {, } \\
\text { Median }=1, \text { Mode }=1\end{array}$ & 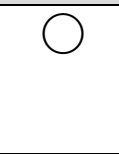 & 0 & 7 & $\cap$ & & & \\
\hline $\begin{array}{l}\text { Provide informal } \\
\text { spaces (e.g. lounge } \\
\text { space, study space, } \\
\text { socializing space) } \\
\text { Mean }=1.05, \text { Range }=1-2, \\
\text { Median=1, Mode }=1 \\
\end{array}$ & 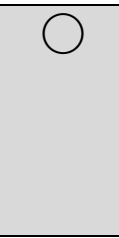 & 0 & 0 & $\cap$ & & & \\
\hline $\begin{array}{l}\text { Provide formal spaces } \\
\text { (e.g. for meetings and } \\
\text { events) } \\
\text { Mean }=1.18 \text {, Range }=1-2 \text {, } \\
\text { Median }=1, \text { Mode }=1\end{array}$ & 0 & $\curvearrowright$ & $\curvearrowright$ & 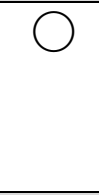 & & & \\
\hline $\begin{array}{l}\text { Offer food services } \\
\text { (e.g. food courts, } \\
\text { cafeterias, restaurants) } \\
\text { Mean }=1.41 \text {, } \text { Range }=1-3, \\
\text { Median }=1, \text { Mode }=1\end{array}$ & $\cap$ & $\cap$ & $\cap$ & 0 & & & \\
\hline $\begin{array}{l}\text { Offer retail services } \\
\text { (e.g. book store, } \\
\text { computer/technology } \\
\text { store, post office) } \\
\text { Mean }=1.86, \text { Range }=1-3, \\
\text { Median }=2, \text { Mode }=2\end{array}$ & $\cap$ & $\cap$ & 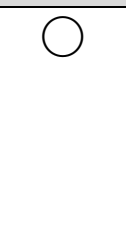 & 7 & 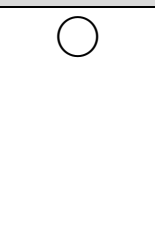 & & \\
\hline $\begin{array}{l}\text { Offer recreation \& } \\
\text { entertainment } \\
\text { opportunities (e.g. } \\
\text { bowling, movies) } \\
\text { Mean }=2.14, \text { Range }=1-5, \\
\text { Median }=2, \text { Mode }=1 \& 3\end{array}$ & $\cap$ & 0 & 0 & 7 & 0 & & \\
\hline $\begin{array}{l}\text { Offer cultural } \\
\text { opportunities (e.g. art } \\
\text { gallery, music or } \\
\text { dance performances) } \\
\text { Mean }=1.45 \text {, Range }=1-3 \text {, } \\
\text { Median }=1, \text { Mode }=1\end{array}$ & 0 & 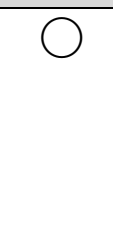 & 0 & $\bigcirc$ & 0 & $\bigcirc$ & 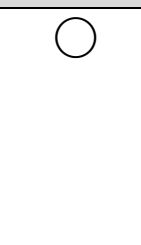 \\
\hline $\begin{array}{l}\text { Offer student } \\
\text { employment } \\
\text { opportunities } \\
\text { Mean }=1.18, \text { Range }=1-2, \\
\text { Median }=1, \text { Mode }=1\end{array}$ & 0 & 0 & 0 & 0 & 0 & 0 & 0 \\
\hline
\end{tabular}




\section{How important is it for the student union to serve each of the following populations?}

\begin{tabular}{|c|c|c|c|c|c|c|c|}
\hline & $\begin{array}{c}\text { Very } \\
\text { Important }\end{array}$ & Important & $\begin{array}{l}\text { Somewhat } \\
\text { Important }\end{array}$ & Neutral & $\begin{array}{c}\text { Somewhat } \\
\text { Unimportant }\end{array}$ & Unimportant & $\begin{array}{c}\text { Very } \\
\text { Unimportant }\end{array}$ \\
\hline $\begin{array}{l}\text { Residential students } \\
\text { Mean }=1.27, \text { Range }=1-3, \\
\text { Median }=1, \text { Mode }=1\end{array}$ & 0 & $\bigcirc$ & 0 & $\Omega$ & & & $\frown$ \\
\hline $\begin{array}{l}\text { Commuter students } \\
\text { Mean }=1.33, \text { Range }=1-3, \\
\text { Median }=1, \text { Mode }=1\end{array}$ & 0 & 0 & 0 & 0 & 0 & & ) \\
\hline $\begin{array}{l}\text { Evening students } \\
\text { Mean }=1.57, \text { Range }=1-3, \\
\text { Median }=2, \text { Mode }=1 \& 2\end{array}$ & R & O & 0 & $\Omega$ & & & 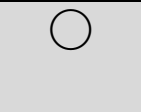 \\
\hline $\begin{array}{l}\text { Virtual / online } \\
\text { students } \\
\text { Mean }=3.10, \text { Range }=2-7, \\
\text { Median }=3, \text { Mode }=3\end{array}$ & $\cap$ & $\cap$ & $\cap$ & $\cap$ & & & \\
\hline $\begin{array}{l}\text { Traditional age } \\
\text { undergraduates } \\
\text { Mean }=1.32, \text { Range }=1-5, \\
\text { Median }=1, \text { Mode }=1\end{array}$ & 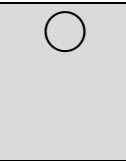 & & $\bar{T}$ & & & & \\
\hline $\begin{array}{l}\text { Non-traditional age } \\
\text { undergraduates } \\
\text { Mean }=1.50, \text { Range }=1-2, \\
\text { Median }=1.5, \text { Mode }=1 \& 2\end{array}$ & ( & & 0 & & & & \\
\hline $\begin{array}{l}\text { Graduate students } \\
\text { Mean }=1.73, \text { Range }=1-3, \\
\text { Median }=2, \text { Mode }=2\end{array}$ & 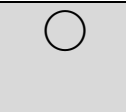 & & 0 & & & & \\
\hline $\begin{array}{l}\text { Prospective students } \\
\text { Mean }=1.68, \text { Range }=1-4, \\
\text { Median }=1, \text { Mode }=1\end{array}$ & 0 & ( & 0 & & & & \\
\hline $\begin{array}{l}\text { Alumni } \\
\text { Mean }=2.45, \text { Range }=1-5, \\
\text { Median } 2.5, \text { Mode }=3\end{array}$ & $\pi$ & & & & & & \\
\hline $\begin{array}{l}\text { Families of current } \\
\text { students or alumni } \\
\text { Mean }=2.59, \text { Range }=1-4, \\
\text { Median }=2.5, \text { Mode }=2\end{array}$ & $\Omega$ & 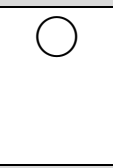 & 0 & & & & \\
\hline $\begin{array}{l}\text { Campus staff and } \\
\text { faculty (as } \\
\text { individuals) } \\
\text { Mean }=1.95, \text { Range }=1-4, \\
\text { Median }=2 \text {, Mode }=2\end{array}$ & 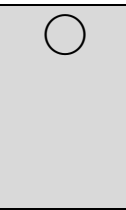 & ) & 0 & $\bigcirc$ & & & \\
\hline $\begin{array}{l}\text { Academic } \\
\text { departments } \\
\begin{array}{l}\text { Mean }=2.45, \text { Range }=1-4, \\
\text { Median }=2, \text { Mode }=2\end{array} \\
\end{array}$ & $\bigcirc$ & $\bigcirc$ & 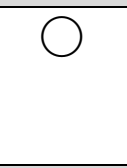 & & & & \\
\hline $\begin{array}{l}\text { Administrative } \\
\text { departments } \\
\text { Mean }=2.36, \text { Range }=1-4, \\
\text { Median }=2, \text { Mode }=2 \\
\end{array}$ & 0 & 0 & 0 & 0 & 0 & ( & 0 \\
\hline $\begin{array}{l}\text { Visitors to the } \\
\text { campus college- } \\
\text { related business / } \\
\text { purposes } \\
\text { Mean }=1.91, \text { Range }=1-3 \text {, } \\
\text { Median }=2, \text { Mode }=1 \& 2\end{array}$ & 0 & $\bigcirc$ & 0 & $\bigcirc$ & $\bigcirc$ & $\bigcirc$ & 0 \\
\hline
\end{tabular}




\begin{tabular}{|l|c|c|c|c|c|c|c|}
\hline & $\begin{array}{c}\text { Very } \\
\text { Important }\end{array}$ & Important & $\begin{array}{c}\text { Somewhat } \\
\text { Important }\end{array}$ & Neutral & $\begin{array}{c}\text { Somewhat } \\
\text { Unimportant }\end{array}$ & $\begin{array}{c}\text { Unimportant } \\
\text { Very } \\
\text { Unimportant }\end{array}$ \\
\hline $\begin{array}{l}\text { Visitors to the } \\
\text { campus for non- } \\
\text { college related } \\
\text { purposes } \\
\begin{array}{l}\text { Mean=2.43, Range=1-4, } \\
\text { Median=3, Mode=3 }\end{array}\end{array}$ & - & $\bigcirc$ & $\bigcirc$ & $\bigcirc$ & $\bigcirc$ & $\bigcirc$ & $\bigcirc$ \\
\hline
\end{tabular}

4. Optional: If your responses differ from the apparent consensus (means) in this section, please describe your primary rationale below. (You may also use this space if you would like to comment further on the purposes, missions and populations served by unions).

\section{Part 2 - Services, Programs \& Amenities of the Student Union}

In this study, the "amenities, programs \& services" of the student union answer the "what?" question. They are the specific means or strategies through which the union enacts its mission(s) to fulfill its purpose(s).

For example, the union may offer food courts (a specific amenity/service) as its means of providing food services (a mission), which ultimately fosters community (its larger purpose).

The questions in Part 2 ask you to rate how important it is for various services, programs and amenities to be located or offered within the student union.

\section{How important is it for each of the following services to be located within the student} union?

\begin{tabular}{|c|c|c|c|c|c|c|c|}
\hline & $\begin{array}{c}\text { Very } \\
\text { Important }\end{array}$ & Important & $\begin{array}{l}\text { Somewhat } \\
\text { Important }\end{array}$ & Neutral & $\begin{array}{c}\text { Somewhat } \\
\text { Unimportant }\end{array}$ & Unimportant & $\begin{array}{c}\text { Very } \\
\text { Unimportant }\end{array}$ \\
\hline $\begin{array}{l}\text { Admissions office } \\
\text { Mean }=4.59, \text { Range }=1-7 \text {, } \\
\text { Median }=5, \text { Mode }=6\end{array}$ & & & & & & & \\
\hline $\begin{array}{l}\text { Financial Aid office } \\
\text { Mean }=5.14, \text { Range }=2-7 \text {, } \\
\text { Median }=5 \text {, Mode }=6\end{array}$ & & & & & & & \\
\hline $\begin{array}{l}\text { Registrar's office } \\
\text { Mean }=5.05, \text { Range }=2-7, \\
\text { Median }=5, \text { Mode }=6\end{array}$ & & & & & & & \\
\hline $\begin{array}{l}\text { Dean of Students } \\
\text { office } \\
\text { Mean }=3.50, \text { } \text { Range }=1-7 \text {, } \\
\text { Median }=4, \text { Mode }=4\end{array}$ & & & & & & & \\
\hline
\end{tabular}




\begin{tabular}{|c|c|c|c|c|c|c|c|}
\hline & $\begin{array}{c}\text { Very } \\
\text { Important }\end{array}$ & Important & $\begin{array}{l}\text { Somewhat } \\
\text { Important }\end{array}$ & Neutral & $\begin{array}{c}\text { Somewhat } \\
\text { Unimportant }\end{array}$ & Unimportant & $\begin{array}{c}\text { Very } \\
\text { Unimportant }\end{array}$ \\
\hline $\begin{array}{l}\text { Career Services office } \\
\text { Mean }=3.50, \text { Range }=1-7, \\
\text { Median }=3, \text { Mode }=3\end{array}$ & 0 & 0 & 0 & 0 & & & \\
\hline $\begin{array}{l}\text { Counselling Services } \\
\text { office } \\
\text { Mean }=4.68, \text { Range }=2-7, \\
\text { Median }=5, \text { Mode }=4\end{array}$ & 0 & $\bigcirc$ & 0 & $\Omega$ & 0 & & \\
\hline $\begin{array}{l}\text { Health \& Wellness } \\
\text { Services office } \\
\text { Mean }=4.09, \text { Range }=2-7 \text {, } \\
\text { Median }=4, \text { Mode }=4 \\
\end{array}$ & $\Omega$ & $\Omega$ & 0 & $\Omega$ & $\bigcirc$ & & \\
\hline $\begin{array}{l}\text { Homecoming / Alumni } \\
\text { Relations office } \\
\text { Mean }=4.19, \text { Range }=1-7, \\
\text { Median }=4, \text { Mode }=5\end{array}$ & & & & & & & \\
\hline 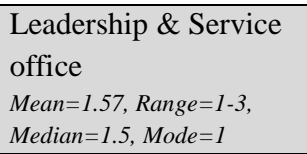 & $\bigcirc$ & 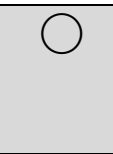 & & & & & \\
\hline $\begin{array}{l}\text { Multicultural Center } \\
\text { Mean }=2.27, \text { Range }=1-7 \text {, } \\
\text { Median }=2, \text { Mode }=2\end{array}$ & $\Omega$ & $\Omega$ & & & & & \\
\hline $\begin{array}{l}\text { Student Activities } \\
\text { office } \\
\text { Mean }=1.18, \text { Range }=1-3 \text {, } \\
\text { Median }=1, \text { Mode }=1\end{array}$ & 0 & & & & & & \\
\hline $\begin{array}{l}\text { Student Government } \\
\text { office } \\
\text { Mean }=1.36, \text { } \text { Range }=1-4 \text {, } \\
\text { Median }=1, \text { Mode }=1\end{array}$ & & & & & & & \\
\hline $\begin{array}{l}\begin{array}{l}\text { Student Newspaper } \\
\text { office } \\
\text { Mean }=3.09, \text { Range }=1-7, \\
\text { Median }=3, \text { Mode }=3\end{array} \\
\end{array}$ & & & & & & & \\
\hline $\begin{array}{l}\text { Student Organization } \\
\text { office } \\
\text { Mean }=1.18, \text { Range }=1-3, \\
\text { Median }=1, \text { Mode }=1 \\
\end{array}$ & & & C & & & & \\
\hline $\begin{array}{l}\text { Student Programming } \\
\text { Board office } \\
\text { Mean }=1.18, \text { Range }=1-3, \\
\text { Median }=1, \text { Mode }=1\end{array}$ & & 0 & 0 & ( & & & \\
\hline $\begin{array}{l}\text { Victim Advocacy } \\
\text { office } \\
\text { Mean }=3.76, \text { Range }=2-7, \\
\text { Median }=4, \text { Mode }=4\end{array}$ & ( & 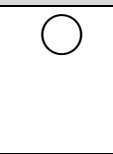 & 0 & & 0 & & \\
\hline $\begin{array}{l}\text { Academic Support \& } \\
\text { Tutoring Services } \\
\text { Mean }=4.67, \text { Range }=2-6 \text {, } \\
\text { Median }=5, \text { Mode }=5 \\
\end{array}$ & 0 & $\Omega$ & 7 & 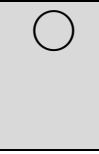 & 0 & & \\
\hline $\begin{array}{l}\text { Library Services } \\
\text { Mean }=5.19, \text { Range }=2-7, \\
\text { Median }=5, \text { Mode }=5\end{array}$ & 0 & 0 & 0 & 0 & R & ) & $\bigcirc$ \\
\hline $\begin{array}{l}\text { Event } / \text { Conference } \\
\text { Planning Services } \\
\text { Mean }=1.82, \text { Range }=1-3 \text {, } \\
\text { Median }=2, \text { Mode }=2 \\
\end{array}$ & 0 & 0 & 0 & 0 & 0 & O & 0 \\
\hline
\end{tabular}




\begin{tabular}{|c|c|c|c|c|c|c|c|}
\hline & $\begin{array}{c}\text { Very } \\
\text { Important }\end{array}$ & Important & $\begin{array}{l}\text { Somewhat } \\
\text { Important }\end{array}$ & Neutral & $\begin{array}{c}\text { Somewhat } \\
\text { Unimportant }\end{array}$ & Unimportant & $\begin{array}{c}\text { Very } \\
\text { Unimportant }\end{array}$ \\
\hline $\begin{array}{l}\text { Event Production / } \\
\text { Audio-visual Services } \\
\text { Mean }=1.73, \text { Range }=1-5, \\
\text { Median }=1.5, \text { Mode }=1 \\
\end{array}$ & & $\cap$ & & $\cap$ & & & \\
\hline $\begin{array}{l}\text { Room Reservations } \\
\text { office } \\
\text { Mean }=1.29, \text { Range }=1-3 \text {, } \\
\text { Median }=1, \text { Mode }=1\end{array}$ & $\Omega$ & $\Omega$ & $\bigcirc$ & $\Omega$ & D & & \\
\hline $\begin{array}{l}\text { ID Card / University } \\
\text { Card Services } \\
\text { Mean }=2.36, \text { Range }=1-5, \\
\text { Median }=2, \text { Mode }=2\end{array}$ & ? & 0 & & 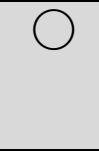 & & & \\
\hline $\begin{array}{l}\text { Parking Services } \\
\text { Mean }=4.95, \text { Range }=2-7, \\
\text { Median }=5, \text { Mode }=4 \& 7\end{array}$ & $\bigcirc$ & $\cap$ & 0 & $\bigcap$ & & & \\
\hline $\begin{array}{l}\text { Ticket Outlet / Office } \\
\text { (e.g. athletics, cultural } \\
\text { events) } \\
\text { Mean }=2.36, \text { Range }=1-3, \\
\text { Median }=2.5, \text { Mode }=3\end{array}$ & $\Omega$ & $\Omega$ & $\cap$ & 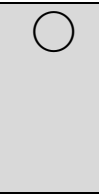 & 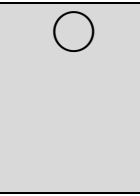 & & \\
\hline $\begin{array}{l}\text { Information desk } \\
\text { services }(\underline{\text { staffed }}) \\
\text { Mean }=1.18, \text { Range }=1-2 \text {, } \\
\text { Median }=1, \text { Mode }=1\end{array}$ & 0 & 0 & $\bigcirc$ & 0 & $\bigcirc$ & & \\
\hline $\begin{array}{l}\begin{array}{l}\text { Information kiosk } \\
\text { (unstaffed }) \\
\text { Mean }=2.36, \text { Range }=1-4, \\
\text { Median }=2.5, \text { Mode }=1\end{array} \\
\end{array}$ & 0 & 0 & 0 & 0 & 0 & ) & 0 \\
\hline
\end{tabular}

\section{How important is it for each of the following types of programming to be located or} offered within the student union?

\begin{tabular}{|c|c|c|c|c|c|c|c|}
\hline & $\begin{array}{c}\text { Very } \\
\text { Important }\end{array}$ & Important & $\begin{array}{l}\text { Somewhat } \\
\text { Important }\end{array}$ & Neutral & $\begin{array}{c}\text { Somewhat } \\
\text { Unimportant }\end{array}$ & Unimportant & $\begin{array}{c}\text { Very } \\
\text { Unimportant }\end{array}$ \\
\hline $\begin{array}{l}\underline{\text { Recruitment }} \\
\text { programming (e.g. } \\
\text { student tours, } \\
\text { recruitment events, } \\
\text { open houses, } \\
\text { orientation) } \\
\text { Mean }=1.77 \text {, } \text { Range }=1-4 \text {, } \\
\text { Median }=2, \text { Mode }=1 \& 2\end{array}$ & & & & & & & \\
\hline $\begin{array}{l}\text { Passive co-curricula } \\
\text { programming } \\
\text { Mean }=1.68, \text { } \text { ange }=1-3 \text {, } \\
\text { Median }=1.5, \text { Mode }=1\end{array}$ & & & & & & & \\
\hline $\begin{array}{l}\text { Active co-curricular } \\
\text { programming } \\
\text { Mean }=1.23, \text { } \text { Range }=1-2, \\
\text { Median }=1, \text { Mode }=1\end{array}$ & & & & & & & \\
\hline $\begin{array}{l}\text { Multicultural } \\
\text { programming } \\
\text { Mean }=1.36, \text { } \text { Range }=1-3 \text {, } \\
\text { Median }=1, \text { Mode }=1\end{array}$ & & & & & & & \\
\hline $\begin{array}{l}\text { Student-organized } \\
\text { programming } \\
\text { Mean }=1.00, \text { Range }=0, \\
\text { Median }=1, \text { Mode }=1\end{array}$ & & & & & & & \\
\hline
\end{tabular}




\begin{tabular}{|c|c|c|c|c|c|c|c|}
\hline & $\begin{array}{c}\text { Very } \\
\text { Important }\end{array}$ & Important & $\begin{array}{l}\text { Somewhat } \\
\text { Important }\end{array}$ & Neutral & $\begin{array}{c}\text { Somewhat } \\
\text { Unimportant }\end{array}$ & Unimportant & $\begin{array}{c}\text { Very } \\
\text { Unimportant }\end{array}$ \\
\hline $\begin{array}{l}\text { Formal educational } \\
\text { opportunities (e.g. } \\
\text { conferences, lectures, } \\
\text { symposia) } \\
\text { Mean }=1.73 \text {, Range }=1-4 \text {, } \\
\text { Median }=2 \text {, Mode }=2\end{array}$ & $\bigcirc$ & 0 & & ? & & & \\
\hline $\begin{array}{l}\text { Formal social } \\
\text { opportunities (e.g. } \\
\text { dinners, dances, } \\
\text { parties) } \\
\text { Mean=1.23, Range }=1-3 \text {, } \\
\text { Median=1, Mode }=1\end{array}$ & $\cap$ & $\cap$ & 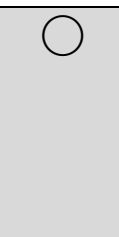 & $\cap$ & & & \\
\hline $\begin{array}{l}\text { Formal cultural events } \\
\text { (e.g. music or dance } \\
\text { performances } \\
\text { Mean }=1.27 \text {, Range }=1-3 \text {, } \\
\text { Median }=1, \text { Mode }=1\end{array}$ & 0 & 0 & $\bigcirc$ & $\cap$ & $\cap$ & & 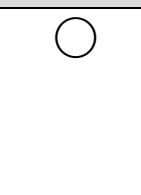 \\
\hline $\begin{array}{l}\text { Leadership \& service } \\
\text { opportunities for } \\
\text { students } \\
\text { Mean }=1.23 \text {, Range }=1-2 \text {, } \\
\text { Median }=1 \text {, Mode }=1\end{array}$ & 0 & 0 & $\bigcirc$ & O & O & 0 & ( \\
\hline $\begin{array}{l}\text { For-credit laboratories } \\
\text { \& experiences } \\
\text { Mean }=4.50, \text { } \text { Range }=2-7, \\
\text { Median }=4.5, \text { Mode }=3\end{array}$ & 0 & $\bigcirc$ & $\bigcirc$ & 0 & ? & $\Omega$ & 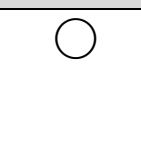 \\
\hline
\end{tabular}

\section{How important is the student union's involvement in each of the following roles in programming?}

\begin{tabular}{|c|c|c|c|c|c|c|c|}
\hline & $\begin{array}{c}\text { Very } \\
\text { Important }\end{array}$ & Important & $\begin{array}{l}\text { Somewhat } \\
\text { Important }\end{array}$ & Neutral & $\begin{array}{c}\text { Somewhat } \\
\text { Unimportant }\end{array}$ & Unimportant & $\begin{array}{c}\text { Very } \\
\text { Unimportant }\end{array}$ \\
\hline $\begin{array}{l}\text { Place - (The student } \\
\text { union provides a } \\
\text { venue or place, but } \\
\text { other offices or groups } \\
\text { design and offer the } \\
\text { programming.) } \\
\text { Mean }=1.27, \text { Range }=1-5 \text {, } \\
\text { Median }=1, \text { Mode }=1\end{array}$ & & & & & & & \\
\hline $\begin{array}{l}\text { Provider }- \text { (The } \\
\text { student union staff } \\
\text { designs and offers the } \\
\text { programming.) } \\
\text { Mean }=1.82, \text { Range }=1-5 \text {, } \\
\text { Median }=1, \text { Mode }=1\end{array}$ & & & & & & & \\
\hline $\begin{array}{l}\text { Partner - (The student } \\
\text { union staff partners } \\
\text { with other groups or } \\
\text { offices to design and } \\
\text { offer the } \\
\text { programming.) } \\
\text { Mean }=1.45, \text { Range }=1-3 \text {, } \\
\text { Median }=1, \text { Mode }=1\end{array}$ & & & & & & & \\
\hline
\end{tabular}




\section{How important is it for the following types of spaces to be located or offered within the union?}

\begin{tabular}{|c|c|c|c|c|c|c|c|}
\hline & $\begin{array}{c}\text { Very } \\
\text { Important }\end{array}$ & Important & $\begin{array}{l}\text { Somewhat } \\
\text { Important }\end{array}$ & Neutral & $\begin{array}{c}\text { Somewhat } \\
\text { Unimportant }\end{array}$ & Unimportant & $\begin{array}{c}\text { Very } \\
\text { Unimportant }\end{array}$ \\
\hline $\begin{array}{l}\text { Large-scale informal } \\
\text { gathering places (e.g. } \\
\text { lounge spaces) } \\
\text { Mean }=1.14, \text { Range }=1-3, \\
\text { Median }=1, \text { Mode }=1\end{array}$ & & & & & & & \\
\hline $\begin{array}{l}\text { Small-scale informal } \\
\text { gathering places (e.g. } \\
\text { nooks) } \\
\text { Mean }=1.09, \text { Range }=1-2, \\
\text { Median }=1, \text { Mode }=1\end{array}$ & & & & & & & \\
\hline $\begin{array}{l}\text { Large group study } \\
\text { spaces } \\
\text { Mean }=2.86, \text { Range }=1-5, \\
\text { Median }=3, \text { Mode }=3 \\
\end{array}$ & & & & & & & \\
\hline $\begin{array}{l}\text { Small group / } \\
\text { individual study } \\
\text { spaces } \\
\text { Mean }=2.00, \text { Range }=1-3, \\
\text { Median }=2, \text { Mode }=2 \\
\end{array}$ & & & & & & & \\
\hline $\begin{array}{l}\text { Open spaces } \\
\text { Mean }=1.41, \text { Range }=1-3, \\
\text { Median }=1, \text { Mode }=1\end{array}$ & & & & & & & \\
\hline $\begin{array}{l}\text { Atrium } \\
\text { Mean }=2.45, \text { Range }=1-5, \\
\text { Median }=2, \text { Mode }=2\end{array}$ & & & & & & & \\
\hline $\begin{array}{l}\text { Outdoor spaces/areas } \\
\text { (for eating, studying, } \\
\text { socializing, etc) } \\
\text { Mean }=1.86, \text { Range }=1-4, \\
\text { Median }=2, \text { Mode }=1 \& 2\end{array}$ & & & & & & & \\
\hline $\begin{array}{l}\text { Quiet areas } \\
\text { Mean }=2.27, \text { Range }=1-5, \\
\text { Median }=2, \text { Mode }=2\end{array}$ & & & & & & & \\
\hline $\begin{array}{l}\text { Sleeping spaces } \\
\text { Mean }=4.45, \text { } \text { Range }=2-7, \\
\text { Median }=4.5, \text { Mode }=5\end{array}$ & & & & & & & \\
\hline $\begin{array}{l}\text { Spiritual / prayer } \\
\text { spaces } \\
\text { Mean }=3.50, \text { Range }=1-6 \text {, } \\
\text { Median }=3.5, \text { Mode }=4\end{array}$ & & & & & & & \\
\hline $\begin{array}{l}\text { Large-scale formal } \\
\text { gathering spaces (e.g. } \\
\text { performance halls, ball } \\
\text { rooms, banquet \& } \\
\text { multi-purpose rooms) } \\
\text { Mean }=1.00 \text {, } \\
\text { Range }=0, \text { Median }=1 \text {, } \\
\text { Mode }=1\end{array}$ & & & & & & & \\
\hline $\begin{array}{l}\text { Small-scale formal } \\
\text { gathering spaces (e.g. } \\
\text { classrooms, meeting } \\
\text { rooms) } \\
\text { Mean }=1.14, \text { } \text { Range }=1-3 \text {, } \\
\text { Median }=1, \text { Mode }=1\end{array}$ & & & & & & & \\
\hline
\end{tabular}




\section{How important is it for each of the following amenities to be in the student union?}

\begin{tabular}{|c|c|c|c|c|c|c|c|}
\hline & $\begin{array}{c}\text { Very } \\
\text { Important }\end{array}$ & Important & $\begin{array}{l}\text { Somewhat } \\
\text { Important }\end{array}$ & Neutral & $\begin{array}{c}\text { Somewhat } \\
\text { Unimportant }\end{array}$ & Unimportant & $\begin{array}{c}\text { Very } \\
\text { Unimportant }\end{array}$ \\
\hline $\begin{array}{l}\text { Food court } \\
\text { Mean }=1.50, \text { Range }=1-3 \text {, } \\
\text { Median }=1, \text { Mode }=1\end{array}$ & 0 & 0 & 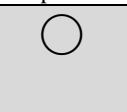 & 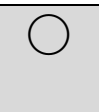 & & 0 & $\Omega$ \\
\hline $\begin{array}{l}\text { Cafeteria } \\
\text { Mean }=3.27 \text {, Range }=1-7, \\
\text { Median }=3, \text { Mode }=3\end{array}$ & $\bigcirc$ & 0 & & & & ) & 0 \\
\hline $\begin{array}{l}\text { Fast-service / fast-food } \\
\text { restaurant } \\
\text { Mean }=1.73, \text { Range }=1-3, \\
\text { Median }=2, \text { Mode }=1\end{array}$ & 0 & 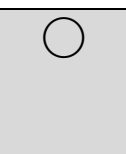 & & & & & \\
\hline $\begin{array}{l}\text { Full service/ sit-down } \\
\text { restaurant } \\
\text { Mean }=3.18, \text { Range }=1-6, \\
\text { Median }=3, \text { Mode }=3\end{array}$ & $\bigcirc$ & 0 & & & & & 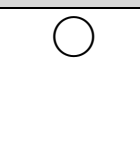 \\
\hline $\begin{array}{l}\text { Pub serving alcohol } \\
\text { Mean }=3.55, \text { Range }=1-7 \text {, } \\
\text { Median }=3.5, \text { Mode }=4\end{array}$ & $\Omega$ & 0 & & ) & & & 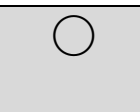 \\
\hline $\begin{array}{l}\text { Coffee Shop } \\
\text { Mean }=1.59, \text { Range }=1-3 \text {, } \\
\text { Median }=2, \text { Mode }=2\end{array}$ & 0 & 0 & & & & & ( \\
\hline $\begin{array}{l}\text { Internet café } \\
\text { Mean }=2.86, \text { Range }=1-6, \\
\text { Median }=3, \text { Mode }=2,3, \& 4\end{array}$ & 0 & 0 & & ) & & & ( \\
\hline $\begin{array}{l}\text { Catering services for } \\
\text { events and meetings } \\
\text { Mean }=1.77, \text { Range }=1-5 \text {, } \\
\text { Median }=1, \text { Mode }=1\end{array}$ & $\bar{T}$ & D & & $\bar{T}$ & & & 0 \\
\hline $\begin{array}{l}\text { Showers } \\
\text { Mean }=4.95, \text { Range }=2-7 \text {, } \\
\text { Median }=5, \text { Mode }=4\end{array}$ & 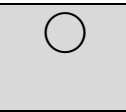 & 0 & & 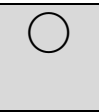 & & & \\
\hline $\begin{array}{l}\text { Gender neutral } \\
\text { bathrooms } \\
\text { Mean }=2.27, \text { Range }=1-4 \text {, } \\
\text { Median }=2, \text { Mode }=1\end{array}$ & 0 & ) & ( & D & & & \\
\hline $\begin{array}{l}\text { Lounge spaces with } \\
\text { televisions } \\
\text { Mean }=2.00, \text { Range }=1-5, \\
\text { Median }=2, \text { Mode }=2\end{array}$ & $\overline{7}$ & 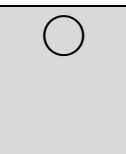 & 0 & & & 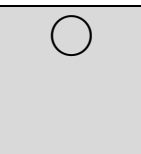 & ( \\
\hline $\begin{array}{l}\text { Locker rentals } \\
\text { Mean }=3.64, \text { Range }=2-5 \text {, } \\
\text { Median }=4, \text { Mode }=3 \& 44\end{array}$ & $\bigcirc$ & 0 & C & 0 & ) & 0 & ( \\
\hline $\begin{array}{l}\text { Bowling, billiard, } \\
\text { table-tennis center } \\
\text { Mean }=2.95, \text { Range }=1-5, \\
\text { Median }=3, \text { Mode }=2 \& 3 \\
\end{array}$ & $\Omega$ & $\Omega$ & ( & & & 0 & \\
\hline $\begin{array}{l}\text { Gaming centers }- \\
\text { electronic / video } \\
\text { Mean }=2.86, \text { Range }=1-5, \\
\text { Median }=3, \text { Mode }=3\end{array}$ & $\bigcirc$ & 0 & 0 & $\bigcirc$ & ( & $\bigcirc$ & C \\
\hline $\begin{array}{l}\text { Gaming centers - non- } \\
\text { electronic (e.g. table } \\
\text { games) } \\
\text { Mean }=3.14, \text { Range }=1-5 \text {, } \\
\text { Median }=3 \text {, Mode }=2\end{array}$ & 0 & 0 & 0 & 0 & 0 & 0 & 0 \\
\hline
\end{tabular}




\begin{tabular}{|l|c|c|c|c|c|c|c|}
\hline & $\begin{array}{c}\text { Very } \\
\text { Important }\end{array}$ & Important & $\begin{array}{c}\text { Somewhat } \\
\text { Important }\end{array}$ & Neutral & $\begin{array}{c}\text { Somewhat } \\
\text { Unimportant }\end{array}$ & Unimportant & $\begin{array}{c}\text { Very } \\
\text { Unimportant }\end{array}$ \\
\hline $\begin{array}{l}\text { Movie theatres } \\
\text { Mean=2.64, Range=1-5, } \\
\text { Median=3, Mode=3 }\end{array}$ & $\bigcirc$ & $\bigcirc$ & $\bigcirc$ & $\bigcirc$ & $\bigcirc$ & $\bigcirc$ & $\bigcirc$ \\
\hline $\begin{array}{l}\text { Outdoor recreation } \\
\text { equipment rental } \\
\text { Meann=3.91, Range=2-7, } \\
\text { Median }=3.5, \text { Mode=3 }\end{array}$ & $\bigcirc$ & $\bigcirc$ & $\bigcirc$ & $\bigcirc$ & $\bigcirc$ & $\bigcirc$ & $\bigcirc$ \\
\hline $\begin{array}{l}\text { Craft centers } \\
\text { Meani-4.00, Range=1-6, } \\
\text { Median=4, Mode=3 }\end{array}$ & $\bigcirc$ & $\bigcirc$ & $\bigcirc$ & $\bigcirc$ & $\bigcirc$ & $\bigcirc$ & $\bigcirc$ \\
\hline $\begin{array}{l}\text { Art galleries } \\
\text { Mean=2.77, Range=1-5, } \\
\text { Median=2, Mode=2 }\end{array}$ & $\bigcirc$ & $\bigcirc$ & $\bigcirc$ & $\bigcirc$ & $\bigcirc$ & $\bigcirc$ & $\bigcirc$ \\
\hline $\begin{array}{l}\text { Art (dispersed } \\
\text { throughout building) } \\
\text { Mean=1.77, Range=1-3, } \\
\text { Median=2, Mode=1 }\end{array}$ & $\bigcirc$ & $\bigcirc$ & $\bigcirc$ & $\bigcirc$ & $\bigcirc$ & $\bigcirc$ & $\bigcirc$ \\
\hline
\end{tabular}

\section{0. (Amenities, continued) How important is it for each of the following amenities to be in the student union?}

\begin{tabular}{|c|c|c|c|c|c|c|c|}
\hline & $\begin{array}{c}\text { Very } \\
\text { Important }\end{array}$ & Important & $\begin{array}{l}\text { Somewhat } \\
\text { Important }\end{array}$ & Neutral & $\begin{array}{c}\text { Somewhat } \\
\text { Unimportant }\end{array}$ & Unimportant & $\begin{array}{c}\text { Very } \\
\text { Unimportant }\end{array}$ \\
\hline $\begin{array}{l}\text { Book store } \\
\text { Mean }=2.14, \text { Range }=1-4 \text {, } \\
\text { Median }=2, \text { Mode }=1\end{array}$ & & & & & & & \\
\hline $\begin{array}{l}\text { Convenience store } \\
\text { Mean }=1.86, \text { Range }=1-4 \text {, } \\
\text { Median }=2, \text { Mode }=1\end{array}$ & & & & & & & \\
\hline $\begin{array}{l}\text { Banking services } \\
\text { Mean }=2.45, \text { Range }=1-4, \\
\text { Median }=2.5, \text { } \text { Mode }=3\end{array}$ & & & & & & & \\
\hline $\begin{array}{l}\text { ATM machine } \\
\text { Mean }=1.45, \text { } \text { Range }=1-2, \\
\text { Median }=1, \text { Mode }=1\end{array}$ & & & & & & & \\
\hline $\begin{array}{l}\text { Post office / mailing } \\
\text { services } \\
\text { Mean }=2.41, \text { Range }=1-5 \text {, } \\
\text { Median }=2, \text { Mode }=2\end{array}$ & & & & & & & \\
\hline $\begin{array}{l}\text { Travel agency } \\
\text { services } \\
\text { Mean }=4.82, \text { Range }=2-7, \\
\text { Median }=5, \text { Mode }=4\end{array}$ & & & & & & & \\
\hline $\begin{array}{l}\text { Barber } / \text { Beauty } \\
\text { shops } \\
\text { Mean }=4.59, \text { Range }=2-6 \text {, } \\
\text { Median }=4, \text { Mode }=4\end{array}$ & & & & & & & \\
\hline $\begin{array}{l}\text { Computer labs } \\
\text { Mean }=3.33, \text { Range }=1-6 \text {, } \\
\text { Median }=3, \text { Mode }=3\end{array}$ & & & & & & & \\
\hline $\begin{array}{l}\text { Computer stations/ } \\
\text { kiosks (not in a lab } \\
\text { room) } \\
\text { Mean }=2.24, \text { Range }=1-5, \\
\text { Median }=2, \text { Mode }=2\end{array}$ & & & & & & & \\
\hline $\begin{array}{l}\text { Copy } / \text { print services } \\
\text { Mean }=2.59, \text { Range }=1-5, \\
\text { Median }=3, \text { Mode }=3\end{array}$ & & & & & & & \\
\hline
\end{tabular}




\begin{tabular}{|c|c|c|c|c|c|c|c|}
\hline & $\begin{array}{c}\text { Very } \\
\text { Important }\end{array}$ & Important & $\begin{array}{l}\text { Somewhat } \\
\text { Important }\end{array}$ & Neutral & $\begin{array}{l}\text { Somewhat } \\
\text { Unimportant }\end{array}$ & Unimportant & $\begin{array}{c}\text { Very } \\
\text { Unimportant } \\
\end{array}$ \\
\hline $\begin{array}{l}\text { Printer stations / } \\
\text { kiosks (not in a } \\
\text { copy/print shop) } \\
\text { Mean }=2.45 \text {, Range }=1-5 \text {, } \\
\text { Median }=2, \text { Mode }=2\end{array}$ & 0 & 0 & 0 & 0 & $\bigcirc$ & 0 & 0 \\
\hline $\begin{array}{l}\text { Wireless internet } \\
\text { service } \\
\text { Meann=1.00, Range }=0, \\
\text { Median }=1, \text { Mode }=1\end{array}$ & 0 & 0 & 0 & 0 & $\bigcirc$ & 0 & 0 \\
\hline $\begin{array}{l}\text { Phone \& device } \\
\text { charging stations } \\
\text { Meann } 1.82, \text { Range }=1-4,4 \\
\text { Median }=2, \text { Mode }=2 \& 4\end{array}$ & 0 & 0 & 0 & 0 & 0 & 0 & 0 \\
\hline $\begin{array}{l}\text { Hotel connected to } \\
\text { the union } \\
\text { Mean } 4.73 \text {, Range }=2-7, \\
\text { Median }=5, \text { Mode } 4 \& 6\end{array}$ & 0 & 0 & 0 & 0 & 0 & 0 & 0 \\
\hline \multicolumn{8}{|c|}{$\begin{array}{l}\text { 11. Optional: If your responses differ from the apparent consensus (means) in this } \\
\text { section, please describe your primary rationale below. (You may also use this space if } \\
\text { you would like to comment further on the services, programs \& amenities of unions.) }\end{array}$} \\
\hline
\end{tabular}

\section{Part 3 - Attributes of Student Unions}

In this study, the "attributes" of the student union refer to characteristics which may influence the union's effectiveness in providing the specific amenities \& services (the "what"), through which it enacts its missions (the "how"), to fulfill its purposes (the "why").

The survey focuses on two types of attributes:

1. Physical attributes (e.g. location, design, physical condition)

2. Human attributes (e.g. people-related characteristics)

Continuing the example offered previously: a union may offer a food court (a specific amenity) as a means of providing food services (a mission), which contributes to fostering community (a larger purpose). However, attributes such as the location of the union building and design of the food court may influence how frequently students use that amenity or satisfaction they derive from it.

The questions in Part 3 ask you to rate the importance of various attributes of student unions. 


\section{How important is each of the following physical attributes of student union locations?}

\begin{tabular}{|c|c|c|c|c|c|c|c|}
\hline & $\begin{array}{c}\text { Very } \\
\text { Important }\end{array}$ & Important & $\begin{array}{l}\text { Somewhat } \\
\text { Important }\end{array}$ & Neutral & $\begin{array}{c}\text { Somewhat } \\
\text { Unimportant }\end{array}$ & Unimportant & $\begin{array}{c}\text { Very } \\
\text { Unimportant }\end{array}$ \\
\hline $\begin{array}{l}\text { Located close to the } \\
\text { physical center of } \\
\text { campus } \\
\begin{array}{l}\text { Mean }=1.64, \text { Range }=1-3, \\
\text { Median }=1, \text { Mode }=1\end{array}\end{array}$ & & & & & & & \\
\hline $\begin{array}{l}\text { Located in a high- } \\
\text { traffic area / pedestrian } \\
\text { crossroads of the } \\
\text { campus } \\
\text { Mean }=1.48, \text { Range }=1-4, \\
\text { Median }=1, \text { Mode }=1\end{array}$ & & & & & & & \\
\hline $\begin{array}{l}\begin{array}{l}\text { Located close to } \\
\text { residence halls }\end{array} \\
\text { Mean }=2.18, \text { } \text { ange }=1-5, \\
\text { Median }=2, \text { Mode }=2\end{array}$ & & & & & & & \\
\hline $\begin{array}{l}\text { Located close to the } \\
\text { library } \\
\text { Mean }=3.05, \\
\text { Range }=1-5, \text { Median } 3, \\
\text { Mode }=3\end{array}$ & & & & & & & \\
\hline $\begin{array}{l}\text { Located close to } \\
\text { parking } \\
\text { Mean }=1.86, \text { } \text { Range }=1-5, \\
\text { Median }=2, \text { Mode }=2\end{array}$ & & & & & & & \\
\hline $\begin{array}{l}\text { Located close to } \underline{\text { mass }} \\
\underline{\text { transit }} \\
\begin{array}{l}\text { Mean }=2.68, \text { Range }=1-5, \\
\text { Median }=3, \text { Mode }=2 \& 3\end{array}\end{array}$ & & & & & & & \\
\hline
\end{tabular}

\section{How important is each of the following physical attributes of student union exteriors?}

\begin{tabular}{|c|c|c|c|c|c|c|c|}
\hline & $\begin{array}{c}\text { Very } \\
\text { Important }\end{array}$ & Important & $\begin{array}{l}\text { Somewhat } \\
\text { Important }\end{array}$ & Neutral & $\begin{array}{c}\text { Somewhat } \\
\text { Unimportant }\end{array}$ & Unimportant & $\begin{array}{c}\text { Very } \\
\text { Unimportant } \\
\end{array}$ \\
\hline $\begin{array}{l}\text { Human scale design } \\
\text { (no more than } 3 \\
\text { stories high) } \\
\text { Mean }=3.23, \text { Range }=1-5, \\
\text { Median }=3.5, \text { Mode }=4\end{array}$ & & & & & & & \\
\hline $\begin{array}{l}\text { Attractive design of } \\
\text { exterior landscaping } \\
\text { Mean }=1.73, \text { Range }=1-3, \\
\text { Median }=1, \text { Mode }=1\end{array}$ & & & & & & & \\
\hline $\begin{array}{l}\text { Attractive design of } \\
\text { building exterior } \\
\text { Mean }=1.55, \text { Range }=1-3, \\
\text { Median }=1, \text { Mode }=1\end{array}$ & & & & & & & \\
\hline $\begin{array}{l}\text { Physical condition of } \\
\text { the building exterior } \\
\text { (Well }- \text { maintained) } \\
\text { Mean }=1.36 \text {, Range }=1-2 \text {, } \\
\text { Median }=1, \text { Mode }=1\end{array}$ & & & & & & & \\
\hline $\begin{array}{l}\text { Cleanliness of } \\
\text { building exterior } \\
\text { Mean }=1.41, \text { } \text { Range }=1-2 \text {, } \\
\text { Median }=1, \text { Mode }=1\end{array}$ & & & & & & & \\
\hline
\end{tabular}




\begin{tabular}{|l|c|c|c|c|c|c|c|}
\hline & $\begin{array}{c}\text { Very } \\
\text { Important }\end{array}$ & Important & $\begin{array}{c}\text { Somewhat } \\
\text { Important }\end{array}$ & Neutral & $\begin{array}{c}\text { Somewhat } \\
\text { Unimportant }\end{array}$ & Unimportant & $\begin{array}{c}\text { Very } \\
\text { Unimportant }\end{array}$ \\
\hline $\begin{array}{l}\text { Clearly defined } \\
\text { entrance }\end{array}$ & $\bigcirc$ & $\bigcirc$ & $\bigcirc$ & $\bigcirc$ & $\bigcirc$ & $\bigcirc$ & $\bigcirc$ \\
$\begin{array}{l}\text { Mean }=1.27 \text {, Range }=1-3, \\
\text { Median=1, Mode }=1\end{array}$ & $\bigcirc$ & $\bigcirc$ & $\bigcirc$ & $\bigcirc$ & $\bigcirc$ & $\bigcirc$ & $\bigcirc$ \\
\hline $\begin{array}{l}\text { Clear exterior } \\
\text { signage } \\
\begin{array}{l}\text { Mean }=1.45 \text {, Range }=1-3, \\
\text { Median=1, Mode=1 }\end{array}\end{array}$ & $\bigcirc$ & $\bigcirc$ & & & \\
\hline
\end{tabular}

\section{How important is each of the following physical attributes of student union interiors?}

\begin{tabular}{|c|c|c|c|c|c|c|c|}
\hline & $\begin{array}{c}\text { Very } \\
\text { Important }\end{array}$ & Important & $\begin{array}{l}\text { Somewhat } \\
\text { Important }\end{array}$ & Neutral & $\begin{array}{c}\text { Somewhat } \\
\text { Unimportant }\end{array}$ & Unimportant & $\begin{array}{c}\text { Very } \\
\text { Unimportant }\end{array}$ \\
\hline $\begin{array}{l}\text { Attractive design of } \\
\text { building interior } \\
\text { Mean } 1.23, \text { Range }=1-3, \\
\text { Median }=1, \text { Mode }=1\end{array}$ & $\bigcirc$ & $\cap$ & & $\cap$ & & & \\
\hline $\begin{array}{l}\text { Physical condition of } \\
\text { the building interior } \\
\text { (well }- \text { maintained) } \\
\text { Mean }=1.14 \text {, Range }=1-2 \text {, } \\
\text { Median }=1 \text {, Mode }=1\end{array}$ & $\cap$ & & 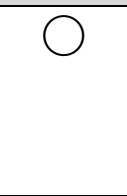 & & & & \\
\hline $\begin{array}{l}\text { Cleanliness of building } \\
\text { interior } \\
\text { Mean }=1.14, \text { Range }=1-2, \\
\text { Median }=1, \text { Mode }=1\end{array}$ & $\cap$ & 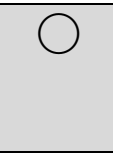 & $\overline{7}$ & $\cap$ & & & D \\
\hline $\begin{array}{l}\text { Clear interior signage } \\
\& \text { directions } \\
\text { Mean }=1.32, \text { Range }=1-2 \text {, } \\
\text { Median }=1 . \text { Mode }=1\end{array}$ & 0 & $\cap$ & 0 & ? & & & ) \\
\hline $\begin{array}{l}\text { ADA Accessible / } \\
\text { Barrier free } \\
\text { Mean }=1.18, \text { Range }=1-2, \\
\text { Median }=1, \text { Mode }=1\end{array}$ & 0 & 0 & 0 & 0 & & & 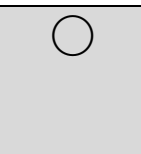 \\
\hline $\begin{array}{l}\text { Lots of windows / } \\
\text { Natural lighting } \\
\text { Mean }=1.41, \text { Range }=1-2, \\
\text { Median }=1, \text { Mode }=1\end{array}$ & $\bigcirc$ & 0 & 0 & 0 & & & ( \\
\hline $\begin{array}{l}\text { "Open" feel to the } \\
\text { building interior } \\
\text { Mean }=1.41, \text { Range }=1-2, \\
\text { Median }=1, \text { Mode }=1\end{array}$ & 0 & 0 & 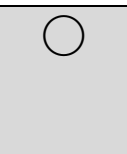 & 0 & 0 & & ( \\
\hline $\begin{array}{l}\text { Adequate lighting } \\
\text { fixtures } \\
\text { Mean }=1.41, \text { Range }=1-2, \\
\text { Median }=1 . \text { Mode }=1\end{array}$ & $\bigcirc$ & $\bigcirc$ & $\bigcirc$ & $O$ & 0 & 0 & 0 \\
\hline $\begin{array}{l}\text { Adequate \& } \\
\text { appropriate } \\
\text { technological } \\
\text { capability / } \\
\text { infrastructure } \\
\text { Mean=1.27, Range }=1-2 \text {, } \\
\text { Median=1, Mode }=1 \\
\end{array}$ & 0 & 0 & 0 & 0 & 0 & $\cap$ & $\bigcirc$ \\
\hline
\end{tabular}




\begin{tabular}{|l|c|c|c|c|c|c|c|}
\hline & $\begin{array}{c}\text { Very } \\
\text { Important }\end{array}$ & Important & $\begin{array}{c}\text { Somewhat } \\
\text { Important }\end{array}$ & Neutral & $\begin{array}{c}\text { Somewhat } \\
\text { Unimportant }\end{array}$ & Unimportant & $\begin{array}{c}\text { Very } \\
\text { Unimportant }\end{array}$ \\
\hline $\begin{array}{l}\text { Adequate \& } \\
\text { appropriate space for } \\
\text { all the various } \\
\text { functions / usage of } \\
\text { the union } \\
\text { Mean=1.18, Range=1-2, } \\
\text { Median=1, Mode=1 }\end{array}$ & $\bigcirc$ & $\bigcirc$ & $\bigcirc$ & $\bigcirc$ & $\bigcirc$ & $\bigcirc$ & $\bigcirc$ \\
\hline $\begin{array}{l}\text { Interior plantings / } \\
\text { plant life within the } \\
\text { union } \\
\text { Mean=2.45, Range=1-5, } \\
\text { Median=2, Mode=2 }\end{array}$ & $\bigcirc$ & $\bigcirc$ & $\bigcirc$ & $\bigcirc$ & $\bigcirc$ & $\bigcirc$ & $\bigcirc$ \\
\hline $\begin{array}{l}\text { Noise-proofing/ } \\
\begin{array}{l}\text { Sound-proofing } \\
\text { (reduce sound transfer } \\
\text { between areas) } \\
\text { Mean=2.23, Range=1-4, } \\
\text { Median=2, Mode=2 }\end{array}\end{array}$ & $\bigcirc$ & $\bigcirc$ & $\bigcirc$ & $\bigcirc$ & $\bigcirc$ & $\bigcirc$ & $\bigcirc$ \\
\hline
\end{tabular}

\section{5. (Interiors, continued) How important is each of the following physical attributes of student union interiors?}

\begin{tabular}{|c|c|c|c|c|c|c|c|}
\hline & $\begin{array}{c}\text { Very } \\
\text { Important }\end{array}$ & Important & $\begin{array}{l}\text { Somewhat } \\
\text { Important }\end{array}$ & Neutral & $\begin{array}{c}\text { Somewhat } \\
\text { Unimportant }\end{array}$ & Unimportant & $\begin{array}{c}\text { Very } \\
\text { Unimportant }\end{array}$ \\
\hline $\begin{array}{l}\text { Behavioral zoning } \\
\text { (e.g. clearly defined } \\
\text { places for eating, } \\
\text { shopping, studying, } \\
\text { relaxing) } \\
\text { Mean=2.81, } \text { Range }=1-5 \text {, } \\
\text { Median }=3, \text { Mode }=2\end{array}$ & & & & & & & \\
\hline $\begin{array}{l}\text { Good flow / traffic } \\
\text { pattern between } \\
\text { services and amenities } \\
\text { Mean }=1.50, \text { Range }=1-3 \text {, } \\
\text { Median }=1, \text { Mode }=1\end{array}$ & & & & & & & \\
\hline $\begin{array}{l}\text { Conveniently clustered } \\
\text { offices and services } \\
\text { ("one stop shop") } \\
\text { Mean }=2.14 \text {, Range }=1-3 \text {, } \\
\text { Median }=2, \text { Mode }=2\end{array}$ & & & & & & & \\
\hline $\begin{array}{l}\text { Has a focal point that } \\
\text { brings people together } \\
\text { (e.g. lounge, porch) } \\
\text { Mean }=1.59, \text { Range }=1-3 \text {, } \\
\text { Median }=1, \text { Mode }=1\end{array}$ & & & & & & & \\
\hline $\begin{array}{l}\text { Has "sticky spaces" } \\
\text { where people want to } \\
\text { come and stay } \\
\text { (regardless of } \\
\text { transaction needs) } \\
\text { Mean=1.55, Range }=1-3, \\
\text { Median }=1, \text { Mode }=1\end{array}$ & & & & & & & \\
\hline $\begin{array}{l}\text { Seating styles } / \text { types } \\
\text { encourage interaction } \\
\text { Mean }=1.36, \text { Range }=1-2, \\
\text { Median }=1, \text { Mode }=1\end{array}$ & & & & & & & \\
\hline
\end{tabular}




\begin{tabular}{|c|c|c|c|c|c|c|c|}
\hline & $\begin{array}{c}\text { Very } \\
\text { Important }\end{array}$ & Important & $\begin{array}{l}\text { Somewhat } \\
\text { Important }\end{array}$ & Neutral & $\begin{array}{c}\text { Somewhat } \\
\text { Unimportant }\end{array}$ & Unimportant & $\begin{array}{c}\text { Very } \\
\text { Unimportant }\end{array}$ \\
\hline $\begin{array}{l}\text { Seating \& tables can } \\
\text { be moved around } \\
\text { (modular) } \\
\text { Mean }=1.59, \text { Range }=1-3 \text {, } \\
\text { Median }=2, \text { Mode }=2\end{array}$ & 0 & 0 & & 0 & & 0 & \\
\hline $\begin{array}{l}\text { Flexible, multipurpose } \\
\text { design / moveable } \\
\text { walls } \\
\text { Mean }=1.91, \text { Range }=1-5, \\
\text { Median }=2, \text { Mode }=2\end{array}$ & $\bigcirc$ & $\bigcirc$ & $\cap$ & $\bigcirc$ & & & 0 \\
\hline $\begin{array}{l}\text { Individual climate } \\
\text { control in rooms/areas } \\
\text { (heating/ac) } \\
\text { Mean }=2.77, \text { Range }=1-5, \\
\text { Median }=3, \text { Mode }=2\end{array}$ & 0 & 0 & ) & & & & \\
\hline $\begin{array}{l}\text { Comfortable interiors } \\
\text { and furnishings } \\
\text { Mean }=1.32, \text { Range }=1-2, \\
\text { Median }=1, \text { Mode }=1\end{array}$ & 0 & 0 & & & & & \\
\hline $\begin{array}{l}\text { Stylistically modern or } \\
\text { timeless interiors and } \\
\text { furnishings (not } \\
\text { obviously dated) } \\
\text { Mean }=1.82, \text { Range }=1-3, \\
\text { Median }=2, \text { Mode }=2\end{array}$ & 0 & 0 & 6 & C & 0 & & \\
\hline $\begin{array}{l}\text { Engaging environment } \\
\text { Mean }=1.36, \text { Range }=1-3, \\
\text { Median }=1, \text { Mode }=1\end{array}$ & 0 & 0 & 0 & 0 & 0 & 0 & 0 \\
\hline $\begin{array}{l}\text { "Fun," playful } \\
\text { environment } \\
\text { Mean=1.68, Range=1-4, } \\
\text { Median }=1, \text { Mode }=1\end{array}$ & 0 & 0 & 0 & 0 & $\bigcirc$ & 0 & 0 \\
\hline
\end{tabular}

\section{How important is each of the following human attributes of student unions?}

\begin{tabular}{|c|c|c|c|c|c|c|c|}
\hline & $\begin{array}{c}\text { Very } \\
\text { Important }\end{array}$ & Important & $\begin{array}{l}\text { Somewhat } \\
\text { Important }\end{array}$ & Neutral & $\begin{array}{c}\text { Somewhat } \\
\text { Unimportant }\end{array}$ & Unimportant & $\begin{array}{c}\text { Very } \\
\text { Unimportant }\end{array}$ \\
\hline $\begin{array}{l}\text { Staff is knowledgeable } \\
\text { / well-trained } \\
\text { Mean }=1.09, \text { Range }=1-2 \text {, } \\
\text { Median }=1, \text { Mode }=1\end{array}$ & 0 & O & 0 & O & 2 & & 0 \\
\hline $\begin{array}{l}\text { Staff is student } \\
\text { focused / committed } \\
\text { Mean } 1.09, \text { Range }=1-2, \\
\text { Median }=1, \text { Mode }=1\end{array}$ & 0 & 0 & $\curvearrowright$ & 7 & 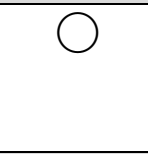 & & D \\
\hline $\begin{array}{l}\text { Staff is friendly } \\
\text { Mean }=1.00, \text { Range }=0, \\
\text { Median }=1, \text { Mode }=1\end{array}$ & 0 & O & 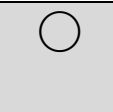 & 0 & 0 & & \\
\hline $\begin{array}{l}\text { Staff is diverse } \\
\text { Mean }=1.68, \\
\text { Range }=1-7, \text { Median }=1 \text {, } \\
\text { Mode }=1\end{array}$ & 0 & $\bigcirc$ & $\bigcirc$ & $\bigcirc$ & $\bigcirc$ & 0 & $\bigcirc$ \\
\hline $\begin{array}{l}\text { Staff includes student } \\
\text { employees } \\
\begin{array}{l}\text { Mean }=1.09, \text { Range }=1-2, \\
\text { Median }=1, \text { Mode }=1\end{array}\end{array}$ & $O$ & 0 & 0 & O & O & 0 & C \\
\hline
\end{tabular}




\begin{tabular}{|c|c|c|c|c|c|c|c|}
\hline & $\begin{array}{c}\text { Very } \\
\text { Important }\end{array}$ & Important & $\begin{array}{l}\text { Somewhat } \\
\text { Important }\end{array}$ & Neutral & $\begin{array}{c}\text { Somewhat } \\
\text { Unimportant }\end{array}$ & Unimportant & $\begin{array}{c}\text { Very } \\
\text { Unimportant }\end{array}$ \\
\hline $\begin{array}{l}\text { Staff size is adequate } \\
\text { Mean }=1.41, \text { Range }=1-3, \\
\text { Median } 1, \text { Mode }=1\end{array}$ & 0 & 0 & 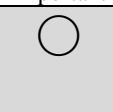 & 0 & & 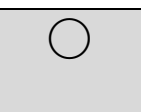 & \\
\hline $\begin{array}{l}\text { Student union has } \\
\text { strong partnerships } \\
\text { with admissions / } \\
\text { enrollment services } \\
\text { Mean }=2.23, \text { Range }=1-4 \text {, } \\
\text { Median }=2 \text {, Mode }=2 \\
\end{array}$ & $O$ & ? & 0 & 0 & 0 & & \\
\hline 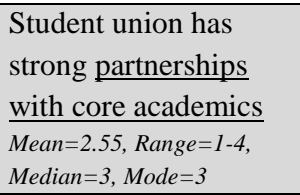 & $\bigcap$ & $\Omega$ & 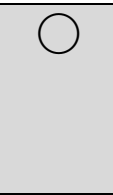 & & 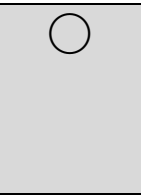 & & ) \\
\hline $\begin{array}{l}\text { Artifacts communicate } \\
\text { school spirit / history } \\
\begin{array}{l}\text { Mean }=1.82, \text { Range }=1-3, \\
\text { Median }=2, \text { Mode }=2\end{array}\end{array}$ & 0 & $\bigcirc$ & 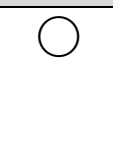 & & & & \\
\hline $\begin{array}{l}\text { Artifacts communicate } \\
\text { human diversity } \\
\text { Mean }=2.05, \text { Range }=1-6, \\
\text { Median }=2, \text { Mode }=2\end{array}$ & 0 & $\Omega$ & $\cap$ & & $\cap$ & & \\
\hline $\begin{array}{l}\text { Services are high } \\
\text { quality } \\
\text { Mean }=1.09, \text { Range }=1-2, \\
\text { Median }=1, \text { Mode }=1\end{array}$ & $\bigcap$ & $\Omega$ & O & $\bigcirc$ & $\cap$ & 0 & \\
\hline $\begin{array}{l}\text { Services are fast } \\
\text { Mean }=1.86, \text { Range }=1-4 \text {, } \\
\text { Median }=2, \text { Mode }=1\end{array}$ & 0 & 0 & 0 & 0 & 0 & 0 & \\
\hline $\begin{array}{l}\text { Services are essential / } \\
\text { destination services } \\
\text { that students need \& } \\
\text { must visit } \\
\text { Mean }=1.64, \text { Range }=1-3, \\
\text { Median }=2, \text { Mode }=2\end{array}$ & $O$ & $\bigcirc$ & $\bigcirc$ & $\bigcirc$ & 0 & O & O \\
\hline
\end{tabular}

\section{7. (Human attributes, continued) How important is each of the following human attributes of student unions?}

\begin{tabular}{|c|c|c|c|c|c|c|c|}
\hline & $\begin{array}{c}\text { Very } \\
\text { Important }\end{array}$ & Important & $\begin{array}{l}\text { Somewhat } \\
\text { Important }\end{array}$ & Neutral & $\begin{array}{c}\text { Somewhat } \\
\text { Unimportant }\end{array}$ & Unimportant & $\begin{array}{c}\text { Very } \\
\text { Unimportant }\end{array}$ \\
\hline $\begin{array}{l}\text { Variety and options } \\
\text { in dining } \\
\text { Mean }=1.41, \text { Range }=1-2, \\
\text { Median }=1, \text { Mode }=1\end{array}$ & & & & & & & \\
\hline $\begin{array}{l}\text { Variety and options } \\
\text { in lounge areas } \\
\text { Mean }=1.73, \text { } \text { Range }=1-3, \\
\text { Median }=2, \text { Mode }=2\end{array}$ & & & & & & & \\
\hline $\begin{array}{l}\text { Variety and options } \\
\text { in purposes for } \\
\text { visiting the building } \\
\text { (e.g. mixed use } \\
\text { building) } \\
\text { Mean }=1.45, \text { Range }=1-3 \text {, } \\
\text { Median }=1, \text { Mode }=1\end{array}$ & & & & & & & \\
\hline
\end{tabular}




\begin{tabular}{|c|c|c|c|c|c|c|c|}
\hline & $\begin{array}{c}\text { Very } \\
\text { Important }\end{array}$ & Important & $\begin{array}{l}\text { Somewhat } \\
\text { Important }\end{array}$ & Neutral & $\begin{array}{c}\text { Somewhat } \\
\text { Unimportant }\end{array}$ & Unimportant & $\begin{array}{c}\text { Very } \\
\text { Unimportant }\end{array}$ \\
\hline $\begin{array}{l}\text { Late /weekend hours } \\
\text { for students services } \\
\text { in building } \\
\text { Mean }=2.00, \text { Range }=1-4 \text {, } \\
\text { Median }=2, \text { Mode }=2\end{array}$ & 0 & 0 & 0 & 0 & & 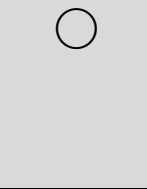 & \\
\hline $\begin{array}{l}\text { Late /weekend hours } \\
\text { for retail services } \\
\text { Mean }=2.59, \text { Range }=1-5, \\
\text { Median }=3, \text { Mode }=3\end{array}$ & 0 & 0 & 0 & $\bigcirc$ & & 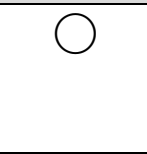 & ) \\
\hline $\begin{array}{l}\text { Late } / \text { weekend hours } \\
\text { for food services } \\
\text { Mean }=2.00, \text { Range }=1-4, \\
\text { Median }=2, \text { Mode }=1\end{array}$ & 0 & 0 & 0 & $\cap$ & & $\bigcirc$ & ) \\
\hline $\begin{array}{l}\text { Late /weekend hours } \\
\text { for entertainment / } \\
\text { recreation offerings } \\
\text { Mean }=1.76, \text { Range }=1-5, \\
\text { Median }=1, \text { Mode }=1\end{array}$ & 0 & 0 & 0 & 0 & & ) & ) \\
\hline $\begin{array}{l}\text { Prices at the various } \\
\text { food and retail outlets } \\
\text { are affordable for } \\
\text { students } \\
\begin{array}{l}\text { Mean }=1.55, \text { Range }=1-3, \\
\text { Median }=1, \text { Mode }=1\end{array}\end{array}$ & 0 & 0 & 0 & 0 & 0 & 0 & ) \\
\hline $\begin{array}{l}\text { Union feels } \\
\text { welcoming / inviting } \\
\text { Mean }=1.14, \text { Range }=1-2, \\
\text { Median }=1, \text { Mode }=1\end{array}$ & 0 & 0 & 0 & 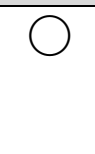 & ) & & \\
\hline $\begin{array}{l}\text { Union feels like a } \\
\text { safe place- } \\
\text { physically } \\
\text { Mean }=1.20, \text { Range }=1-2, \\
\text { Median }=1, \text { Mode }=1\end{array}$ & 0 & 0 & 0 & 0 & $\cap$ & 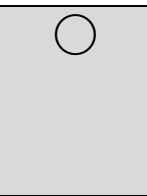 & \\
\hline $\begin{array}{l}\text { Union feels like a } \\
\text { safe place }- \\
\text { psychologically } \\
\begin{array}{l}\text { Mean }=1.14, \text { Range }=1-2, \\
\text { Median }=1, \text { Mode }=1\end{array}\end{array}$ & 0 & 0 & 0 & 0 & 0 & 0 & $\bigcirc$ \\
\hline $\begin{array}{l}\text { Union conveys to } \\
\text { students that they } \\
\text { matter } \\
\text { Mean }=1.05, \text { Range }=1-2, \\
\text { Median }=1, \text { Mode }=1\end{array}$ & 0 & 0 & 0 & 0 & 0 & 0 & 0 \\
\hline $\begin{array}{l}\text { 18. Optional: If y } \\
\text { section, pleas } \\
\text { you would like }\end{array}$ & $\begin{array}{l}\text { respe } \\
\text { escribe } \\
\text { comm }\end{array}$ & $\begin{array}{l}\text { diffe } \\
\text { Ir pri } \\
\text { furthe }\end{array}$ & $\begin{array}{l}\text { from } t \\
\text { y ratio } \\
\text { the } p h\end{array}$ & l & $\begin{array}{l}\text { consens } \\
\text { (You may attri } \\
\text { man }\end{array}$ & $\begin{array}{l}\text { (means) i } \\
\text { so use thi } \\
\text { tes of uni }\end{array}$ & $\begin{array}{l}\text { this } \\
\text { pace if } \\
\text { s.) }\end{array}$ \\
\hline
\end{tabular}




\section{Part 4 - Barriers \& Constraints for Student Unions}

In this study, "barriers \& constraints" refer to specific issues or concerns which may prohibit or impede the union's ability or effectiveness in fulfilling its purpose(s) and mission(s).

While a lack of any desirable attribute, amenity or service can be a barrier or constraint, this section focuses on four specific things:

1. Physical constraints

2. Knowledge constraints

3. Financial constraints

4. Political constraints

The questions in Part 4 ask you to rate the importance of various barriers \& constraints facing student unions.

\section{How important is each of the following physical constraints in influencing student union effectiveness?}

\begin{tabular}{|c|c|c|c|c|c|c|c|}
\hline & $\begin{array}{c}\text { Very } \\
\text { Important }\end{array}$ & Important & $\begin{array}{l}\text { Somewhat } \\
\text { Important }\end{array}$ & Neutral & $\begin{array}{c}\text { Somewhat } \\
\text { Unimportant }\end{array}$ & Unimportant & $\begin{array}{c}\text { Very } \\
\text { Unimportant }\end{array}$ \\
\hline $\begin{array}{l}\text { Location - poor } \\
\text { original choice / } \\
\text { peripheral to campus } \\
\text { Mean }=1.50, \text { Range }=1-3 \text {, } \\
\text { Median }=1, \text { Mode }=1\end{array}$ & & & & & & & \\
\hline $\begin{array}{l}\text { Location - displaced / } \\
\text { center of campus has } \\
\text { shifted as campus } \\
\text { grew } \\
\text { Mean }=2.09, \text { Range }=1-5, \\
\text { Median }=2, \text { Mode }=2\end{array}$ & & & & & & & \\
\hline $\begin{array}{l}\underline{\text { Size }}-\text { Inadequate to } \\
\text { accommodate desired } \\
\text { purposes (can't fit all } \\
\text { the functions in) } \\
\text { Mean }=1.55, \text { Range }=1-4, \\
\text { Median }=1, \text { Mode }=1\end{array}$ & & & & & & & \\
\hline $\begin{array}{l}\underline{\text { Size }}-\text { Inadequate to } \\
\text { serve level of usage / } \\
\text { student enrollment } \\
\text { (crowded usage) } \\
\text { Mean }=1.48, \text { Range }=1-3, \\
\text { Median }=1, \text { Mode }=1\end{array}$ & & & & & & & \\
\hline $\begin{array}{l}\text { Comprehensiveness - } \\
\text { Missing key services } \\
\& \text { amenities that } \\
\text { should be in the union } \\
\text { Mean }=1.86, \text { Range }=1-3, \\
\text { Median }=2, \text { Mode }=2\end{array}$ & & & & & & & \\
\hline $\begin{array}{l}\text { Design - outdated and } \\
\text { unappealing } \\
\text { Mean }=1.64, \text { Range }=1-3, \\
\text { Median1.5, Mode }=1\end{array}$ & & & & & & & \\
\hline
\end{tabular}




\begin{tabular}{|c|c|c|c|c|c|c|c|}
\hline & $\begin{array}{c}\text { Very } \\
\text { Important }\end{array}$ & Important & $\begin{array}{l}\text { Somewhat } \\
\text { Important }\end{array}$ & Neutral & $\begin{array}{c}\text { Somewhat } \\
\text { Unimportant }\end{array}$ & Unimportant & $\begin{array}{c}\text { Very } \\
\text { Unimportant }\end{array}$ \\
\hline $\begin{array}{l}\text { Design - poor building } \\
\text { design with too many } \\
\text { doors, stairwells, } \\
\text { corners } \\
\text { Mean }=1.77, \text { Range }=1-3, \\
\text { Median }=2, \text { Mode }=2\end{array}$ & 0 & 0 & O & 0 & & ) & \\
\hline $\begin{array}{l}\text { Design }- \text { not ADA } \\
\text { compliant / accessible } \\
\text { Mean }=1.50, \text { Range }=1-3, \\
\text { Median }=1, \text { Mode }=1\end{array}$ & $\bigcirc$ & 0 & 0 & $\Omega$ & $\cap$ & $\cap$ & 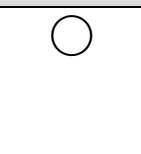 \\
\hline $\begin{array}{l}\text { Design - hard walls \& } \\
\text { fixed equipment with } \\
\text { limited adaptability / } \\
\text { flexibility } \\
\text { Mean }=2.14, \text { Range }=1-4, \\
\text { Median }=2, \text { Mode }=2\end{array}$ & 0 & $\Omega$ & 0 & $\cap$ & & & \\
\hline $\begin{array}{l}\begin{array}{l}\text { Infrastructure - } \\
\text { aging/poor } \\
\text { infrastructure (e.g. } \\
\text { HVAC, plumbing, } \\
\text { wiring) } \\
\text { Mean }=1.41 \text {, Range }=1-3 \text {, } \\
\text { Median }=1 \text {, Mode }=1\end{array} \\
\end{array}$ & 0 & 0 & 0 & 0 & & ) & \\
\hline $\begin{array}{l}\text { Infrastructure }- \\
\text { asbestos, lead, or other } \\
\text { health concerns must } \\
\text { be addressed } \\
\text { Mean }=1.41, \text { Range }=1-3, \\
\text { Median }=1, \text { Mode }=1\end{array}$ & 0 & $\Omega$ & 0 & & & & \\
\hline $\begin{array}{l}\text { Building }- \text { neglected, } \\
\text { poorly maintained, run } \\
\text { down, worn out } \\
\text { Mean }=1.29, \text { Range }=1-2, \\
\text { Median }=1, \text { Mode }=1\end{array}$ & $\bigcirc$ & $\cap$ & D & & D & & \\
\hline $\begin{array}{l}\text { Building }- \text { need to } \\
\text { preserve desired } \\
\text { architectural, historic } \\
\text { or traditional value } \\
\text { Mean }=2.18, \text { Range }=1-5, \\
\text { Median }=2, \text { Mode }=2\end{array}$ & 0 & 0 & 0 & 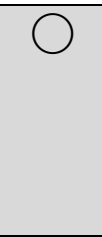 & C & ) & \\
\hline $\begin{array}{l}\text { Building }- \text { need to } \\
\text { keep union within one } \\
\text { building } \\
\text { Meaning.09, Range }=1-5, \\
\text { Median }=3, \text { Mode }=3\end{array}$ & 0 & $\bigcirc$ & 0 & $\bigcirc$ & $\bigcirc$ & 0 & 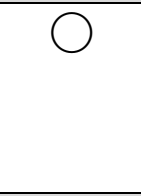 \\
\hline $\begin{array}{l}\text { Building }- \text { need to } \\
\text { split union across } \\
\text { multiple buildings } \\
\text { Mean }=3.59, \text { Range }=1-6, \\
\text { Median }=4, \text { Mode }=4 \& 5\end{array}$ & 0 & 0 & 0 & 0 & 0 & 0 & 0 \\
\hline
\end{tabular}




\section{How important is each of the following knowledge constraints in influencing student union effectiveness?}

\begin{tabular}{|c|c|c|c|c|c|c|c|}
\hline & $\begin{array}{c}\text { Very } \\
\text { Important }\end{array}$ & Important & $\begin{array}{l}\text { Somewhat } \\
\text { Important }\end{array}$ & Neutral & $\begin{array}{c}\text { Somewhat } \\
\text { Unimportant }\end{array}$ & Unimportant & $\begin{array}{c}\text { Very } \\
\text { Unimportant }\end{array}$ \\
\hline $\begin{array}{l}\text { Needs assessment - } \\
\text { need to identify } \\
\text { current } \& \text { future } \\
\text { student needs for the } \\
\text { union } \\
\text { Mean }=1.59, \text { Range }=1-3 \text {, } \\
\text { Median }=1.5, \text { Mode }=1\end{array}$ & & & & & & & \\
\hline $\begin{array}{l}\text { User input - need to } \\
\text { seek input from } \\
\text { multiple consumers / } \\
\text { populations served by } \\
\text { the union } \\
\text { Mean }=1.33, \text { Range }=1-2 \text {, } \\
\text { Median }=1, \text { Mode }=1\end{array}$ & & & & & & & \\
\hline $\begin{array}{l}\underline{\text { Satisfaction }} \\
\text { assessment } \\
\text { measure union's } \\
\text { effectiveness in } \\
\text { meeting student \& } \\
\text { community needs } \\
\text { Mean }=1.45, \text { Range }=1-3 \text {, } \\
\text { Median }=1, \text { Mode }=1\end{array}$ & & & & & & & \\
\hline $\begin{array}{l}\text { Outcomes assessment } \\
\text { - need to measure and } \\
\text { prove the union's } \\
\text { contribution to the } \\
\text { educational \& co- } \\
\text { curricular process } \\
\text { Mean }=1.73, \text { Range }=1-5 \text {, } \\
\text { Median }=1.5, \text { Mode }=1\end{array}$ & & & & & & & \\
\hline $\begin{array}{l}\text { Staff - have } \\
\text { insufficient awareness } \\
\text { of their role in student } \\
\text { development as } \\
\text { educators } \\
\text { Mean }=1.59, \text { Range }=1-2, \\
\text { Median=2, Mode }=2\end{array}$ & & & & & & & \\
\hline $\begin{array}{l}\text { Staff - have } \\
\text { insufficient knowledge } \\
\text { about student } \\
\text { development theory } \\
\begin{array}{l}\text { Mean }=2.29, \text { Range }=1-5, \\
\text { Median }=2, \text { Mode }=2\end{array}\end{array}$ & & & & & & & \\
\hline $\begin{array}{l}\text { Staff - have } \\
\text { insufficient knowledge } \\
\text { about student learning } \\
\text { outcomes \& } \\
\text { assessment } \\
\text { Mean }=2.05, \text { Range }=1-3, \\
\text { Median }=2, \text { Mode }=2\end{array}$ & & & & & & & \\
\hline
\end{tabular}




\begin{tabular}{|c|c|c|c|c|c|c|c|}
\hline & $\begin{array}{c}\text { Very } \\
\text { Important }\end{array}$ & Important & $\begin{array}{l}\text { Somewhat } \\
\text { Important }\end{array}$ & Neutral & $\begin{array}{l}\text { Somewhat } \\
\text { Unimportant }\end{array}$ & Unimportant & $\begin{array}{c}\text { Very } \\
\text { Unimportan }\end{array}$ \\
\hline $\begin{array}{l}\text { Staff }- \text { have difficulty } \\
\text { in recruiting and } \\
\text { retaining student- } \\
\text { focused union staff } \\
\text { Meann } 1.55, \text { Range }=1-2,2 \\
\text { Median }=2, \text { Mode }=2\end{array}$ & 0 & 0 & 0 & 0 & 0 & 0 & 0 \\
\hline $\begin{array}{l}\text { Staff - need more } \\
\text { student involvement in } \\
\text { union programming } \\
\text { and management } \\
\text { Mean } 1.59, \text { Range }=1-4, \\
\text { Median } 1.5, \text {, Mode }=1\end{array}$ & 0 & 0 & 0 & 0 & 0 & 0 & 0 \\
\hline $\begin{array}{l}\text { Outsourced service } \\
\text { providers - do not } \\
\text { understand / value / } \\
\text { uphold importance of } \\
\text { student employment as } \\
\text { a developmental } \\
\text { process } \\
\text { Meann=2.09, Range }=1-4, \\
\text { Median }=2, \text { Mode }=2\end{array}$ & 0 & 0 & 0 & 0 & 0 & 0 & 0 \\
\hline $\begin{array}{l}\text { Academic affairs - } \\
\text { lack understanding or } \\
\text { appreciation of student } \\
\text { development \& the } \\
\text { union } \\
\text { Mean }=2.00, \text { Range }=1-3 \text {, } \\
\text { Median }=2, \text { Mode }=2\end{array}$ & 0 & 0 & $\mathrm{O}$ & 0 & 0 & 0 & $\mathrm{O}$ \\
\hline $\begin{array}{l}\text { Campus leaders - lack } \\
\text { understanding or } \\
\text { appreciation of student } \\
\text { development \& the } \\
\text { union } \\
\text { Meann } 1.68, \text { Range }=1-3, \\
\text { Median }=2 \text {, Mode }=2\end{array}$ & 0 & 0 & 0 & 0 & 0 & 0 & 0 \\
\hline $\begin{array}{l}\text { General management - } \\
\text { insufficient } \\
\text { understanding of } \\
\text { "whole enterprise" of } \\
\text { the union } \\
\text { Meann } 1.52, \text { Range }=1-4 \text {, } \\
\text { Median }=1, \text { Mode }=1\end{array}$ & 0 & 0 & 0 & 0 & 0 & 0 & 0 \\
\hline $\begin{array}{l}\text { General management }- \\
\text { inappropriate } \\
\text { administrative } \\
\text { paradigms (e.g. } \\
\text { "facilities" framework } \\
\text { vs "student } \\
\text { development" } \\
\text { framework } \\
\text { Mean=1.68, Rangee }=1-3, \\
\text { Mediann=2, Mode }=2\end{array}$ & 0 & 0 & 0 & 0 & 0 & 0 & 0 \\
\hline
\end{tabular}




\begin{tabular}{|c|c|c|c|c|c|c|c|}
\hline & $\begin{array}{c}\text { Very } \\
\text { Important }\end{array}$ & Important & $\begin{array}{l}\text { Somewhat } \\
\text { Important }\end{array}$ & Neutral & $\begin{array}{c}\text { Somewhat } \\
\text { Unimportant }\end{array}$ & Unimportant & $\begin{array}{c}\text { Very } \\
\text { Unimportant } \\
\text { Unt }\end{array}$ \\
\hline $\begin{array}{l}\text { General management - } \\
\text { space is used } \\
\text { inefficiently } \\
\text { Mean }=2.00, \text { Range }=1-3, \\
\text { Median }=2, \text { Mode }=2\end{array}$ & 0 & 0 & 0 & 0 & $\cap$ & 0 & 0 \\
\hline $\begin{array}{l}\text { General management - } \\
\text { student union has lost } \\
\text { its focus on students } \\
\text { Mean }=1.64, \text { Range }=1-6, \\
\text { Median }=1, \text { Mode }=1\end{array}$ & 0 & 0 & 0 & 0 & 0 & 0 & 0 \\
\hline
\end{tabular}

\section{How important is each of the following financial constraints in influencing student} union effectiveness?

\begin{tabular}{|c|c|c|c|c|c|c|c|}
\hline & $\begin{array}{c}\text { Very } \\
\text { Important }\end{array}$ & Important & $\begin{array}{l}\text { Somewhat } \\
\text { Important }\end{array}$ & Neutral & $\begin{array}{c}\text { Somewhat } \\
\text { Unimportant }\end{array}$ & Unimportant & $\begin{array}{c}\text { Very } \\
\text { Unimportant }\end{array}$ \\
\hline $\begin{array}{l}\text { Expenses }- \text { technology } \\
\text { (e.g. increasing costs } \\
\text { or inadequate budget) } \\
\text { Mean }=1.62, \text { Range }=1-3 \text {, } \\
\text { Median }=2, \text { Mode }=2\end{array}$ & & & & & & & \\
\hline $\begin{array}{l}\text { Expenses - union } \\
\text { operations (e.g. } \\
\text { increasing costs or } \\
\text { inadequate budget for } \\
\text { utilities, supplies, } \\
\text { equipment) } \\
\text { Mean }=1.50, \text { Range }=1-2 \text {, } \\
\text { Median }=1.5, \text { Mode }=1 \& 2\end{array}$ & & & & & & & \\
\hline $\begin{array}{l}\text { Expenses }-\underline{\text { staffing }} \\
\text { (e.g. increasing costs } \\
\text { or inadequate budget } \\
\text { for number of staff; } \\
\text { operating hours) } \\
\text { Mean }=1.50, \text { Range }=1-2 \text {, } \\
\text { Median }=1.5, \text { Mode }=1 \& 2\end{array}$ & & & & & & & \\
\hline $\begin{array}{l}\text { Expenses - basic } \\
\text { refurbishments \& } \\
\underline{\text { upgrades (e.g. }} \\
\text { increasing costs or } \\
\text { inadequate budget for } \\
\text { furniture \& lighting } \\
\text { replacement) } \\
\text { Mean }=1.59, \text { Range }=1-2 \text {, } \\
\text { Median }=2, \text { Mode }=2\end{array}$ & & & & & & & \\
\hline $\begin{array}{l}\text { Expenses - needed } \\
\text { maintenance (e.g. } \\
\text { increasing costs or } \\
\text { inadequate budget) } \\
\text { Mean }=1.52, \text { Range }=1-2 \text {, } \\
\text { Median }=2, \text { Mode }=2\end{array}$ & & & & & & & \\
\hline
\end{tabular}




\begin{tabular}{|c|c|c|c|c|c|c|c|}
\hline & $\begin{array}{c}\text { Very } \\
\text { Important }\end{array}$ & Important & $\begin{array}{l}\text { Somewhat } \\
\text { Important }\end{array}$ & Neutral & $\begin{array}{c}\text { Somewhat } \\
\text { Unimportant }\end{array}$ & Unimportant & $\begin{array}{c}\text { Very } \\
\text { Unimportant }\end{array}$ \\
\hline $\begin{array}{l}\text { Revenues -allocations } \\
\text { from institution's } \\
\text { general operating } \\
\text { budget insufficient to } \\
\text { support union } \\
\text { Mean }=2.27, \text { Range }=1-6, \\
\text { Median }=2 \text {, Mode }=1\end{array}$ & 0 & 0 & 0 & 0 & I & & \\
\hline $\begin{array}{l}\text { Revenues }- \text { student } \\
\text { fees insufficient to } \\
\text { support union } \\
\text { Mean }=1.82, \text { Range }=1-5, \\
\text { Median }=2, \text { Mode }=1\end{array}$ & 0 & 尺 & ? & $\Omega$ & 0 & & \\
\hline $\begin{array}{l}\text { Revenues }- \text { fundraising } \\
\text { insufficient to support } \\
\text { union (e.g. gifts, } \\
\text { donations) } \\
\text { Mean }=2.86, \text { Range }=1-6 \text {, } \\
\text { Median }=4 \text {, Mode }=3 \\
\end{array}$ & 0 & 0 & ? & 0 & & & \\
\hline $\begin{array}{l}\text { Revenues - } \\
\text { overreliance on } \\
\text { student fee support } \\
\text { (e.g. need to reduce, } \\
\text { concerns for college } \\
\text { costs \& student debt) } \\
\text { Mean }=1.82, \text { Range }=1-3, \\
\text { Median }=2, \text { Mode }=1\end{array}$ & $\cap$ & $\cap$ & 0 & 0 & 0 & & \\
\hline $\begin{array}{l}\text { Revenues - need to } \\
\text { increase use of the } \\
\text { union service } \\
\text { Mean }=1.95, \text { Range }=1-4 \text {, } \\
\text { Median }=2 \text {, Mode }=2\end{array}$ & & & & 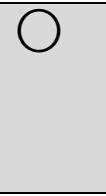 & 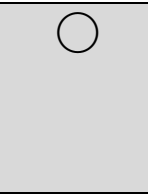 & & D \\
\hline $\begin{array}{l}\text { Revenues - unions } \\
\text { must resort to } \\
\text { becoming malls with } \\
\text { outsourced retail stores } \\
\text { in order to remain } \\
\text { financially viable. } \\
\text { Mean }=3.00, \text { Range }=1-7, \\
\text { Median }=3, \text { Mode }=2\end{array}$ & 0 & ) & ( & 0 & 0 & & D \\
\hline $\begin{array}{l}\text { Revenues }- \text { unions } \\
\text { must resort to serving } \\
\text { paying public purposes } \\
\text { more than non-paying } \\
\text { student purposes in } \\
\text { order to remain } \\
\text { financially viable } \\
\text { Mean }=2.50, \text { Range }=1-7 \text {, } \\
\text { Median }=2, \text { Mode }=2\end{array}$ & 0 & 0 & 0 & 0 & 0 & 2 & 0 \\
\hline $\begin{array}{l}\text { Auxiliary enterprise - } \\
\text { ineffective financial } \\
\text { model supporting } \\
\text { union (e.g. adequacy, } \\
\text { predictability) } \\
\text { Mean }=2.41, \text { Range }=1-6, \\
\text { Median }=2, \text { Mode }=2 \\
\end{array}$ & O & 0 & $\mathrm{O}$ & 0 & 0 & 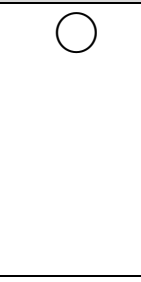 & 0 \\
\hline
\end{tabular}




\begin{tabular}{|c|c|c|c|c|c|c|c|}
\hline & $\begin{array}{c}\text { Very } \\
\text { Important }\end{array}$ & Important & $\begin{array}{l}\text { Somewhat } \\
\text { Important }\end{array}$ & Neutral & $\begin{array}{c}\text { Somewhat } \\
\text { Unimportant }\end{array}$ & Unimportant & $\begin{array}{c}\text { Very } \\
\text { Unimportant }\end{array}$ \\
\hline $\begin{array}{l}\text { Auxiliary enterprise - } \\
\text { difficult to be self- } \\
\text { supporting } \\
\text { Mean }=2.23, \text { Range }=1-5, \\
\text { Median }=2, \text { Mode }=2\end{array}$ & 0 & 0 & 0 & 0 & $\frown$ & & \\
\hline $\begin{array}{l}\text { Auxiliary enterprise - } \\
\text { burdensome } \\
\text { expectation that union } \\
\text { will make \& } \\
\text { contribute excess } \\
\text { revenues to add to } \\
\text { institutional budget } \\
\text { Mean }=2.18, \text { Range }=1-6, \\
\text { Median }=2, \text { Mode }=1 \& 2\end{array}$ & 0 & $\cap$ & $\bigcirc$ & $\Omega$ & $\bigcirc$ & $\bigcirc$ & ) \\
\hline $\begin{array}{l}\text { Capital expenses - } \\
\text { lack of funding for } \\
\text { union construction, } \\
\text { renovation and } \\
\text { expansion } \\
\text { Mean }=1.73 \text {, Range }=1-4 \text {, } \\
\text { Median }=2 \text {, Mode }=1\end{array}$ & ) & $\Omega$ & & ( & 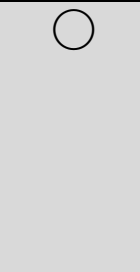 & & \\
\hline $\begin{array}{l}\text { Capital expenses - } \\
\text { lack of state support / } \\
\text { appropriations for } \\
\text { union construction, } \\
\text { renovation and } \\
\text { expansion } \\
\text { Mean }=2.09, \text { Range }=1-6, \\
\text { Median }=2, \text { Mode }=1\end{array}$ & 0 & $\Omega$ & $\Omega$ & 0 & $\bigcirc$ & $\bigcirc$ & $\bigcirc$ \\
\hline $\begin{array}{l}\text { Capital expenses - } \\
\text { bond issues (e.g. poor } \\
\text { university bond rating, } \\
\text { failure to make bond } \\
\text { payments) } \\
\text { Mean }=2.45, \text { Range }=1-4 \text {, } \\
\text { Median }=2.5, \text { Mode }=1 \\
\end{array}$ & 0 & 0 & 0 & 0 & 0 & 0 & 0 \\
\hline
\end{tabular}

\section{How important is each of the following political constraints in influencing student} union effectiveness?

\begin{tabular}{|c|c|c|c|c|c|c|c|}
\hline & $\begin{array}{c}\text { Very } \\
\text { Important }\end{array}$ & Important & $\begin{array}{l}\text { Somewhat } \\
\text { Important }\end{array}$ & Neutral & $\begin{array}{c}\text { Somewhat } \\
\text { Unimportant }\end{array}$ & Unimportant & $\begin{array}{c}\text { Very } \\
\text { Unimportant }\end{array}$ \\
\hline $\begin{array}{l}\text { Competition on } \\
\text { campus (e.g. similar } \\
\text { services \& amenities } \\
\text { offered in other } \\
\text { academic or support } \\
\text { buildings) } \\
\text { Mean }=2.32, \text { Range }=1-6, \\
\text { Median }=2, \text { Mode }=2\end{array}$ & 0 & & & & & & \\
\hline $\begin{array}{l}\text { Competition off } \\
\text { campus (e.g. similar } \\
\text { service \& amenity } \\
\text { providers in town) } \\
\text { Mean }=3.27, \text { Range }=1-7, \\
\text { Median }=3, \text { Mode }=3\end{array}$ & & & & & & & \\
\hline
\end{tabular}




\begin{tabular}{|c|c|c|c|c|c|c|c|}
\hline & $\begin{array}{c}\text { Very } \\
\text { Important }\end{array}$ & Important & $\begin{array}{l}\text { Somewhat } \\
\text { Important }\end{array}$ & Neutral & $\begin{array}{c}\text { Somewhat } \\
\text { Unimportant }\end{array}$ & Unimportant & $\begin{array}{c}\text { Very } \\
\text { Unimportant }\end{array}$ \\
\hline $\begin{array}{l}\text { Prioritization of } \\
\text { student union in the } \\
\text { institutional budget } \\
\text { process } \\
\text { Mean }=1.95 \text {, } \text { Range }=1-4 \text {, } \\
\text { Median }=2 \text {, } \text { Mode }=2\end{array}$ & 0 & $\cap$ & 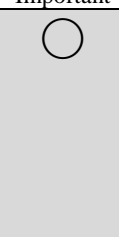 & $\cap$ & & & \\
\hline $\begin{array}{l}\text { Respect for / } \\
\text { autonomy of student } \\
\text { union (e.g. institution } \\
\text { appropriates union } \\
\text { space for non-union } \\
\text { purposes such as } \\
\text { storage or } \\
\text { administrative } \\
\text { offices) } \\
\text { Mean }=1.50 \text {, } \\
\text { Range }=1-3, \text { Median- } 1 \text {, } \\
\text { Mode }=1\end{array}$ & $\cap$ & $\cap$ & 0 & $\cap$ & $\cap$ & & \\
\hline $\begin{array}{l}\text { Lack of influence of } \\
\text { union directors in } \\
\text { institutional decision- } \\
\text { making } \\
\text { Mean }=1.73 \text {, Range }=1-3 \text {, } \\
\text { Median }=2 \text {, } \text { Mode }=2\end{array}$ & 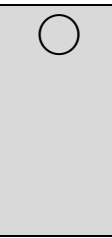 & & $\cap$ & & & & \\
\hline $\begin{array}{l}\text { Lack of respect from } \\
\text { / partnership with } \\
\text { academic affairs } \\
\text { Mean }=2.27, \text { Range }=1-3, \\
\text { Median }=2, \text { Mode }=2\end{array}$ & $\cap$ & $\partial$ & $\cap$ & 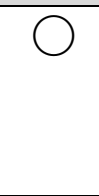 & 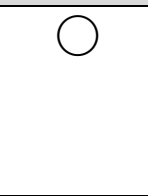 & & ( \\
\hline $\begin{array}{l}\text { Campus policies and } \\
\text { politics (e.g. } \\
\text { prohibitive influence } \\
\text { on union operations } \\
\& \text { innovation) } \\
\text { Mean }=2.14, \text { Range }=1-3 \text {, } \\
\text { Median }=2, \text { Mode }=2\end{array}$ & 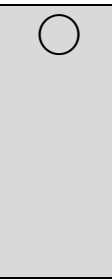 & 0 & 0 & 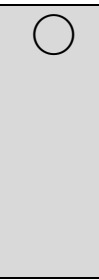 & 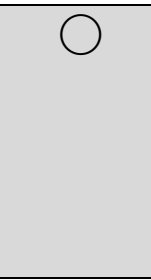 & & ( \\
\hline $\begin{array}{l}\text { Inadequate / unclear } \\
\text { organizational } \\
\text { structure of union } \\
\text { (e.g. unclear } \\
\text { responsibilities, } \\
\text { inadequate } \\
\text { coordination, groups } \\
\text { vie for leadership) } \\
\text { Mean }=2.50, \text { Range }=1-6, \\
\text { Median }=2, \text { Mode }=2\end{array}$ & 0 & 0 & 0 & $\bigcirc$ & 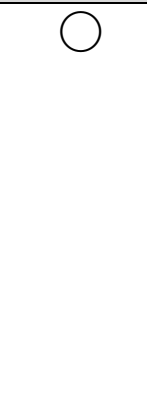 & 0 & 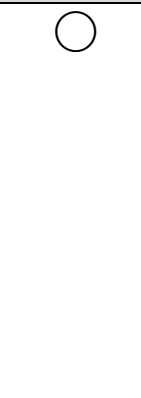 \\
\hline
\end{tabular}

23. Optional: If your responses differed from the apparent consensus (means) in this section, please describe your primary rationale below. (You may also use this space if you would like to comment further on the barriers \& constraints facing unions.) 


\section{Part 5 - The Student Union of the Future}

The questions below list several sustaining and changing forces that are effecting student unions.

$\underline{\text { Sustaining Forces are those things that support the core purposes and a continued need }}$ for the student union.

Changing Forces are those things that may introduce new missions, change some of the ways that union fulfills its purposes)

The questions in Part 5 ask you to rate how important these various forces are, in shaping the student union of the future.

\section{How important is each of the following sustaining forces in influencing the student union of the future?}

\begin{tabular}{|c|c|c|c|c|c|c|c|}
\hline & $\begin{array}{c}\text { Very } \\
\text { Important }\end{array}$ & Important & $\begin{array}{l}\text { Somewhat } \\
\text { Important }\end{array}$ & Neutral & $\begin{array}{c}\text { Somewhat } \\
\text { Unimportant }\end{array}$ & Unimportant & $\begin{array}{c}\text { Very } \\
\text { Unimportant }\end{array}$ \\
\hline $\begin{array}{l}\text { Basic human / student } \\
\text { need to connect and } \\
\text { belong to the campus } \\
\text { community } \\
\text { Mean }=1.27, \text { Range }=1-2, \\
\text { Median=1, } \text { Mode }=1\end{array}$ & & & & & & & \\
\hline $\begin{array}{l}\text { Continued need for } \\
\text { students to have a } \\
\text { "living room," a place } \\
\text { to feel "at home." } \\
\text { Mean=1.32, Range }=1-3, \\
\text { Median=1, Mode }=1\end{array}$ & & & & & & & \\
\hline $\begin{array}{l}\text { Continued need for co- } \\
\text { curricular skill } \\
\text { building (e.g. } \\
\text { responsibility, } \\
\text { leadership, } \\
\text { communication) } \\
\text { Mean }=1.45, \text { Range }=1-3 \text {, } \\
\text { Median }=1, \text { Mode }=1\end{array}$ & & & & & & & \\
\hline $\begin{array}{l}\text { Continued need for a } \\
\text { "welcome center" that } \\
\text { makes an impression } \\
\text { for students, alumni } \\
\text { and visitors, instills } \\
\text { loyalty, \& conveys the } \\
\text { campus' identity story } \\
\text { Mean }=1.55 \text {, Range }=1-3 \text {, } \\
\text { Median }=1, \text { Mode }=1\end{array}$ & & & & & & & \\
\hline $\begin{array}{l}\text { Importance of student } \\
\text { development in } \\
\text { institution's mission } \\
\text { and strategic plan } \\
\text { Mean }=1.50, \text { Range }=1-3, \\
\text { Median }=1, \text { Mode }=1\end{array}$ & & & & & & & \\
\hline
\end{tabular}




\begin{tabular}{|c|c|c|c|c|c|c|c|}
\hline & $\begin{array}{c}\text { Very } \\
\text { Important }\end{array}$ & Important & $\begin{array}{l}\text { Somewhat } \\
\text { Important }\end{array}$ & Neutral & $\begin{array}{l}\text { Somewhat } \\
\text { Unimportant }\end{array}$ & Unimportant & $\begin{array}{c}\text { Very } \\
\text { Unimportant }\end{array}$ \\
\hline $\begin{array}{l}\text { Importance of } \\
\text { providing a human, } \\
\text { high-touch location on } \\
\text { campus, as human } \\
\text { interactions are } \\
\text { increasingly mediated } \\
\text { through technology } \\
\text { Mean }=1.41, \text { Range }=1-3 \text {, } \\
\text { Median }=1, \text { Mode }=1\end{array}$ & O & O & & O & $\bigcirc$ & & \\
\hline $\begin{array}{l}\text { Importance of the } \\
\text { union's services \& } \\
\text { amenities to the } \\
\text { campus community } \\
\text { Mean }=1.36, \text { Range }=1-3, \\
\text { Median }=1, \text { Mode }=1\end{array}$ & 0 & O & 0 & D & 0 & 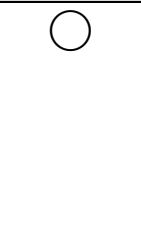 & ) \\
\hline $\begin{array}{l}\text { Institutional } \\
\text { commitment to the } \\
\text { union concept } \\
\text { Mean }=1.52, \text { Range }=1-3 \text {, } \\
\text { Median }=1, \text { Mode }=1\end{array}$ & 0 & 0 & 0 & 0 & $\Omega$ & $\Omega$ & 0 \\
\hline
\end{tabular}

\section{How important is each of the following changing forces in influencing the student union of the future?}

\begin{tabular}{|c|c|c|c|c|c|c|c|}
\hline & $\begin{array}{c}\text { Very } \\
\text { Important }\end{array}$ & Important & $\begin{array}{l}\text { Somewhat } \\
\text { Important }\end{array}$ & Neutral & $\begin{array}{c}\text { Somewhat } \\
\text { Unimportant }\end{array}$ & Unimportant & $\begin{array}{c}\text { Very } \\
\text { Unimportant }\end{array}$ \\
\hline $\begin{array}{l}\text { Globalization } \\
\text { Mean }=2.36, \text { Range }=1-5, \\
\text { Median }=2, \text { Mode }=2\end{array}$ & & & & & & & \\
\hline $\begin{array}{l}\text { Sustainability / Eco- } \\
\text { awareness } \\
\begin{array}{l}\text { Mean }=1.91, \text { Range }=1-3, \\
\text { Median }=2, \text { Mode }=2\end{array}\end{array}$ & & & & & & & \\
\hline $\begin{array}{l}\text { Changing student } \\
\text { populations / needs } \\
\text { (e.g. difficult to } \\
\text { forecast what future } \\
\text { students will need) } \\
\text { Mean }=1.77, \text { Range }=1-3 \text {, } \\
\text { Median }=2, \text { Mode }=2\end{array}$ & & & & & & & \\
\hline $\begin{array}{l}\text { Online classes (e.g. } \\
\text { keeping more students } \\
\text { off of campus, } \\
\text { changing primacy of a } \\
\text { residential college } \\
\text { experience) } \\
\text { Mean }=2.59, \text { Range }=1-6 \text {, } \\
\text { Median }=2.5, \text { Mode }=3\end{array}$ & & & & & & & \\
\hline $\begin{array}{l}\text { Evening \& weekend } \\
\text { classes (e.g. changing } \\
\text { needs for union's } \\
\text { operating hours) } \\
\text { Mean }=2.45, \text { Range }=1-5, \\
\text { Median }=2, \text { Mode }=2\end{array}$ & & & & & & & \\
\hline
\end{tabular}




\begin{tabular}{|c|c|c|c|c|c|c|c|}
\hline \multirow{2}{*}{$\begin{array}{l}\text { Finding new ways to } \\
\text { create a sense of } \\
\text { community } \\
\text { Mean=1.59, Range }=1-5, \\
\text { Median=1, Mode }=1\end{array}$} & $\begin{array}{c}\text { Very } \\
\text { Important }\end{array}$ & Important & $\begin{array}{l}\text { Somewhat } \\
\text { Important }\end{array}$ & Neutral & $\begin{array}{c}\text { Somewhat } \\
\text { Unimportant }\end{array}$ & Unimportant & $\begin{array}{c}\text { Very } \\
\text { Unimportant }\end{array}$ \\
\hline & 0 & 0 & 0 & 0 & $\bigcirc$ & 0 & 7 \\
\hline $\begin{array}{l}\text { Finding new ways to } \\
\text { engage students / } \\
\text { compete for their time } \\
\text { and attention } \\
\text { Mean }=1.50 \text {, Range }=1-4, \\
\text { Median }=1, \text { Mode }=1\end{array}$ & 0 & $\bigcirc$ & 0 & 0 & 0 & 0 & 0 \\
\hline $\begin{array}{l}\text { Technology-mediated } \\
\text { human interaction (e.g. } \\
\text { social media \& virtual } \\
\text { services threaten need } \\
\text { for physical unions; } \\
\text { virtual vs. physical } \\
\text { union) } \\
\text { Mean }=1.95, \text { Range }=1-5, \\
\text { Median }=2, \text { Mode }=2\end{array}$ & 0 & 0 & 0 & 0 & 0 & $\bigcirc$ & 0 \\
\hline $\begin{array}{l}\text { Pace of technological } \\
\text { change (e.g. difficult } \\
\text { to forecast, keep pace } \\
\text { with, and afford) } \\
\text { Mean }=1.71, \text { Range }=1-3, \\
\text { Median }=2, \text { Mode }=1\end{array}$ & 0 & $\bigcirc$ & 0 & $\bigcirc$ & $\bigcirc$ & $\bigcirc$ & $\bigcirc$ \\
\hline $\begin{array}{l}\text { 26. Optional: If yo } \\
\text { section, please } \\
\text { you would like } \\
\text { future of the st }\end{array}$ & $\begin{array}{l}\text { ir respo } \\
\text { lescribe } \\
\text { o comme } \\
\text { dent uni }\end{array}$ & $\begin{array}{l}\text { es diffe } \\
\text { pur pri } \\
\text { t furthe } \\
\text { t.) }\end{array}$ & $\begin{array}{l}\text { from } t \\
\text { y ratio } \\
\text { the su }\end{array}$ & $\begin{array}{l}\text { appar } \\
\text { le belo } \\
\text { ining }\end{array}$ & $\begin{array}{l}\text { t consenst } \\
\text { (You ma. } \\
\text { changing }\end{array}$ & $\begin{array}{l}\text { (means) i } \\
\text { lso use th } \\
\text { ces influe }\end{array}$ & $\begin{array}{l}\text { this } \\
\text { space if } \\
\text { cing the }\end{array}$ \\
\hline
\end{tabular}

\section{Thank you for completing this survey!}

Please click below on the "done" button to submit your responses. 


\section{APPENDIX O \\ THANK YOU, ROUND III}

\section{Dear Director,}

Thank you for completing all three rounds of the Delphi study on student union amenities that matter. The purpose of this study was to understand and forecast the changing role of the student union in the modern era. By participating, you have provided key insight about student union purposes and amenities for professionals who work in student union management.

The survey administration period closed on July 10, and I am now analyzing the results. If you would like to receive a copy of the survey results, please contact me at:

Western Illinois University

Office of Student Activities

University Union

1 University Circle

Macomb, IL 61455-1390

309-298-3232 (office)

309-255-0449 (cell)

ma-janisz@wiu.edu

Sincerely,

Michelle A. Janisz

Doctoral Candidate

Educational Administrations and Foundations

Illinois State University 


\section{APPENDIX P \\ ROUND II AND III RESULTS}

The questionnaire results for Rounds II and III are presented in this appendix, in order of the question number. Within each question, items are reported in the order of the mean score.

\section{Table P1}

\section{Purposes of Student Unions}

Q1: How important is it for the student union to serve each of the following purposes (roles)?

\begin{tabular}{|c|c|c|c|c|}
\hline \multirow{5}{*}{$\begin{array}{l}\text { Building, creating or fostering } \\
\text { community }\end{array}$} & & Round II & Round III & Agreement \\
\hline & Mean & 1.00 & 1.14 & $86.4 \%=1$ \\
\hline & Range & 0 & $1-2$ & $13.6 \%=2$ \\
\hline & Median & 1 & 1 & $\therefore 100 \%=1,2$ \\
\hline & Mode & 1 & 1 & $\sqrt{ }$ True Consensus \\
\hline \multirow[t]{5}{*}{ Supporting student success } & & Round II & Round III & Agreement \\
\hline & Mean & 1.23 & 1.38 & $61.9 \%=1$ \\
\hline & Range & $1-2$ & $1-2$ & $38.1 \%=2$ \\
\hline & Median & 1 & 1 & $\therefore 100 \%=1,2$ \\
\hline & Mode & 1 & 1 & $\sqrt{ }$ Consensus \\
\hline \multirow{5}{*}{$\begin{array}{l}\text { Serving as the "living room" for } \\
\text { the campus }\end{array}$} & & Round II & Round III & Agreement \\
\hline & Mean & 1.27 & 1.45 & \multirow{4}{*}{$\begin{array}{l}68.2 \%=1 \\
27.3 \%=2 \\
\therefore 95.5 \%=1,2 \\
\sqrt{ } \text { Consensus }\end{array}$} \\
\hline & Range & $1-3$ & $1-5$ & \\
\hline & Median & 1 & 1 & \\
\hline & Mode & 1 & 1 & \\
\hline \multirow{5}{*}{$\begin{array}{l}\text { Serving as the "welcome } \\
\text { center" for the campus }\end{array}$} & \multicolumn{2}{|r|}{ Round II } & Round III & Agreement \\
\hline & Mean & 1.55 & 1.64 & $50.0 \%=1$ \\
\hline & Range & $1-3$ & $1-3$ & $36.4 \%=2$ \\
\hline & Median & 1 & 1.5 & $\therefore 86.4 \%=1,2$ \\
\hline & Mode & 1 & 1 & $\sqrt{ }$ Consensus \\
\hline
\end{tabular}

$\mathrm{N}=22$ 
Table P2

\section{Missions of the Student Union}

\section{Q2: How important is it for the union to serve each of the following missions?}

\begin{tabular}{|c|c|c|c|c|}
\hline \multirow{5}{*}{$\begin{array}{l}\text { Provide informal spaces (e.g. } \\
\text { lounge space, study space, } \\
\text { socializing space) }\end{array}$} & & Round II & Round III & Agreement \\
\hline & Mean & 1.05 & 1.14 & \multirow{4}{*}{$\begin{array}{l}86.4 \%=1 \\
13.6 \%=2 \\
\therefore 100 \%=1,2 \\
\sqrt{ } \text { True Consensus }\end{array}$} \\
\hline & Range & $1-2$ & $1-2$ & \\
\hline & Median & 1 & 1 & \\
\hline & Mode & 1 & 1 & \\
\hline \multirow{5}{*}{$\begin{array}{l}\text { Provide formal spaces (e.g. for } \\
\text { meetings and events) }\end{array}$} & & Round II & Round III & Agreement \\
\hline & Mean & 1.18 & 1.27 & $72.7 \%=1$ \\
\hline & Range & $1-2$ & $1-2$ & $27.3 \%=2$ \\
\hline & Median & 1 & 1 & $\therefore 100 \%=1,2$ \\
\hline & Mode & 1 & 1 & $\sqrt{ }$ Consensus \\
\hline \multirow{5}{*}{$\begin{array}{l}\text { Support co-curricular student } \\
\text { development \& learning }\end{array}$} & & Round II & Round III & Agreement \\
\hline & Mean & 1.23 & 1.32 & \multirow{4}{*}{$\begin{array}{l}72.7 \%=1 \\
22.7 \%=2 \\
\therefore 95.4 \%=1,2 \\
\sqrt{ } \text { Consensus }\end{array}$} \\
\hline & Range & $1-2$ & $1-3$ & \\
\hline & Median & 1 & 1 & \\
\hline & Mode & 1 & 1 & \\
\hline \multirow{5}{*}{$\begin{array}{l}\text { Offer food services (e.g. food } \\
\text { courts, cafeterias, restaurants) }\end{array}$} & & Round II & Round III & Agreement \\
\hline & Mean & 1.41 & 1.36 & $63.6 \%=1$ \\
\hline & Range & $1-2$ & $1-2$ & $36.4 \%=2$ \\
\hline & Median & 1 & 1 & $\therefore 100 \%=1,2$ \\
\hline & Mode & 1 & 1 & $\sqrt{ }$ Consensus \\
\hline \multirow{5}{*}{$\begin{array}{l}\text { Offer student employment } \\
\text { opportunities }\end{array}$} & & Round II & Round III & Agreement \\
\hline & Mean & 1.18 & 1.36 & $68.2 \%=1$ \\
\hline & Range & $1-2$ & $1-3$ & $27.3 \%=2$ \\
\hline & Median & 1 & 1 & $\therefore 95.5 \%=1,2$ \\
\hline & Mode & 1 & 1 & $\sqrt{ }$ Consensus \\
\hline \multirow[t]{5}{*}{ Support student retention } & & Round II & Round III & Agreement \\
\hline & Mean & 1.55 & 1.59 & $59.1 \%=1$ \\
\hline & Range & $1-3$ & $1-4$ & $27.3 \%=2$ \\
\hline & Median & 1 & 1 & $\therefore 96.4 \%=1,2$ \\
\hline & Mode & 1 & 1 & $\sqrt{ }$ Consensus \\
\hline \multirow[t]{5}{*}{ Offer cultural opportunities } & & Round II & Round III & Agreement \\
\hline & Mean & 1.45 & 1.77 & $45.5 \%=1$ \\
\hline & Range & $1-3$ & $1-4$ & $36.4 \%=2$ \\
\hline & Median & 1 & 2 & $\therefore 81.9 \%=1,2$ \\
\hline & Mode & 1 & 1 & $\sqrt{ }$ Consensus \\
\hline \multirow[t]{5}{*}{ Support student recruitment } & & Round II & Round III & Agreement \\
\hline & Mean & 1.77 & 1.82 & $40.9 \%=1$ \\
\hline & Range & $1-4$ & $1-4$ & $40.9 \%=2$ \\
\hline & Median & 2 & 2 & $\therefore 81.8 \%=1,2$ \\
\hline & Mode & 2 & $1+2$ & $\sqrt{ }$ Consensus \\
\hline
\end{tabular}


(Continued) Q2: How important is it for the union to serve each of the following missions?

\begin{tabular}{lllll}
\hline $\begin{array}{l}\text { Offer retail services (e.g. } \\
\text { bookstore, } \\
\text { computer/technology store, post } \\
\text { office) }\end{array}$ & Mean & 1.86 & Round III & Agreement \\
\cline { 2 - 5 } & Range & $1-3$ & 1.86 & $36.4 \%=1$ \\
& Median & 2 & $1-3$ & $40.9 \%=2$ \\
& Mode & 2 & 2 & $\begin{array}{l}\text { V } \\
\text { Consensus }\end{array}$ \\
& & Round II & Round III & Agreement \\
\hline $\begin{array}{llll}\text { Offer recreation \& } \\
\text { entertainment opportunities }\end{array}$ (e.g. bowling, movies) & Mean & 2.14 & 2.00 & $22.7 \%=1$ \\
& Range & $1-5$ & $1-3$ & $54.5 \%=2$ \\
& Median & 2 & 2 & $\therefore 77.2 \%=1,2$ \\
& Mode & $1+3$ & 2 & $\sqrt{ }$ Consensus \\
\hline Support curricular/classroom & & Round II & Round III & Agreement \\
student learning & Mean & 2.59 & 2.45 & $13.6 \%=1$ \\
& Range & $1-5$ & $1-5$ & $45.5 \%=2$ \\
& Median & 2.5 & 2 & $\therefore 61.9 \%=1,2$ \\
& Mode & 2 & 2 & No Consensus \\
\hline
\end{tabular}

$\mathrm{N}=22$

\section{Table P3}

Populations Served by Student Unions

Q3: How important is it for the union to serve each of the following populations?

\begin{tabular}{|c|c|c|c|c|}
\hline \multirow[t]{5}{*}{ Traditional age undergraduate } & & Round II & Round III & Agreement \\
\hline & Mean & 1.32 & 1.14 & $86.4 \%=1$ \\
\hline & Range & $1-5$ & $1-2$ & $13.6 \%=2$ \\
\hline & Median & 1 & 1 & $\therefore 100.0 \%=1,2$ \\
\hline & Mode & 1 & 1 & $\sqrt{ }$ True Consensus \\
\hline \multirow[t]{5}{*}{ Residential students } & & Round II & Round III & Agreement \\
\hline & Mean & 1.27 & 1.32 & $77.3 \%=1$ \\
\hline & Range & $1-3$ & $1-3$ & $13.4 \%=2$ \\
\hline & Median & 1 & 1 & $\therefore 90.7 \%=1,2$ \\
\hline & Mode & 1 & 1 & $\sqrt{\text { True Consensus }}$ \\
\hline \multirow[t]{5}{*}{ Commuter students } & & Round II & Round III & Agreement \\
\hline & Mean & 1.33 & 1.32 & $72.7 \%=1$ \\
\hline & Range & $1-3$ & $1-3$ & $22.7 \%=2$ \\
\hline & Median & 1 & 1 & $\therefore 95.4 \%=1,2$ \\
\hline & Mode & 1 & 1 & $\sqrt{ }$ Consensus \\
\hline \multirow[t]{5}{*}{ Evening student } & & Round II & Round III & Agreement \\
\hline & Mean & 1.57 & 1.41 & $68.2 \%=1$ \\
\hline & Range & $1-3$ & $1-4$ & $22.7 \%=2$ \\
\hline & Median & 2 & 1 & $\therefore 90.9 \%=1,2$ \\
\hline & Mode & $1+2$ & 1 & $\sqrt{ }$ Consensus \\
\hline
\end{tabular}


(Continued) Q3: How important is it for the union to serve each of the following populations?

\begin{tabular}{|c|c|c|c|c|}
\hline \multirow{5}{*}{$\begin{array}{l}\text { Nontraditional age } \\
\text { undergraduates }\end{array}$} & \multicolumn{2}{|r|}{ Round II } & Round III & Agreement \\
\hline & Mean & 1.50 & 1.59 & $40.9 \%=1$ \\
\hline & Range & $1-5$ & $1-2$ & $59.1 \%=2$ \\
\hline & Median & 1 & 1 & $\therefore 100.0 \%=1,2$ \\
\hline & Mode & 1 & 1 & $\sqrt{ }$ Consensus \\
\hline \multirow[t]{5}{*}{ Graduate students } & \multicolumn{2}{|r|}{ Round II } & Round III & Agreement \\
\hline & Mean & 1.73 & 1.68 & $45.5 \%=1$ \\
\hline & Range & $1-3$ & $1-3$ & $40.1 \%=2$ \\
\hline & Median & 2 & 2 & $\therefore 85.6 \%=1,2$ \\
\hline & Mode & 2 & 2 & $\sqrt{ }$ Consensus \\
\hline \multirow[t]{5}{*}{ Prospective students } & \multicolumn{2}{|r|}{ Round II } & Round III & Agreement \\
\hline & Mean & 1.68 & 1.82 & $36.4 \%=1$ \\
\hline & Range & $1-4$ & $1-3$ & $45.5 \%=2$ \\
\hline & Median & 1 & 2 & $\therefore 81.9 \%=1,2$ \\
\hline & Mode & 1 & 2 & $\sqrt{ }$ Consensus \\
\hline \multirow{5}{*}{$\begin{array}{l}\text { Campus staff and faculty (as } \\
\text { individuals) }\end{array}$} & \multicolumn{2}{|r|}{ Round II } & Round III & Agreement \\
\hline & Mean & 1.95 & 1.86 & $31.8 \%=1$ \\
\hline & Range & $1-4$ & $1-4$ & $54.5 \%=2$ \\
\hline & Median & 2 & 2 & $\therefore 86.3 \%=1,2$ \\
\hline & Mode & 2 & 2 & $\sqrt{ }$ Consensus \\
\hline \multirow{5}{*}{$\begin{array}{l}\text { Visitors to the campus for other } \\
\text { college-related } \\
\text { business/purposes }\end{array}$} & & Round II & Round III & Agreement \\
\hline & Mean & 1.91 & 2.18 & $18.2 \%=1$ \\
\hline & Range & $1-3$ & $1-5$ & $59.1 \%=2$ \\
\hline & Median & 2 & 2 & $\therefore 77.3 \%=1,2$ \\
\hline & Mode & $1+2$ & 2 & $\sqrt{\text { Consensus }}$ \\
\hline \multirow[t]{5}{*}{ Alumni } & \multicolumn{2}{|r|}{ Round II } & Round III & Agreement \\
\hline & Mean & 2.45 & 2.50 & $45.5 \%=1$ \\
\hline & Range & $1-5$ & $1-5$ & $36.4 \%=2$ \\
\hline & Median & 2.5 & 2 & $\therefore 81.9 \%=1,2$ \\
\hline & Mode & 3 & 2 & $\sqrt{ }$ Consensus \\
\hline \multirow{5}{*}{$\begin{array}{l}\text { Visitors to the campus for non- } \\
\text { college related purposes }\end{array}$} & & Round II & Round III & Agreement \\
\hline & Mean & 2.43 & 2.55 & $9.1 \%=1$ \\
\hline & Range & $1-4$ & $1-4$ & $31.8 \%=2$ \\
\hline & Median & 3 & 3 & $\therefore 40.9 \%=1,2$ \\
\hline & Mode & 3 & 3 & No Consensus \\
\hline \multirow[t]{5}{*}{ Academic departments } & \multicolumn{2}{|r|}{ Round II } & Round III & Agreement \\
\hline & Mean & 2.45 & 2.59 & $18.2 \%=1$ \\
\hline & Range & $1-4$ & $1-4$ & $22.7 \%=2$ \\
\hline & Median & 2 & 3 & $\therefore 40.9 \%=1,2$ \\
\hline & Mode & 2 & 3 & No Consensus \\
\hline
\end{tabular}


(Continued) Q3: How important is it for the union to serve each of the following populations?

\begin{tabular}{|c|c|c|c|c|}
\hline \multirow[t]{2}{*}{ Administrative departments } & & Round II & Round III & Agreement \\
\hline & $\begin{array}{l}\text { Mean } \\
\text { Range } \\
\text { Median } \\
\text { Mode }\end{array}$ & $\begin{array}{l}2.36 \\
1-4 \\
2 \\
2\end{array}$ & $\begin{array}{l}2.64 \\
1-4 \\
3 \\
2.5\end{array}$ & $\begin{array}{l}9.1 \%=1 \\
36.4 \%=2 \\
\therefore 45.5 \%=1,2 \\
\text { No Consensus }\end{array}$ \\
\hline \multirow{2}{*}{$\begin{array}{l}\text { Families of current students or } \\
\text { alumni }\end{array}$} & & Round II & Round III & Agreement \\
\hline & $\begin{array}{l}\text { Mean } \\
\text { Range } \\
\text { Median } \\
\text { Mode }\end{array}$ & $\begin{array}{l}2.59 \\
1-4 \\
2.5 \\
2\end{array}$ & $\begin{array}{l}2.82 \\
1-5 \\
3 \\
3\end{array}$ & $\begin{array}{l}4.5 \%=1 \\
22.7 \%=2 \\
\therefore 27.2 \%=1,2 \\
\text { No Consensus }\end{array}$ \\
\hline \multirow[t]{2}{*}{ Virtual/online student } & & Round II & Round III & Agreement \\
\hline & $\begin{array}{l}\text { Mean } \\
\text { Range } \\
\text { Median } \\
\text { Mode }\end{array}$ & $\begin{array}{l}3.10 \\
2-7 \\
3 \\
3\end{array}$ & $\begin{array}{l}3.14 \\
1-6 \\
3 \\
3\end{array}$ & $\begin{array}{l}9.1 \%=1 \\
13.6 \%=2 \\
\therefore 22.7 \%=1,2 \\
\text { No Consensus }\end{array}$ \\
\hline
\end{tabular}

$\mathrm{N}=22$

\section{Table P4}

\section{Services Located within Student Unions}

Q5: How important is for each of the following services to be located within the student union?

\begin{tabular}{|c|c|c|c|c|}
\hline \multirow[t]{5}{*}{ Student Activities Office } & & Round II & Round III & Agreement \\
\hline & Mean & 1.18 & 1.18 & $86.4 \%=1$ \\
\hline & Range & $1-3$ & $1-3$ & $9.0 \%=2$ \\
\hline & Median & 1 & 1 & $\therefore 95.4 \%=1,2$ \\
\hline & Mode & 1 & 1 & $\sqrt{ }$ True Consensus \\
\hline \multirow[t]{5}{*}{ Student Government Office } & & Round II & Round III & Agreement \\
\hline & Mean & 1.36 & 1.18 & $86.4 \%=1$ \\
\hline & Range & $1-4$ & $1-3$ & $9.0 \%=2$ \\
\hline & Median & 1 & 1 & $\therefore 95.4 \%=1,2$ \\
\hline & Mode & 1 & 1 & $\sqrt{ }$ True Consensus \\
\hline \multirow{5}{*}{$\begin{array}{l}\text { Student Programming Board } \\
\text { Office }\end{array}$} & & Round II & Round III & Agreement \\
\hline & Mean & 1.18 & 1.23 & $81.8 \%=1$ \\
\hline & Range & $1-3$ & $1-3$ & $13.6 \%=2$ \\
\hline & Median & 1 & 1 & $95.4 \therefore \%=1,2$ \\
\hline & Mode & 1 & 1 & $\sqrt{ }$ True Consensus \\
\hline \multirow[t]{5}{*}{ Student Organization Office } & & Round II & Round III & Agreement \\
\hline & Mean & 1.18 & 1.27 & $77.3 \%=1$ \\
\hline & Range & $1-3$ & $1-3$ & $18.1 \%=2$ \\
\hline & Median & 1 & 1 & $\therefore 95.4 \%=1,2$ \\
\hline & Mode & 1 & 1 & $\sqrt{ }$ True Consensus \\
\hline
\end{tabular}


(Continued) Q5: How important is for each of the following services to be located within the student union?

\begin{tabular}{|c|c|c|c|c|}
\hline \multirow{5}{*}{$\begin{array}{l}\text { Information Desk Services } \\
\text { (staffed) }\end{array}$} & & Round II & Round III & Agreement \\
\hline & Mean & 1.18 & 1.41 & \multirow{4}{*}{$\begin{array}{l}72.7 \%=1 \\
18.2 \%=2 \\
\therefore 90.9 \%=1,2 \\
\sqrt{ } \text { Consensus }\end{array}$} \\
\hline & Range & $1-2$ & $1-4$ & \\
\hline & Median & 1 & 1 & \\
\hline & Mode & 1 & 1 & \\
\hline \multirow[t]{5}{*}{ Room Reservations Office } & & Round II & Round III & Agreement \\
\hline & Mean & 1.29 & 1.45 & \multirow{4}{*}{$\begin{array}{l}59.1 \%=1 \\
36.4 \%=2 \\
\therefore 95.5 \%=1,2 \\
\sqrt{ } \text { Consensus }\end{array}$} \\
\hline & Range & $1-3$ & $1-3$ & \\
\hline & Median & 1 & 1 & \\
\hline & Mode & 2 & 3 & \\
\hline \multirow{5}{*}{$\begin{array}{l}\text { Event/Conference Planning } \\
\text { Services }\end{array}$} & & Round II & \multicolumn{2}{|l|}{ Round III } \\
\hline & Mean & 1.82 & 2.05 & $31.8 \%=1$ \\
\hline & Range & $1-3$ & $1-5$ & $45.5 \%=2$ \\
\hline & Median & 2 & 2 & $\therefore 77.3 \%=1,2$ \\
\hline & Mode & 2 & 2 & $\sqrt{ }$ Consensus \\
\hline \multirow{5}{*}{$\begin{array}{l}\text { Event Production/Audio-visual } \\
\text { Services }\end{array}$} & & Round II & Round III & Agreement \\
\hline & Mean & 1.73 & 2.05 & $31.8 \%=1$ \\
\hline & Range & $1-5$ & $1-5$ & $50.0 \%=2$ \\
\hline & Median & 1.5 & 2 & $\therefore 81.8 \%=1,2$ \\
\hline & Mode & 1 & 2 & $\sqrt{ }$ Consensus \\
\hline \multirow[t]{5}{*}{ Information kiosk (unstaffed) } & & Round II & Round III & Agreement \\
\hline & Mean & 2.36 & 2.14 & $27.3 \%=1$ \\
\hline & Range & $1-4$ & $1-4$ & $36.4 \%=2$ \\
\hline & Median & 2.5 & 2 & $\therefore 63.7 \%=1,2$ \\
\hline & Mode & 1 & 2 & No Consensus \\
\hline \multirow[t]{5}{*}{ Leadership \& Service Office } & & Round II & Round III & Agreement \\
\hline & Mean & 1.57 & 2.18 & $18.2 \%=1$ \\
\hline & Range & $1-3$ & $1-6$ & $59.1 \%=2$ \\
\hline & Median & 1.5 & 2 & $\therefore 77.3 \%=1,2$ \\
\hline & Mode & 1 & 2 & $\sqrt{\text { Consensus }}$ \\
\hline \multirow[t]{5}{*}{ Multicultural Center } & & Round II & Round III & Agreement \\
\hline & Mean & 2.27 & 2.32 & $13.6 \%=1$ \\
\hline & Range & $1-7$ & $1-7$ & $54.5 \%=2$ \\
\hline & Median & 2 & 2 & $\therefore 68.1 \%=1,2$ \\
\hline & Mode & 2 & 2 & No Consensus \\
\hline \multirow[t]{5}{*}{ ID/University Card Services } & & Round II & Round III & Agreement \\
\hline & Mean & 2.36 & 2.59 & $18.2 \%=1$ \\
\hline & Range & $1-5$ & $1-5$ & $31.8 \%=2$ \\
\hline & Median & 2 & 2.5 & $\therefore 50.0 \%=1,2$ \\
\hline & Mode & 2 & 3 & No Consensus \\
\hline
\end{tabular}


(Continued) Q5: How important is for each of the following services to be located within the student union?

\begin{tabular}{|c|c|c|c|c|}
\hline \multirow{5}{*}{$\begin{array}{l}\text { Ticket Outlet/Office (e.g. } \\
\text { Athletics, Cultural Events) }\end{array}$} & & Round II & Round III & Agreement \\
\hline & Mean & 2.36 & 2.73 & \multirow{4}{*}{$\begin{array}{l}9.1 \%=1 \\
36.4 \%=2 \\
\therefore 45.5 \%=1,2 \\
\text { No Consensus }\end{array}$} \\
\hline & Range & $2-5$ & $1-5$ & \\
\hline & Median & 2.5 & 3 & \\
\hline & Mode & 3 & $2+3$ & \\
\hline \multirow[t]{5}{*}{ Student Newspaper Office } & & Round II & Round III & Agreement \\
\hline & Mean & 3.09 & 3.00 & \multirow{4}{*}{$\begin{array}{l}4.5 \%=1 \\
36.4 \%=2 \\
\therefore 40.9 \%=1,2 \\
\text { No Consensus }\end{array}$} \\
\hline & Range & $1-7$ & $1-6$ & \\
\hline & Median & 3 & 3 & \\
\hline & Mode & 2 & 2 & \\
\hline \multirow[t]{5}{*}{ Dean of Students Office } & & Round II & Round III & Agreement \\
\hline & Mean & 3.50 & 3.73 & $9.1 \%=1$ \\
\hline & Range & $1-7$ & $1-7$ & $4.5 \%=2$ \\
\hline & Median & 4 & 4 & $\therefore 13.6 \%=1,2$ \\
\hline & Mode & 4 & 4 & No Consensus \\
\hline \multirow[t]{5}{*}{ Career Services Office } & & Round II & Round III & Agreement \\
\hline & Mean & 3.50 & 3.95 & $4.5 \%=1$ \\
\hline & Range & $1-7$ & $1-7$ & $0.0 \%=2$ \\
\hline & Median & 4 & 4 & $\therefore 4.5 \%=1,2$ \\
\hline & Mode & 4 & 3 & No Consensus \\
\hline \multirow[t]{5}{*}{ Victim Advocacy Office } & & Round II & Round III & Agreement \\
\hline & Mean & 3.76 & 4.00 & $4.5 \%=1$ \\
\hline & Range & $2-7$ & $1-6$ & $0.0 \%=2$ \\
\hline & Median & 4 & 4 & $\therefore 4.5 \%=1,2$ \\
\hline & Mode & 4 & 4 & No Consensus \\
\hline \multirow{5}{*}{$\begin{array}{l}\text { Health \& Wellness Services } \\
\text { Office }\end{array}$} & & Round II & Round III & Agreement \\
\hline & Mean & 4.09 & 4.41 & $0.0 \%=1$ \\
\hline & Range & $2-7$ & $2-7$ & $4.5 \%=2$ \\
\hline & Median & 4 & 5 & $\therefore 4.5 \%=1,2$ \\
\hline & Mode & 4 & 5 & No Consensus \\
\hline \multirow{5}{*}{$\begin{array}{l}\text { Homecoming/Alumni } \\
\text { Relations Office }\end{array}$} & & Round II & Round III & Agreement \\
\hline & Mean & 4.19 & 4.55 & $0.0 \%=1$ \\
\hline & Range & $1-7$ & $2-7$ & $4.5 \%=2$ \\
\hline & Median & 4 & 5 & $\therefore 4.5 \%=1,2$ \\
\hline & Mode & 5 & 5 & No Consensus \\
\hline \multirow[t]{5}{*}{ Admissions Office } & & Round II & Round III & Agreement \\
\hline & Mean & 4.59 & 4.59 & $9.1 \%=1$ \\
\hline & Range & $1-7$ & $1-7$ & $4.5 \%=2$ \\
\hline & Median & 5 & 4 & $\therefore 13.6 \%=1,2$ \\
\hline & Mode & 6 & 5 & No Consensus \\
\hline
\end{tabular}


(Continued) Q5: How important is for each of the following services to be located within the student union?

\begin{tabular}{|c|c|c|c|c|}
\hline \multirow[t]{5}{*}{ Counselling Services } & & Round II & Round III & Agreement \\
\hline & Mean & 4.68 & 4.64 & \multirow{4}{*}{$\begin{array}{l}0.0 \%=1 \\
4.5 \%=2 \\
\therefore 4.5 \%=1,2 \\
\text { No Consensus }\end{array}$} \\
\hline & Range & $2-7$ & $1-7$ & \\
\hline & Median & 5 & 5 & \\
\hline & Mode & 4 & 5 & \\
\hline \multirow{5}{*}{$\begin{array}{l}\text { Academic Support \& Tutoring } \\
\text { Services }\end{array}$} & & Round II & Round III & Agreement \\
\hline & Mean & 4.67 & 4.77 & \multirow{4}{*}{$\begin{array}{l}0.0 \%=1 \\
0.0 \%=2 \\
\therefore 0.0 \%=1,2 \\
\text { No Consensus }\end{array}$} \\
\hline & Range & $2-6$ & $3-6$ & \\
\hline & Median & 5 & 4 & \\
\hline & Mode & 5 & 4 & \\
\hline \multirow[t]{5}{*}{ Parking Services } & & Round II & Round III & Agreement \\
\hline & Mean & 4.95 & 5.14 & $0.0 \%=1$ \\
\hline & Range & $2-7$ & $4-7$ & $0.0 \%=2$ \\
\hline & Median & 5 & 5 & $\therefore 0.0 \%=1,2$ \\
\hline & Mode & 4,7 & 5 & No Consensus \\
\hline \multirow[t]{5}{*}{ Financial Aid Office } & & Round II & Round III & Agreement \\
\hline & Mean & 5.14 & 5.18 & $0.0 \%=1$ \\
\hline & Range & $2-7$ & $3-7$ & $0.0 \%=2$ \\
\hline & Median & 5 & 5 & $\therefore 0.0 \%=1,2$ \\
\hline & Mode & 6 & 5 & No Consensus \\
\hline \multirow[t]{5}{*}{ Registrar's Office } & & Round II & Round III & Agreement \\
\hline & Mean & 5.50 & 5.19 & $0.0 \%=1$ \\
\hline & Range & $2-7$ & $3-7$ & $0.0 \%=2$ \\
\hline & Median & 5 & 5 & $\therefore 0.0 \%=1,2$ \\
\hline & Mode & 6 & 5 & No Consensus \\
\hline \multirow[t]{5}{*}{ Library Services } & & Round II & Round III & Agreement \\
\hline & Mean & 5.19 & 5.59 & $0.0 \%=1$ \\
\hline & Range & $2-7$ & $4-7$ & $0.0 \%=2$ \\
\hline & Median & 5 & 6 & $\therefore 0.0 \%=1,2$ \\
\hline & Mode & 5 & 6,7 & No Consensus \\
\hline
\end{tabular}

$\mathrm{N}=22$ 
Table P5

\section{Programming within Student Unions}

Q6: How important is it for each of the following types of programming to be located or offered within the student union?

\begin{tabular}{|c|c|c|c|c|}
\hline \multirow{5}{*}{$\begin{array}{l}\text { Student organized } \\
\text { programming }\end{array}$} & & Round II & Round III & Agreement \\
\hline & Mean & 1.00 & 1.18 & $81.8 \%=1$ \\
\hline & Range & 0 & $1-2$ & $18.2 \%=2$ \\
\hline & Median & 1 & 1 & $\therefore 100 \%=1,2$ \\
\hline & Mode & 1 & 1 & $\sqrt{ }$ True Consensus \\
\hline \multirow{5}{*}{$\begin{array}{l}\text { Active co-curricular } \\
\text { programming }\end{array}$} & & Round II & Round III & Agreement \\
\hline & Mean & 1.23 & 1.36 & $77.3 \%=1$ \\
\hline & Range & $1-2$ & $1-4$ & $13.6 \%=2$ \\
\hline & Median & 1 & 1 & $\therefore 90.9 \%=1,2$ \\
\hline & Mode & 1 & 1 & $\sqrt{ }$ True Consensus \\
\hline \multirow{5}{*}{$\begin{array}{l}\text { Formal social opportunities } \\
\text { (e.g. dinners, dances, parties) }\end{array}$} & & Round II & Round III & Agreement \\
\hline & Mean & 1.23 & 1.41 & $68.2 \%=1$ \\
\hline & Range & $1-3$ & $1-3$ & $22.7 \%=2$ \\
\hline & Median & 1 & 1 & $\therefore 90.9 \%=1,2$ \\
\hline & Mode & 1 & 1 & $\sqrt{ }$ Consensus \\
\hline \multirow{5}{*}{$\begin{array}{l}\text { Formal cultural events (e.g. } \\
\text { music or dance performances) }\end{array}$} & & Round II & Round III & Agreement \\
\hline & Mean & 1.27 & 1.43 & $71.4 \%=1$ \\
\hline & Range & $1-3$ & $1-5$ & $23.8 \%=2$ \\
\hline & Median & 1 & 1 & $\therefore 95.2 \%=1,2$ \\
\hline & Mode & 1 & 1 & $\sqrt{ }$ Consensus \\
\hline \multirow{5}{*}{$\begin{array}{l}\text { Leadership \& service } \\
\text { opportunities for students }\end{array}$} & & Round II & Round III & Agreement \\
\hline & Mean & 1.23 & 1.45 & $68.2 \%=1$ \\
\hline & Range & $1-2$ & $1-4$ & $22.7 \%=2$ \\
\hline & Median & 1 & 1 & $\therefore 90.9 \%=1,2$ \\
\hline & Mode & 1 & 1 & $\sqrt{ }$ Consensus \\
\hline \multirow[t]{5}{*}{ Multicultural programming } & & Round II & Round III & Agreement \\
\hline & Mean & 1.36 & 1.48 & $57.1 \%=1$ \\
\hline & Range & $1-3$ & $1-3$ & $38.1 \%=2$ \\
\hline & Median & 1 & 1 & $\therefore 95.2 \%=1,2$ \\
\hline & Mode & 1 & 1 & $\sqrt{ }$ Consensus \\
\hline \multirow{5}{*}{$\begin{array}{l}\text { Passive co-curricular } \\
\text { programming }\end{array}$} & & Round II & Round III & Agreement \\
\hline & Mean & 1.68 & 1.95 & $31.8 \%=1$ \\
\hline & Range & $1-3$ & $1-4$ & $45.5 \%=2$ \\
\hline & Median & 1.5 & 2 & $\therefore 77.3 \%=1,2$ \\
\hline & Mode & 1 & 2 & $\sqrt{\text { Consensus }}$ \\
\hline \multirow{5}{*}{$\begin{array}{l}\text { Recruitment programming (e.g. } \\
\text { student tours, recruitment } \\
\text { events, open houses, } \\
\text { orientation) }\end{array}$} & & Round II & Round III & Agreement \\
\hline & Mean & 1.77 & 2.05 & $33.3 \%=1$ \\
\hline & Range & $1-4$ & $1-4$ & $33.3 \%=2$ \\
\hline & Median & 2 & 2 & $66.6 \%=1,2$ \\
\hline & Mode & $1+2$ & $1+2$ & No Consensus \\
\hline
\end{tabular}




\begin{tabular}{lllll}
\hline \multicolumn{3}{l}{$\begin{array}{l}\text { (Continued) Q6: How important is it for each of the following types of programming to be } \\
\text { located or offered within the student union? }\end{array}$} & & \\
\hline $\begin{array}{l}\text { Formal educational } \\
\text { opportunities (e.g. conferences, } \\
\text { lectures, symposia) }\end{array}$ & Round II & Round III & Agreement \\
\cline { 2 - 5 } & Mean & 1.73 & 2.18 & $22.7 \%=1$ \\
& Range & $1-4$ & $1-5$ & $50.0 \%=2$ \\
& Median & 2 & 2 & $72.7 \%=1,2$ \\
& Mode & 2 & 2 & No Consensus \\
\hline For-credit laboratories \& & & Round II & Round III & Agreement \\
experiences & Mean & 4.50 & 4.77 & $0.0 \%=1$ \\
& Range & $2-7$ & $2-7$ & $0.0 \%=2$ \\
& Median & 4.5 & 5 & $50.0 \%=4,5$ \\
& Mode & 3 & 4 & No Consensus \\
\hline
\end{tabular}

$\mathrm{N}=22$

\section{Table P6}

\section{Roles of Student Unions}

\section{Q7: How important the student union's involvement is in each of the following roles in} programming?

\begin{tabular}{|c|c|c|c|c|}
\hline \multirow{5}{*}{$\begin{array}{l}\text { Partner } \\
\text { (The student union staff partner } \\
\text { with other groups or offices to } \\
\text { design and offer the } \\
\text { programming) }\end{array}$} & & Round II & Round III & Agreement \\
\hline & Mean & 1.45 & 1.36 & \multirow{4}{*}{$\begin{array}{l}68.2 \%=1 \\
27.3 \%=2 \\
\therefore 95.5 \%=1,2 \\
\sqrt{ } \text { Consensus }\end{array}$} \\
\hline & Range & $1-3$ & $1-3$ & \\
\hline & Median & 1 & 1 & \\
\hline & Mode & 1 & 1 & \\
\hline \multirow{2}{*}{$\begin{array}{l}\text { Place } \\
\text { (The student union provides a } \\
\text { venue or place, but other } \\
\text { offices or groups design and } \\
\text { offer the programming) }\end{array}$} & & Round II & Round III & Agreement \\
\hline & $\begin{array}{l}\text { Mean } \\
\text { Range } \\
\text { Median } \\
\text { Mode }\end{array}$ & $\begin{array}{l}1.27 \\
1-5 \\
1 \\
1\end{array}$ & $\begin{array}{l}1.52 \\
1-5 \\
1 \\
1\end{array}$ & $\begin{array}{l}71.4 \%=1 \\
19.0 \%=2 \\
\therefore 90.4 \%=1,2 \\
\sqrt{ } \text { Consensus }\end{array}$ \\
\hline \multirow{2}{*}{$\begin{array}{l}\text { Provider } \\
\text { (The student union staff } \\
\text { designs and offers the } \\
\text { programming) }\end{array}$} & & Round II & Round III & Agreement \\
\hline & $\begin{array}{l}\text { Mean } \\
\text { Range } \\
\text { Median } \\
\text { Mode } \\
\end{array}$ & $\begin{array}{l}1.82 \\
1-5 \\
1 \\
1 \\
\end{array}$ & $\begin{array}{l}1.73 \\
1-5 \\
1.5 \\
1 \\
\end{array}$ & $\begin{array}{l}50.0 \%=1 \\
36.4 \%=2 \\
\therefore 86.4 \%=1,2 \\
\sqrt{ } \text { Consensus }\end{array}$ \\
\hline
\end{tabular}

$\mathrm{N}=22$ 
Table P7

\section{Types of Spaces in Student Unions}

Q8: How important is it for the following types of spaces to be located or offered within the union?

\begin{tabular}{|c|c|c|c|c|}
\hline \multirow{5}{*}{$\begin{array}{l}\text { Large-scale formal gathering } \\
\text { spaces (e.g. performance halls, } \\
\text { ballrooms, banquet \& multi- } \\
\text { purpose rooms) }\end{array}$} & & Round II & Round III & Agreement \\
\hline & Mean & 1.00 & 1.05 & \multirow{4}{*}{$\begin{array}{l}95.4 \%=1 \\
4.6 \%=2 \\
\therefore 100 \%=1,2 \\
\sqrt{ } \text { True Consensus }\end{array}$} \\
\hline & Range & 0 & $1-2$ & \\
\hline & Median & 1 & 1 & \\
\hline & Mode & 1 & 1 & \\
\hline \multirow{5}{*}{$\begin{array}{l}\text { Small-scale formal gathering } \\
\text { spaces (e.g. classrooms, } \\
\text { meeting rooms) }\end{array}$} & & Round II & Round III & Agreement \\
\hline & Mean & 1.14 & 1.14 & $86.4 \%=1$ \\
\hline & Range & $1-3$ & $1-2$ & $13.6 \%=2$ \\
\hline & Median & 1 & 1 & $\therefore 100 \%=1,2$ \\
\hline & Mode & 1 & 1 & $\sqrt{ }$ True Consensus \\
\hline \multirow{5}{*}{$\begin{array}{l}\text { Small-scale informal gathering } \\
\text { places (e.g. nooks) }\end{array}$} & & Round II & Round III & Agreement \\
\hline & Mean & 1.09 & 1.19 & $81.0 \%=1$ \\
\hline & Range & $1-2$ & $1-2$ & $19.0 \%=2$ \\
\hline & Median & 1 & 1 & $\therefore 100 \%=1,2$ \\
\hline & Mode & 1 & 1 & $\sqrt{ }$ True Consensus \\
\hline \multirow{5}{*}{$\begin{array}{l}\text { Large-scale informal gathering } \\
\text { places (e.g. lounge spaces) }\end{array}$} & & Round II & Round III & Agreement \\
\hline & Mean & 1.14 & 1.27 & $81.1 \%=1$ \\
\hline & Range & $1-3$ & $1-3$ & $9.0 \%=2$ \\
\hline & Median & 1 & 1 & $\therefore 90.1 \%=1,2$ \\
\hline & Mode & 1 & 1 & $\sqrt{ }$ True Consensus \\
\hline \multirow[t]{5}{*}{ Open spaces } & & Round II & Round III & Agreement \\
\hline & Mean & 1.41 & 1.45 & $68.2 \%=1$ \\
\hline & Range & $1-3$ & $1-3$ & $18.2 \%=2$ \\
\hline & Median & 1 & 1 & $\therefore 86.4 \%=1,2$ \\
\hline & Mode & 1 & 1 & $\sqrt{ }$ Consensus \\
\hline \multirow{5}{*}{$\begin{array}{l}\text { Outdoor spaces/areas (for } \\
\text { eating, studying, socializing, } \\
\text { etc.) }\end{array}$} & & Round II & Round III & Agreement \\
\hline & Mean & 1.86 & 1.73 & $36.4 \%=1$ \\
\hline & Range & $1-4$ & $1-3$ & $54.5 \%=2$ \\
\hline & Median & 2 & 2 & $\therefore 90.9 \%=1,2$ \\
\hline & Mode & $1+2$ & 2 & $\sqrt{ }$ Consensus \\
\hline \multirow[t]{5}{*}{ Quiet areas } & & Round II & Round III & Agreement \\
\hline & Mean & 2.27 & 2.05 & $27.3 \%=1$ \\
\hline & Range & $1-5$ & $1-5$ & $50.0 \%=2$ \\
\hline & Median & 2 & 2 & $\therefore 77.3 \%=1,2$ \\
\hline & Mode & 2 & 2 & $\sqrt{ }$ Consensus \\
\hline
\end{tabular}


(Continued) Q8: How important is it for the following types of spaces to be located or offered within the union?

\begin{tabular}{|c|c|c|c|c|}
\hline \multirow{5}{*}{$\begin{array}{l}\text { Small group/individual study } \\
\text { spaces }\end{array}$} & & Round II & Round III & Agreement \\
\hline & Mean & 2.00 & 2.19 & \multirow{4}{*}{$\begin{array}{l}14.3 \%=1 \\
52.4 \%=2 \\
\therefore 66.7 \%=1,2 \\
\text { No Consensus }\end{array}$} \\
\hline & Range & $1-3$ & $1-3$ & \\
\hline & Median & 2 & 2 & \\
\hline & Mode & 2 & 2 & \\
\hline \multirow[t]{5}{*}{ Atrium } & & Round II & Round III & Agreement \\
\hline & Mean & 2.45 & 2.59 & $22.7 \%=1$ \\
\hline & Range & $1-5$ & $1-5$ & $31.8 \%=2$ \\
\hline & Median & 2 & 2 & $\therefore 54.5 \%=1,2$ \\
\hline & Mode & 2 & 2 & No Consensus \\
\hline \multirow[t]{5}{*}{ Large group study spaces } & & Round II & Round III & Agreement \\
\hline & Mean & 2.86 & 2.82 & $9.1 \%=1$ \\
\hline & Range & $1-5$ & $1-5$ & $22.7 \%=2$ \\
\hline & Median & 3 & 3 & $\therefore 31.8 \%=1,2$ \\
\hline & Mode & 3 & 3 & No Consensus \\
\hline \multirow[t]{5}{*}{ Spiritual/prayer spaces } & & Round II & Round III & Agreement \\
\hline & Mean & 3.50 & 3.15 & $15.5 \%=1$ \\
\hline & Range & $1-6$ & $1-5$ & $15.5 \%=2$ \\
\hline & Median & 3.5 & 4 & $\therefore 31.0 \%=1,2$ \\
\hline & Mode & 4 & 4 & No Consensus \\
\hline \multirow[t]{5}{*}{ Sleeping spaces } & & Round II & Round III & Agreement \\
\hline & Mean & 4.45 & 4.64 & $4.5 \%=1$ \\
\hline & Range & $2-7$ & $1-7$ & $4.5 \%=2$ \\
\hline & Median & 4.5 & 5 & $\therefore 9.0 \%=1,2$ \\
\hline & Mode & 5 & $4+5$ & No Consensus \\
\hline
\end{tabular}

$\mathrm{N}=22$ 
Table P8

\section{Amenities in Student Unions}

Q9 \& Q10: How important is it for each of the following amenities to be in the student union?

\begin{tabular}{|c|c|c|c|c|}
\hline \multirow[t]{6}{*}{ Wireless Internet service } & & Round II & Round III & Agreement \\
\hline & Mean & 1.00 & 1.14 & $90.9 \%=1$ \\
\hline & Range & 0 & $1-3$ & $4.5 \%=2$ \\
\hline & Median & 1 & 1 & $\therefore 95.4 \%=1,2$ \\
\hline & Mode & 1 & 1 & $\sqrt{ }$ True \\
\hline & & & & \\
\hline \multirow[t]{5}{*}{ ATM Machine } & & Round II & Round III & Agreement \\
\hline & Mean & 1.45 & 1.27 & $72.7 \%=1$ \\
\hline & Range & $1-2$ & $1-2$ & $27.3 \%=2$ \\
\hline & Median & 1 & 1 & $\therefore 100.0 \%=1,2$ \\
\hline & Mode & 1 & 1 & $\sqrt{ }$ Consensus \\
\hline \multirow[t]{5}{*}{ Food court } & & Round II & Round III & Agreement \\
\hline & Mean & 1.50 & 1.45 & $59.1 \%=1$ \\
\hline & Range & $1-3$ & $1-3$ & $36.4 \%=2$ \\
\hline & Median & 1 & 1 & $\therefore 95.5 \%=1,2$ \\
\hline & Mode & 1 & 1 & $\sqrt{ }$ Consensus \\
\hline \multirow{5}{*}{$\begin{array}{l}\text { Art (dispersed throughout } \\
\text { building) }\end{array}$} & & Round II & Round III & Agreement \\
\hline & Mean & 1.77 & 1.68 & $40.9 \%=1$ \\
\hline & Range & $1-3$ & $1-3$ & $50.0 \%=2$ \\
\hline & Median & 2 & 2 & $\therefore 90.9 \%=1,2$ \\
\hline & Mode & 1 & 2 & $\sqrt{ }$ Consensus \\
\hline \multirow[t]{5}{*}{ Coffee Shop } & & Round II & Round III & Agreement \\
\hline & Mean & 1.59 & 1.68 & $40.9 \%=1$ \\
\hline & Range & $1-3$ & $1-3$ & $50.0 \%=2$ \\
\hline & Median & 2 & 2 & $\therefore 90.9 \%=1,2$ \\
\hline & Mode & 2 & 2 & $\sqrt{ }$ Consensus \\
\hline \multirow{5}{*}{$\begin{array}{l}\text { Catering services for events } \\
\text { and meetings }\end{array}$} & & Round II & Round III & Agreement \\
\hline & Mean & 1.77 & 1.71 & $57.1 \%=1$ \\
\hline & Range & $1-5$ & $1-4$ & $28.6 \%=2$ \\
\hline & Median & 1 & 1 & $\therefore 85.7 \%=1,2$ \\
\hline & Mode & 1 & 1 & $\sqrt{ }$ Consensus \\
\hline \multirow[t]{5}{*}{ Convenience Store } & & Round II & Round III & Agreement \\
\hline & Mean & 1.86 & 1.73 & $32.8 \%=1$ \\
\hline & Range & $1-4$ & $1-3$ & $63.6 \%=2$ \\
\hline & Median & 2 & 2 & $\therefore 96.4 \%=1,2$ \\
\hline & Mode & 1 & 2 & $\sqrt{ }$ Consensus \\
\hline
\end{tabular}


(Continued) Q9 \& Q10: How important is it for each of the following amenities to be in the student union?

\begin{tabular}{|c|c|c|c|c|}
\hline \multirow{5}{*}{$\begin{array}{l}\text { Phone \& device Charging } \\
\text { stations }\end{array}$} & & Round II & Round III & Agreement \\
\hline & Mean & 1.82 & 1.95 & $22.7 \%=1$ \\
\hline & Range & $1-4$ & $1-4$ & $63.6 \%=2$ \\
\hline & Median & 2 & 2 & $\therefore 86.3 \%=1,2$ \\
\hline & Mode & $2+4$ & 2 & $\sqrt{ }$ Consensus \\
\hline \multirow{5}{*}{$\begin{array}{l}\text { Fast-service/fast-food } \\
\text { restaurant }\end{array}$} & & Round II & Round III & Agreement \\
\hline & Mean & 1.73 & 2.05 & $27.3 \%=1$ \\
\hline & Range & $1-3$ & $1-4$ & $45.5 \%=2$ \\
\hline & Median & 2 & 2 & $\therefore 72.8 \%=1,2$ \\
\hline & Mode & 1 & 2 & No Consensus \\
\hline \multirow[t]{5}{*}{ Lounge spaces with televisions } & & Round II & Round III & Agreement \\
\hline & Mean & 2.00 & 2.05 & $18.2 \%=1$ \\
\hline & Range & $1-5$ & $1-4$ & $63.6 \%=2$ \\
\hline & Median & 2 & 2 & $\therefore 81.8 \%=1,2$ \\
\hline & Mode & 2 & 2 & $\sqrt{\text { Consensus }}$ \\
\hline \multirow{5}{*}{$\begin{array}{l}\text { Computer stations/kiosks (not } \\
\text { in a lab room) }\end{array}$} & & Round II & Round III & Agreement \\
\hline & Mean & 2.24 & 2.09 & $18.2 \%=1$ \\
\hline & Range & $1-5$ & $1-3$ & $54.5 \%=2$ \\
\hline & Median & 2 & 2 & $\therefore 72.7 \%=1,2$ \\
\hline & Mode & 2 & 2 & No Consensus \\
\hline \multirow[t]{5}{*}{ Bookstore } & & Round II & Round III & Agreement \\
\hline & Mean & 2.14 & 2.23 & $22.7 \%=1$ \\
\hline & Range & $1-4$ & $1-4$ & $36.4 \%=2$ \\
\hline & Median & 2 & 2 & $\therefore 59.1 \%=1,2$ \\
\hline & Mode & 1 & $2+3$ & No Consensus \\
\hline \multirow[t]{5}{*}{ Post Office/mailing services } & & Round II & Round III & Agreement \\
\hline & Mean & 2.41 & 2.29 & $14.3 \%=1$ \\
\hline & Range & $1-5$ & $1-3$ & $42.9 \%=2$ \\
\hline & Median & 2 & 2 & $\therefore 56.1 \%=1,2$ \\
\hline & Mode & 2 & $2+3$ & No Consensus \\
\hline \multirow[t]{5}{*}{ Gender-neutral bathrooms } & & Round II & Round III & Agreement \\
\hline & Mean & 2.27 & 2.43 & $33.3 \%=1$ \\
\hline & Range & $1-4$ & $1-7$ & $23.8 \%=2$ \\
\hline & Median & 2 & 2 & $\therefore 57.1 \%=1,2$ \\
\hline & Mode & 1 & 1 & No Consensus \\
\hline \multirow{5}{*}{$\begin{array}{l}\text { Printer stations/kiosks (not in a } \\
\text { copy/print shop) }\end{array}$} & & Round II & Round III & Agreement \\
\hline & Mean & 2.45 & 2.50 & $9.1 \%=1$ \\
\hline & Range & $1-5$ & $1-5$ & $50.0 \%=2$ \\
\hline & Median & 2 & 2 & $\therefore 59.1 \%=1,2$ \\
\hline & Mode & 2 & 2 & No Consensus \\
\hline
\end{tabular}


(Continued) Q9 \& Q10: How important is it for each of the following amenities to be in the student union?

\begin{tabular}{|c|c|c|c|c|}
\hline \multirow[t]{5}{*}{ Copy/Print services } & & Round II & Round III & Agreement \\
\hline & Mean & 2.59 & 2.59 & $9.1 \%=1$ \\
\hline & Range & $1-5$ & $1-4$ & $27.3 \%=2$ \\
\hline & Median & 3 & 3 & $\therefore 36.4 \%=1,2$ \\
\hline & Mode & 3 & 3 & No Consensus \\
\hline \multirow[t]{5}{*}{ Movie Theaters } & & Round II & Round III & Agreement \\
\hline & Mean & 2.64 & 2.64 & $9.1 \%=1$ \\
\hline & Range & $1-5$ & $1-5$ & $31.8 \%=2$ \\
\hline & Median & 3 & 3 & $\therefore 40.9 \%=1,2$ \\
\hline & Mode & 3 & 3 & No Consensus \\
\hline \multirow[t]{5}{*}{ Banking Services } & & Round II & Round III & Agreement \\
\hline & Mean & 2.45 & 2.73 & $18.2 \%=1$ \\
\hline & Range & $1-4$ & $1-5$ & $22.7 \%=2$ \\
\hline & Median & 2.5 & 3 & $\therefore 40.9 \%=1,2$ \\
\hline & Mode & 3 & 3 & No Consensus \\
\hline \multirow[t]{5}{*}{ Internet cafe } & & Round II & Round III & Agreement \\
\hline & Mean & 2.86 & 2.82 & $13.6 \%=1$ \\
\hline & Range & $1-6$ & $1-6$ & $22.3 \%=2$ \\
\hline & Median & 3 & 3 & $\therefore 35.9 \%=1,2$ \\
\hline & Mode & $2,3+4$ & 3 & No Consensus \\
\hline \multirow[t]{5}{*}{ Art Galleries } & & Round II & Round III & Agreement \\
\hline & Mean & 2.77 & 2.91 & $18.2 \%=1$ \\
\hline & Range & $1-5$ & $1-6$ & $22.7 \%=2$ \\
\hline & Median & 2 & 3 & $\therefore 40.9 \%=1,2$ \\
\hline & Mode & 2 & 3 & No Consensus \\
\hline \multirow{5}{*}{$\begin{array}{l}\text { Bowling, billiard, table-tennis } \\
\text { center }\end{array}$} & & Round II & Round III & Agreement \\
\hline & Mean & 2.95 & 3.00 & $9.1 \%=1$ \\
\hline & Range & $1-5$ & $1-5$ & $27.3 \%=2$ \\
\hline & Median & 3 & 3 & $\therefore 36.4 \%=1,2$ \\
\hline & Mode & $2+3$ & 3 & No Consensus \\
\hline \multirow{5}{*}{$\begin{array}{l}\text { Gaming centers-non electronic } \\
\text { (e.g. table games) }\end{array}$} & & Round II & Round III & Agreement \\
\hline & Mean & 3.14 & 3.09 & $4.5 \%=1$ \\
\hline & Range & $1-5$ & $1-5$ & $31.8 \%=2$ \\
\hline & Median & 3 & 3 & $\therefore 36.3 \%=1,2$ \\
\hline & Mode & 2 & 2 & No Consensus \\
\hline \multirow{5}{*}{$\begin{array}{l}\text { Gaming centers- } \\
\text { electronic/video }\end{array}$} & & Round II & Round III & Agreement \\
\hline & Mean & 2.86 & 3.10 & $4.8 \%=1$ \\
\hline & Range & $1-5$ & $1-6$ & $28.6 \%=2$ \\
\hline & Median & 3 & 3 & $\therefore 32.4 \%=1,2$ \\
\hline & Mode & 3 & 3 & No Consensus \\
\hline
\end{tabular}


(Continued) Q9 \& Q10: How important is it for each of the following amenities to be in the student union?

\begin{tabular}{|c|c|c|c|c|}
\hline \multirow[t]{5}{*}{ Cafeteria } & & Round II & Round III & Agreement \\
\hline & Mean & 3.27 & 3.18 & $0.0 \%=1$ \\
\hline & Range & $1-7$ & $2-5$ & $22.7 \%=2$ \\
\hline & Median & 3 & 3 & $\therefore 22.7 \%=1,2$ \\
\hline & Mode & 3 & 3 & No Consensus \\
\hline \multirow[t]{5}{*}{ Full-service/sit down restaurant } & & Round II & Round III & Agreement \\
\hline & Mean & 3.18 & 3.23 & $4.5 \%=1$ \\
\hline & Range & $1-6$ & $1-5$ & $13.6 \%=2$ \\
\hline & Median & 3 & 3 & $\therefore 18.1 \%=1,2$ \\
\hline & Mode & 3 & 3 & No Consensus \\
\hline \multirow[t]{5}{*}{ Pub serving alcohol } & & Round II & Round III & Agreement \\
\hline & Mean & 3.55 & 3.45 & $4.5 \%=1$ \\
\hline & Range & $1-7$ & $1-6$ & $27.3 \%=2$ \\
\hline & Median & 3.5 & 4 & $\therefore 31.8 \%=1,2$ \\
\hline & Mode & 4 & 4 & No Consensus \\
\hline \multirow[t]{5}{*}{ Computer labs } & & Round II & Round III & Agreement \\
\hline & Mean & 3.33 & 3.55 & $0.0 \%=1$ \\
\hline & Range & $1-6$ & $2-6$ & $18.2 \%=2$ \\
\hline & Median & 3 & 3 & $\therefore 18.2 \%=1,2$ \\
\hline & Mode & 3 & 3 & No Consensus \\
\hline \multirow{5}{*}{$\begin{array}{l}\text { Outdoor recreation equipment } \\
\text { rental }\end{array}$} & & Round II & Round III & Agreement \\
\hline & Mean & 3.91 & 3.77 & $0.0 \%=1$ \\
\hline & Range & $2-7$ & $2-7$ & $18.2 \%=2$ \\
\hline & Median & 3.5 & 4 & $\therefore 18.2 \%=1,2$ \\
\hline & Mode & 3 & 4 & No Consensus \\
\hline \multirow[t]{5}{*}{ Craft centers } & & Round II & Round III & Agreement \\
\hline & Mean & 4.00 & 3.81 & $4.8 \%=1$ \\
\hline & Range & $1-6$ & $1-6$ & $19.0 \%=2$ \\
\hline & Median & 4 & 4 & $\therefore 23.8 \%=1,2$ \\
\hline & Mode & 3 & 4 & No Consensus \\
\hline \multirow[t]{5}{*}{ Locker rentals } & & Round II & Round III & Agreement \\
\hline & Mean & 3.64 & 3.82 & $0.0 \%=1$ \\
\hline & Range & $2-5$ & $2-7$ & $27.3 \%=2$ \\
\hline & Median & 4 & 3.5 & $\therefore 27.3 \%=1,2$ \\
\hline & Mode & $3+4$ & 3 & No Consensus \\
\hline \multirow[t]{5}{*}{ Barber/Beauty Shop } & & Round II & Round III & Agreement \\
\hline & Mean & 4.59 & 4.59 & $0.0 \%=1$ \\
\hline & Range & $2-6$ & $2-7$ & $4.5 \%=2$ \\
\hline & Median & 4 & 4.5 & $\therefore 4.5 \%=1,2$ \\
\hline & Mode & 4 & 4 & No Consensus \\
\hline
\end{tabular}


(Continued) Q9 \& Q10: How important is it for each of the following amenities to be in the student union?

\begin{tabular}{|c|c|c|c|c|}
\hline \multirow[t]{5}{*}{ Hotel connected to the Union } & & Round II & Round III & Agreement \\
\hline & Mean & 4.73 & 4.62 & $0.0 \%=1$ \\
\hline & Range & $2-7$ & $2-7$ & $4.8 \%=2$ \\
\hline & Median & 5 & 5 & $\therefore 4.8 \%=1,2$ \\
\hline & Mode & $4+6$ & 5 & No Consensus \\
\hline \multirow[t]{5}{*}{ Travel Agency Services } & & Round II & Round III & Agreement \\
\hline & Mean & 4.82 & 4.64 & $0.0 \%=1$ \\
\hline & Range & $2-7$ & $2-7$ & $9.1 \%=2$ \\
\hline & Median & 5 & 5 & $\therefore 9.1 \%=1,2$ \\
\hline & Mode & 4 & 5 & No Consensus \\
\hline \multirow[t]{5}{*}{ Showers } & & Round II & Round III & Agreement \\
\hline & Mean & 4.95 & 4.91 & $9.1 \%=1$ \\
\hline & Range & $2-7$ & $1-7$ & $0.0 \%=2$ \\
\hline & Median & 5 & 5 & $\therefore 9.1 \%=1,2$ \\
\hline & Mode & 4 & 5 & No Consensus \\
\hline
\end{tabular}

$\mathrm{N}=22$

(Tables continue on following page) 
Table P9

\section{Physical Attributes of Student Union Locations}

Q12: How important are each of the following physical attributes of student union locations?

\begin{tabular}{|c|c|c|c|c|}
\hline \multirow{5}{*}{$\begin{array}{l}\text { Located in a high-traffic } \\
\text { area/pedestrian crossroads of } \\
\text { the campus }\end{array}$} & & Round II & Round III & Agreement \\
\hline & Mean & 1.48 & 1.32 & $61.2 \%=1$ \\
\hline & Range & $1-4$ & $1-2$ & $31.8 \%=2$ \\
\hline & Median & 1 & 1 & $\therefore 93.0 \%=1,2$ \\
\hline & Mode & 1 & 1 & $\sqrt{ }$ Consensus \\
\hline \multirow{5}{*}{$\begin{array}{l}\text { Located close to the physical } \\
\text { center of campus }\end{array}$} & & Round II & Round III & Agreement \\
\hline & Mean & 1.64 & 1.43 & $61.9 \%=1$ \\
\hline & Range & $1-3$ & $1-3$ & $33.3 \%=2$ \\
\hline & Median & 1 & 1 & $\therefore 95.2 \%=1,2$ \\
\hline & Mode & 1 & 1 & $\sqrt{ }$ Consensus \\
\hline \multirow[t]{5}{*}{ Located close to parking } & & Round II & Round III & Agreement \\
\hline & Mean & 1.86 & 2.00 & $27.3 \%=1$ \\
\hline & Range & $1-5$ & $1-5$ & $54.5 \%=2$ \\
\hline & Median & 2 & 2 & $\therefore 91.8 \%=1,2$ \\
\hline & Mode & 2 & 2 & $\sqrt{ }$ Consensus \\
\hline \multirow[t]{5}{*}{ Located close to residence halls } & & Round II & Round III & Agreement \\
\hline & Mean & 2.18 & 2.18 & $18.2 \%=1$ \\
\hline & Range & $1-5$ & $1-5$ & $59.1 \%=2$ \\
\hline & Median & 2 & 2 & $\therefore 77.3 \%=1,2$ \\
\hline & Mode & 2 & 2 & $\sqrt{ }$ Consensus \\
\hline \multirow[t]{5}{*}{ Located close to mass transit } & & Round II & Round III & Agreement \\
\hline & Mean & 2.68 & 2.64 & $9.1 \%=1$ \\
\hline & Range & $1-5$ & $1-5$ & $36.4 \%=2$ \\
\hline & Median & 3 & 3 & $\therefore 45.5 \%=1,2$ \\
\hline & Mode & $2+3$ & 3 & No Consensus \\
\hline \multirow[t]{5}{*}{ Located close to the library } & & Round II & Round III & Agreement \\
\hline & Mean & 3.05 & 2.91 & $4.5 \%=1$ \\
\hline & Range & $1-5$ & $1-5$ & $31.8 \%=2$ \\
\hline & Median & 3 & 3 & $\therefore 36.3 \%=1,2$ \\
\hline & Mode & 3 & 3 & No Consensus \\
\hline
\end{tabular}

$\mathrm{N}=22$ 
Table P10

\section{Physical Attributes of Student Union Exteriors}

Q13: How important is it for each of the following physical attributes of student union exteriors?

\begin{tabular}{|c|c|c|c|c|}
\hline \multirow[t]{2}{*}{ Cleanliness of building exterior } & & Round II & Round III & Agreement \\
\hline & $\begin{array}{l}\text { Mean } \\
\text { Range } \\
\text { Median } \\
\text { Mode }\end{array}$ & $\begin{array}{l}1.41 \\
1-2 \\
1 \\
1\end{array}$ & $\begin{array}{l}1.36 \\
1-3 \\
1 \\
1\end{array}$ & $\begin{array}{l}68.2 \%=1 \\
27.3 \%=2 \\
\therefore 95.5 \%=1,2 \\
\sqrt{ } \text { Consensus }\end{array}$ \\
\hline \multirow[t]{2}{*}{ Clearly defined entrance } & & Round II & Round III & Agreement \\
\hline & $\begin{array}{l}\text { Mean } \\
\text { Range } \\
\text { Median } \\
\text { Mode }\end{array}$ & $\begin{array}{l}1.27 \\
1-3 \\
1 \\
1\end{array}$ & $\begin{array}{l}1.41 \\
1-3 \\
1 \\
1\end{array}$ & $\begin{array}{l}68.2 \%=1 \\
22.7 \%=2 \\
\therefore 90.9 \%=1,2 \\
\sqrt{ } \text { Consensus }\end{array}$ \\
\hline \multirow[t]{2}{*}{ Clear exterior signage } & & Round II & Round III & Agreement \\
\hline & $\begin{array}{l}\text { Mean } \\
\text { Range } \\
\text { Median } \\
\text { Mode }\end{array}$ & $\begin{array}{l}1.45 \\
1-3 \\
1 \\
1\end{array}$ & $\begin{array}{l}1.41 \\
1-3 \\
1 \\
1\end{array}$ & $\begin{array}{l}63.6 \%=1 \\
31.8 \%=2 \\
\therefore 95.4 \%=1,2 \\
\sqrt{ } \text { Consensus }\end{array}$ \\
\hline \multirow{2}{*}{$\begin{array}{l}\text { Physical condition of the } \\
\text { building exterior (well- } \\
\text { maintained) }\end{array}$} & & Round II & Round III & Agreement \\
\hline & $\begin{array}{l}\text { Mean } \\
\text { Range } \\
\text { Median } \\
\text { Mode }\end{array}$ & $\begin{array}{l}1.36 \\
1-2 \\
1 \\
1\end{array}$ & $\begin{array}{l}1.50 \\
1-3 \\
1 \\
1\end{array}$ & $\begin{array}{l}59.1 \%=1 \\
31.8 \%=2 \\
\therefore 90.0 \%=1,2 \\
\sqrt{ } \text { Consensus }\end{array}$ \\
\hline \multirow{2}{*}{$\begin{array}{l}\text { Attractive design of building } \\
\text { exterior }\end{array}$} & & Round II & Round III & Agreement \\
\hline & $\begin{array}{l}\text { Mean } \\
\text { Range } \\
\text { Median } \\
\text { Mode }\end{array}$ & $\begin{array}{l}1.55 \\
1-3 \\
1 \\
1\end{array}$ & $\begin{array}{l}1.59 \\
1-3 \\
1 \\
1\end{array}$ & $\begin{array}{l}54.5 \%=1 \\
31.8 \%=2 \\
\therefore 86.3 \%=1,2 \\
\sqrt{ } \text { Consensus }\end{array}$ \\
\hline \multirow{2}{*}{$\begin{array}{l}\text { Attractive design of exterior } \\
\text { landscaping }\end{array}$} & & Round II & Round III & Agreement \\
\hline & $\begin{array}{l}\text { Mean } \\
\text { Range } \\
\text { Median } \\
\text { Mode }\end{array}$ & $\begin{array}{l}1.73 \\
1-3 \\
1 \\
1\end{array}$ & $\begin{array}{l}1.68 \\
1-4 \\
2 \\
1+2\end{array}$ & $\begin{array}{l}45.5 \%=1 \\
45.5 \%=2 \\
\therefore 91.0 \%=1,2 \\
\sqrt{ } \text { Consensus }\end{array}$ \\
\hline \multirow{2}{*}{$\begin{array}{l}\text { Human scale design (no more } \\
\text { than } 3 \text { stories high) }\end{array}$} & & Round II & Round III & Agreement \\
\hline & $\begin{array}{l}\text { Mean } \\
\text { Range } \\
\text { Median } \\
\text { Mode }\end{array}$ & $\begin{array}{l}3.23 \\
1-5 \\
3.5 \\
4\end{array}$ & $\begin{array}{l}2.73 \\
1-5 \\
3 \\
2+3\end{array}$ & $\begin{array}{l}9.1 \%=1 \\
36.4 \%=2 \\
\therefore 45.5 \%=1,2 \\
\text { No Consensus }\end{array}$ \\
\hline
\end{tabular}

$\mathrm{N}=22$ 
Table P11

\section{Physical Attributes of Student Union Interiors}

\begin{tabular}{|c|c|c|c|c|}
\hline \multicolumn{5}{|c|}{$\begin{array}{l}\text { Q14 \& Q15: How important is each of the following physical attributes of student union } \\
\text { interiors? }\end{array}$} \\
\hline \multirow{5}{*}{$\begin{array}{l}\text { Adequate \& appropriate } \\
\text { technological capability / } \\
\text { infrastructure }\end{array}$} & & Round II & Round III & Agreement \\
\hline & Mean & 1.27 & 1.05 & $95.5 \%=1$ \\
\hline & Range & $1-2$ & $1-2$ & $4.5 \%=2$ \\
\hline & Median & 1 & 1 & $\therefore 100 \%=1,2$ \\
\hline & Mode & 1 & 1 & $\sqrt{ }$ True Consensus \\
\hline \multirow[t]{5}{*}{ Cleanliness of building interior } & & Round II & Round III & Agreement \\
\hline & Mean & 1.14 & 1.09 & $68.2 \%=1$ \\
\hline & Range & $1-2$ & $1-2$ & $22.7 \%=2$ \\
\hline & Median & 1 & 1 & $\therefore 90.9 \%=1,2$ \\
\hline & Mode & 1 & 1 & $\sqrt{ }$ Consensus \\
\hline
\end{tabular}

\begin{tabular}{|c|c|c|c|c|}
\hline \multirow{5}{*}{$\begin{array}{l}\text { Adequate } \& \text { appropriate space } \\
\text { for all the various } \\
\text { functions/usage of the union }\end{array}$} & & Round II & Round III & Agreement \\
\hline & Mean & 1.18 & 1.14 & $86.4 \%=1$ \\
\hline & Range & $1-2$ & $1-2$ & $13.6 \%=2$ \\
\hline & Median & 1 & 1 & $\therefore 100 \%=1,2$ \\
\hline & Mode & 1 & 1 & $\sqrt{ }$ True Consensus \\
\hline \multirow{5}{*}{$\begin{array}{l}\text { Physical condition of the } \\
\text { building interior (well- } \\
\text { maintained) }\end{array}$} & & Round II & Round III & Agreement \\
\hline & Mean & 1.14 & 1.14 & $90.9 \%=1$ \\
\hline & Range & $1-2$ & $1-3$ & $4.5 \%=2$ \\
\hline & Median & 1 & 1 & $\therefore 95.4 \%=1,2$ \\
\hline & Mode & 1 & 1 & $\sqrt{ }$ True Consensus \\
\hline \multirow{5}{*}{$\begin{array}{l}\text { Seating styles/types encourage } \\
\text { interaction }\end{array}$} & & Round II & Round III & Agreement \\
\hline & Mean & 1.36 & 1.18 & $81.8 \%=1$ \\
\hline & Range & $1-2$ & $1-2$ & $18.2 \%=2$ \\
\hline & Median & 1 & 1 & $\therefore 100 \%=1,2$ \\
\hline & Mode & 1 & 1 & $\sqrt{ }$ True Consensus \\
\hline \multirow{5}{*}{$\begin{array}{l}\text { Attractive design of building } \\
\text { interior }\end{array}$} & & Round II & Round III & Agreement \\
\hline & Mean & 1.23 & 1.23 & $81.8 \%=1$ \\
\hline & Range & $1-3$ & $1-3$ & $13.6 \%=2$ \\
\hline & Median & 1 & 1 & $\therefore 95.4 \%=1,2$ \\
\hline & Mode & 1 & 1 & $\sqrt{ }$ True Consensus \\
\hline \multirow[t]{5}{*}{ ADA Accessible } & & Round II & Round III & Agreement \\
\hline & Mean & 1.18 & 1.23 & $77.3 \%=1$ \\
\hline & Range & $1-2$ & $1-2$ & $22.7 \%=2$ \\
\hline & Median & 1 & 1 & $\therefore 100 \%=1,2$ \\
\hline & Mode & 1 & 1 & $\sqrt{ }$ True Consensus \\
\hline \multirow{5}{*}{$\begin{array}{l}\text { Comfortable interiors and } \\
\text { furnishings }\end{array}$} & & Round II & Round III & Agreement \\
\hline & Mean & 1.32 & 1.27 & $72.7 \%=1$ \\
\hline & Range & $1-2$ & $1-2$ & $27.3 \%=2$ \\
\hline & Median & 1 & 1 & $\therefore 100 \%=1,2$ \\
\hline & Mode & 1 & 1 & $\sqrt{ }$ Consensus \\
\hline
\end{tabular}




\section{(Continued) Q14 \& Q15: How important is each of the following physical attributes of student union interiors?}

\begin{tabular}{|c|c|c|c|c|}
\hline \multirow[t]{2}{*}{ Engaging environment } & & Round II & Round III & Agreement \\
\hline & $\begin{array}{l}\text { Mean } \\
\text { Range } \\
\text { Median } \\
\text { Mode }\end{array}$ & $\begin{array}{l}1.36 \\
1-3 \\
1 \\
1\end{array}$ & $\begin{array}{l}1.32 \\
1-2 \\
1 \\
1\end{array}$ & $\begin{array}{l}68.2 \%=1 \\
31.8 \%=2 \\
\therefore 100 \%=1,2 \\
\sqrt{ } \text { Consensus }\end{array}$ \\
\hline \multirow{2}{*}{$\begin{array}{l}\text { Clear interior signage } \& \\
\text { directions }\end{array}$} & & Round II & Round III & Agreement \\
\hline & $\begin{array}{l}\text { Mean } \\
\text { Range } \\
\text { Median } \\
\text { Mode }\end{array}$ & $\begin{array}{l}1.32 \\
1-2 \\
1 \\
1\end{array}$ & $\begin{array}{l}1.32 \\
1-2 \\
1 \\
1\end{array}$ & $\begin{array}{l}68.2 \%=1 \\
31.8 \%=2 \\
\therefore 100 \%=1,2 \\
\sqrt{ } \text { Consensus }\end{array}$ \\
\hline \multirow[t]{2}{*}{ Adequate lighting fixtures } & & Round II & Round III & Agreement \\
\hline & $\begin{array}{l}\text { Mean } \\
\text { Range } \\
\text { Median } \\
\text { Mode }\end{array}$ & $\begin{array}{l}1.41 \\
1-2 \\
1 \\
1\end{array}$ & $\begin{array}{l}1.32 \\
1-2 \\
1 \\
1\end{array}$ & $\begin{array}{l}61.2 \%=1 \\
31.8 \%=2 \\
\therefore 93.0 \%=1,2 \\
\sqrt{ } \text { Consensus }\end{array}$ \\
\hline \multirow{2}{*}{$\begin{array}{l}\text { Has "sticky-spaces" where } \\
\text { people want to come and stay } \\
\text { (regardless of transaction } \\
\text { needs) }\end{array}$} & & Round II & Round III & Agreement \\
\hline & $\begin{array}{l}\text { Mean } \\
\text { Range } \\
\text { Median } \\
\text { Mode }\end{array}$ & $\begin{array}{l}1.55 \\
1-3 \\
1 \\
1\end{array}$ & $\begin{array}{l}1.41 \\
1-3 \\
1 \\
1\end{array}$ & $\begin{array}{l}63.6 \%=1 \\
31.8 \%=2 \\
\therefore 95.4 \%=1,2 \\
\sqrt{ } \text { Consensus }\end{array}$ \\
\hline \multirow{2}{*}{$\begin{array}{l}\text { Lots of windows/Natural } \\
\text { lighting }\end{array}$} & & Round II & Round III & Agreement \\
\hline & $\begin{array}{l}\text { Mean } \\
\text { Range } \\
\text { Median } \\
\text { Mode }\end{array}$ & $\begin{array}{l}1.41 \\
1-2 \\
1 \\
1\end{array}$ & $\begin{array}{l}1.41 \\
1-3 \\
1 \\
1\end{array}$ & $\begin{array}{l}68.2 \%=1 \\
22.7 \%=2 \\
\therefore 90.9 \%=1,2 \\
\sqrt{ } \text { Consensus }\end{array}$ \\
\hline \multirow{2}{*}{$\begin{array}{l}\text { "Open feel" to the building } \\
\text { interior }\end{array}$} & & Round II & Round III & Agreement \\
\hline & $\begin{array}{l}\text { Mean } \\
\text { Range } \\
\text { Median } \\
\text { Mode }\end{array}$ & $\begin{array}{l}1.41 \\
1-2 \\
1 \\
1\end{array}$ & $\begin{array}{l}1.45 \\
1-3 \\
1 \\
1\end{array}$ & $\begin{array}{l}63.6 \%=1 \\
27.3 \%=2 \\
\therefore 90.9 \%=1,2 \\
\sqrt{ } \text { Consensus }\end{array}$ \\
\hline \multirow{2}{*}{$\begin{array}{l}\text { Seating \& tables can be moved } \\
\text { around (modular) }\end{array}$} & & Round II & Round III & Agreement \\
\hline & $\begin{array}{l}\text { Mean } \\
\text { Range } \\
\text { Median } \\
\text { Mode }\end{array}$ & $\begin{array}{l}1.59 \\
1-3 \\
2 \\
2\end{array}$ & $\begin{array}{l}1.50 \\
1-2 \\
1.5 \\
1+2\end{array}$ & $\begin{array}{l}50.0 \%=1 \\
50.0 \%=2 \\
\therefore 100 \%=1,2 \\
\sqrt{ } \text { Consensus }\end{array}$ \\
\hline \multirow{2}{*}{$\begin{array}{l}\text { Good flow/traffic pattern } \\
\text { between services and amenities }\end{array}$} & & Round II & Round III & Agreement \\
\hline & $\begin{array}{l}\text { Mean } \\
\text { Range } \\
\text { Median } \\
\text { Mode }\end{array}$ & $\begin{array}{l}1.50 \\
1-3 \\
1 \\
1\end{array}$ & $\begin{array}{l}1.50 \\
1-3 \\
1 \\
1\end{array}$ & $\begin{array}{l}54.5 \%=1 \\
40.9 \%=2 \\
\therefore 95.4 \%=1,2 \\
\sqrt{ } \text { Consensus }\end{array}$ \\
\hline
\end{tabular}




\section{(Continued) Q14 \& Q15: How important is each of the following physical attributes of student union interiors?}

\begin{tabular}{|c|c|c|c|c|}
\hline \multirow{5}{*}{$\begin{array}{l}\text { Has a focal point that } \\
\text { brings people together } \\
\text { (e.g. lounge, porch) }\end{array}$} & & Round II & Round III & Agreement \\
\hline & Mean & 1.59 & 1.55 & $50.0 \%=1$ \\
\hline & Range & $1-3$ & $1-3$ & $45.5 \%=2$ \\
\hline & Median & 1 & 1 & $\therefore 95.5 \%=1,2$ \\
\hline & Mode & 1 & 1 & $\sqrt{ }$ Consensus \\
\hline \multirow[t]{5}{*}{ Fun," playful environment } & & Round II & Round III & Agreement \\
\hline & Mean & 1.68 & 1.55 & $50.0 \%=1$ \\
\hline & Range & $1-4$ & $1-3$ & $45.5 \%=2$ \\
\hline & Median & 1 & 1.5 & $\therefore 95.5 \%=1,2$ \\
\hline & Mode & 1 & 1 & $\sqrt{ }$ Consensus \\
\hline \multirow{5}{*}{$\begin{array}{l}\text { Conveniently clustered offices } \\
\text { and services ("one-stop shop") }\end{array}$} & & Round II & Round III & Agreement \\
\hline & Mean & 2.14 & 1.73 & $31.8 \%=1$ \\
\hline & Range & $1-3$ & $1-3$ & $63.6 \%=2$ \\
\hline & Median & 2 & 2 & $\therefore 94.4 \%=1,2$ \\
\hline & Mode & 2 & 2 & $\sqrt{ }$ Consensus \\
\hline \multirow{5}{*}{$\begin{array}{l}\text { Stylistically modern or timeless } \\
\text { interiors and furnishings (not } \\
\text { obviously dated) }\end{array}$} & & Round II & Round III & Agreement \\
\hline & Mean & 1.82 & 1.81 & $38.1 \%=1$ \\
\hline & Range & $1-3$ & $1-3$ & $42.9 \%=2$ \\
\hline & Median & 2 & 2 & $\therefore 81.0 \%=1,2$ \\
\hline & Mode & 2 & 2 & $\sqrt{ }$ Consensus \\
\hline \multirow{5}{*}{$\begin{array}{l}\text { Noise-proofing/Sound-proofing } \\
\text { (reduce sound transfer between } \\
\text { areas) }\end{array}$} & & Round II & Round III & Agreement \\
\hline & Mean & 2.23 & 1.91 & $27.3 \%=1$ \\
\hline & Range & $1-4$ & $1-3$ & $54.5 \%=2$ \\
\hline & Median & 2 & 2 & $\therefore 81.8 \%=1,2$ \\
\hline & Mode & 2 & 2 & $\sqrt{ }$ Consensus \\
\hline \multirow{5}{*}{$\begin{array}{l}\text { Flexible multipurpose } \\
\text { design/moveable walls }\end{array}$} & & Round II & Round III & Agreement \\
\hline & Mean & 1.91 & 1.91 & $31.8 \%=1$ \\
\hline & Range & $1-5$ & $1-3$ & $45.5 \%=2$ \\
\hline & Median & 2 & 2 & $\therefore 77.2 \%=1,2$ \\
\hline & Mode & 2 & 2 & $\sqrt{ }$ Consensus \\
\hline \multirow{5}{*}{$\begin{array}{l}\text { Behavioral zoning (e.g. clearly } \\
\text { defined places for eating, } \\
\text { shopping, studying, relaxing) }\end{array}$} & & Round II & Round III & Agreement \\
\hline & Mean & 2.81 & 2.05 & $22.7 \%=1$ \\
\hline & Range & $1-5$ & $1-3$ & $50.0 \%=2$ \\
\hline & Median & 3 & 2 & $\therefore 72.2 \%=1,2$ \\
\hline & Mode & 2 & 2 & No Consensus \\
\hline
\end{tabular}


(Continued) Q14 \& Q15: How important is each of the following physical attributes of student union interiors?

\begin{tabular}{|c|c|c|c|c|}
\hline \multirow{5}{*}{$\begin{array}{l}\text { Interior plantings/plant life } \\
\text { within the union }\end{array}$} & & Round II & Round III & Agreement \\
\hline & Mean & 2.45 & 2.32 & $36.4 \%=2$ \\
\hline & Range & $1-5$ & $1-4$ & $18.2 \%=1$ \\
\hline & Median & 2 & 2 & $\therefore 54.6 \%=1,2$ \\
\hline & Mode & 2 & 3 & No Consensus \\
\hline \multirow{5}{*}{$\begin{array}{l}\text { Individual climate control in } \\
\text { rooms/areas (heating/ac) }\end{array}$} & & Round II & Round III & Agreement \\
\hline & Mean & 2.77 & 2.36 & $22.7 \%=1$ \\
\hline & Range & $1-5$ & $1-4$ & $27.3 \%=2$ \\
\hline & Median & 3 & 2.5 & $\therefore 50.0 \%=1,2$ \\
\hline & Mode & 2 & 3 & $\sqrt{ }$ Consensus \\
\hline $\mathrm{N}=22$ & & & & \\
\hline
\end{tabular}

(Tables continue on following page.) 
Table P12

\section{Human Attributes of Student Unions}

Q16 \& Q17: How important is each of the following human attributes of student unions?

\begin{tabular}{|c|c|c|c|c|}
\hline \multirow{5}{*}{$\begin{array}{l}\text { Staff is student } \\
\text { focused/committed }\end{array}$} & & Round II & Round III & Agreement \\
\hline & Mean & 1.09 & 1.00 & $100.0 \%=1$ \\
\hline & Range & $1-2$ & 0 & $0.0 \%=2$ \\
\hline & Median & 1 & 1 & $\therefore 100.0 \%=1,2$ \\
\hline & Mode & 1 & 1 & $\sqrt{ }$ True Consensus \\
\hline \multirow{5}{*}{$\begin{array}{l}\text { Staff includes student } \\
\text { employees }\end{array}$} & & Round II & Round III & Agreement \\
\hline & Mean & 1.09 & 1.00 & $100.0 \%=1$ \\
\hline & Range & $1-2$ & 0 & $0.0 \%=2$ \\
\hline & Median & 1 & 1 & $\therefore 100.0 \%=1,2$ \\
\hline & Mode & 1 & 1 & $\sqrt{ }$ True Consensus \\
\hline \multirow{5}{*}{$\begin{array}{l}\text { Union conveys to students that } \\
\text { they matter }\end{array}$} & & Round II & Round III & Agreement \\
\hline & Mean & 1.05 & 1.00 & $100.0 \%=1$ \\
\hline & Range & $1-2$ & 0 & $0.0 \%=2$ \\
\hline & Median & 1 & 1 & $\therefore 100.0 \%=1,2$ \\
\hline & Mode & 1 & 1 & $\sqrt{ }$ True Consensus \\
\hline \multirow{5}{*}{$\begin{array}{l}\text { Staff is knowledgeable/well- } \\
\text { trained }\end{array}$} & & Round II & Round III & Agreement \\
\hline & Mean & 1.09 & 1.09 & $90.9 \%=1$ \\
\hline & Range & $1-2$ & $1-2$ & $9.1 \%=2$ \\
\hline & Median & 1 & 1 & $\therefore 100.0 \%=1,2$ \\
\hline & Mode & 1 & 1 & $\sqrt{ }$ True Consensus \\
\hline \multirow[t]{5}{*}{ Staff is friendly } & & Round II & Round III & Agreement \\
\hline & Mean & 1.00 & 1.09 & $90.9 \%=1$ \\
\hline & Range & 0 & $1-2$ & $9.1 \%=2$ \\
\hline & Median & 1 & 1 & $\therefore 100.0 \%=1,2$ \\
\hline & Mode & 1 & 1 & $\sqrt{\text { True Consensus }}$ \\
\hline \multirow[t]{5}{*}{ Union feels welcoming/inviting } & & Round II & Round III & Agreement \\
\hline & Mean & 1.14 & 1.09 & $90.9 \%=1$ \\
\hline & Range & $1-2$ & $1-2$ & $9.1 \%=2$ \\
\hline & Median & 1 & 1 & $\therefore 100.0 \%=1,2$ \\
\hline & Mode & 1 & 1 & $\sqrt{ }$ True Consensus \\
\hline \multirow{5}{*}{$\begin{array}{l}\text { Union feels like a safe place, } \\
\text { physically }\end{array}$} & & Round II & Round III & Agreement \\
\hline & Mean & 1.20 & 1.09 & $90.9 \%=1$ \\
\hline & Range & $1-2$ & $1-2$ & $9.1 \%=2$ \\
\hline & Median & 1 & 1 & $\therefore 100.0 \%=1,2$ \\
\hline & Mode & 1 & 1 & $\sqrt{ }$ True Consensus \\
\hline \multirow{5}{*}{$\begin{array}{l}\text { Union feels like a safe place, } \\
\text { psychologically }\end{array}$} & & Round II & Round III & Agreement \\
\hline & Mean & 1.14 & 1.14 & $86.4 \%=1$ \\
\hline & Range & $1-2$ & $1-2$ & $13.6 \%=2$ \\
\hline & Median & 1 & 1 & $\therefore 100 \%=1,2$ \\
\hline & Mode & 1 & 1 & $\sqrt{ }$ True Consensus \\
\hline
\end{tabular}


(Continued) Q16 \& Q17: How important is each of the following human attributes of student unions?

\begin{tabular}{|c|c|c|c|c|}
\hline \multirow{5}{*}{ Services are high quality } & & Round II & Round III & Agreement \\
\hline & Mean & 1.09 & 1.14 & $86.4 \%=1$ \\
\hline & Range & $1-2$ & $1-2$ & $13.6 \%=2$ \\
\hline & Median & 1 & 1 & $\therefore 100 \%=1,2$ \\
\hline & Mode & 1 & 1 & $\sqrt{ }$ True Consensus \\
\hline \multirow{5}{*}{$\begin{array}{l}\text { Variety and options in purposes } \\
\text { for visiting the building (e.g. } \\
\text { mixed use building) }\end{array}$} & & Round II & Round III & Agreement \\
\hline & Mean & 1.45 & 1.23 & $77.3 \%=1$ \\
\hline & Range & $1-3$ & $1-2$ & $22.7 \%=2$ \\
\hline & Median & 1 & 1 & $\therefore 100 \%=1,2$ \\
\hline & Mode & 1 & 1 & $\sqrt{ }$ True Consensus \\
\hline \multirow[t]{5}{*}{ Staff size is adequate } & & Round II & Round III & Agreement \\
\hline & Mean & 1.41 & 1.27 & $72.7 \%=1$ \\
\hline & Range & $1-3$ & $1-2$ & $27.3 \%=2$ \\
\hline & Median & 1 & 1 & $\therefore 100 \%=1,2$ \\
\hline & Mode & 1 & 1 & $\sqrt{\text { Consensus }}$ \\
\hline \multirow[t]{5}{*}{ Variety and options in dining } & & Round II & Round III & Agreement \\
\hline & Mean & 1.41 & 1.36 & $68.2 \%=1$ \\
\hline & Range & $1-2$ & $1-3$ & $27.3 \%=2$ \\
\hline & Median & 1 & 1 & $\therefore 95.5 \%=1,2$ \\
\hline & Mode & 1 & 1 & $\sqrt{\text { Consensus }}$ \\
\hline \multirow[t]{5}{*}{ Staff is diverse } & & Round II & Round III & Agreement \\
\hline & Mean & 1.68 & 1.55 & $59.1 \%=1$ \\
\hline & Range & $1-7$ & $1-5$ & $36.4 \%=2$ \\
\hline & Median & 1 & 1 & $\therefore 95.5 \%=1,2$ \\
\hline & Mode & 1 & 1 & $\sqrt{\text { Consensus }}$ \\
\hline \multirow{5}{*}{$\begin{array}{l}\text { Variety and options in lounge } \\
\text { areas }\end{array}$} & & Round II & Round III & Agreement \\
\hline & Mean & 1.73 & 1.57 & $52.4 \%=1$ \\
\hline & Range & $1-3$ & $1-3$ & $38.1 \%=2$ \\
\hline & Median & 2 & 1 & $\therefore 90.5 \%=1,2$ \\
\hline & Mode & 2 & 1 & $\sqrt{\text { Consensus }}$ \\
\hline \multirow{5}{*}{$\begin{array}{l}\text { Services are } \\
\text { essential/destination services } \\
\text { that students need (must visit) }\end{array}$} & & Round II & Round III & Agreement \\
\hline & Mean & 1.64 & 1.57 & $47.6 \%=1$ \\
\hline & Range & $1-3$ & $1-3$ & $47.6 \%=2$ \\
\hline & Median & 2 & 2 & $\therefore 95.2 \%=1,2$ \\
\hline & Mode & 2 & $1+2$ & $\sqrt{\text { Consensus }}$ \\
\hline \multirow{5}{*}{$\begin{array}{l}\text { Prices at the various food and } \\
\text { retail outlets are affordable for } \\
\text { students }\end{array}$} & & Round II & Round III & Agreement \\
\hline & Mean & 1.55 & 1.59 & $50.0 \%=1$ \\
\hline & Range & $1-3$ & $1-3$ & $40.9 \%=2$ \\
\hline & Median & 1 & 1.5 & $\therefore 90.9 \%=1,2$ \\
\hline & Mode & 1 & 1 & $\sqrt{\text { Consensus }}$ \\
\hline
\end{tabular}




\section{(Continued) Q16 \& Q17: How important is each of the following human attributes of student unions?}

\begin{tabular}{|c|c|c|c|c|}
\hline \multirow{5}{*}{$\begin{array}{l}\text { Late/weekend hours for } \\
\text { entertainment/recreation } \\
\text { offerings }\end{array}$} & & Round II & Round III & Agreement \\
\hline & Mean & 1.76 & 1.59 & $45.5 \%=1$ \\
\hline & Range & $1-5$ & $1-3$ & $50.0 \%=2$ \\
\hline & Median & 1 & 2 & $\therefore 95.5 \%=1,2$ \\
\hline & Mode & 1 & 2 & $\sqrt{ }$ Consensus \\
\hline \multirow{5}{*}{$\begin{array}{l}\text { Artifacts communicate school } \\
\text { spirit/history }\end{array}$} & & Round II & Round III & Agreement \\
\hline & Mean & 1.82 & 1.64 & $45.5 \%=1$ \\
\hline & Range & $1-3$ & $1-3$ & $45.5 \%=2$ \\
\hline & Median & 2 & 2 & $\therefore 91.0 \%=1,2$ \\
\hline & Mode & 2 & $1+2$ & $\sqrt{ }$ Consensus \\
\hline \multirow{5}{*}{$\begin{array}{l}\text { Artifacts communicate human } \\
\text { diversity }\end{array}$} & & Round II & Round III & Agreement \\
\hline & Mean & 2.05 & 1.82 & $31.8 \%=1$ \\
\hline & Range & $1-6$ & $1-3$ & $54.5 \%=2$ \\
\hline & Median & 2 & 2 & $\therefore 96.3 \%=1,2$ \\
\hline & Mode & 2 & 2 & $\sqrt{ }$ Consensus \\
\hline \multirow{5}{*}{$\begin{array}{l}\text { Late/weekend hours for student } \\
\text { services in the building }\end{array}$} & & Round II & Round III & Agreement \\
\hline & Mean & 2.00 & 1.91 & $36.4 \%=1$ \\
\hline & Range & $1-4$ & $1-4$ & $40.9 \%=2$ \\
\hline & Median & 2 & 2 & $\therefore 77.3 \%=1,2$ \\
\hline & Mode & 2 & 2 & $\sqrt{ }$ Consensus \\
\hline \multirow{5}{*}{ Services are fast } & & Round II & Round III & Agreement \\
\hline & Mean & 1.86 & 1.91 & $22.7 \%=1$ \\
\hline & Range & $1-4$ & $1-4$ & $68.2 \%=2$ \\
\hline & Median & 2 & 2 & $\therefore 90.9 \%=1,2$ \\
\hline & Mode & 1 & 2 & $\sqrt{ }$ Consensus \\
\hline \multirow{5}{*}{$\begin{array}{l}\text { Late/weekend hours for food } \\
\text { services }\end{array}$} & & Round II & Round III & Agreement \\
\hline & Mean & 2.00 & 2.00 & $28.6 \%=1$ \\
\hline & Range & $1-4$ & $1-5$ & $52.4 \%=2$ \\
\hline & Median & 2 & 2 & $\therefore 81.0 \%=1,2$ \\
\hline & Mode & 1 & 2 & $\sqrt{ }$ Consensus \\
\hline \multirow{5}{*}{$\begin{array}{l}\text { Student union has strong } \\
\text { partnerships with } \\
\text { admissions/enrollment services }\end{array}$} & & Round II & Round III & Agreement \\
\hline & Mean & 2.23 & 2.36 & $13.6 \%=1$ \\
\hline & Range & $1-4$ & $1-5$ & $54.5 \%=2$ \\
\hline & Median & 2 & 2 & $\therefore 68.1 \%=1,2$ \\
\hline & Mode & 2 & 2 & No Consensus \\
\hline \multirow{5}{*}{$\begin{array}{l}\text { Late/weekend hours for retail } \\
\text { services }\end{array}$} & & Round II & Round III & Agreement \\
\hline & Mean & 2.59 & 2.45 & $9.1 \%=1$ \\
\hline & Range & $1-5$ & $1-5$ & $45.5 \%=2$ \\
\hline & Median & 3 & 2 & $\therefore 54.6 \%=1,2$ \\
\hline & Mode & 3 & 2 & No Consensus \\
\hline
\end{tabular}




\section{(Continued) Q16 \& Q17: How important is each of the following human attributes of student unions?}

\begin{tabular}{lllll}
\hline Student union has strong & & Round II & Round III & Agreement \\
\cline { 2 - 4 } partnerships with core & Mean & 2.55 & 2.45 & $9.1 \%=1$ \\
academics & Range & $1-4$ & $1-3$ & $36.4 \%=2$ \\
& Median & 3 & 3 & $\therefore 45.5 \%=1,2$ \\
& Mode & 3 & 3 & No Consensus \\
\hline
\end{tabular}

\section{Table P13}

\section{Physical Constraints for Student Unions}

Q19: How important is each of the following physical constraints, in influencing student union effectiveness?

\begin{tabular}{|c|c|c|c|c|}
\hline \multirow{5}{*}{$\begin{array}{l}\text { Building - neglected, poorly } \\
\text { maintained, run down, worn } \\
\text { out }\end{array}$} & & Round II & Round III & Agreement \\
\hline & Mean & 1.29 & 1.25 & $75.0 \%=1$ \\
\hline & Range & $1-2$ & $1-2$ & $25.0 \%=2$ \\
\hline & Median & 1 & 1 & $\therefore 100 \%=1,2$ \\
\hline & Mode & 1 & 1 & $\sqrt{ }$ True Consensus \\
\hline \multirow{5}{*}{$\begin{array}{l}\text { Infrastructure-aging/poor } \\
\text { infrastructure (e.g. HVAC, } \\
\text { plumbing, wiring) }\end{array}$} & & Round II & Round III & Agreement \\
\hline & Mean & 1.41 & 1.36 & $63.6 \%=1$ \\
\hline & Range & $1-3$ & $1-2$ & $36.4 \%=2$ \\
\hline & Median & 1 & 1 & $\therefore 100 \%=1,2$ \\
\hline & Mode & 1 & 1 & $\sqrt{\text { Consensus }}$ \\
\hline \multirow{5}{*}{$\begin{array}{l}\text { Design-not ADA } \\
\text { compliant/accessible }\end{array}$} & & Round II & Round III & Agreement \\
\hline & Mean & 1.50 & 1.48 & $61.9 \%=1$ \\
\hline & Range & $1-3$ & $1-3$ & $28.6 \%=2$ \\
\hline & Median & 1 & 1 & $\therefore 90.4 \%=1,2$ \\
\hline & Mode & 1 & 1 & $\sqrt{ }$ Consensus \\
\hline \multirow{5}{*}{$\begin{array}{l}\text { Infrastructure-asbestos, lead, or } \\
\text { other health concerns must be } \\
\text { addressed }\end{array}$} & & Round II & Round III & Agreement \\
\hline & Mean & 1.41 & 1.59 & $59.1 \%=1$ \\
\hline & Range & $1-3$ & $1-3$ & $22.7 \%=2$ \\
\hline & Median & 1 & 1 & $\therefore 91.8 \%=1,2$ \\
\hline & Mode & 1 & 1 & $\sqrt{ }$ Consensus \\
\hline \multirow{5}{*}{$\begin{array}{l}\text { Size-inadequate to } \\
\text { accommodate desired purposes } \\
\text { (can't fit all the functions in) }\end{array}$} & & Round II & Round III & Agreement \\
\hline & Mean & 1.55 & 1.64 & $54.5 \%=1$ \\
\hline & Range & $1-4$ & $1-4$ & $31.8 \%=2$ \\
\hline & Median & 1 & 1 & $\therefore 86.3 \%=1,2$ \\
\hline & Mode & 1 & 1 & $\sqrt{ }$ Consensus \\
\hline
\end{tabular}




\begin{tabular}{|c|c|c|c|c|}
\hline \multicolumn{5}{|c|}{$\begin{array}{l}\text { (Continued) Q19: How important is each of the following physical constraints, in influencin } \\
\text { student union effectiveness? }\end{array}$} \\
\hline \multirow{5}{*}{$\begin{array}{l}\text { Size-inadequate to serve level } \\
\text { of usage/student enrollment } \\
\text { (crowded usage) }\end{array}$} & & Round II & Round III & Agreement \\
\hline & Mean & 1.48 & 1.64 & $50.0 \%=1$ \\
\hline & Range & $1-3$ & $1-4$ & $40.9 \%=2$ \\
\hline & Median & 1 & 1.5 & $\therefore 90.9 \%=1,2$ \\
\hline & Mode & 1 & 1 & $\sqrt{ }$ Consensus \\
\hline \multirow{5}{*}{$\begin{array}{l}\text { Comprehensiveness-missing } \\
\text { key services \& amenities that } \\
\text { should be in the union }\end{array}$} & & Round II & Round III & Agreement \\
\hline & Mean & 1.86 & 1.73 & $45.5 \%=1$ \\
\hline & Range & $1-3$ & $1-3$ & $36.4 \%=2$ \\
\hline & Median & 2 & 2 & $\therefore 91.9 \%=1,2$ \\
\hline & Mode & 2 & 1 & $\sqrt{ }$ Consensus \\
\hline \multirow{5}{*}{$\begin{array}{l}\text { Location-poor original } \\
\text { choice/peripheral to campus }\end{array}$} & & Round II & Round III & Agreement \\
\hline & Mean & 1.50 & 1.73 & $40.9 \%=1$ \\
\hline & Range & $1-3$ & $1-3$ & $45.5 \%=2$ \\
\hline & Median & 1 & 2 & $\therefore 86.4 \%=1,2$ \\
\hline & Mode & 1 & 2 & $\sqrt{ }$ Consensus \\
\hline \multirow{5}{*}{$\begin{array}{l}\text { Design-outdated and } \\
\text { unappealing }\end{array}$} & & Round II & Round III & Agreement \\
\hline & Mean & 1.64 & 1.73 & $40.9 \%=1$ \\
\hline & Range & $1-3$ & $1-3$ & $45.5 \%=2$ \\
\hline & Median & 1.5 & 2 & $\therefore 86.4 \%=1,2$ \\
\hline & Mode & 1 & 2 & $\sqrt{ }$ Consensus \\
\hline \multirow{5}{*}{$\begin{array}{l}\text { Design-poor building design } \\
\text { with too many doors, } \\
\text { stairwells, corners }\end{array}$} & & Round II & Round III & Agreement \\
\hline & Mean & 1.77 & 1.91 & $36.4 \%=` 1$ \\
\hline & Range & $1-3$ & $1-3$ & $36.4 \%=2$ \\
\hline & Median & 2 & 2 & $\therefore 72.8 \%=1,1$ \\
\hline & Mode & 2 & $1+2$ & No Consensus \\
\hline \multirow{5}{*}{$\begin{array}{l}\text { Design-hard walls \& fixed } \\
\text { equipment with limited } \\
\text { adaptability/flexibility }\end{array}$} & & Round II & Round III & Agreement \\
\hline & Mean & 2.14 & 2.05 & $27.3 \%=1$ \\
\hline & Range & $1-4$ & $1-3$ & $40.9 \%=2$ \\
\hline & Median & 2 & 2 & $\therefore 68.2 \%=1,2$ \\
\hline & Mode & 2 & 2 & No Consensus \\
\hline \multirow{5}{*}{$\begin{array}{l}\text { Location-displaced/center of } \\
\text { campus has shifted as campus } \\
\text { grew }\end{array}$} & & Round II & Round III & Agreement \\
\hline & Mean & 2.09 & 2.09 & $13.6 \%=1$ \\
\hline & Range & $1-5$ & $1-4$ & $68.2 \%=2$ \\
\hline & Median & 2 & 2 & $\therefore 81.8 \%=1,2$ \\
\hline & Mode & 2 & 2 & $\sqrt{ }$ Consensus \\
\hline \multirow{5}{*}{$\begin{array}{l}\text { Building-need to preserve } \\
\text { desired architectural, historic or } \\
\text { traditional value }\end{array}$} & & Round II & Round III & Agreement \\
\hline & Mean & 2.18 & 2.18 & $18.2 \%=1$ \\
\hline & Range & $1-5$ & $1-3$ & $45.5 \%=2$ \\
\hline & Median & 2 & 2 & $\therefore 63.7 \%=1,2$ \\
\hline & Mode & 2 & 2 & No Consensus \\
\hline
\end{tabular}




\begin{tabular}{|c|c|c|c|c|}
\hline \multicolumn{5}{|c|}{$\begin{array}{l}\text { (Continued) Q19: How important is each of the following physical constraints, in influencing } \\
\text { student union effectiveness? }\end{array}$} \\
\hline \multirow{5}{*}{$\begin{array}{l}\text { Building-need to keep union } \\
\text { within one building }\end{array}$} & & Round II & Round III & Agreement \\
\hline & Mean & 3.09 & 2.91 & $13.6 \%=1$ \\
\hline & Range & $1-5$ & $1-6$ & $45.5 \%=2$ \\
\hline & Median & 3 & 3 & $\therefore 69.1 \%=1,2$ \\
\hline & Mode & 3 & 3 & No Consensus \\
\hline \multirow{5}{*}{$\begin{array}{l}\text { Building-need to split union } \\
\text { across multiple buildings }\end{array}$} & & Round II & Round III & Agreement \\
\hline & Mean & 3.59 & 3.68 & $4.5 \%=1$ \\
\hline & Range & $1-6$ & $1-7$ & $18.2 \%=2$ \\
\hline & Median & 4 & 3 & $\therefore 22.7 \%=1,2$ \\
\hline & Mode & $4+5$ & 3 & No Consensus \\
\hline
\end{tabular}

\section{Table P14}

\section{Knowledge Constraints for Student Unions}

Q20: How important is each of the following knowledge constraints, in influencing student union effectiveness?

\begin{tabular}{|c|c|c|c|c|}
\hline \multirow{5}{*}{$\begin{array}{l}\text { User input-need to seek input } \\
\text { from multiple } \\
\text { consumers/populations served } \\
\text { by the union }\end{array}$} & & Round II & Round III & Agreement \\
\hline & Mean & 1.33 & 1.23 & $77.3 \%=1$ \\
\hline & Range & $1-2$ & $1-2$ & $22.7 \%=2$ \\
\hline & Median & 1 & 1 & $\therefore 100 \%=1,2$ \\
\hline & Mode & 1 & 1 & $\sqrt{ }$ True Consensus \\
\hline \multirow{5}{*}{$\begin{array}{l}\text { General management-student } \\
\text { union has lost its focus on } \\
\text { students }\end{array}$} & & Round II & Round III & Agreement \\
\hline & Mean & 1.64 & 1.24 & $76.2 \%=1$ \\
\hline & Range & $1-6$ & $1-2$ & $23.8 \%=2$ \\
\hline & Median & 1 & 1 & $\therefore 100 \%=1,2$ \\
\hline & Mode & 1 & 1 & $\sqrt{ }$ True Consensus \\
\hline \multirow{5}{*}{$\begin{array}{l}\text { Satisfaction assessment-need to } \\
\text { measure union's effectiveness } \\
\text { in meeting student \& } \\
\text { community needs }\end{array}$} & & Round II & Round III & Agreement \\
\hline & Mean & 1.45 & 1.32 & $68.2 \%=1$ \\
\hline & Range & $1-3$ & $1-2$ & $31.8 \%=2$ \\
\hline & Median & 1 & 1 & $\therefore 100 \%=1,2$ \\
\hline & Mode & 1 & 1 & $\sqrt{ }$ Consensus \\
\hline \multirow{5}{*}{$\begin{array}{l}\text { Needs assessment-need to } \\
\text { identify current \& future } \\
\text { student needs for the union }\end{array}$} & & Round II & Round III & Agreement \\
\hline & Mean & 1.59 & 1.45 & $54.5 \%=1$ \\
\hline & Range & $1-3$ & $1-2$ & $45.5 \%=2$ \\
\hline & Median & 1.5 & 1 & $\therefore 100 \%=1,2$ \\
\hline & Mode & 1 & 1 & $\sqrt{ }$ Consensus \\
\hline
\end{tabular}


(Continued) Q20: How important is each of the following knowledge constraints, in influencing student union effectiveness?

\begin{tabular}{|c|c|c|c|c|}
\hline \multirow{5}{*}{$\begin{array}{l}\text { General management- } \\
\text { insufficient understanding of } \\
\text { "whole enterprise" of the union }\end{array}$} & & Round II & Round III & Agreement \\
\hline & Mean & 1.52 & 1.50 & $50.0 \%=1$ \\
\hline & Range & $1-4$ & $1-2$ & $50.0 \%=2$ \\
\hline & Median & 1 & 1.5 & $\therefore 100 \%=1,2$ \\
\hline & Mode & 1 & $1+2$ & $\sqrt{ }$ Consensus \\
\hline \multirow{5}{*}{$\begin{array}{l}\text { Staff-have insufficient } \\
\text { awareness of their role in } \\
\text { student development as } \\
\text { educators }\end{array}$} & & Round II & Round III & Agreement \\
\hline & Mean & 1.59 & 1.59 & $45.5 \%=1$ \\
\hline & Range & $1-2$ & $1-3$ & $50.0 \%=2$ \\
\hline & Median & 2 & 2 & $\therefore 95.5 \%=1,2$ \\
\hline & Mode & 2 & 2 & $\sqrt{ }$ Consensus \\
\hline \multirow{5}{*}{$\begin{array}{l}\text { General management-use } \\
\text { inappropriate administrative } \\
\text { paradigms (e.g. "facilities" } \\
\text { framework vs. "student } \\
\text { development" framework }\end{array}$} & & Round II & Round III & Agreement \\
\hline & Mean & 1.68 & 1.64 & $40.9 \%=1$ \\
\hline & Range & $1-3$ & $1-3$ & $54.6 \%=2$ \\
\hline & Median & 2 & 2 & $\therefore 95.4 \%=1,2$ \\
\hline & Mode & 2 & 2 & $\sqrt{ }$ Consensus \\
\hline \multirow{5}{*}{$\begin{array}{l}\text { Outcomes assessment-need to } \\
\text { measure and prove the union's } \\
\text { contribution to the educational } \\
\& \text { co-curricular process }\end{array}$} & & Round II & Round III & Agreement \\
\hline & Mean & 1.73 & 1.73 & $45.5 \%=1$ \\
\hline & Range & $1-5$ & $1-3$ & $36.4 \%=2$ \\
\hline & Median & 1.5 & 2 & $\therefore 81.9 \%=1,2$ \\
\hline & Mode & 1 & 1 & $\sqrt{ }$ Consensus \\
\hline \multirow{5}{*}{$\begin{array}{l}\text { Staff-have difficulty in } \\
\text { recruiting and retaining } \\
\text { student-focused union staff }\end{array}$} & & Round II & Round III & Agreement \\
\hline & Mean & 1.55 & 1.77 & $45.5 \%=1$ \\
\hline & Range & $1-2$ & $1-5$ & $40.9 \%=2$ \\
\hline & Median & 2 & 2 & $\therefore 86.4 \%=1,2$ \\
\hline & Mode & 2 & 1 & $\sqrt{ }$ Consensus \\
\hline \multirow{5}{*}{$\begin{array}{l}\text { Campus leaders-lack } \\
\text { understanding or appreciation } \\
\text { of student development \& the } \\
\text { union }\end{array}$} & & Round II & Round III & Agreement \\
\hline & Mean & 1.68 & 1.81 & $28.6 \%=1$ \\
\hline & Range & $1-3$ & $1-3$ & $61.9 \%=2$ \\
\hline & Median & 2 & 2 & $\therefore 90.5 \%=1,2$ \\
\hline & Mode & 2 & 2 & $\sqrt{ }$ Consensus \\
\hline \multirow{5}{*}{$\begin{array}{l}\text { Staff-need more student } \\
\text { involvement in union } \\
\text { programming and management }\end{array}$} & & Round II & Round III & Agreement \\
\hline & Mean & 1.59 & 1.82 & $45.5 \%=1$ \\
\hline & Range & $1-4$ & $1-3$ & $27.3 \%=2$ \\
\hline & Median & 1.5 & 2 & $\therefore 72.8 \%=1,2$ \\
\hline & Mode & 1 & 1 & No Consensus \\
\hline \multirow{5}{*}{$\begin{array}{l}\text { General management-space is } \\
\text { used inefficiently }\end{array}$} & & Round II & Round III & Agreement \\
\hline & Mean & 2.00 & 1.90 & $14.3 \%=1$ \\
\hline & Range & $1-3$ & $1-3$ & $80.9 \%=2$ \\
\hline & Median & 2 & 2 & $\therefore 95.2 \%=1,2$ \\
\hline & Mode & 2 & 2 & $\sqrt{ }$ Consensus \\
\hline
\end{tabular}




\begin{tabular}{|c|c|c|c|c|}
\hline \multicolumn{5}{|c|}{$\begin{array}{l}\text { (Continued) Q20: How important is each of the following knowledge constraints, in } \\
\text { influencing student union effectiveness? }\end{array}$} \\
\hline \multirow{5}{*}{$\begin{array}{l}\text { Staff-have insufficient } \\
\text { knowledge about student } \\
\text { learning outcomes \& } \\
\text { assessment }\end{array}$} & & Round II & Round III & Agreement \\
\hline & Mean & 2.05 & 1.95 & $18.2 \%=1$ \\
\hline & Range & $1-3$ & $1-3$ & $68.2 \%=2$ \\
\hline & Median & 2 & 2 & $\therefore 86.4 \%=1,2$ \\
\hline & Mode & 2 & 2 & $\sqrt{ }$ Consensus \\
\hline \multirow{5}{*}{$\begin{array}{l}\text { Outsourced service providers- } \\
\text { do not understand/value/uphold } \\
\text { importance of student } \\
\text { employment as a } \\
\text { developmental process }\end{array}$} & & Round II & Round III & Agreement \\
\hline & Mean & 2.09 & 2.05 & $18.2 \%=1$ \\
\hline & Range & $1-4$ & $1-4$ & $68.2 \%=2$ \\
\hline & Median & 2 & 2 & $\therefore 86.4 \%=1,2$ \\
\hline & Mode & 2 & 2 & $\sqrt{ }$ Consensus \\
\hline \multirow{5}{*}{$\begin{array}{l}\text { Academic affairs-lack } \\
\text { understanding or appreciation } \\
\text { of student development \& the } \\
\text { union }\end{array}$} & & Round II & Round III & Agreement \\
\hline & Mean & 2.00 & 2.16 & $15.8 \%=1$ \\
\hline & Range & $1-3$ & $1-5$ & $63.2 \%=2$ \\
\hline & Median & 2 & 2 & $\therefore 79.0 \%=1,2$ \\
\hline & Mode & 2 & 2 & $\sqrt{ }$ Consensus \\
\hline
\end{tabular}

$\mathrm{N}=22$

\section{Table P15}

\section{Financial Constraints for Student Unions}

Q21: How important is each of the following financial constraints, in influencing student union effectiveness?

\begin{tabular}{|c|c|c|c|c|}
\hline \multirow{5}{*}{$\begin{array}{l}\text { Capital expenses-bond issues } \\
\text { (e.g. poor university bond rating, } \\
\text { failure to make bond payments) }\end{array}$} & & Round II & Round III & Agreement \\
\hline & Mean & 2.45 & 1.27 & $31.8 \%=1$ \\
\hline & Range & $1-4$ & $1-7$ & $31.8 \%=2$ \\
\hline & Median & 2.5 & 2 & $\therefore 63.6 \%=1,2$ \\
\hline & Mode & 1 & $1+2$ & No Consensus \\
\hline \multirow{5}{*}{$\begin{array}{l}\text { Expenses-union operations } \\
\text { (e.g. increasing costs or inadequate } \\
\text { budget for utilities, supplies, } \\
\text { equipment) }\end{array}$} & & Round II & Round III & Agreement \\
\hline & Mean & 1.50 & 1.45 & $63.6 \%=1$ \\
\hline & Range & $1-2$ & $1-3$ & $27.3 \%=2$ \\
\hline & Median & 1.5 & 1 & $\therefore 90.0 \%=1,2$ \\
\hline & Mode & $1+2$ & 1 & $\sqrt{ }$ Consensus \\
\hline \multirow{5}{*}{$\begin{array}{l}\text { Expenses-needed maintenance (e.g. } \\
\text { increasing costs or inadequate } \\
\text { budget) }\end{array}$} & & Round II & Round III & Agreement \\
\hline & Mean & 1.52 & 1.50 & $54.6 \%=1$ \\
\hline & Range & $1-2$ & $1-3$ & $40.9 \%=2$ \\
\hline & Median & 2 & 1 & $\therefore 95.5 \%=1,2$ \\
\hline & Mode & 2 & 1 & $\sqrt{ }$ Consensus \\
\hline
\end{tabular}


(Continued) Q21: How important is each of the following financial constraints, in influencing student union effectiveness?

\begin{tabular}{|c|c|c|c|c|}
\hline \multirow{5}{*}{$\begin{array}{l}\text { Revenues-overreliance on student } \\
\text { fee support } \\
\text { (e.g. need to reduce, concern for } \\
\text { college costs \& student debt }\end{array}$} & & Round II & Round III & Agreement \\
\hline & Mean & 1.82 & 1.50 & $50.1 \%=1$ \\
\hline & Range & $1-3$ & $1-4$ & $36.4 \%=2$ \\
\hline & Median & 2 & 1 & $\therefore 86.5 \%=1,2$ \\
\hline & Mode & 1 & 1 & $\sqrt{ }$ Consensus \\
\hline \multirow{5}{*}{$\begin{array}{l}\text { Capital expenses-lack of funding for } \\
\text { union construction, renovation and } \\
\text { expansion }\end{array}$} & & Round II & Round III & Agreement \\
\hline & Mean & 1.73 & 1.64 & $54.5 \%=1$ \\
\hline & Range & $1-4$ & $1-4$ & $31.8 \%=2$ \\
\hline & Median & 2 & 1 & $\therefore 86.3 \%=1,2$ \\
\hline & Mode & 1 & 1 & $\sqrt{ }$ Consensus \\
\hline \multirow{5}{*}{$\begin{array}{l}\text { Expenses-staffing } \\
\text { (e.g. increasing costs or inadequate } \\
\text { budget for number of staff, } \\
\text { operating hours) }\end{array}$} & & Round II & Round III & Agreement \\
\hline & Mean & 1.50 & 1.64 & $45.5 \%=1$ \\
\hline & Range & $1-2$ & $1-3$ & $45.5 \%=2$ \\
\hline & Median & 1.5 & 2 & $\therefore 91.0 \%=1,2$ \\
\hline & Mode & $1+2$ & $1+2$ & $\sqrt{ }$ Consensus \\
\hline \multirow{5}{*}{$\begin{array}{l}\text { Expenses-technology } \\
\text { (e.g. increasing costs or inadequate } \\
\text { budget) }\end{array}$} & & Round II & Round III & Agreement \\
\hline & Mean & 1.62 & 1.64 & $40.9 \%=1$ \\
\hline & Range & $1-3$ & $1-3$ & $54.6 \%=2$ \\
\hline & Median & 2 & 2 & $\therefore 95.5 \%=1,2$ \\
\hline & Mode & 2 & 2 & $\sqrt{ }$ Consensus \\
\hline \multirow{5}{*}{$\begin{array}{l}\text { Expenses-basic refurbishments \& } \\
\text { upgrades } \\
\text { (e.g. increasing costs or inadequate } \\
\text { budget for furniture \& lighting } \\
\text { replacement) }\end{array}$} & & Round II & Round III & Agreement \\
\hline & Mean & 1.59 & 1.77 & $36.4 \%=1$ \\
\hline & Range & $1-2$ & $1-3$ & $50.0 \%=2$ \\
\hline & Median & 2 & 2 & $\therefore 86.4 \%=1,2$ \\
\hline & Mode & 2 & 2 & $\sqrt{ }$ Consensus \\
\hline \multirow{5}{*}{$\begin{array}{l}\text { Revenues-need to increase use of the } \\
\text { union service }\end{array}$} & & Round II & Round III & Agreement \\
\hline & Mean & 1.95 & 1.82 & $31.8 \%=1$ \\
\hline & Range & $1-4$ & $1-3$ & $54.5 \%=2$ \\
\hline & Median & 2 & 2 & $\therefore 85.3 \%=1,2$ \\
\hline & Mode & 2 & 2 & $\sqrt{ }$ Consensus \\
\hline \multirow{5}{*}{$\begin{array}{l}\text { Revenues-insufficient student fees } \\
\text { to support union }\end{array}$} & & Round II & Round III & \\
\hline & Mean & 1.82 & 1.91 & $40.9 \%=1$ \\
\hline & Range & $1-5$ & $1-5$ & $36.4 \%=2$ \\
\hline & Median & 2 & 2 & $\therefore 77.3 \%=1,2$ \\
\hline & Mode & 1 & 1 & $\sqrt{ }$ Consensus \\
\hline \multirow{5}{*}{$\begin{array}{l}\text { Revenues-insufficient allocations } \\
\text { from institution's general operating } \\
\text { budget to support union }\end{array}$} & & Round II & Round III & Agreement \\
\hline & Mean & 2.27 & 1.95 & $33.3 \%=1$ \\
\hline & Range & $1-6$ & $1-5$ & $52.4 \%=2$ \\
\hline & Median & 2 & 2 & $\therefore 85.7 \%=1,2$ \\
\hline & Mode & 1 & 2 & $\sqrt{ }$ Consensus \\
\hline
\end{tabular}


(Continued) Q21: How important is each of the following financial constraints, in influencing student union effectiveness?

\begin{tabular}{|c|c|c|c|c|}
\hline \multirow{5}{*}{$\begin{array}{l}\text { Auxiliary enterprise-burdensome } \\
\text { expectation that union will make } \\
\text { and contribute excess revenues to } \\
\text { add to institutional budget }\end{array}$} & & Round II & Round III & Agreement \\
\hline & Mean & 2.18 & 2.00 & $33.3 \%=1$ \\
\hline & Range & $1-6$ & $1-4$ & $42.9 \%=2$ \\
\hline & Median & 2 & 2 & $\therefore 76.2 \%=1,2$ \\
\hline & Mode & $1+2$ & 2 & $\sqrt{ }$ Consensus \\
\hline \multirow{5}{*}{$\begin{array}{l}\text { Auxiliary enterprise-difficult to be } \\
\text { self-supporting }\end{array}$} & & Round II & Round III & Agreement \\
\hline & Mean & 2.23 & 2.09 & $18.2 \%=1$ \\
\hline & Range & $1-5$ & $1-4$ & $63.6 \%=2$ \\
\hline & Median & 2 & 2 & $\therefore 81.8 \%=1,2$ \\
\hline & Mode & 2 & 2 & $\sqrt{ }$ Consensus \\
\hline \multirow{5}{*}{$\begin{array}{l}\text { Auxiliary enterprise-ineffective } \\
\text { financial model supporting union } \\
\text { (e.g. predictability, adequacy) }\end{array}$} & & Round II & Round III & Agreement \\
\hline & Mean & 2.41 & 2.09 & $18.2 \%=1$ \\
\hline & Range & $1-6$ & $1-4$ & $59.1 \%=2$ \\
\hline & Median & 2 & 2 & $\therefore 77.3 \%=1,2$ \\
\hline & Mode & 2 & 2 & $\sqrt{\text { Consensus }}$ \\
\hline \multirow{5}{*}{$\begin{array}{l}\text { Capital expenses-lack of state } \\
\text { support/appropriations for union } \\
\text { construction, renovation and } \\
\text { expansion }\end{array}$} & & Round II & Round III & Agreement \\
\hline & Mean & 2.09 & 2.18 & $31.8 \%=1$ \\
\hline & Range & $1-6$ & $1-7$ & $40.9 \%=2$ \\
\hline & Median & 2 & 2 & $\therefore 72.7 \%=1,2$ \\
\hline & Mode & 1 & 2 & No Consensus \\
\hline \multirow{5}{*}{$\begin{array}{l}\text { Revenues-unions must resort to } \\
\text { serving paying public purposes more } \\
\text { than non-paying student purposes in } \\
\text { order to remain financially viable }\end{array}$} & & Round II & Round III & Agreement \\
\hline & Mean & 2.50 & 2.41 & $45.5 \%=2$ \\
\hline & Range & $1-7$ & $1-4$ & $13.6 \%=1$ \\
\hline & Median & 2 & 2 & $\therefore 59.1 \%=1,2$ \\
\hline & Mode & 2 & 2 & No Consensus \\
\hline \multirow{5}{*}{$\begin{array}{l}\text { Revenues-insufficient fundraising to } \\
\text { support union (e.g. gifts, donations) }\end{array}$} & & Round II & Round III & Agreement \\
\hline & Mean & 2.86 & 2.68 & $18.8 \%=1$ \\
\hline & Range & $1-6$ & $1-6$ & $18.2 \%=2$ \\
\hline & Median & 4 & 2 & $\therefore 37.0 \%=1,2$ \\
\hline & Mode & 3 & 3 & No Consensus \\
\hline \multirow{5}{*}{$\begin{array}{l}\text { Revenues-unions must resort to } \\
\text { becoming malls with outsourced } \\
\text { retail stores in order to remain } \\
\text { financially viable }\end{array}$} & & Round II & Round III & Agreement \\
\hline & Mean & 2.50 & 2.82 & $4.5 \%=1$ \\
\hline & Range & $1-7$ & $1-5$ & $27.3 \%=2$ \\
\hline & Median & 3 & 3 & $\therefore 31.8 \%=1,2$ \\
\hline & Mode & 2 & 3 & No Consensus \\
\hline
\end{tabular}

$\mathrm{N}=22$ 


\section{Table P16}

\section{Political Constraints for Student Unions}

Q22: How important is each of the following political constraints, in influencing student union effectiveness?

\begin{tabular}{|c|c|c|c|c|}
\hline \multirow{5}{*}{$\begin{array}{l}\text { Respect for/autonomy of student } \\
\text { union (e.g. institution appropriates } \\
\text { union space for non-union purposes } \\
\text { such as storage or administrative } \\
\text { offices) }\end{array}$} & & Round II & Round III & Agreement \\
\hline & Mean & 1.50 & 1.59 & $45.5 \%=1$ \\
\hline & Range & $1-3$ & $1-3$ & $50.0 \%=2$ \\
\hline & Median & 1 & 2 & $\therefore 95.5 \%=1,2$ \\
\hline & Mode & 1 & 2 & $\sqrt{ }$ Consensus \\
\hline \multirow{5}{*}{$\begin{array}{l}\text { Lack of influence of union directors } \\
\text { in institutional decision making }\end{array}$} & & Round II & Round III & Agreement \\
\hline & Mean & 1.73 & 1.77 & $45.5 \%=1$ \\
\hline & Range & $1-3$ & $1-4$ & $36.4 \%=2$ \\
\hline & Median & 2 & 2 & $\therefore 81.9 \%=1,2$ \\
\hline & Mode & 2 & 1 & $\sqrt{ }$ Consensus \\
\hline \multirow{5}{*}{$\begin{array}{l}\text { Campus policies and politics (e.g. } \\
\text { prohibitive influence on union } \\
\text { operations \& innovation) }\end{array}$} & & Round II & Round III & Agreement \\
\hline & Mean & 2.14 & 2.00 & $31.8 \%=1$ \\
\hline & Range & $1-3$ & $1-4$ & $45.5 \%=2$ \\
\hline & Median & 2 & 2 & $\therefore 77.2 \%=1,2$ \\
\hline & Mode & 2 & 2 & $\sqrt{ }$ Consensus \\
\hline \multirow{5}{*}{$\begin{array}{l}\text { Prioritization of student union in the } \\
\text { institutional budget process }\end{array}$} & & Round II & Round III & Agreement \\
\hline & Mean & 1.95 & 2.05 & $22.7 \%=1$ \\
\hline & Range & $1-4$ & $1-5$ & $59.1 \%=2$ \\
\hline & Median & 2 & 2 & $\therefore 81.8 \%=1,2$ \\
\hline & Mode & 2 & 2 & $\sqrt{ }$ Consensus \\
\hline \multirow{5}{*}{$\begin{array}{l}\text { Inadequate/unclear organizational } \\
\text { structure of union (e.g. unclear } \\
\text { responsibilities, inadequate } \\
\text { coordination, groups vie for } \\
\text { leadership) }\end{array}$} & & Round II & Round III & Agreement \\
\hline & Mean & 2.50 & 2.32 & $22.7 \%=1$ \\
\hline & Range & $1-6$ & $1-4$ & $31.8 \%=2$ \\
\hline & Median & 2 & 2 & $\therefore 55.5 \%=1,2$ \\
\hline & Mode & 2 & 3 & No Consensus \\
\hline \multirow{5}{*}{$\begin{array}{l}\text { Competition on campus (e.g. similar } \\
\text { services \& amenities offered in other } \\
\text { academic or support buildings) }\end{array}$} & & Round II & Round III & Agreement \\
\hline & Mean & 2.32 & 2.41 & $18.2 \%=1$ \\
\hline & Range & $1-6$ & $1-5$ & $40.9 \%=2$ \\
\hline & Median & 2 & 2 & $\therefore 58.1 \%=1,2$ \\
\hline & Mode & 2 & 2 & No Consensus \\
\hline \multirow{5}{*}{$\begin{array}{l}\text { Lack of respect from/partnership } \\
\text { with academic affairs }\end{array}$} & & Round II & Round III & Agreement \\
\hline & Mean & 2.27 & 2.59 & $45.6 \%=2$ \\
\hline & Range & $1-3$ & $1-5$ & $13.6 \%=1$ \\
\hline & Median & 2 & 2 & $\therefore 59.2 \%=1,2$ \\
\hline & Mode & 2 & 2 & No Consensus \\
\hline \multirow{5}{*}{$\begin{array}{l}\text { Competition off campus (e.g. similar } \\
\text { service \& amenity providers in town) }\end{array}$} & & Round II & Round III & Agreement \\
\hline & Mean & 3.27 & 2.76 & $19.0 \%=1$ \\
\hline & Range & $1-7$ & $1-5$ & $14.3 \%=2$ \\
\hline & Median & 3 & 3 & $\therefore 33.3 \%=1,2$ \\
\hline & Mode & 3 & 3 & No Consensus \\
\hline
\end{tabular}


Table P17

\section{Sustaining Forces and the Future of Student Unions}

Q24: How important is each of the following sustaining forces, in influencing the student union of the future?

\begin{tabular}{|c|c|c|c|c|}
\hline \multirow{5}{*}{$\begin{array}{l}\text { Importance of the union's services } \\
\& \text { amenities to the campus } \\
\text { community }\end{array}$} & & Round II & Round III & Agreement \\
\hline & Mean & 1.36 & 1.14 & $86.4 \%=1$ \\
\hline & Range & $1-3$ & $1-2$ & $13.6 \%=2$ \\
\hline & Median & 1 & 1 & $\therefore 100 \%=1,2$ \\
\hline & Mode & 1 & 1 & $\sqrt{ }$ True Consensus \\
\hline \multirow{5}{*}{$\begin{array}{l}\text { Basic human/student need to } \\
\text { connect and belong to the campus } \\
\text { community }\end{array}$} & & Round II & Round III & Agreement \\
\hline & Mean & 1.27 & 1.18 & $81.8 \%=1$ \\
\hline & Range & $1-2$ & $1-2$ & $18.2 \%=2$ \\
\hline & Median & 1 & 1 & $\therefore 100 \%=1,2$ \\
\hline & Mode & 1 & 1 & $\sqrt{ }$ True Consensus \\
\hline \multirow{5}{*}{$\begin{array}{l}\text { Continued need for students to have } \\
\text { a "living room," a place to feel "at } \\
\text { home." }\end{array}$} & & Round II & Round III & Agreement \\
\hline & Mean & 1.32 & 1.32 & $72.7 \%=1$ \\
\hline & Range & $1-3$ & $1-3$ & $22.7 \%=2$ \\
\hline & Median & 1 & 1 & $\therefore 95.4 \%=1,2$ \\
\hline & Mode & 1 & 1 & $\sqrt{ }$ Consensus \\
\hline \multirow{5}{*}{$\begin{array}{l}\text { Institutional commitment to the } \\
\text { union concept }\end{array}$} & & Round II & Round III & Agreement \\
\hline & Mean & 1.52 & 1.32 & $72.7 \%=1$ \\
\hline & Range & $1-3$ & $1-3$ & $22.7 \%=2$ \\
\hline & Median & 1 & 1 & $\therefore 95.4 \%=1,2$ \\
\hline & Mode & 1 & 1 & $\sqrt{ }$ Consensus \\
\hline \multirow{5}{*}{$\begin{array}{l}\text { Importance of providing a human, } \\
\text { high-touch location on campus, as } \\
\text { human interactions are increasingly } \\
\text { mediated through technology }\end{array}$} & & Round II & Round III & Agreement \\
\hline & Mean & 1.41 & 1.27 & $77.3 \%=1$ \\
\hline & Range & $1-3$ & $1-3$ & $18.2 \%=2$ \\
\hline & Median & 1 & 1 & $\therefore 95.5 \%=1,2$ \\
\hline & Mode & 1 & 1 & $\sqrt{ }$ True Consensus \\
\hline \multirow{5}{*}{$\begin{array}{l}\text { Continued need for co-curricular } \\
\text { skill building (e.g. responsibility, } \\
\text { leadership, communication) }\end{array}$} & & Round II & Round III & Agreement \\
\hline & Mean & 1.45 & 1.27 & $77.2 \%=1$ \\
\hline & Range & $1-3$ & $1-3$ & $\begin{array}{l}18.2 \%=2 \\
.05 \%-12\end{array}$ \\
\hline & Median & 1 & 1 & $\ddot{\sqrt{ }}$ True Consensus \\
\hline & Mode & 1 & 1 & \\
\hline \multirow{5}{*}{$\begin{array}{l}\text { Importance of student development } \\
\text { in institution's mission and strategic } \\
\text { plan }\end{array}$} & & Round II & Round III & Agreement \\
\hline & Mean & 1.50 & 1.50 & $59.1 \%=1$ \\
\hline & Range & $1-3$ & $1-4$ & $36.4 \%=2$ \\
\hline & Median & 1 & 1 & $\therefore 94.5 \%=1,2$ \\
\hline & Mode & 1 & 1 & $\sqrt{ }$ Consensus \\
\hline \multirow{5}{*}{$\begin{array}{l}\text { Continued need for a "welcome } \\
\text { center" that makes an impression for } \\
\text { students, alumni and visitors, and } \\
\text { conveys the campus' identity story, } \\
\text { instills loyalty }\end{array}$} & & Round II & Round III & Agreement \\
\hline & Mean & 1.55 & 1.55 & $59.1 \%=1$ \\
\hline & Range & $1-3$ & $1-3$ & $27.3 \%=2$ \\
\hline & Median & 1 & 1 & $\therefore 86.4 \%=1,2$ \\
\hline & Mode & 1 & 1 & $\sqrt{ }$ Consensus \\
\hline
\end{tabular}

$\mathrm{N}=22$ 


\section{Table P18}

\section{Changing Forces and the Future of Student Unions}

Q25: How important is each of the following changing forces, in influencing the student union of the future?

\begin{tabular}{|c|c|c|c|c|}
\hline \multirow{5}{*}{$\begin{array}{l}\text { Finding new ways to engage } \\
\text { students/compete for their time and } \\
\text { attention }\end{array}$} & & Round II & Round III & Agreement \\
\hline & Mean & 1.50 & 1.45 & $54.5 \%=1$ \\
\hline & Range & $1-4$ & $1-2$ & $45.5 \%=2$ \\
\hline & Median & 1 & 1 & $\therefore 100 \%=1,2$ \\
\hline & Mode & 1 & 1 & $\sqrt{ }$ Consensus \\
\hline \multirow{5}{*}{$\begin{array}{l}\text { Changing student populations/needs } \\
\text { (e.g. difficult to forecast what future } \\
\text { students will need) }\end{array}$} & & Round II & Round III & Agreement \\
\hline & Mean & 1.77 & 1.50 & $54.5 \%=1$ \\
\hline & Range & $1-3$ & $1-3$ & $40.9 \%=2$ \\
\hline & Median & 2 & 1 & $\therefore 95.4 \%=1,2$ \\
\hline & Mode & 2 & 1 & $\sqrt{ }$ Consensus \\
\hline \multirow{5}{*}{$\begin{array}{l}\text { Finding new ways to create a sense } \\
\text { of community }\end{array}$} & & Round II & Round III & Agreement \\
\hline & Mean & 1.59 & 1.52 & $52.4 \%=1$ \\
\hline & Range & $1-5$ & $1-3$ & $45.5 \%=2$ \\
\hline & Median & 1 & 1 & $\therefore 97.9 \%=1,2$ \\
\hline & Mode & 1 & 1 & $\sqrt{ }$ Consensus \\
\hline \multirow[t]{5}{*}{ Sustainability/Eco-awareness } & & Round II & Round III & Agreement \\
\hline & Mean & 1.91 & 1.73 & $36.4 \%=1$ \\
\hline & Range & $1-3$ & $1-3$ & $54.5 \%=2$ \\
\hline & Median & 2 & 2 & $\therefore 90.9 \%=1,2$ \\
\hline & Mode & 2 & 2 & $\sqrt{ }$ Consensus \\
\hline \multirow{5}{*}{$\begin{array}{l}\text { Pace of technological change (e.g. } \\
\text { difficult to forecast, keep pace with, } \\
\text { and afford) }\end{array}$} & & Round II & Round III & Agreement \\
\hline & Mean & 1.71 & 1.82 & $36.4 \%=1$ \\
\hline & Range & $1-3$ & $1-3$ & $45.4 \%=2$ \\
\hline & Median & 2 & 2 & $\therefore 81.8 \%=1,2$ \\
\hline & Mode & 1 & 2 & $\sqrt{ }$ Consensus \\
\hline \multirow{5}{*}{$\begin{array}{l}\text { Technology-mediated human } \\
\text { interaction (e.g. social media \& } \\
\text { virtual vs. physical union) }\end{array}$} & & Round II & Round III & Agreement \\
\hline & Mean & 1.95 & 2.05 & $18.2 \%=1$ \\
\hline & Range & $1-5$ & $1-4$ & $63.6 \%=2$ \\
\hline & Median & 2 & 2 & $\therefore 81.8 \%=1,2$ \\
\hline & Mode & 2 & 2 & $\sqrt{ }$ Consensus \\
\hline \multirow[t]{5}{*}{ Globalization } & & Round II & Round III & Agreement \\
\hline & Mean & 2.36 & 2.09 & $31.8 \%=1$ \\
\hline & Range & $1-5$ & $1-5$ & $36.4 \%=2$ \\
\hline & Median & 2 & 2 & $\therefore 68.2 \%=1,2$ \\
\hline & Mode & 2 & 2 & No Consensus \\
\hline \multirow{5}{*}{$\begin{array}{l}\text { Online classes (e.g. keeping more } \\
\text { students off of campus, changing } \\
\text { primacy of a residential college) }\end{array}$} & & Round II & Round III & Agreement \\
\hline & Mean & 2.59 & 2.82 & $0.0 \%=1$ \\
\hline & Range & $1-6$ & $2-7$ & $40.9 \%=2$ \\
\hline & Median & 2.5 & 3 & $\therefore 40.9 \%=1,2$ \\
\hline & Mode & 3 & 3 & No Consensus \\
\hline
\end{tabular}


(Continued) Q25: How important is each of the following changing forces, in influencing the student union of the future?

\begin{tabular}{lllll}
\hline Evening \& weekend classes (e.g. & & Round II & Round III & Agreement \\
\cline { 2 - 5 } $\begin{array}{llll}\text { changing needs for union's operating } \\
\text { hours) }\end{array}$ & Mean & 2.45 & 2.91 & $0.0 \%=1$ \\
& Range & $1-5$ & $2-6$ & $40.9 \%=2$ \\
& Median & 2 & 3 & $\therefore 40.9 \%=1,2$ \\
& Mode & 2 & $2+3$ & No Consensus \\
\hline
\end{tabular}

$\mathrm{N}=22$ 